\title{
Análise de blocos de concreto armado sobre duas estacas com cálice totalmente embutido mediante presença de viga de travamento
}

\author{
Rodrigo Barros
}

Dissertação apresentada à Escola de Engenharia de São Carlos da Universidade de São Paulo, como parte dos requisitos para obtenção do Título de Mestre em Engenharia de Estruturas

Orientador: José Samuel Giongo 
AUTORIZO A REPRODUÇÃO E DIVULGAÇÃO TOTAL OU PARCIAL DESTE TRABALHO, POR QUALQUER MEIO CONVENCIONAL OU ELETRÔNICO, PARA FINS DE ESTUDO E PESQUISA, DESDE QUE CITADA A FONTE.

Ficha catalográfica preparada pela Seção de Tratamento

da Informação do Serviço de Biblioteca - EESC/USP

B277a Barros, Rodrigo

Análise de blocos de concreto armado sobre duas estacas com cálices totalmente embutido mediante presença de viga de travamento / Rodrigo Barros; José Samuel Giongo. - São Carlos, 2009.

Dissertação (Mestrado-Programa de Pós-Graduação em Engenharia de Estruturas) - - Escola de Engenharia de São Carlos da Universidade de São Paulo, 2009.

1. Blocos sobre estacas. 2. Cálice de fundação embutido. 3. Viga de travamento. 4. Bielas e tirantes. I. Título. 
FOLHA DE JULGAMENTO

\section{Candidato: Engenheiro RODRIGO BARROS}

Dissertação defendida e julgada em 22/05/2009 perante a Comissão Julgadora:

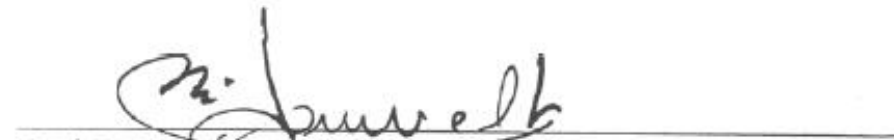

Prof. Dr. JOSÉ SAMUEL GIONGO (Orientador)

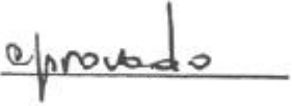

(Escola de Engenharia de São Carlos/USP)
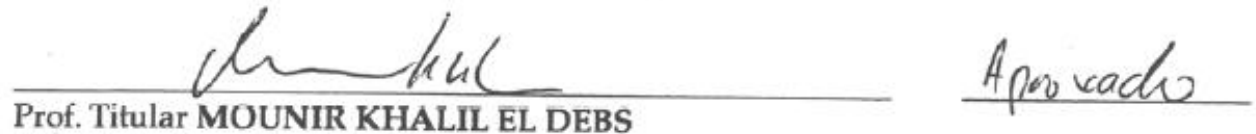

(Escola de Engenharia de São Carlos/USP)

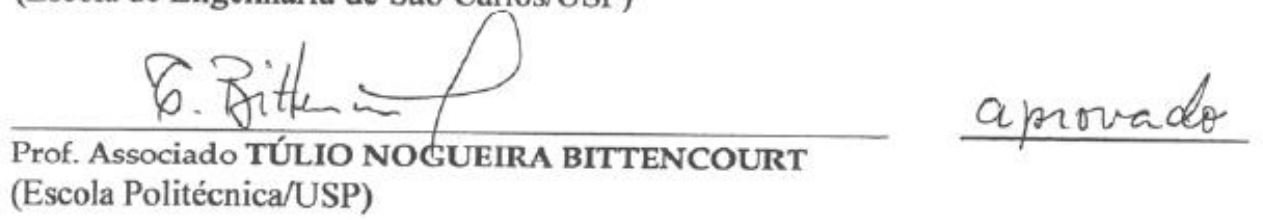

(Escola Politécnica/USP)
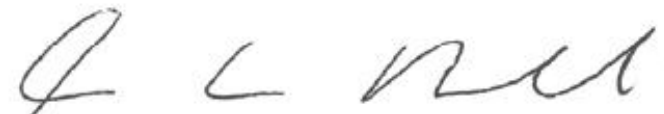

Prof. Associado MARCIO ANTONIO RAMALHO

Coordenador do Programa de Pós-Graduação em

Engenharia Civil (Engenharia de Estruturas)

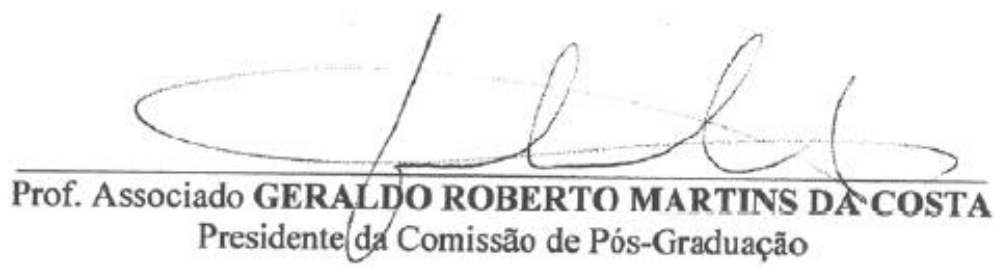



Aos meus pais, Denilde e José, minhas irmãs Kátia, Cássia e Claudia, com amor e gratidão. 

"Mais valem duas pedras no meio do caminho, do que uma nos rins"

Marcondes Maia 



\section{Agradecimentos}

Ao final de mais uma etapa da minha vida, agradeço primeiramente a Deus por ter abençoado e me guiado nas minhas escolhas.

Aos meus pais: Denilde e José; minhas irmãs: Kátia, Cássia e Claudia e minha tia Marisa, pelo apoio de sempre e por acreditarem e confiarem nas minhas decisões.

Aos meus grandes amigos da cidade de Natal: Arthunio, Morais, Thyago, Guru, Moreno, Gustavo, Pablo, Iuri, Marcelão, André Felipe, Ianne, Stéphanie, Talita, Natália, entre tantos outros que confiaram e acreditaram em mim, em especial aos Discípulos de Deda.

Aos amigos da UFRN: Tommy, Jocilene, Sarah, Rick, Marcelo Cortez, Diogo, Mauricéa, Francisco, Vinícius, Rafael, Pânico e Marquito pelo incentivo e pelos bons momentos que compartilhamos ao longo da graduação.

Aos professores da UFRN Roberto José de Medeiros, Joel Araújo, Pétrus da Nóbrega e Selma da Nóbrega pelo incentivo ao ingresso na pós-graduação.

Aos amigos Raimundo, Jônatas, Vinicius e Wanderson, que me acolheram na sua república nos primeiros dias em São Carlos.

A colônia "natalense” em São Carlos: Raimundo, Jônatas, Vinícius, Manoel Dênis, Valmiro, Chris, Rodolfo, Hidelbrando, Osvaldo e Vagner, que de alguma maneira contribuem para diminuir a distância da terra "Natal".

Aos integrantes da república chiqueiro: Giovanni, Hugo e Wanderson (Mineiro), "bacharéis" com os quais tenho a oportunidade de morar, e que tornam a estada em São Carlos mais agradável. Sem dúvida, uma segunda família.

As amizades incondicionais de Renata, Cynthia e Ana Paula, pessoas sensacionais que tive a oportunidade de conhecer e conviver, e que, apesar da distância, estarão sempre presentes na minha vida.

A todos os colegas e amigos do departamento de estruturas: Aref, Dorival, Jesus 1 e 2, Rodrigo "Slow", Saulo, Érica, Baiano, Socorro, Marcela, Ísis, Denise, João César, Antônio, Robenson, Ellen, Gabriela, Wagner, Carlos, Jônas, André, Fernando, Francisco, Mairal e tantos outros colegas que sempre estiveram presentes nos momentos de estudo e de descontração.

Ao Leonardo e Dani Bezerra, o casal mais "nota 10” que conheci em Sanca. 
Ao pessoal do futebol e do vôlei, pelos momentos de descontração.

Ao Walter, Rômulo e Rodrigo Paccola pelo auxílio com o programa DIANA.

Ao professor José Samuel Giongo pela orientação, amizade, conselhos e por acreditar na realização desse trabalho.

Aos Engenheiros Rodrigo Delalibera e Fernando Menezes pelas contribuições no trabalho.

Ao cantor Falcão, pelo show realizado em São Carlos no baile brega 2008

Ao CNPq pela bolsa de mestrado concedida.

Aos funcionários e professores do Departamento de Engenharia de Estruturas da ESSCUSP. 


\section{Resumo}

BARROS, R. (2009). Análise de blocos de concreto armado sobre duas estacas com cálice totalmente embutido mediante presença de viga de travamento. São Carlos, 2009. Dissertação (Mestrado) - Escola de Engenharia de São Carlos, Universidade de São Paulo.

Esta pesquisa estuda o comportamento de blocos de concreto armado sobre duas estacas com cálice totalmente embutido, utilizado na ligação pilar-fundação de estruturas de concreto prémoldado. Particularmente, foi avaliado o efeito que a viga de travamento provoca no bloco quando apoiada nas paredes laterais do cálice. Foi desenvolvida análise numérica tridimensional utilizando programa baseado no método dos elementos finitos (MEF), na qual foi considerada a não-linearidade física dos materiais. Para avaliação do programa adotado, realizou-se análise comparativa de resultados experimentais e numéricos obtidos por meio de outro programa. Nos blocos estudados variou-se a espessura e o tipo de conformação das paredes do cálice, o ângulo de inclinação da biela e a intensidade das ações na viga de travamento. Os resultados indicam que a presença da viga de travamento não altera de modo significativo o comportamento do bloco, e que a parede do cálice é capaz de transferir a força proveniente da viga em direção às estacas de modo eficaz. Por meio das tensões nas barras da armadura principal, foi possível obter a força no tirante e o ângulo de inclinação da biela antes da ruína dos modelos. Constatou-se que os ângulos apresentaram maior inclinação do que as utilizadas no dimensionamento, que por sua vez foi feito baseado nos modelos de bielas e tirantes.

Palavras-chave: blocos sobre estacas; cálice de fundação embutido, viga de travamento, modelo de bielas e tirantes. 

BARROS, R. (2009). Analysis of two pile caps reinforced concrete with embedded socket by presence of locking beam. São Carlos, 2009. Dissertation (Master) - School of Engineering of São Carlos, University of São Paulo.

The present research studies the behavior of two pile caps reinforced concrete with embedded socked used in connections of pre-cast concrete structures. It was particularly evaluated the effect provoked by the locking beam on the pile-caps when supported by the socket lateral walls. Three-dimensional numerical analyses using software based on finite element method (FEM) were developed considering the nonlinear physical behavior of the material. To evaluate the adopted software, a comparative analysis was made using numerical and experimental results obtained from other software. In the pile caps studied, it was noticed a variation in the wall thickness, socket interface, strut angle inclination and action on beam. The results show that the presence of beam does not change significantly the pile caps behavior and that the socket wall is able to transfer effectively the force from the beam to the pile caps. By the tensions on the bars of longitudinal reinforcement, it was possible to obtain the force on the tie and the strut angle inclination before the collapse of models. It was found that the angles present more inclinations than those used in the design, which was made based on strut and tie model.

Keywords: pile caps; embedded socket foundation; locking beam; strut-and-tie model. 

Figura 1. 1- Perspectiva do bloco de fundações com cálice externo 26

Figura 1. 2- Perspectiva do bloco de fundações com cálice parcialmente embutido ......................................22

Figura 1. 3- Perspectiva do bloco de fundações com cálice totalmente embutido..............................................227

Figura 2. 1 - Blocos sobre duas estacas, Blévot \& Frémy (1967) .................................................................... 32

Figura 2. 2 - Blocos sobre três estacas, Blévot \& Frémy (1967). ............................................................ 33

Figura 2. 3 - Blocos sobre quatro estacas, Blévot \& Frémy (1967) ........................................................... 35

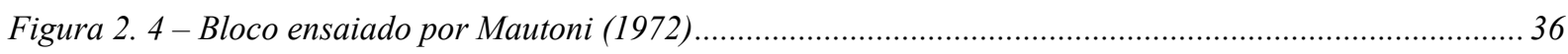

Figura 2. 5 - Propriedades geométricas de bloco com “armadura em bigode”, Mautoni (1972) ...................... 37

Figura 2. 6-Detalhamento e ancoragem das barras, Taylor \& Clarke (1976)................................................. 38

Figura 2. 7 - Configurações de ruína observadas por Taylor \& Clarke (1976)............................................... 39

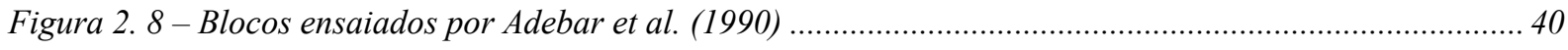

Figura 2. 9 - Modelo de Biela e Tirante sugerido por Adebar et al. (1990).................................................... 42

Figura 2. 10 - Bloco sobre três estacas analisado por IYER e SAM (1991) .................................................. 43

Figura 2. 11 - Modelos de biela e tirante para blocos sobre duas estacas, Nori \& Tharval (2007)...................50

Figura 2. 12 - Geometria do cálice e forças transmitidas à fundação-adaptado de El Debs (2000) ................52

Figura 2.13 - Transferência das ações no cálice de fundação com interface lisa-adaptado de El Debs (2000)

Figura 2. 14 - Forças nas paredes do cálice com interface lisa e rugosa-adaptado de Leonhardt \& Mönnig (1978)

Figura 2. 15 - Transferência de esforços no colarinho segundo Leonhardt \& Mönnig (1978) - adaptado de El

Debs (2000)

Figura 2. 16 - Indicações de dimensionamento das paredes 3 e 4 como consolo curto - adaptado de El Debs (2000) 57

Figura 2. 17 - Esquema das principais armaduras do cálice ...................................................................5 58

Figura 2. 18 - Esquema de forças segundo Willert \& Kesser (1983) .............................................................60

Figura 2. 19 - Esquema de forças atuantes no pilar - Silva (1998) ........................................................ 65

Figura 2. 20 - Modelo de cálculo para bloco com cálice embutido, sem considerar o atrito na junta pilar-bloco

- Silva (1998)

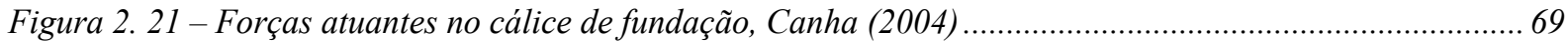

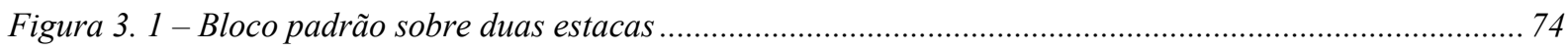

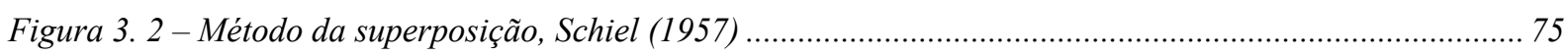

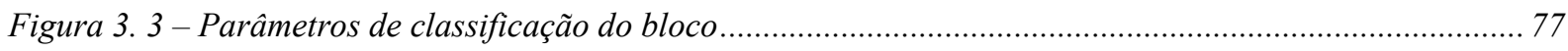


Figura 3. 4 - Distância entre estaca e a face do bloco, Alonso (1983)..............................................................80

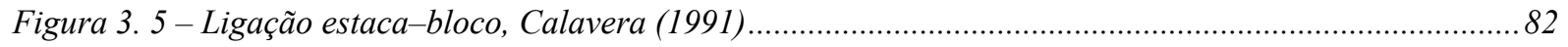

Figura 3. 6 - Comprimento de ancoragem em blocos sobre estacas, Calavera (1991)....................................85

Figura 3. 7 - Divisão de uma estrutura em regiões B e D, "Strut-and-Tie Resource Web Site”........................90

Figura 3. 8-Configurações da biela de compressão, "Strut-and-Tie Resource Web Site”................................91

Figura 3. 9 - Aplicação do caminho de cargas em blocos sobre duas estacas, Munhoz (2004)........................ 94

Figura 4. 1 - Energia de fraturamento na tração, Farias (2008) ........................................................... 100

Figura 4. 2 - Modelos Constitutivos à tração pré-definidos, disponíveis em Diana (2005b) ............................ 104

Figura 4. 3 - Modelos Constitutivos à compressão pré-definidos, disponíveis em Diana (2005b) .................... 104

Figura 4. 4 - Fator de redução devido a fissuração lateral, DIANA (2005b) ................................................. 105

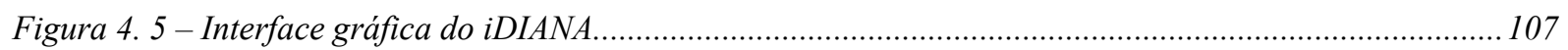

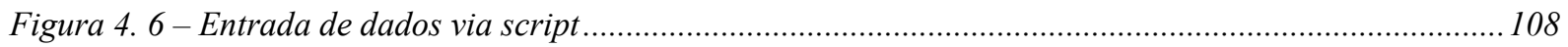

Figura 4. 7 - Curva força versus deslocamento, obtida com critério de comprimento de arco.........................111

Figura 4. 8-DIANA, critério de convergência em energia ............................................................................. 112

Figura 4. 9 - Elemento CHX60 com função aproximadora em deslocamentos ........................................... 114

Figura 4. 10 - Influência do fator de retenção ao cisalhamento $\beta$..................................................................119

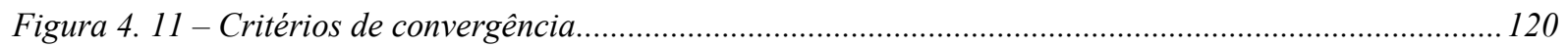

Figura 4. 12 - Modo de aplicação do carregamento ........................................................................... 121

Figura 4.13 - "Fixed crack model “versus "Rotating crack mcdel ”............................................................. 122

Figura 4. 14 - Ação em forma de pressão e deslocamento imposto................................................................... 123

Figura 4. 15 - Métodos de resolução do sistema de equações não-lineares..................................................... 124

Figura 4. 16 - Modelo B35e0 calculado via “iteration based sizes"................................................................ 125

Figura 4. 17 - B35E0, Influência do número de passos de carga ................................................................... 126

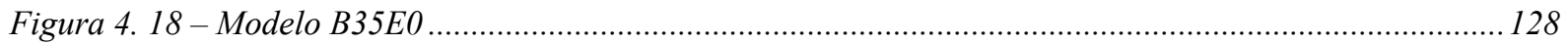

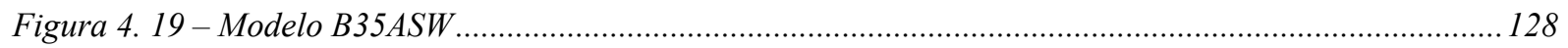

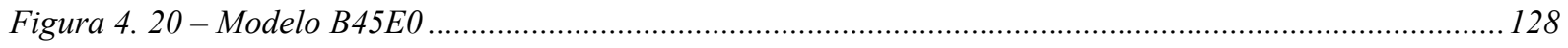

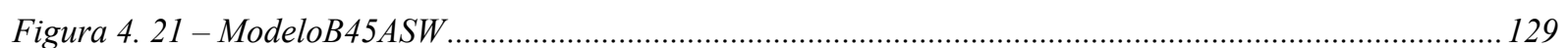

Figura 4. 22 - Panorama de fissuração do bloco B35E0.................................................................................... 130

Figura 4. 23 - Tensões principais de compressão e tração no bloco B35E0 ................................................ 130

Figura 4. 24 - Panorama de fissuração do bloco B35 ASW ............................................................................... 131

Figura 4. 25 - Tensões principais de compressão e tração no bloco B35ASW............................................. 132

Figura 4. 26 - Panorama de fissuração do bloco B45E0..................................................................................... 133

Figura 4. 27 - Tensões principais de compressão e tração no bloco B45E0 ................................................... 133

Figura 4. 28 - Panorama de fissuração do bloco B45ASW ........................................................................ 134

Figura 4. 29 - Tensões principais de compressão e tração no bloco B45E0 .................................................. 134

Figura 4. 30 - Tensões nas barras da armadura longitudinal dos modelos B35E0, B35ASW, B45E0 e B45ASW,

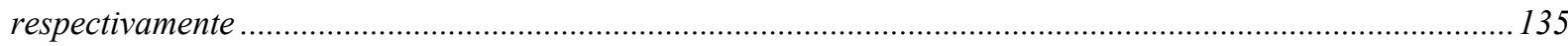

Figura 4. 31 - Curva força vs. deslocamentos dos modelos B35E0, B35ASW, B45E0 e B45ASW, respectivamente 
Figura 5. 1 - Situação de projeto analisada 141

Figura 5. 2 - Blocos em argamassa utilizados sobre a viga de travamento ................................................ 143

Figura 5. 3 - Malha de elementos finitos dos BLH75A45_15_CV1 e BRH65A55_15 ..................................... 146

Figura 5. 4-Modelo BLH75A45_15_cvl com ações e condições de contorno . 146

Figura 5. 5 - Barras dos estribos verticais e armadura de costura; barras dos estribos horizontais e armadura de punção, respectivamente.

Figura 5. 6-Barras da armadura vertical principal e secundária; barras da armadura horizontal principal e secundária, respectivamente.....

Figura 5. 7 - Barras da armadura da viga, pilar, estacas e armadura longitudinal; modelo com barras das armaduras completas

Figura 5. 8-Elemento CQ48I, DIANA (2005a)..... 149

Figura 5. 9 - Configuração da região de interface entre o pilar e o graute.. 150

Figura 5. 10 - Modelo modificado de Mohr-Coulomb - Chen (1982)........................................................... 151

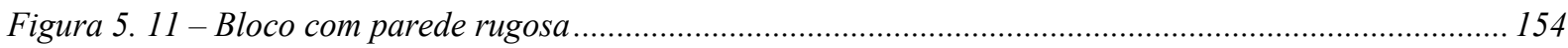

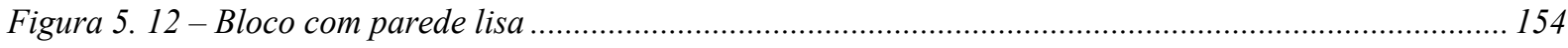

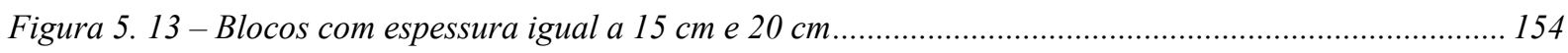

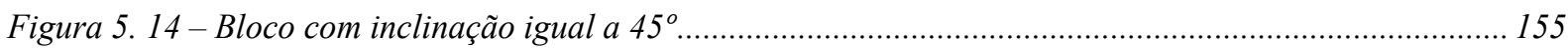

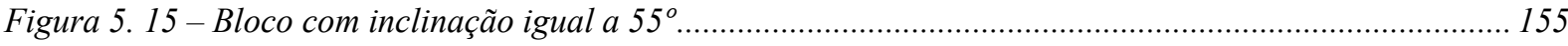

Figura 5. 16 - Comparação de blocos com e sem viga de travamento ........................................................... 157

Figura 5. 17 - Blocos de parede rugosa com viga de travamento ............................................................... 157

Figura 5. 18 - Comparação de blocos com e sem viga de travamento ......................................................... 158

Figura 5. 19 - Blocos de parede lisa com viga de travamento ................................................................ 158

Figura 5. 20 - Comparação de blocos com e sem viga de travamento ..................................................... 159

Figura 5. 21 - Blocos de parede rugosa com viga de travamento .................................................................. 159

Figura 5. 22 - Comparação de blocos com e sem viga de travamento .......................................................... 160

Figura 5. 23 - Blocos de parede lisa com viga de travamento ............................................................. 161

Figura 5. 24 - Fluxo de tensões nos modelos BLH75A45_15 .................................................................... 162

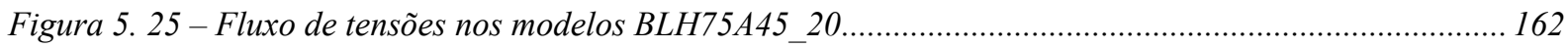

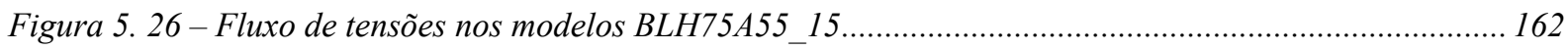

Figura 5. 27 - Fluxo de tensões nos modelos BLH75A55_20 ............................................................ 163

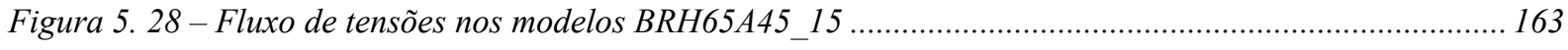

Figura 5. 29 - Fluxo de tensões nos modelos BRH65A45_20 …................................................................ 163

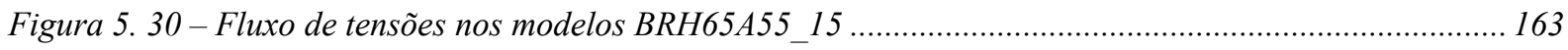

Figura 5. 31 - Fluxo de tensões nos modelos BRH65A55_20 ........................................................... 164

Figura 5. 32 - Tensões principais de compressão e tração nos modelos BLH75A45_15............................... 165

Figura 5. 33 - Tensões principais de compressão e tração nos modelos BLH75A45_20.............................. 165

Figura 5. 34 - Tensões principais de compressão e tração nos modelos BLH75A55_15................................ 166

Figura 5. 35 - Tensões principais de compressão e tração nos modelos BLH75A55_20............................... 166

Figura 5. 36 - Tensões principais de compressão e tração nos modelos BRH65A45_15 ............................ 167 
Figura 5. 37 -Tensões principais de compressão e tração nos modelos BRH65A45_20.................................167

Figura 5. 38 -Tensões principais de compressão e tração nos modelos BRH65A55_15................................168

Figura 5. 39 -Tensões principais de compressão e tração nos modelos BRH65A55_20..................................168

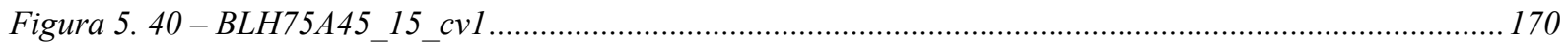

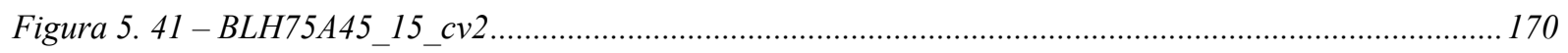

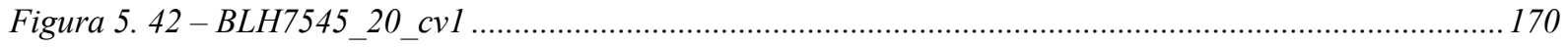

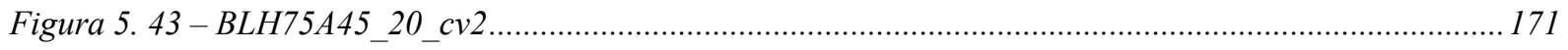

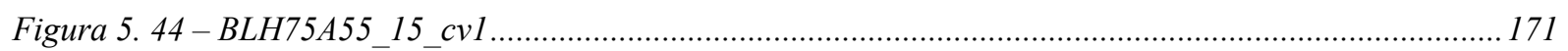

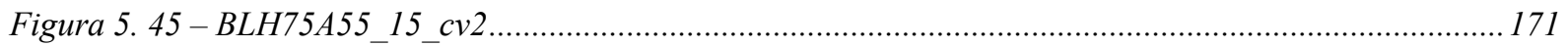

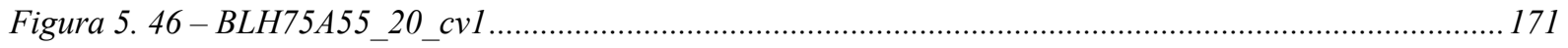

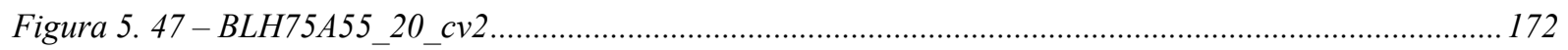

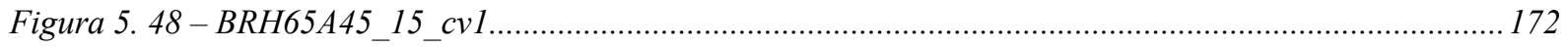

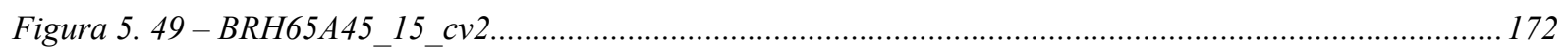

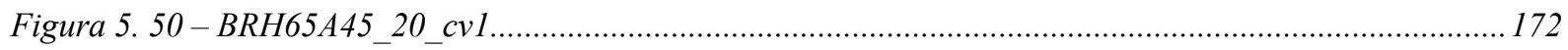

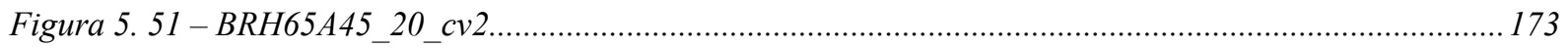

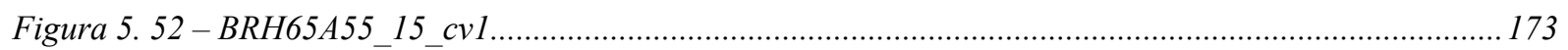

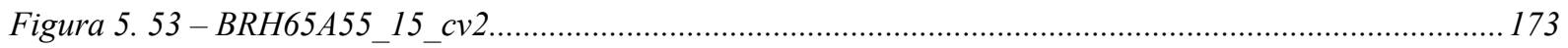

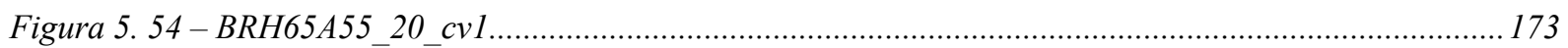

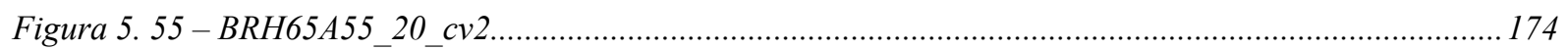

Figura 5. 56 - Barras da armadura principal do tirante .................................................................. 176

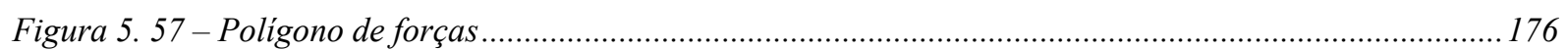

Figura 5. 58 - Tensão nas barras das armaduras dos modelos BLH75A45_15 _...................................... 177

Figura 5. 59 - Tensão nas barras das armaduras dos modelos BLH75A45_20 ........................................ 177

Figura 5. 60 - Tensão nas barras das armaduras dos modelos BLH75A55_15 ......................................... 177

Figura 5. 61 - Tensão nas barras das armaduras dos modelos BLH75A55_20 ........................................ 177

Figura 5. 62 - Tensão nas barras das armaduras dos modelos BRH65A45_15 _......................................... 177

Figura 5. 63 - Tensão nas barras das armaduras dos modelos BRH65A45 20.......................................... 178

Figura 5. 64 - Tensão nas barras das armaduras dos modelos BRH65A55_15 ......................................178

Figura 5. 65 - Tensão nas barras das armaduras dos modelos BRH65A55_20........................................... 178 


\section{CAPÍTULO 1 - INTRODUÇÃo}

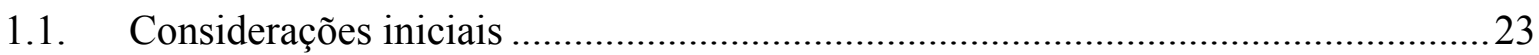

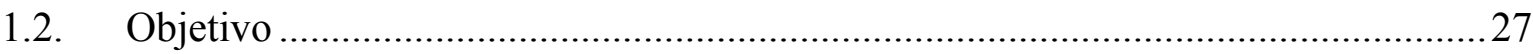

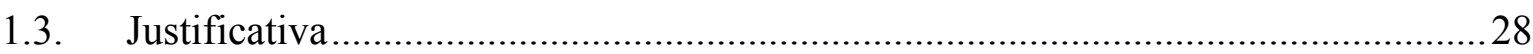

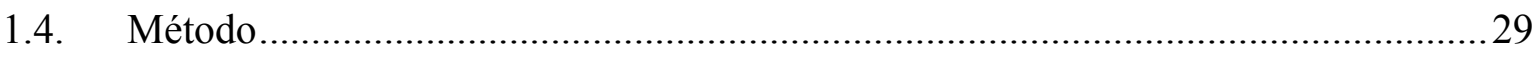

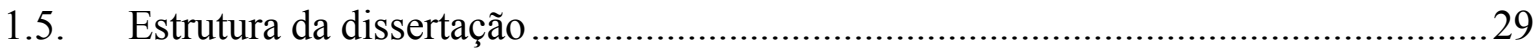

\section{CAPÍTULO 2 - REVISÃO BIBLIOGRÁFICA}

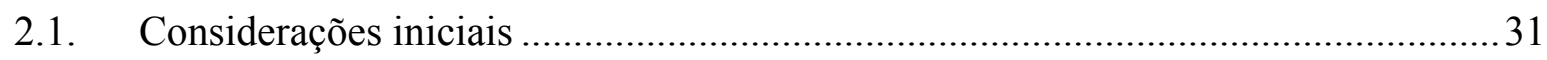

2.2. Pesquisas com ênfase no bloco de fundação ...................................................... 31

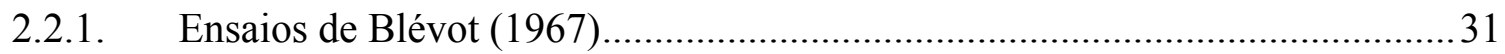

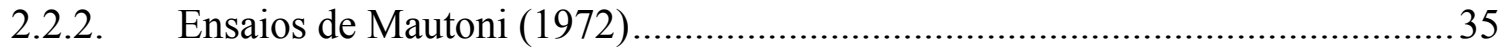

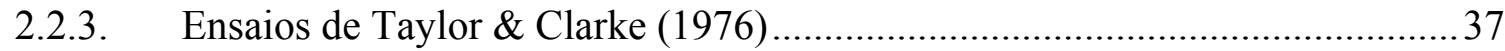

2.2.4. Ensaios de Adebar, Kuchma e Collins (1990)...............................................40

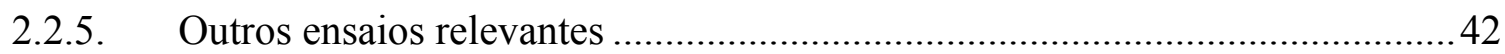

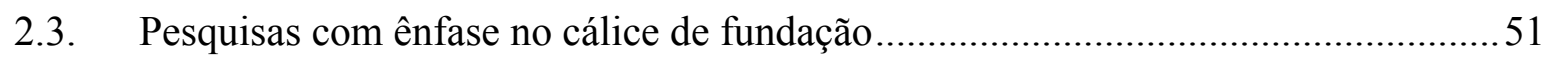

2.3.1. Modelo de Leonhardt \& Mönnig (1978) e NBR 9062:1985 ............................51

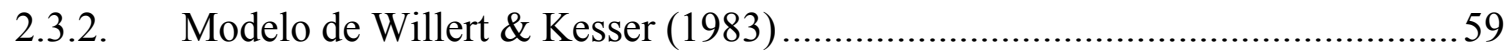

2.3.3. Outros estudos relevantes para cálice de fundações......................................... 63

\section{CAPÍTULO 3 - ASPECTOS DE PROJETO DE BLOCOS SOBRE ESTACAS}

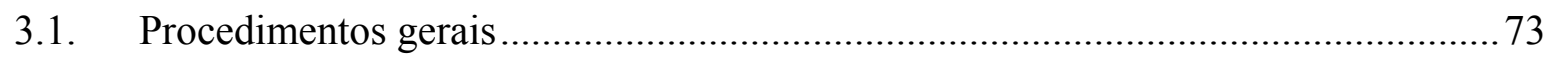

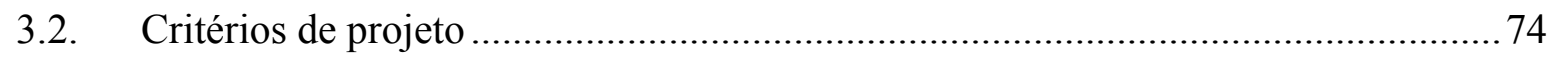

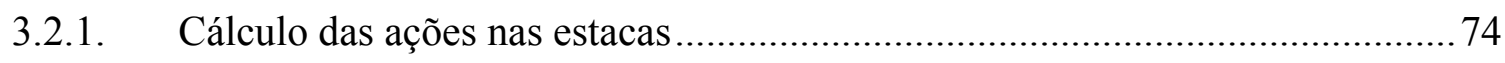

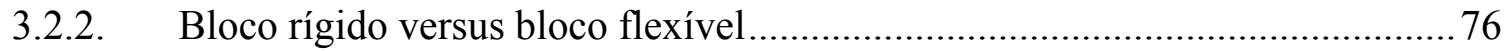

3.2.3. Recomendações a respeito da altura do bloco ............................................... 78 


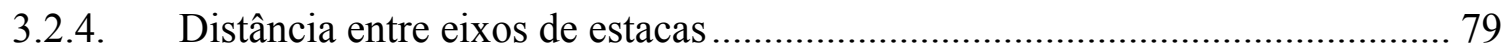

3.2.5. Distância entre eixo da estaca e a face do bloco ............................................ 80

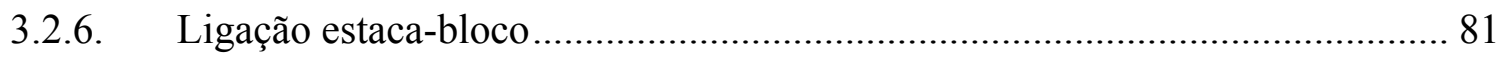

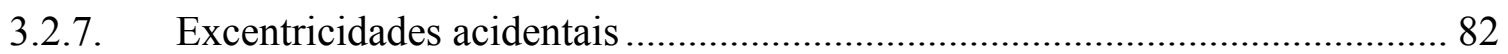

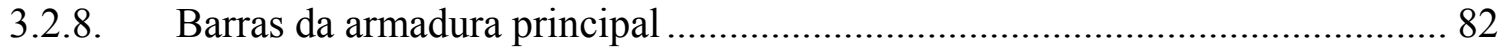

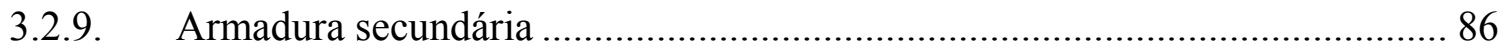

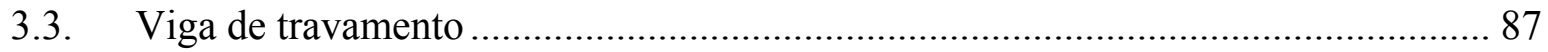

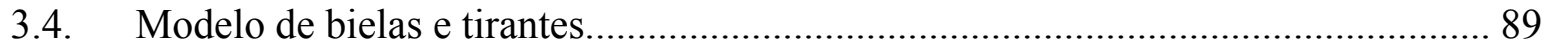

\section{CAPÍTULO 4 - AVALIAÇÃO DOS MODELOS NUMÉRICOS}

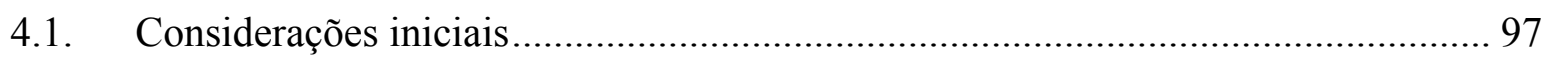

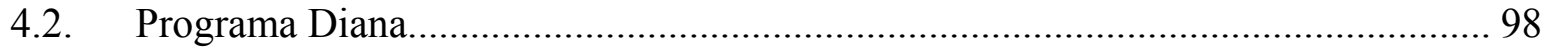

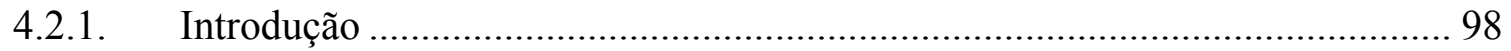

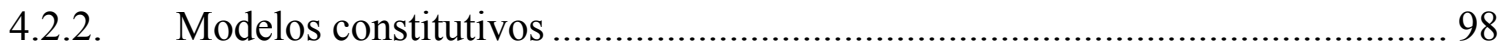

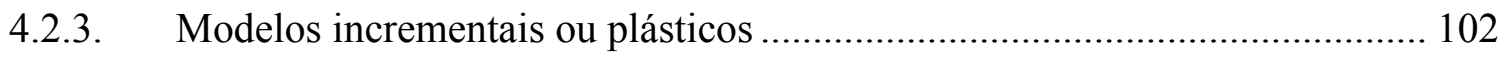

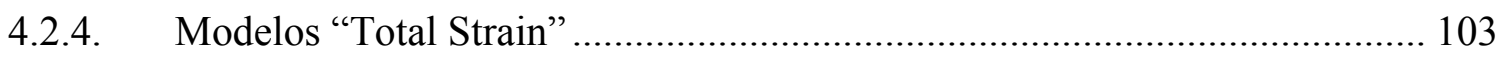

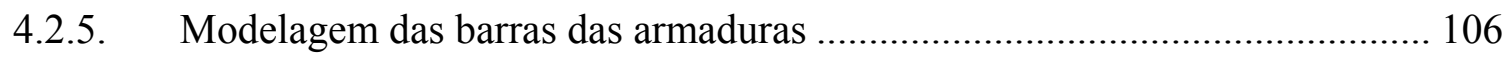

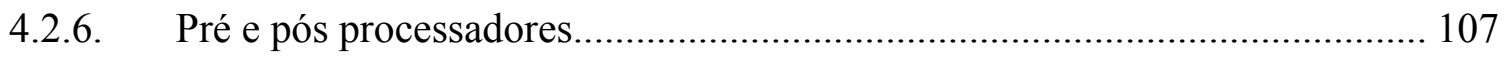

4.2.7. Critérios de solução do sistema de equações não-lineares.............................. 109

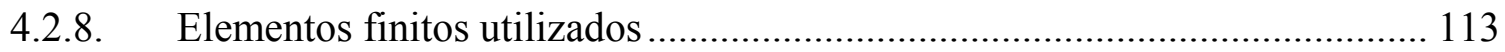

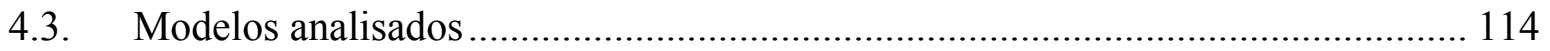

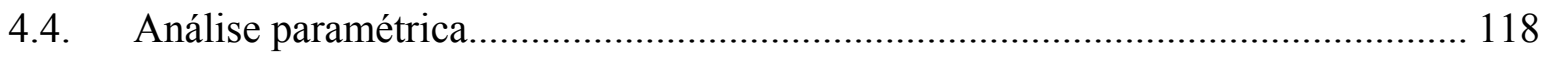

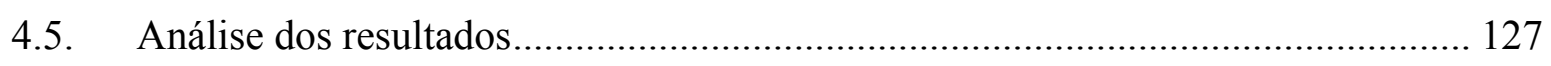

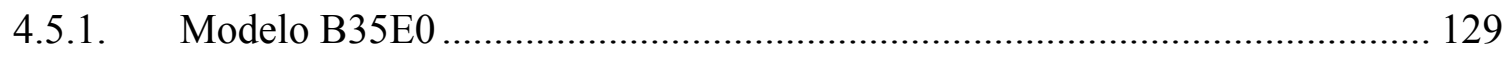

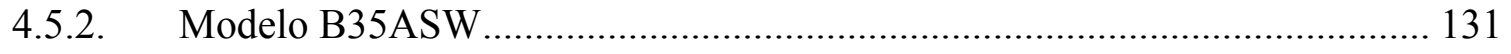

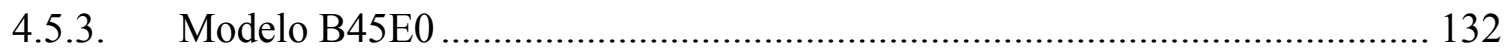

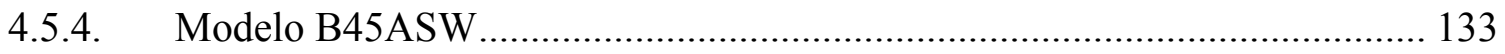

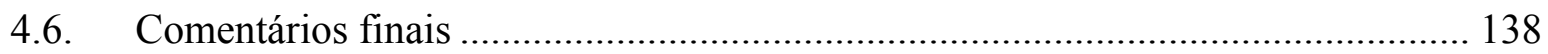

\section{CAPÍTULO 5 - BLOCO SOBRE DUAS ESTACAS COM CÁLICE EMBUTIDO}

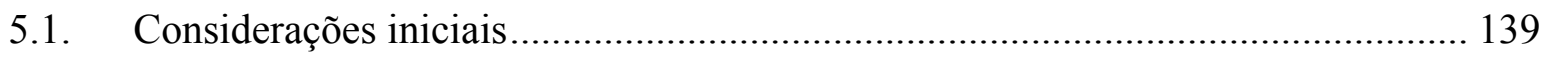

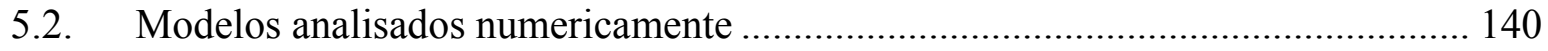




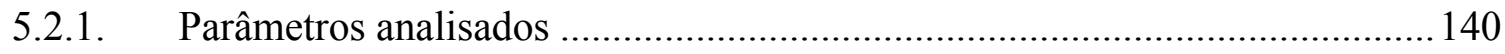

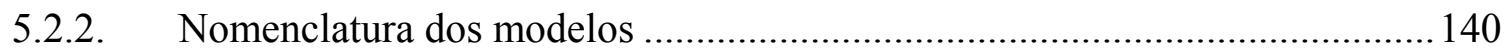

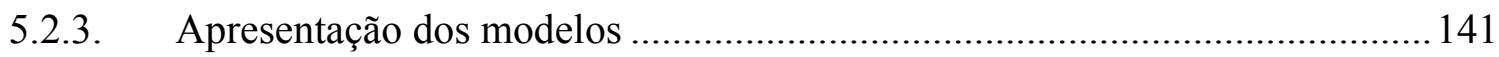

5.2.4. Geometria dos modelos e propriedades mecânicas ....................................... 143

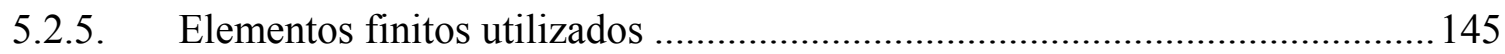

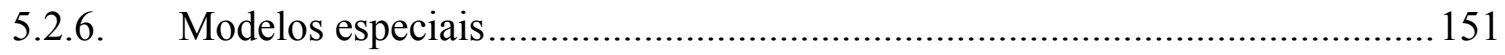

5.3. Apresentação e análise dos resultados............................................................. 153

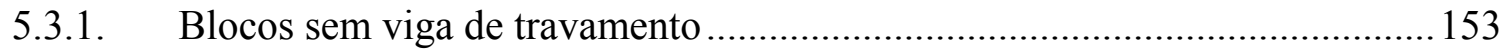

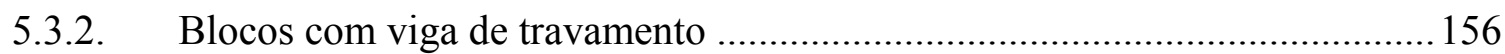

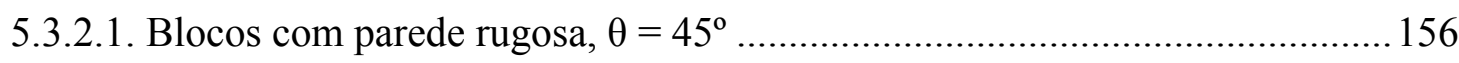

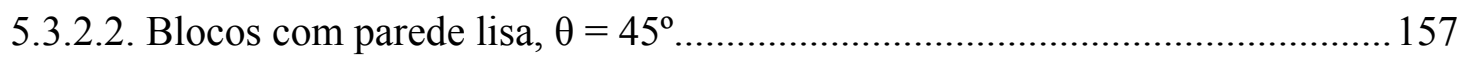

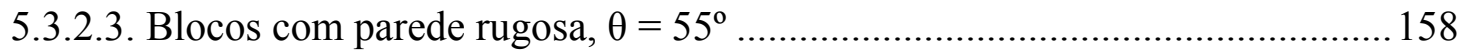

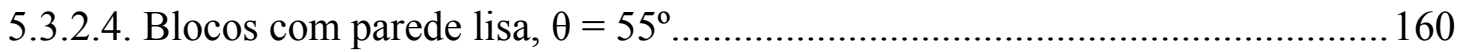

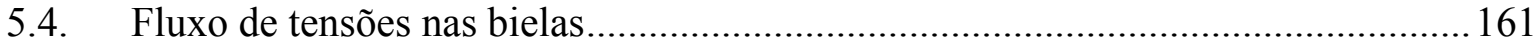

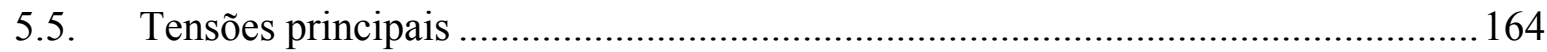

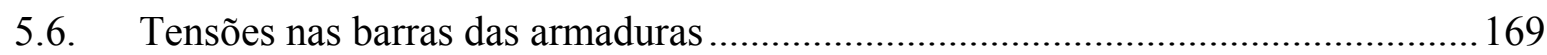

5.7. Resultados numéricos versus resultados analíticos .............................................. 174

\section{CAPÍTULO 6 - CONCLUSÃO}

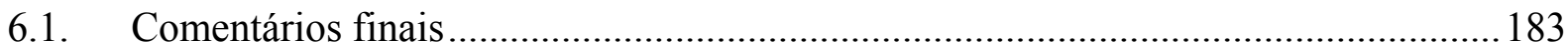

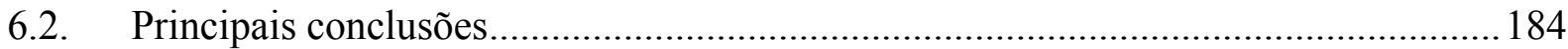

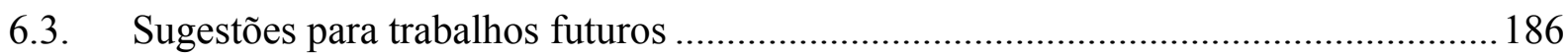

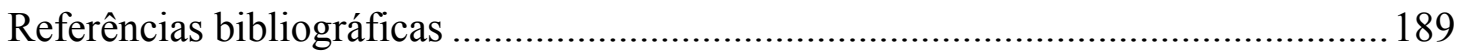





\section{Capítulo}

\section{Introdução}

\subsection{Considerações iniciais}

A escolha do tipo de fundação a ser utilizada numa obra depende essencialmente de parâmetros técnicos e econômicos que devem ser avaliados pelo engenheiro responsável pelo projeto. Diversos parâmetros a respeito do solo, tais como estratificação do terreno, situações topográficas, intensidade das ações, disposição das edificações limítrofes, bem como os tipos de fundação possíveis de serem realizados, são importantes para que se obtenha a melhor solução em termos da fundação a ser adotada.

Quanto ao tipo de fundação, estas podem ser classificadas em fundação direta (ou superficial) e fundação profunda. Fundação direta é aquela em que as camadas superiores do terreno são capazes de absorver e dispersar as ações oriundas da superestrutura. Nesse tipo de fundação, destaca-se o uso corrente de sapatas e blocos.

Quando as camadas superiores do terreno não são capazes de resistir às ações, é necessário recorrer a camadas mais profundas do solo, realizando, portanto, o uso de fundações profundas. Dentre as diversas soluções disponíveis, o uso de estacas de concreto armado é uma das mais difundidas no meio técnico, podendo ser dimensionadas considerando apenas sua resistência de ponta ou com o uso de atrito lateral, dependendo da situação. Porém, o uso desse tipo de solução requer um novo elemento estrutural capaz de realizar a ligação entre os pilares e as estacas. Tal elemento é conhecido como bloco de coroamento, bloco de 
fundação ou mesmo bloco sobre estacas. Segundo a ABNT NBR 6118:2003, "blocos são estruturas de volume usadas para transmitir às estacas as cargas de fundação".

Elementos de volume são aqueles em que as três dimensões possuem a mesma ordem de grandeza, não sendo válida, portanto, a hipótese de Bernoulli. Por não serem suficientemente longos para que se dissipem as tensões localizadas, as seções não permanecem planas após a deformação, tornando complexa a análise estrutural. Ainda de acordo com a ABNT NBR 6118:2003, os blocos são classificados como rígidos ou flexíveis. No caso de blocos rígidos o modelo estrutural adotado para cálculo e dimensionamento deve ser tridimensional, linear ou não, ou modelo de biela-tirante tridimensional, sendo esse último recomendado por definir melhor a distribuição de forças nas bielas e tirantes. No caso de blocos flexíveis, recomendam-se verificações mais completas, desde a distribuição das ações nas estacas e nos tirantes de tração, até a necessidade de verificação à punção.

O código americano ACI-318 (1994), o Inglês BS 8110 (1985) e o Indiano IS 2911 (1979) adotam hipóteses simplificadas com relação à geometria e as propriedades do material, e realizam análise elástica das tensões, recomendando o uso da teoria da flexão para dimensionamento do bloco sobre estacas. A norma espanhola EHE (2002), por sua vez, fornece expressões que permitem determinar a área das barras de armadura para os casos mais freqüentes de blocos sobre estacas, conforme o modelo de treliça adotado.

Os métodos usuais de dimensionamento de blocos sobre estacas utilizados no Brasil são baseados no código modelo CEB-FIP, Boletim 73 (1970) e no Método das Bielas. O CEBFIP recomenda o uso da teoria da flexão para blocos cuja distância entre a face externa do pilar e o eixo da estaca mais afastada esteja entre um terço e metade da altura do bloco. $\mathrm{O}$ método sugere o cálculo à flexão numa seção de referência interna em relação ao pilar, distante 0,15 vez a dimensão do pilar na direção considerada. Para verificações da capacidade resistente à força cortante, define-se uma seção de referência externa distante da face do pilar 
de um comprimento igual à metade da altura do bloco, e no caso de blocos sobre estacas vizinhas ao pilar a seção é considerada na própria face do pilar.

O método das bielas, por sua vez, foi desenvolvido baseado nos resultados experimentais de Blévot \& Frémy (1967), e considera a existência de uma treliça tridimensional no interior do bloco, composta por barras comprimidas (bielas) e tracionadas (tirantes). A força nas bielas é verificada pela resistência a compressão do concreto, enquanto que a força nos tirantes deve ser absorvida pelas barras de aço da armadura. Recomenda-se uma verificação das tensões nas regiões nodais, ou seja, no encontro pilar-bloco e blocoestaca.

O surgimento de novas tecnologias assim como o avanço na indústria da construção civil atinge diretamente os processos construtivos no que diz respeito ao tempo de construção, aumento da produtividade e redução de desperdício. Nesse cenário, o uso do concreto prémoldado se torna cada vez mais disseminado no meio técnico, por atender a essas novas exigências.

Estrutura em concreto pré-moldado é aquela que foi moldada em parte ou no todo fora do local definitivo de utilização. Diferencia-se de uma estrutura moldada in loco por apresentar diversas fases transitórias como desforma, armazenamento, transporte e montagem. Outro ponto importante no uso de estruturas pré-moldadas é o fato das peças serem fabricadas separadamente, necessitando, portanto, de elementos capazes de realizar a ligação entre essas peças.

A ligação se torna um ponto delicado e de grande importância na fase de projeto e construção, pois, caso não seja bem planejada, pode comprometer a rapidez e agilidade do uso de elementos pré-moldados, além de influenciar diretamente no comportamento estrutural desses elementos. 
De um modo geral, o uso de ligações mais simples desfavorece a distribuição de esforços, tornando alguns elementos mais solicitados a momentos fletores. Já as ligações que tentam reproduzir um comportamento monolítico do concreto, ou seja, com a transmissão de momentos entre os elementos, possuem um maior grau de dificuldade na sua execução, dependendo assim do bom senso do projetista em cada situação.

Os blocos sobre estacas são peças importantes quando da ligação do pilar pré-moldado com a fundação. Dentre as possíveis formas de ligação desses elementos, destaca-se o uso de blocos de fundação com cálice ou colarinho por apresentarem relativa facilidade de construção, possibilidade de ajuste e de transmissão de momentos dos pilares para as estacas.

O cálice é a parte do bloco que recebe o pilar pré-moldado, funcionando como um encaixe entre esses elementos, podendo ter as paredes lisas ou rugosas. O pilar fica em contato com o cálice num trecho denominado comprimento de embutimento $\ell_{e m b}$. Nesse tipo de ligação, três situações de cálices são admitidas conforme Figuras 1.1, 1.2 e 1.3: totalmente externo ao bloco, parcialmente embutido ou totalmente embutido no bloco.
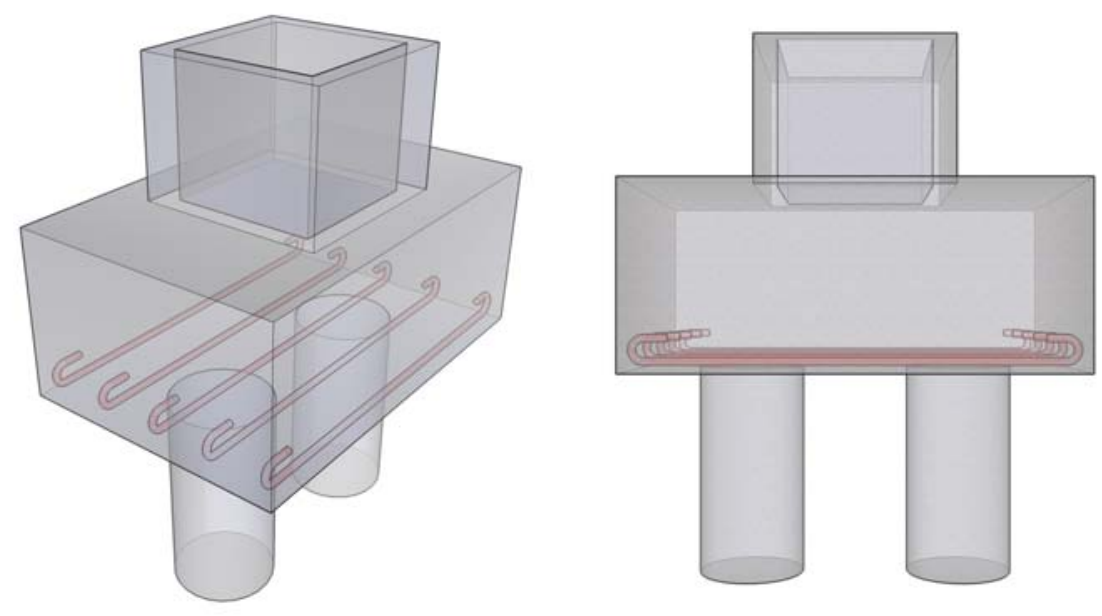

Figura 1. 1- Perspectiva do bloco de fundações com cálice externo 

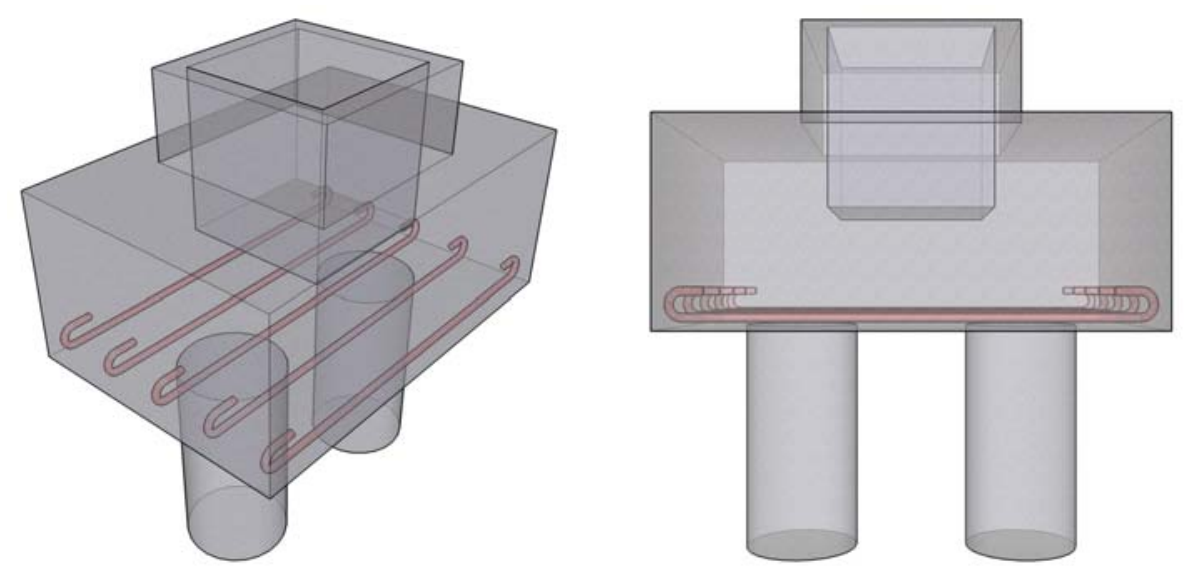

Figura 1. 2- Perspectiva do bloco de fundações com cálice parcialmente embutido
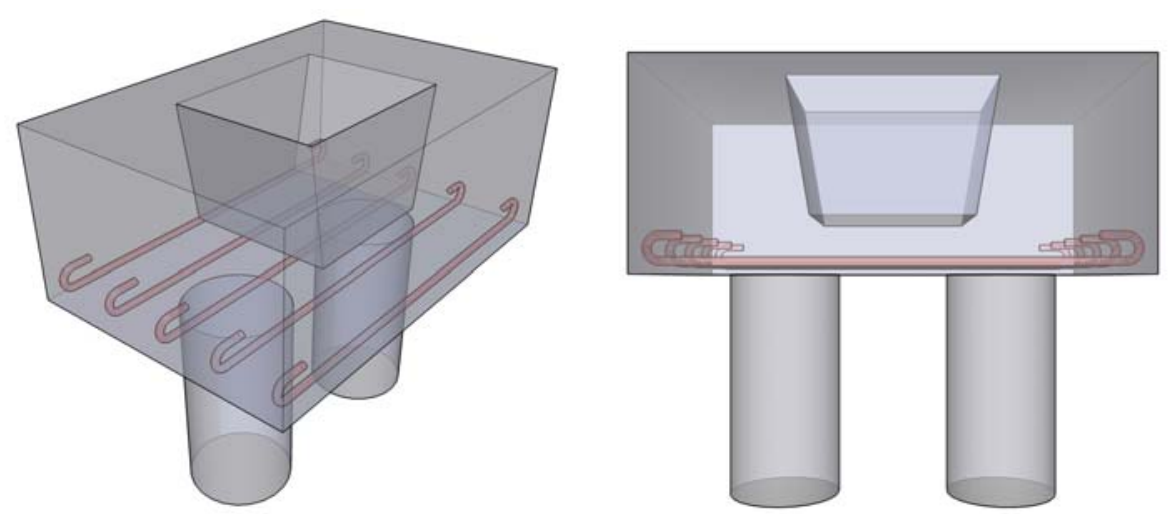

Figura 1. 3- Perspectiva do bloco de fundações com cálice totalmente embutido

Neste trabalho é dada ênfase ao bloco de fundação com cálice totalmente embutido. Particularmente, é investigado o comportamento do bloco mediante presença de viga de travamento vinculada à parede do bloco.

\subsection{Objetivo}

Os principais objetivos desse trabalho são:

- Estudar o comportamento de blocos sobre duas estacas com cálice totalmente embutido, utilizado na ligação pilar-fundação. 
- Analisar a influência que a presença da viga de travamento provoca no bloco de fundações com cálice embutido, verificando fluxo e distribuição de tensões principais, bem como curvas do tipo força versus deslocamento.

- Avaliar a eficácia do programa computacional DIANA na simulação numérica de modelos de blocos sobre duas estacas.

\subsection{Justificativa}

O uso cada vez mais freqüente de elementos pré-moldados em estruturas usuais exige que os engenheiros tenham conhecimento técnico e prático a respeito do assunto. No caso de elementos pré-moldados, existe ainda uma vasta lacuna a ser preenchida com base em pesquisas e experimentos.

Diante desse cenário, o elemento bloco sobre estacas utilizado na ligação pilarfundação, ainda apresenta comportamento em parte desconhecido pelo meio técnico, que se utiliza de recomendações práticas na sua construção, principalmente nos casos em que o cálice se apresenta totalmente embutido no bloco. Pesquisas como as de Canha (2004), Jaguaribe Jr. (2005) e Ebelling (2006) forneceram respostas a muitas dúvidas a respeito do comportamento do pilar e da ligação pilar-fundação utilizando cálice totalmente externo.

Assim, em virtude da ausência de bibliografia específica a respeito de cálice totalmente embutido, e, dando continuidade aos estudos a respeito de ligações em estruturas de concreto pré-moldado realizadas pelo Departamento de Engenharia de Estruturas da EESC-USP, justifica-se a realização desse trabalho. 


\subsection{Método}

Para as análises realizadas nesse trabalho, utilizaram-se resultados provenientes de modelos teóricos e analíticos, assim como resultados obtidos por meio de modelos numéricos utilizando o programa computacional DIANA baseado no método dos elementos finitos. Nesses modelos foram consideradas as não linearidades físicas do concreto e das barras de aço das armaduras.

Foi desenvolvida uma avaliação dos modelos numéricos do programa DIANA utilizando resultados experimentais e numéricos de outros pesquisadores. Esses últimos foram obtidos por meio do programa computacional ANSYS, bastante difundido no meio técnico. Com essa avaliação, foi possível estabelecer um modelo numérico capaz de fornecer bons resultados aos modelos de blocos sobre duas estacas com cálice totalmente embutido.

\subsection{Estrutura da dissertação}

A dissertação está dividida em seis capítulos, sendo que o primeiro apresenta as considerações iniciais, os objetivos e as justificativas para realização do trabalho.

O capítulo dois apresenta a revisão bibliográfica, na qual é feito um apanhado geral dos trabalhos desenvolvidos nessa área. Particularmente, a revisão encontra-se dividida em dois aspectos, sendo que o primeiro engloba os trabalhos de blocos sobre estacas e o segundo os trabalhos com ênfase no cálice de fundação.

O capítulo três faz uma revisão dos critérios de projetos usualmente utilizados no dimensionamento de blocos sobre estacas. São apresentadas recomendações de códigos normativos, bem como de pesquisadores renomados na área. 
O capítulo quatro apresenta informações a respeito da simulação numérica, na qual foi utilizado o programa computacional DIANA. São feitos alguns comentários a respeito da utilização do programa, modelos constitutivos, interface gráfica via pré e pós processadores e ferramentas específicas do DIANA. Ao final, é apresentado um modelo numérico capaz de representar o comportamento de blocos sobre duas estacas, obtido por meio de resultados experimentais e numéricos de outros pesquisadores.

O capítulo cinco apresenta os modelos de blocos com cálice totalmente embutido mediante presença da viga de travamento. São apresentados resultados referentes ao comportamento do bloco, fluxo e distribuição de tensões principais, tensões nas barras das armaduras e curvas do tipo força versus deslocamento.

O capítulo seis apresenta as principais conclusões obtidas no trabalho, bem como algumas sugestões para trabalhos futuros. 


\subsection{Considerações iniciais}

Neste capítulo é apresentado um resumo de diversas pesquisas feitas a respeito do comportamento estrutural de blocos de fundação, bem como do comportamento do cálice de fundação, necessário para a ligação com pilar pré-moldado. O texto encontra-se segmentado em duas partes distintas: na primeira apresentam-se os trabalhos com ênfase no elemento bloco de fundação, enquanto que na segunda encontram-se os trabalhos com ênfase no cálice de fundação. Ao longo da revisão, sempre que necessário, é apresentada uma análise crítica do material existente na literatura técnica.

\subsection{Pesquisas com ênfase no bloco de fundação}

\subsubsection{Ensaios de Blévot (1967)}

Buscando compreender o comportamento do método das bielas, os pesquisadores franceses Blévot \& Frémy (1967) realizaram ensaios em blocos sobre duas, três e quatro estacas, submetidos à ação de força centrada. Em todas as situações foi analisado o comportamento do bloco mediante diversos arranjos da armadura.

No caso dos blocos sobre duas estacas, foi adotada a largura do bloco de $40 \mathrm{~cm}$, e dimensões do pilar e das estacas de $30 \mathrm{~cm}$. O arranjo das barras da armadura, por sua vez, foi dividido em dois grupos: o primeiro com barras lisas dispostas sobre as estacas e com 
ganchos nas extremidades; o segundo grupo era composto por barras com nervuras, porém desprovidas de ganchos. Para ambos os modelos, a distância entre as estacas foi de quatro vezes o diâmetro da mesma, e a biela de compressão se manteve sempre com uma inclinação superior a $40^{\circ}$ em relação à face inferior do bloco. A Figura 2.1 representa os modelos ensaiados.
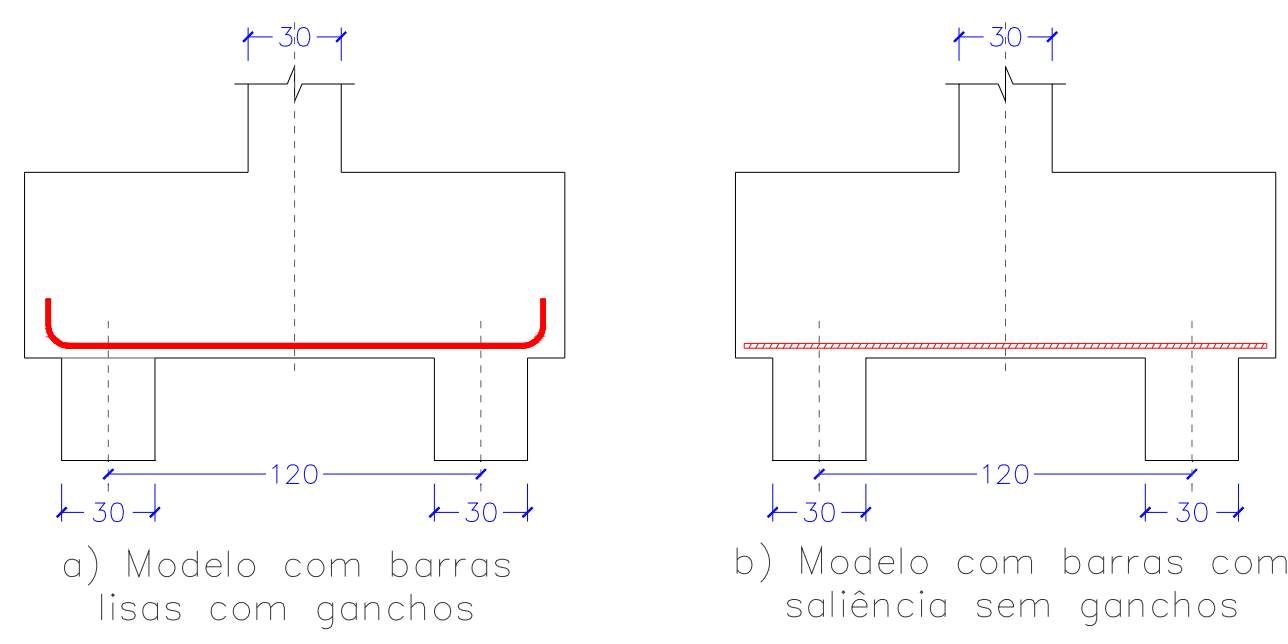

Figura 2. 1 - Blocos sobre duas estacas, Blévot \& Frémy (1967).

Após os ensaios, Blévot \& Frémy (1967) observaram a ocorrência de diversas fissuras ao longo da face lateral do bloco e na face inferior, antes da ruína, que por sua vez aconteceu de três modos: ruína por ruptura da biela de concreto próximo as estacas; ruptura da biela de compressão próximo ao pilar; e ruptura da biela de compressão próximo às estacas e ao pilar simultaneamente.

Verificou-se, também, que a tensão de compressão no concreto no encontro do pilar com o bloco superou em cerca de $40 \%$ o valor da sua resistência característica $f_{\text {ck. }}$ Já nas armaduras, constatou-se o escorregamento das barras com saliências e sem ganchos, o que não ocorreu nos modelos de barras lisas. 
Diante do exposto, Blévot \& Frémy (1967) concluíram que os blocos sobre duas estacas precisam ter a biela de compressão inclinada em relação a sua face inferior com ângulo dentro do intervalo da expressão 2.1:

$45^{0} \leq \theta \leq 55^{0}$

Tratando dos blocos sobre três estacas, Blévot variou o arranjo das armaduras, dividindo os blocos em cinco grupos: a) Barras dispostas segundo os lados do bloco; b) Barras em laço contornando as estacas; c) Barras segundo as medianas do bloco; d) Barras combinadas segundo os lados e as medianas; e) Barras dispostas em malha.
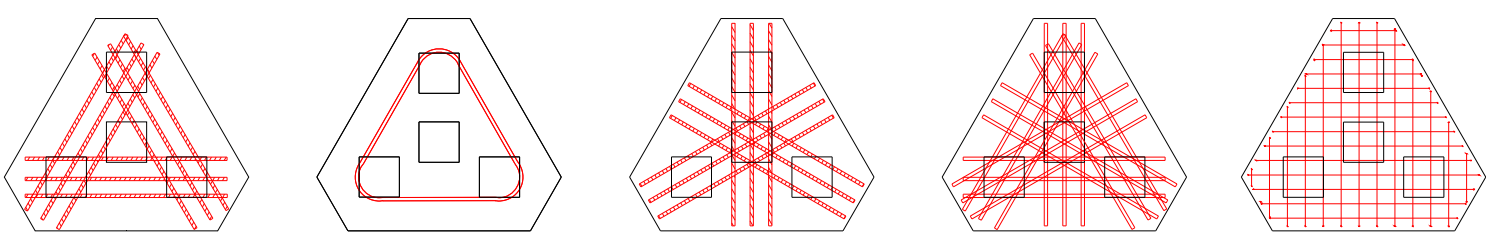

Figura 2. 2 - Blocos sobre três estacas, Blévot \& Frémy (1967).

Os quatro primeiros modelos da Figura 2.2 apresentaram boa eficiência, sendo que no modelo $d$ as barras segundo os lados deve ser preponderante em relação às barras das medianas. Já o modelo $e$ apresentou força de ruína próxima de $50 \%$ em relação ao valor de dimensionamento. Na maioria dos casos a ruína se deu por fendilhamento do concreto próximo as estacas.

Segundo Leonhardt \& Mönnig (1978), uma das justificativas para a ruína precoce dos blocos com distribuição em malha é a falta de armadura de suspensão, pois "em situações em que a distância entre os eixos das estacas for maior que três vezes o diâmetro das mesmas, faz-se necessário dispor, no banzo, armadura de suspensão”. Entretanto, essa não pode ser a principal justificativa, uma vez que a geometria de todos os grupos de blocos é a mesma. 
Os modelos dos grupos $a$ e $b$ apresentaram melhor comportamento em relação à fissuração segundo os lados do bloco, porém não apresentaram um bom comportamento em relação à face inferior do bloco, indicando a necessidade de se dispor de uma armadura mínima para limitar as aberturas das fissuras proveniente das tensões de tração nessa região.

O comportamento do bloco em relação à punção também foi observado e constatou-se que, mantendo a inclinação da biela superior a $40^{\circ}$, não existe o risco da ocorrência de punção.

Nos modelos com ângulo de inclinação da biela entre $40^{\circ}$ e $55^{\circ}$, a força de ruína obtida nos ensaios foi superior ao previsto pela analogia das bielas. Entretanto, nos casos em que as bielas se encontram com uma inclinação inferior a $40^{\circ}$, os fenômenos de ruptura ocorreram de forma complexa e, no caso de inclinação superior a $55^{\circ}$, ocorreu deslizamento das bielas de compressão, indicando um comportamento típico de consolo curto. Para as duas últimas situações, os valores de ruína obtidos nos ensaios foram inferiores aos de dimensionamento mostrando-se, portanto, contra a segurança.

Com exceção do modelo $e$, todos os outros chegaram à ruína com ações superiores ao previsto de acordo com o método das bielas, indicando que o método é confiável, e ocorreram por escoamento da armadura principal. Em nenhum caso observou-se ruína por punção.

Recomenda-se, portanto, que a inclinação das bielas de compressão para blocos sobre três estacas seja a mesma dos blocos sobre duas estacas.

Blévot \& Frémy (1967) também realizaram ensaios em blocos sobre quatro estacas, variando o arranjo das barras da armadura em cinco grupos: a) Barras dispostas segundo os lados do bloco, sobre as estacas; b) Barras em laço contornando as estacas; c) Barras segundo as diagonais do bloco, passando sobre a projeção do pilar; d) Barras combinadas segundo as diagonais e em laço; e) Barras disposta em malha. 

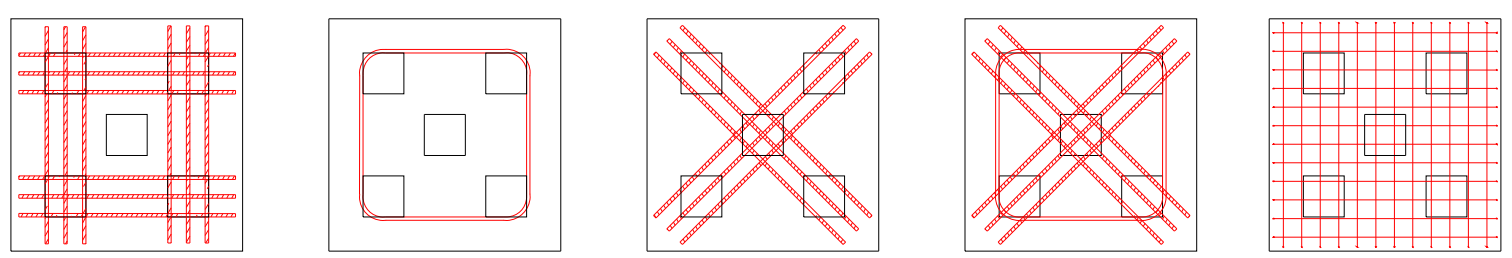

Figura 2. 3 - Blocos sobre quatro estacas, Blévot \& Frémy (1967)

Os blocos com arranjo das armaduras nos casos $a$ até $d$ obtiveram bom comportamento em relação à força de ruína. Entretanto, os blocos da situação $e$ (armadura em malha) atingiram a ruptura com valores próximos a $80 \%$ em relação aos demais modelos.

Em termos de fissuração os blocos com barras da armadura dispostas sobre as diagonais apresentaram intensa fissuração para pequenas intensidades de força. $\mathrm{O}$ modelo $b$ apresentou fissuras com aberturas excessivas na parte inferior do bloco, indicando a necessidade de se dispor de uma armadura mínima para limitar essas aberturas. O grupo $d$ obteve melhor comportamento em relação à fissuração.

Em todos os modelos sobre quatro estacas observou-se que a ruína ocorreu a partir de fissuras formadas no encontro estaca-bloco. Em nenhuma situação ocorreu ruína por punção. Os resultados obtidos mostraram-se coerentes com os valores teóricos de dimensionamento, baseados no método das bielas.

\subsubsection{Ensaios de Mautoni (1972)}

Mautoni (1972) realizou ensaios em blocos sobre duas estacas, com o intuito de analisar os mecanismos de ruína e determinar a força última no bloco, em função da ruptura das bielas de compressão. Para tanto, fez uso de uma expressão desenvolvida por ele, e que leva em consideração a taxa crítica de armadura. 
Os modelos ensaiados são representativos de blocos sobre duas estacas, bem como podem ser utilizados para estudos de consolo sem armadura de costura. No total, foram ensaiados vinte blocos com duas disposições das barras das armaduras: a) Barras da armadura em laçada contínua na horizontal; b) "Barras da armadura em bigode" com ganchos na extremidade.

Os blocos tiveram largura fixada em $15 \mathrm{~cm}$, assim como a largura do pilar. As estacas possuíam largura de $10 \mathrm{~cm}$, e espaçamento entre eixos variando entre $30 \mathrm{~cm}$ e $45 \mathrm{~cm}$. A altura dos blocos teve valor mínimo de $25 \mathrm{~cm}$, e também foi variada nos modelos. A Figura 2.4 apresenta um dos blocos ensaiados por Mautoni (1972).

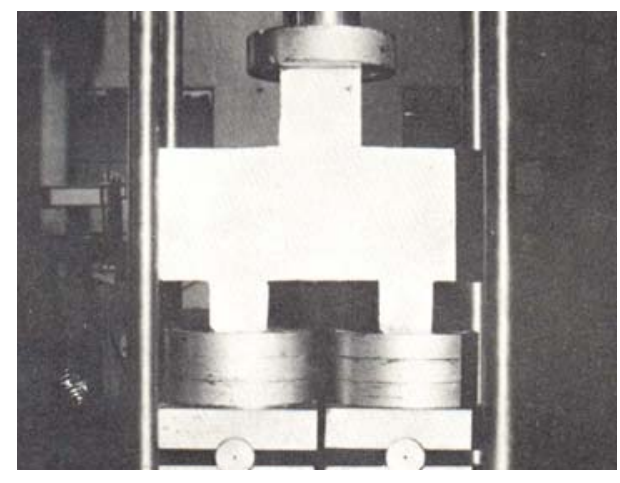

Figura 2. 4 - Bloco ensaiado por Mautoni (1972)

A armadura "em bigode" da Figura 2.5 possuía dois trechos semicirculares, melhorando as condições de ancoragem, além de ter ganchos nas extremidades. As barras da armadura em laçada contínua foram dispostas em camadas, sendo que suas extremidades eram semicirculares e separadas por um trecho central retangular.

Durante a realização dos ensaios, Mautoni (1972) observou que as primeiras fissuras ocorreram quando a força atingia cerca de $40 \%$ da força de ruína, e surgiam no meio do vão na região inferior do bloco. Quando as forças atingiam por volta de $70 \%$ da força última, não havia o surgimento de novas fissuras, ocorrendo apenas aumento das aberturas existentes. Observou-se, também, que as fissuras ocorriam sempre paralelas às bielas de compressão. 
A principal conclusão dos ensaios de Mautoni (1972) para blocos sobre duas estacas foi o estabelecimento de um método capaz de determinar a força última no bloco, bem como os mecanismos de ruína. A ruína ocorreu sempre por fendilhamento das bielas de compressão, apresentando ruptura entre as faces interna da estaca e do pilar. Esse tipo de colapso não é o ideal, por se tratar de ruptura frágil, sendo que a situação ideal é a de que ocorresse o prévio escoamento das barras das armaduras, ocasionando assim uma ruptura dúctil.

Por fim, Mautoni (1972) relatou as desvantagens de cada tipo de armadura. A armadura em laçada horizontal apresentou dificuldades de execução, e por se apresentar em diversas camadas, provocou redução da altura útil dos blocos. Já a "armadura em bigode” apresentou um grande consumo de aço, além de possuir inconvenientes na sua ancoragem. A Figura 2.5 apresenta as propriedades geométricas de um bloco com "armadura em bigode".

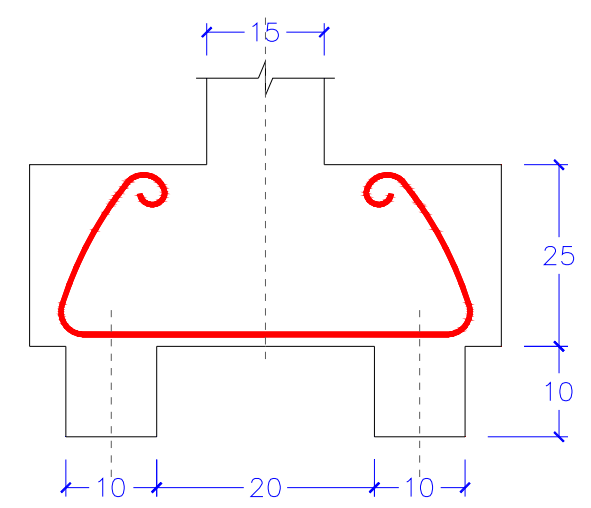

Figura 2. 5 - Propriedades geométricas de bloco com "armadura em bigode", Mautoni (1972)

\subsubsection{Ensaios de Taylor \& Clarke (1976)}

Taylor \& Clarke (1976) apresentaram resultados de ensaios experimentais realizados em blocos sobre quatro estacas. O principal objetivo foi analisar a influência das disposições das armaduras. Para tanto, foram estudados três distribuições de barras da armadura e quatro diferentes tipos de ancoragem. 
A distribuição das barras das armaduras foi feita em três grupos: a) Barras da armadura distribuída em malha; b) Barras da armadura segundo os lados; c) Barras da armadura segundo as diagonais do bloco. Os quatro tipos de ancoragem usados foram: 1) Ancoragem reta; 2) Ancoragem com gancho; 3) Ancoragem com gancho prolongado até a face superior do bloco; 4) Ancoragem até a face superior do bloco, com gancho na extremidade.

A altura dos blocos foi fixada em $45 \mathrm{~cm}$. O diâmetro das estacas bem como a dimensão do pilar, possuía $20 \mathrm{~cm}$, e o espaçamento entre estacas adotado foi de duas vezes o diâmetro. Foram ensaiados blocos quadrados com larguras de $75 \mathrm{~cm}$ e de $95 \mathrm{~cm}$. Essas dimensões indicam que a biela de compressão possuía uma inclinação superior a $60^{\circ}$, diferente, portanto, das recomendações de Blévot.
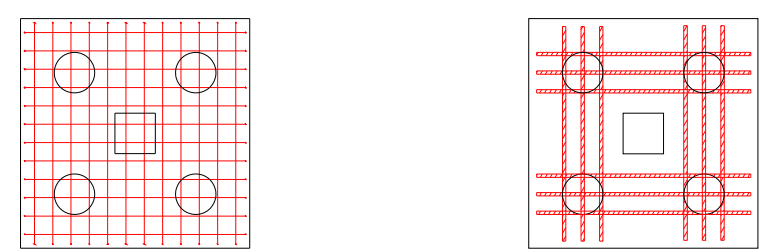

a) Armadura distribuida em malha
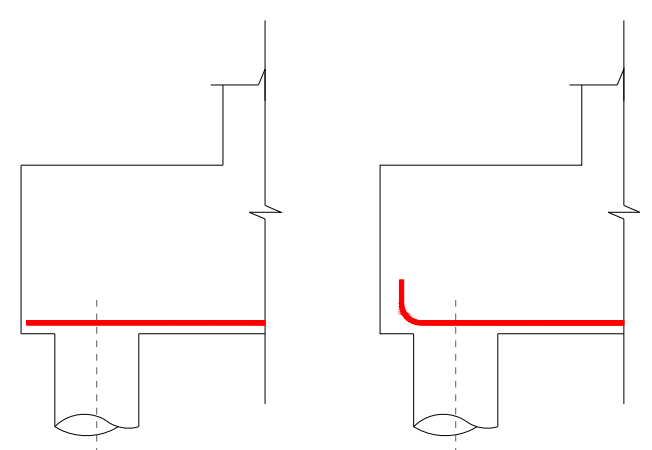
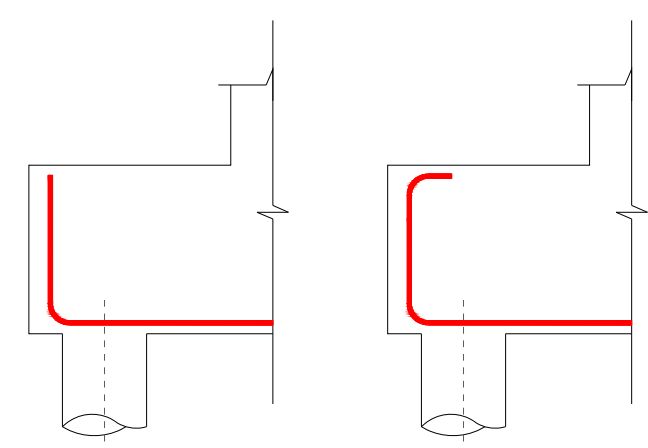

Figura 2. 6 - Detalhamento e ancoragem das barras, Taylor \& Clarke (1976) 
Durante a realização dos ensaios, todos os blocos tiveram praticamente o mesmo comportamento. Primeiramente, surgiram fissuras verticais nas linhas entre estacas nas quatro faces do bloco. A ruína se deu por fendilhamento, em virtude das fissuras inclinadas que surgiram de maneira brusca e paralelas à biela de compressão. Foram observadas duas formas diferentes de ruptura por fendilhamento. A primeira delas é própria da ruptura por cisalhamento em vigas, e pode ser vista na Figura 7-a, enquanto que a segunda pode ser observada na Figura 7-b.
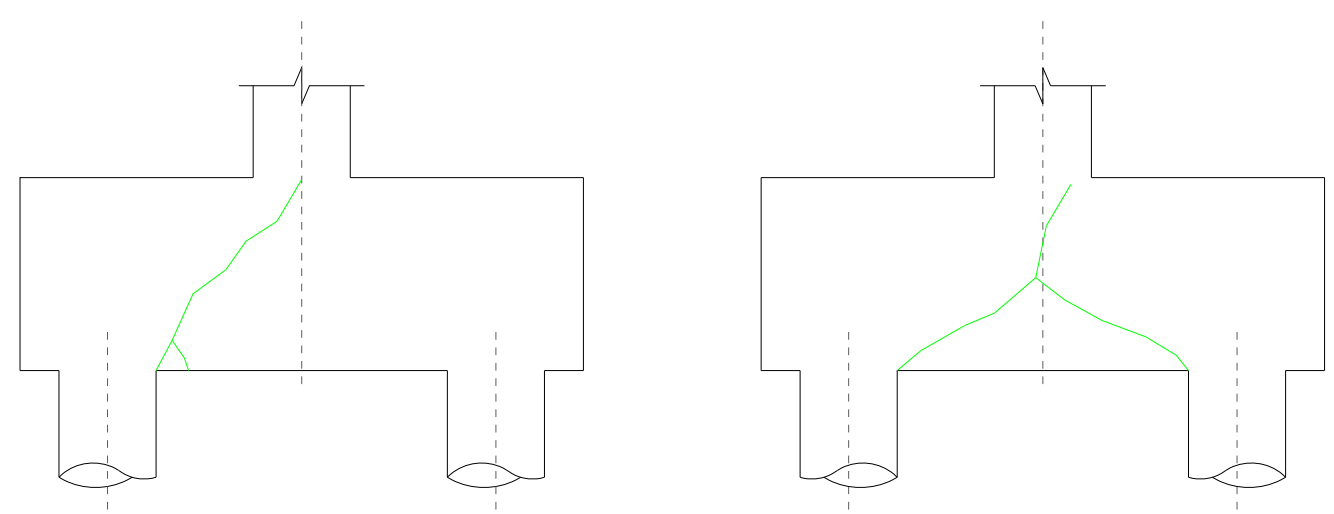

Figura 2. 7 - Configurações de ruína observadas por Taylor \& Clarke (1976)

A respeito do comportamento das ancoragens das barras, observou-se que as do tipo $1 \mathrm{e}$ 2, combinadas com barras distribuídas segundo os lados, obtiveram uma força de ruína cerca de $15 \%$ superior às demais combinações. As armaduras com distribuição em malha e segundo as diagonais tiveram praticamente a mesma força de ruína.

No caso de armadura distribuída em malha, verificou-se uma maior influência do tipo de ancoragem. Nesse caso, a ancoragem do tipo 3 forneceu uma força última cerca de $30 \%$ maior do que as do tipo 1 e 2 . Segundo Taylor \& Clarke (1976), isso se deve ao fato de que quando as barras da armadura são detalhadas com prolongamento vertical, a mesma funciona como armadura de suspensão, além de aumentar a capacidade resistente do bloco à força cortante. 
Em relação ao tipo de ancoragem 4, nenhum aumento significativo da força de ruína foi registrado.

\subsubsection{Ensaios de Adebar, Kuchma e Collins (1990)}

Adebar et al. (1990) realizaram ensaios em blocos de concreto armado sobre quatro e seis estacas, com o intuito de verificar a viabilidade do modelo tridimensional para o método de bielas e tirantes.

Foram observadas relações do tipo força versus deslocamento, valores de forças de reação nas estacas, deformações nas barras da armadura longitudinal bem como valores de forças que provocaram fissuração e ruína dos modelos.

A respeito da geometria dos blocos, os mesmos possuíam estacas com $20 \mathrm{~cm}$ de diâmetro e a força era aplicada numa área de $30 \mathrm{~cm}$ x $30 \mathrm{~cm}$, sendo que todos os modelos tinham altura útil em torno de $60 \mathrm{~cm}$. Os diversos modelos bem como a distribuição das barras das armaduras podem ser verificados na Figura 2.8.
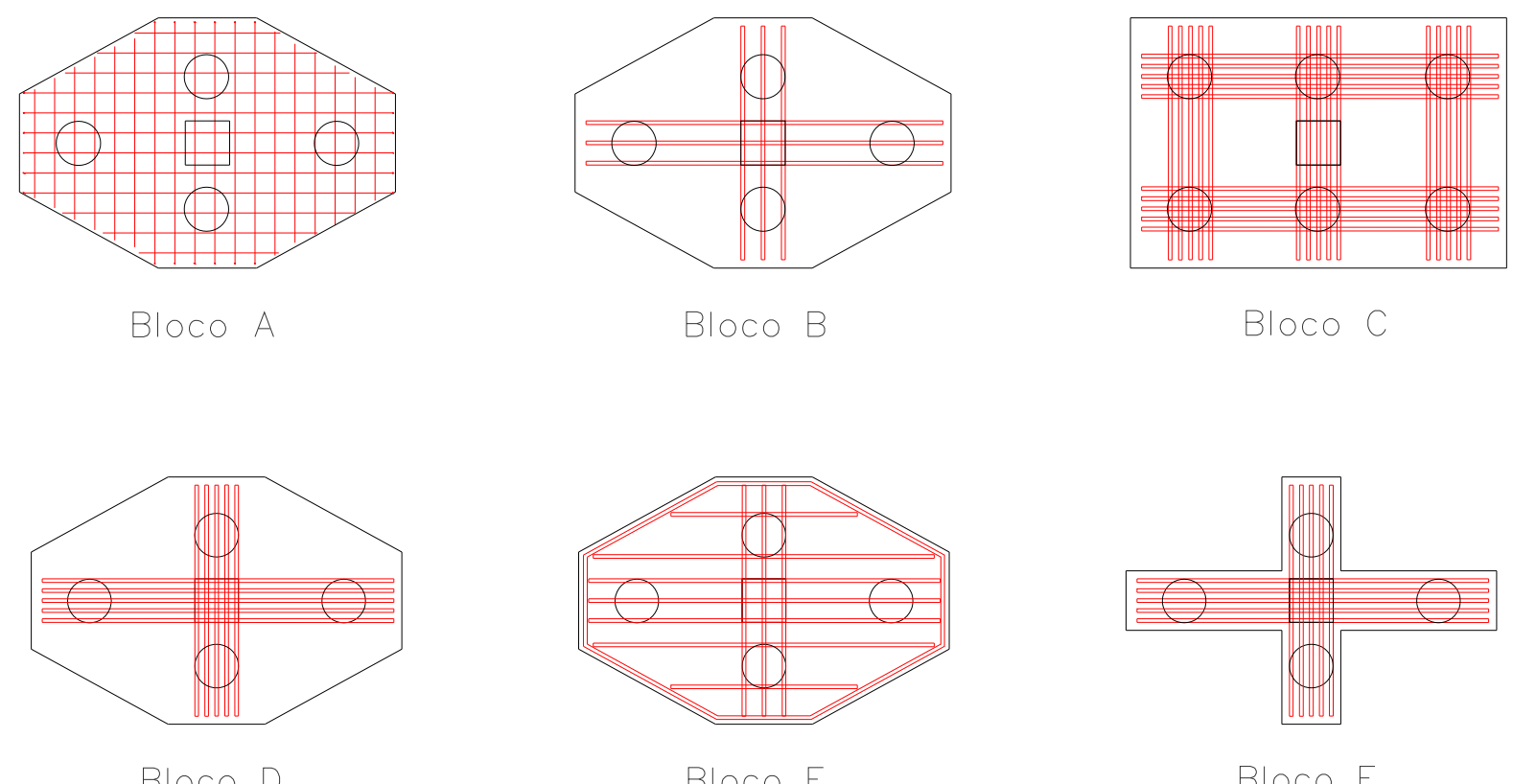

Figura 2. 8 - Blocos ensaiados por Adebar et al. (1990) 
Os blocos foram dimensionados segundo os critérios do ACI 318 (1983) e algumas recomendações do método de bielas e tirantes, sendo que sua principal diferença era o arranjo das armaduras. O Modelo A foi dimensionado segundo critérios do ACI 318 (1983) e era o modelo que possuía a menor área de barras da armadura longitudinal. Os modelos $\mathrm{B}, \mathrm{C}$ e D foram dimensionados segundo o método de bielas e tirantes, sendo que o modelo D possuía o dobro da área das barras da armadura do modelo B. O modelo E tinha as mesmas propriedades do modelo $\mathrm{D}$, porém possuía a armadura de distribuição segundo critérios do ACI 318 (1983). O último modelo foi construído para investigar uma hipótese do ACI 318 (1983) na qual o bloco tinha arranjo de armadura idêntico ao do modelo D, porém possuía reentrância nos quatro lados. De acordo com o ACI 318 (1983), esse modelo deve ter a força de ruína inferior ao modelo $\mathrm{D}$, enquanto que no método de bielas e tirantes, a força de ruína deve ser a mesma para os dois modelos.

As principais conclusões obtidas por Adebar et al. (1990) indicam que o código do ACI 318 (1983) não se mostrou compatível com os resultados experimentais. Resultados melhores foram obtidos de acordo com o método de bielas e tirantes. O modelo A apresentou força de ruína cerca de $83 \%$ do valor esperado, enquanto que o modelo B teve força de ruína cerca de $10 \%$ superior ao valor de dimensionamento.

Segundo os pesquisadores, os resultados do modelo A não foram compatíveis pelo fato do ACI 318 (1983) não considerar a altura do bloco no modelo de cálculo, e desprezar a influência da quantidade e da distribuição das barras da armadura longitudinal no bloco. Os blocos de grandes alturas, por suas vezes, sofreram grandes deformações antes da ruína, pois não foram flexíveis o suficiente para redistribuir os esforços solicitantes. Além disso, os pesquisadores concluíram que o comportamento estrutural dos blocos foi bem diferente do comportamento de uma viga. Apenas o modelo $F$ se comportou como duas vigas interceptadas ortogonalmente, comprovando a hipótese do ACI 318 (1983). 
Quanto à ruína dos modelos, os mesmos romperam por fendilhamento da biela de compressão, e não por esmagamento das mesmas. O fendilhamento ocorre em virtude da expansão das tensões de compressão, provocando tração na direção perpendicular as bielas. O modelo $\mathrm{F}$, que teve comportamento de viga, apresentou ruína por cisalhamento da viga mais curta, e não houve escoamento das barras da armadura longitudinal.

Com base nos resultados experimentais e em modelos numéricos baseados no método dos elementos finitos, Adebar et al. (1990) sugeriram um modelo refinado de biela e tirantes para dimensionamento de blocos sobre estacas. De acordo com a Figura 2.9, nota-se a expansão das tensões de compressão na biela de concreto e o surgimento de tensões de tração atravessando a biela. Assim, os pesquisadores sugeriram a existência de um tirante extra perpendicular à biela, com o intuito de absorver essas tensões. O tirante pode ser de concreto, desde que a resistência à tração do material seja respeitada.
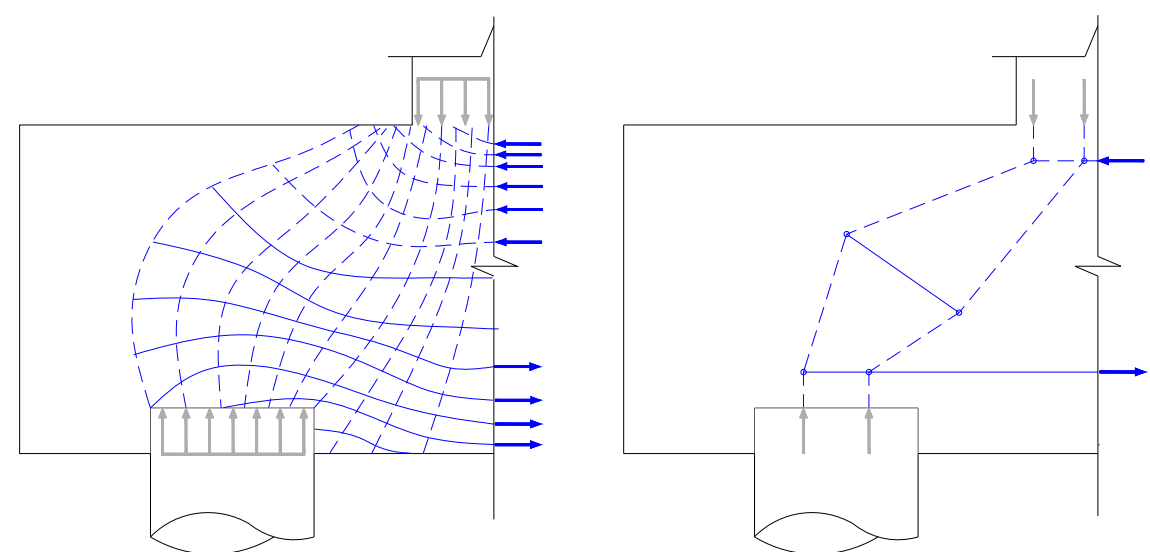

Figura 2. 9 - Modelo de Biela e Tirante sugerido por Adebar et al. (1990)

\subsubsection{Outros ensaios relevantes}

Iyer \& Sam (1991) conduziram análise elástica linear tridimensional em blocos sobre três estacas. Foi apresentada uma solução para as equações da teoria da elasticidade, dadas em termos do vetor de Galerkin, e as componentes desse vetor em termos de séries duplas de 
Fourier. As distribuições de tensões foram obtidas em função das condições de contorno, considerando a superposição dos efeitos de quatro soluções elásticas tridimensionais, para bloco retangular submetidos a diversos carregamentos. O bloco analisado encontra-se na Figura 2.10.
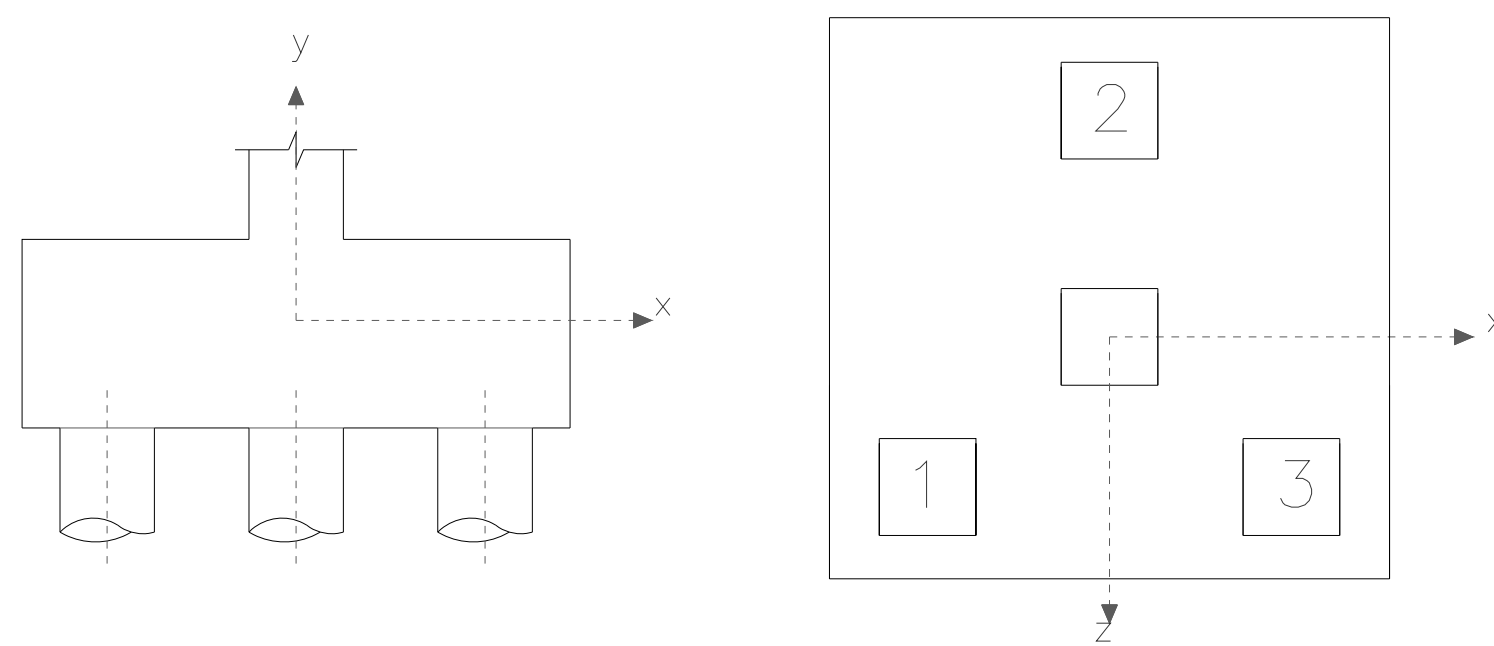

Figura 2. 10 - Bloco sobre três estacas analisado por IYER e SAM (1991)

Embora o bloco fosse de concreto armado, as análises feitas pelos pesquisadores consideraram o material com comportamento elástico linear, homogêneo e isotrópico. Essas análises indicaram uma solução inicial para a distribuição de tensões.

A análise indicou que as tensões máximas de tração na direção X ocorrem no plano YZ, em uma seção posicionada entre as estacas 1 e 3, quando se tem uma relação entre altura do bloco e espaçamento entre estacas igual à unidade. À medida que essa relação vai diminuindo, percebe-se que a seção onde atuam as máximas tensões de tração se aproxima da seção que contém o centro de gravidade do bloco. Com relação à direção $\mathrm{Z}$, ocorre comportamento semelhante, porém a seção com as máximas tensões de tração se situa no plano XY, entre a face do pilar e a estaca 2.

Os pesquisadores concluíram que dos métodos existentes, tanto a analogia de treliça de Blévot \& Frémy (1967) como a teoria de flexão, que considera o bloco como uma viga 
simplesmente apoiada nas estacas, apresentam resultados satisfatórios, mesmo não apresentando posição e magnitude das tensões de tração com requerida precisão.

Iyer \& Sam (1992) repetiram as mesmas análises feitas no ano anterior, porém utilizando blocos sobre duas e quatro estacas.

Iyer \& Sam (1995) realizaram uma análise numérica não-linear, via método dos elementos finitos, para blocos sobre quatro estacas. O objetivo dessa análise era obter o comportamento das tensões, deslocamentos, deformações nas barras das armaduras, panorama de fissuração e a força de ruína.

Os modelos analisados tinham a mesma geometria, resistência do concreto e taxa geométrica de armadura, sendo variado apenas o arranjo das mesmas. Para o bloco sobre quatro estacas, foram consideradas três disposições para as barras das armaduras: barras distribuídas em malha; barras sobre estacas e barras em diagonal passando pelas estacas e pela projeção do pilar. Os modelos foram submetidos a diferentes carregamentos e, para consideração da não linearidade foi adotado o comportamento multiaxial de compressão do concreto incluindo deformações plásticas, fissuração do concreto e alteração do coeficiente de Poisson.

Os resultados obtidos por meio da análise numérica foram bastante divergentes dos resultados apresentados em outras pesquisas baseadas em ensaios experimentais. Segundo Iyer \& Sam (1995), o arranjo das barras das armaduras que resultou em maior força de ruína foi o que possuía distribuição em malha, enquanto que o arranjo com distribuição sobre as estacas obteve menor força última. O problema ocorreu, provavelmente, por causa do tipo de elemento finito utilizado para representar o concreto e as barras das armaduras, que provavelmente não conseguiu representar bem o comportamento existente entre esses materiais. 
Os pesquisadores perceberam ainda que, para pequenas intensidades de força, o comportamento de viga foi predominante no bloco, enquanto que para maiores intensidades a responsável pela resistência do bloco foi a diagonal comprimida.

Miguel (2000), em sua tese de doutorado, realizou ensaios experimentais e numéricos em blocos sobre três estacas, verificando também a ocorrência de escorregamento de barras com saliência. Entretanto, tal escorregamento só ocorreu após a ruptura da biela de compressão.

A pesquisadora concluiu que o método das bielas sugerido por Blévot \& Frémy (1967) mostrou-se conservador em relação à força de ruína. Em todos os modelos, a ruptura ocorreu por fendilhamento da diagonal comprimida, acompanhada do escoamento das barras da armadura longitudinal.

Miguel (2000) propôs valores limites para as tensões normais nas regiões nodais do bloco, isto é, no encontro pilar bloco e estaca bloco. Para a região nodal superior, a tensão ficou limitada em $0,40 \cdot f_{c m}$ independente do diâmetro da estaca. Na região nodal inferior, a tensão foi limitada a $0,50 \cdot f_{c m}$ para estacas com diâmetro de $20 \mathrm{~cm}$, e $0,30 \cdot f_{c m}$ para estacas com diâmetro de $30 \mathrm{~cm}$.

É importante relatar que é consenso no meio técnico que os modelos de cálculo para blocos sobre estacas baseados nos estudos de Blévot \& Frémy (1967) devem possuir limitações das tensões nas regiões nodais. Essa limitação é baseada na resistência característica do concreto a compressão.

Munhoz (2004), em sua dissertação de mestrado, realizou um estudo comparativo por meio de modelos analíticos e numéricos baseados no método dos elementos finitos. Nesse estudo, foi considerada a ação de força centrada em blocos sobre uma, duas, três, quatro e cinco estacas, e optou-se por variar as dimensões do diâmetro das estacas, bem como as da seção transversal do pilar. A autora adotou o comportamento do material como elástico linear, 
na qual não pôde ser considerado o efeito da perda de rigidez do bloco causada pela fissuração, nem o escoamento das barras da armadura longitudinal.

Munhoz (2004) constatou diferenças entre os modelos analíticos e numéricos, bem como no fluxo de tensões, quando da formação dos campos e trajetórias das mesmas. Analisando as direções das tensões principais, a pesquisadora propôs um modelo mais refinado de biela e tirante. Outra conclusão da pesquisadora foi que, no caso de blocos sobre cinco estacas, a disposição das estacas segundo os vértices de um quadrado e uma estaca no centro geométrico, não é a melhor alternativa a ser utilizada, visto que a estaca central recebe a maior parte da força aplicada. Uma solução melhor seria a adoção de estacas dispostas nos vértices de um pentágono regular.

Souza (2004) estudou elementos estruturais nos quais não é válida a hipótese de Bernoulli de que seções planas permanecem planas após a deformação do elemento. Como exemplos desses elementos, citam-se os dentes gerber, vigas-parede, consolos e blocos de fundação. Esses elementos podem ser divididos em regiões B e D, ou seja, regiões de Bernoulli e regiões de descontinuidade.

Para análise das regiões D, o pesquisador utilizou o método dos elementos finitos, método de bielas e tirantes e método Corda-Painel. Destaca-se nesse trabalho a utilização do programa DIANA, baseado no método dos elementos finitos, no qual o efeito da nãolinearidade física do concreto é melhor representado quando comparado a outros programas.

Souza (2004) simulou no programa DIANA blocos sobre duas estacas ensaiados por Mautoni (1972). Os resultados obtidos por meio da análise não-linear indicaram uma grande variação dos valores e, sua aplicabilidade nos escritórios de cálculo é questionada, haja vista o tempo requerido para obtenção dos resultados. O autor recomenda que a analise não-linear seja feita apenas para projeto de obras de grande porte, que necessitem de uma análise mais criteriosa. 
Delalibera \& Giongo (2004 - a) simularam numericamente blocos sobre duas estacas, com o intuito de investigar a influência das dimensões do pilar e das estacas no comportamento estrutural do elemento bloco de fundação. Para tanto, foi considerado na análise numérica o efeito da não-linearidade física e geométrica, bem como a aderência perfeita entre aço e concreto. Os autores concluíram, por meio de uma análise estatística, que o fator preponderante na determinação dos valores das tensões nas regiões nodal superior e inferior, é a altura do bloco.

Delalibera \& Giongo $(2004-$ b) simularam vinte e sete blocos sobre três estacas alinhadas. Os blocos possuíam as mesmas propriedades geométricas, variando o ângulo de inclinação da biela de compressão $\left(30^{\circ}, 45^{\circ}\right.$ e $\left.60^{\circ}\right)$, bem como as rigidezes de cada bloco, além do tipo de solo que servia de apoio as estacas.

Por meio do critério ANOVA (análise de variância), os autores concluíram que a rigidez do bloco, assim como a representação do solo como contínuo, têm importância relevante na distribuição de forças na cabeça das estacas. Em situações que a interação estaca-solo pode ser desconsiderada, o fator de maior relevância é o ângulo de inclinação da biela de compressão.

Os autores concluíram que os blocos mais rígidos, isto é, de maior inclinação da diagonal comprimida, apresentam uma melhor distribuição das forças na cabeça das estacas.

Souza \& Bittencourt (2006) analisaram numericamente o comportamento de blocos sobre estacas com o objetivo de discutir a classificação dos blocos em rígidos ou flexíveis, propondo o Método das Bielas e o Modelo de Viga como soluções viáveis para o problema de dimensionamento.

Os autores apresentam resultados de análises não-lineares, efetuadas para blocos rígidos sobre quatro estacas com diferentes disposições para as barras de aço da armadura longitudinal, com o objetivo de apresentar as potencialidades do Método dos Elementos 
Finitos e dos modelos de fissuração distribuída em problemas de fraturamento tridimensionais.

Após análise de vários ensaios experimentais relatados na literatura técnica, os pesquisadores concluíram que a ruína dos modelos se deu por fendilhamento da diagonal comprimida seguido do esmagamento da mesma junto às zonas nodais inferior e superior, ou seja, no encontro pilar-bloco e estaca-bloco. Por fim, sugerem que se utilize uma malha na face inferior do bloco com intuito de limitar as aberturas de fissuras e evitar a ruína prematura dos blocos.

Delalibera (2006), em sua tese de doutorado, estudou numérica e experimentalmente blocos sobre duas estacas submetidos à ação de força centrada e excêntrica. Inicialmente, procedeu-se uma análise numérica tridimensional com a consideração da não-linearidade física e geométrica, assim como o efeito da fissuração e do posicionamento das barras de aço da armadura longitudinal.

O pesquisador constatou que a geometria da biela de compressão diverge dos modelos usualmente sugeridos por outros autores. Por meio do critério ANOVA (análise de variância) o autor verificou que as variáveis preponderantes são: o ângulo de inclinação da biela de compressão, a área da seção transversal do pilar, e a posição da força de compressão.

Delalibera (2006) realizou ensaio experimental em quatorze blocos, com o intuito de observar a geometria da biela de compressão, bem como verificar a eficiência dos ganchos das barras da armadura longitudinal na ancoragem das mesmas.

O pesquisador constatou que, no caso de blocos rígidos, a deformação nos ganchos foi próxima de zero. Comportamento similar foi observado por Adebar et al. (1990) e Miguel (2000). Tratando de blocos rígidos, a ABNT NBR 6118:2003 exige a presença desses ganchos no detalhamento das barras da armadura principal de tração. O autor verificou também que as deformações nas barras de aço não são constantes, sofrendo significativa 
redução nas seções que atravessam a biela de compressão. Esse efeito ocorre em virtude do confinamento que a biela comprimida provoca nas barras da armadura longitudinal, principalmente na região sobre as estacas. Esses resultados foram confirmados por meio de análise numérica não-linear e tridimensional, na qual foi considerado o fenômeno da fissuração do concreto. Por fim, em função dos resultados obtidos, o autor propõe modelos de bielas e tirantes aplicados a bloco sobre duas estacas.

Ramos (2007) realizou análise numérica em um bloco de fundação sobre dez estacas. O objetivo da pesquisa foi estudar o comportamento das reações de apoio nas estacas do bloco de fundação, quando da variação de alguns parâmetros. Nesse caso, variou-se a altura do bloco, a intensidade das ações (força concentrada e momento) e o tipo de apoio proporcionado pelo solo, sendo deformável ou indeformável.

O pesquisador concluiu que os resultados obtidos por meio da análise numérica divergem dos obtidos com base nos critérios usuais de dimensionamento de blocos sobre várias estacas, uma vez que esses critérios não levam em conta a altura do bloco nem o tipo de vinculação empregado.

Ramos (2007) verificou ainda que, na pior situação, houve variação de mais de $200 \%$ nas reações das estacas comparando com os valores obtidos analiticamente, e percebeu também que as estacas mais próximas ao pilar recebem uma maior parcela da ação solicitante. O autor verificou ainda que a resistência característica a compressão do concreto tem pouca influência na determinação da rigidez dos blocos, sendo a altura dos blocos e o tipo de vinculação fatores de maior relevância.

Nori \& Tharval (2007) apresentam aplicações do método de bielas e tirantes para blocos sobre duas, três e quatro estacas. Os pesquisadores comparam os valores das forças nos blocos sobre estacas obtidos por meio do modelo de biela e tirante, com os obtidos levando-se em 
conta o comportamento de viga, no qual são calculadas as forças numa seção de referência, que é a face do pilar.

Os pesquisadores utilizaram espaçamento entre estacas de duas vezes e meia o diâmetro da estaca e recomendam que, na utilização de bielas e tirantes, a altura do bloco não seja inferior à metade do espaçamento entre as mesmas. A Figura 2.11 apresenta a geometria e as forças em dois diferentes modelos de biela e tirante para bloco sobre duas estacas.

A respeito do modelo, os pesquisadores afirmam que a posição das bielas e dos tirantes depende não somente da estrutura, mas também do tipo de ação que atua sobre a mesma. Por mais simples que seja uma estrutura, existem várias combinações de ações possíveis, o que conduz a diversas configurações de bielas e tirantes. Os pesquisadores atentaram para o fato de que as maiores forças nos tirantes ocorrem para as maiores reações nas estacas. Dentre as várias configurações possíveis para o posicionamento das bielas e dos tirantes, é recomendando utilizar o modelo em que exista o menor número de tirantes.
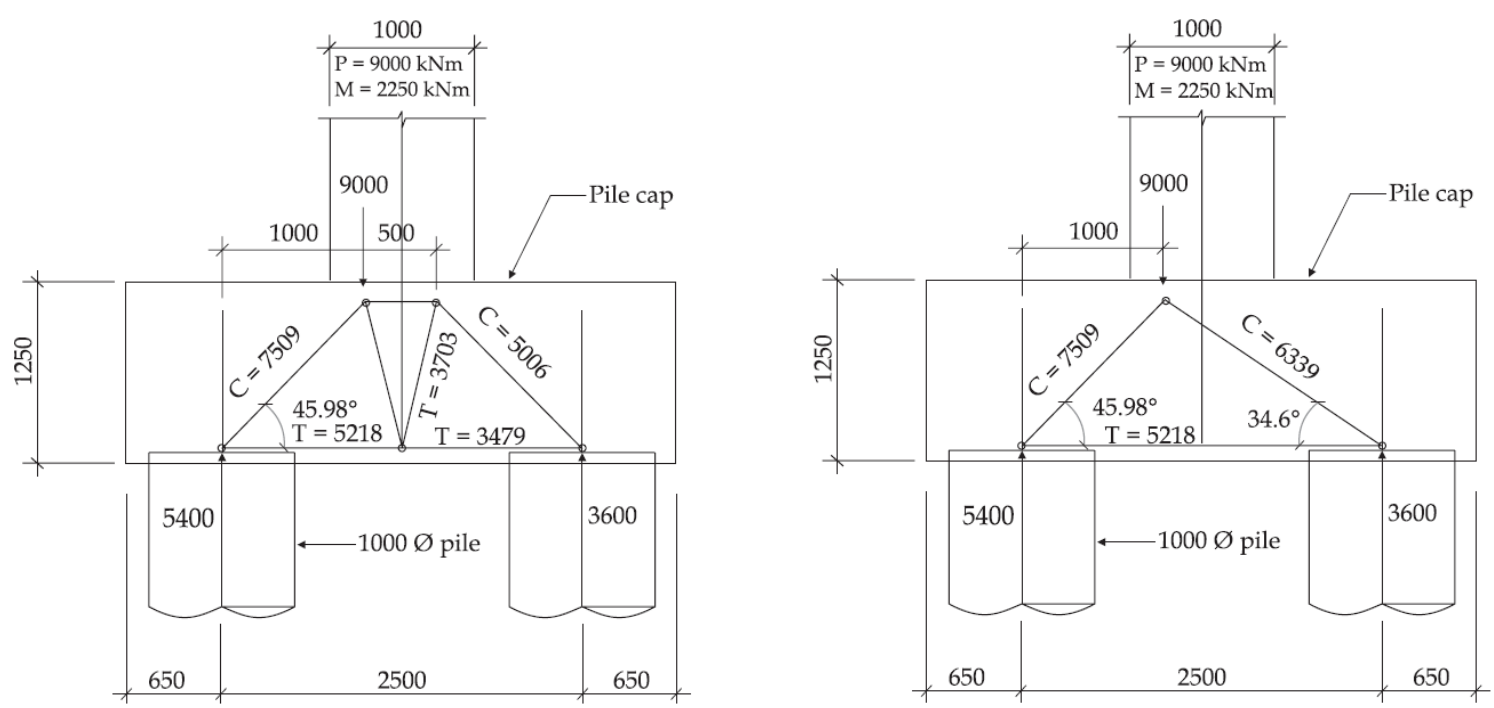

Figura 2. 11 - Modelos de biela e tirante para blocos sobre duas estacas, Nori \& Tharval (2007)

Nori \& Tharval (2007) sugerem verificar as tensões nas regiões nodais baseado nas expressões do ACI 318:2005. Recomendam ainda que não se utilize ângulos pequenos entre 
bielas e tirantes, devendo sempre que possível utilizar valores superiores a $45^{\circ}$, embora o ACI 318:2005 permita ângulos de até $25^{\circ}$.

Por fim, os pesquisadores concluem que o método de bielas e tirantes resulta em valores confiáveis para dimensionamento do estado limite último, evitando colapso da estrutura. Entretanto, recomenda-se dispor de armaduras adicionais, além das dos tirantes, que tenham outras finalidades, como construtiva, e de evitar fissuração excessiva do bloco de fundação.

\subsection{Pesquisas com ênfase no cálice de fundação}

\subsubsection{Modelo de Leonhardt \& Mönnig (1978) e NBR 9062:1985}

Os modelos de cálculo adotados para dimensionamento da ligação pilar-fundação por meio de cálice externo baseiam-se nas recomendações feitas por Leonhardt \& Mönnig (1978) e pela ABNT NBR 9062:1985.

De um modo geral, os modelos de cálculo diferenciam-se de acordo com a conformação da superfície da parede do cálice, podendo esta ser lisa ou rugosa. Para qualquer dessas superfícies, tanto a ABNT NBR 9062:1985 como Leonhardt \& Mönnig (1978) recomendam que o trecho do pilar em contato com a parede do cálice tenha a mesma conformação. A Figura 2.12 reproduz um esquema geral da geometria e das forças transmitidas à fundação. 

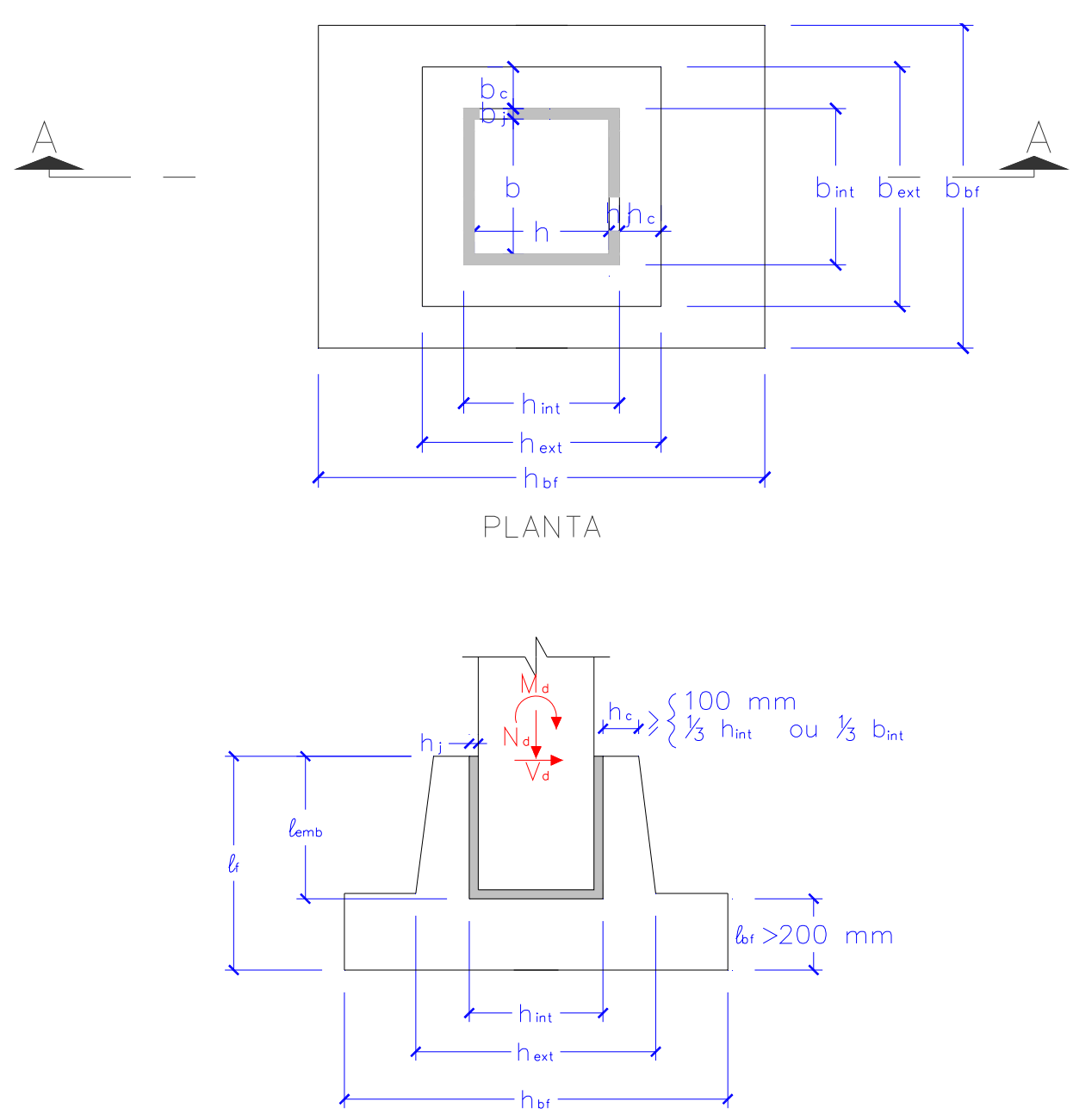

Figura 2. 12 - Geometria do cálice e forças transmitidas à fundação - adaptado de El Debs (2000)

A espessura da parede deve ser igual a um terço da menor distância interna entre as paredes do cálice, ou a $10 \mathrm{~cm}$, utilizando sempre o maior desses valores. A distância entre o fundo do cálice e o fundo da sapata deve ter um valor mínimo de $20 \mathrm{~cm}$.

Para o caso de superfícies rugosas, recomenda-se que a superfície lateral do pilar e a parede do cálice tenham nervuras ou mossas, que podem ser obtidas com a utilização de fôrmas onduladas ou denteadas. Será considerada superfície rugosa aquela que possuir ao menos $1 \mathrm{~cm}$ de saliência a cada $10 \mathrm{~cm}$ de profundidade da parede.

A ligação pilar-fundação está garantida quando do preenchimento do espaço entre as paredes do cálice e do pilar. Esse espaço tem a finalidade de facilitar o posicionamento do 
pilar em planta e em nível, por meio do uso de cunhas dispostas nas quatro paredes do cálice. As cunhas têm a função de impedir o movimento lateral do pilar, e só serão removidas quando do preenchimento desse espaço, que deve ser feito com graute ou concreto. O concreto de preenchimento deve ter resistência igual ou superior a do pilar ou do colarinho e ser adensado por meio de vibrador de agulha. Não se recomenda para essa distância valor inferior a $5 \mathrm{~cm}$, a menos do uso de graute auto adensável. A Figura 2.13 ilustra o mecanismo de transferência das forças atuantes para a base e para as paredes do cálice de fundação, com conformação da parede lisa.
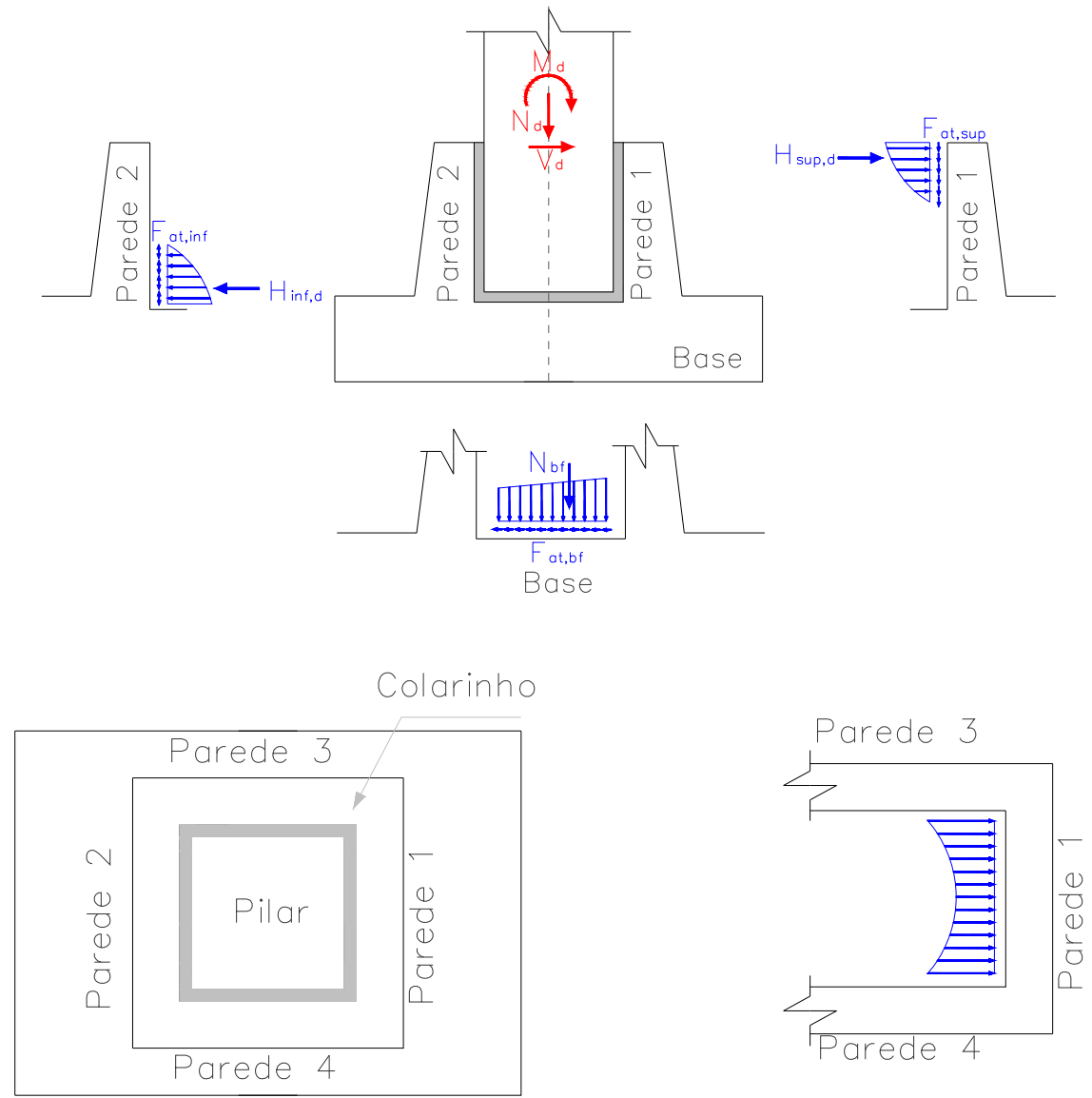

Figura 2. 13 - Transferência das ações no cálice de fundação com interface lisa - adaptado de EI Debs (2000)

A parcela do pilar que permanece em contato com o cálice é chamada de comprimento de embutimento $\ell_{\text {emb }}$. Esse comprimento, por sua vez, é função da excentricidade do 
carregamento, e da interface das paredes do cálice. A tabela a seguir contém os valores sugeridos por Leonhardt \& Mönnig (1978) e pela ABNT NBR 9062:1985.

Tabela 2.1 - Comprimento de embutimento do pilar segundo Leonhardt \& Mönnig (1978) e ABNT NBR 9062:1985

\begin{tabular}{c|c|c|c|c}
\hline \hline \multirow{2}{*}{ Interface } & \multicolumn{2}{|c|}{$\frac{M_{d}}{N_{d} h} \leq \mathbf{0 , 1 5}$} & \multicolumn{2}{c}{$\frac{M_{d}}{N_{d} h} \geq 0,15$} \\
\cline { 2 - 5 } & $\begin{array}{c}\text { NBR } \\
\mathbf{9 0 6 2 : 1 9 8 5}\end{array}$ & $\begin{array}{c}\text { Leonhardt \& } \\
\text { Mönnig (1978) }\end{array}$ & $\begin{array}{c}\text { NBR } \\
\mathbf{9 0 6 2 : 1 9 8 5}\end{array}$ & $\begin{array}{c}\text { Leonhardt \& } \\
\text { Mönnig (1978) }\end{array}$ \\
\hline Lisa & $1,50 h$ & $1,68 \cdot h$ & $2,00 \cdot h$ & $2,80 h$ \\
\hline Rugosa & $1,20 h$ & $1,20 h$ & $1,60 h$ & $2,00 h$ \\
\hline \hline
\end{tabular}

Conforme a Figura 2.14, a resultante das tensões nas paredes do cálice também é influenciada pela interface das mesmas. Quando se trata de parede rugosa, supõe-se que a resultante horizontal $H_{\text {inf,d }}$ é transmitida de forma concentrada para o fundo da parede transversal 2, aumentando assim o braço de alavanca $\mathrm{z}$ e reduzindo a intensidade das tensões.

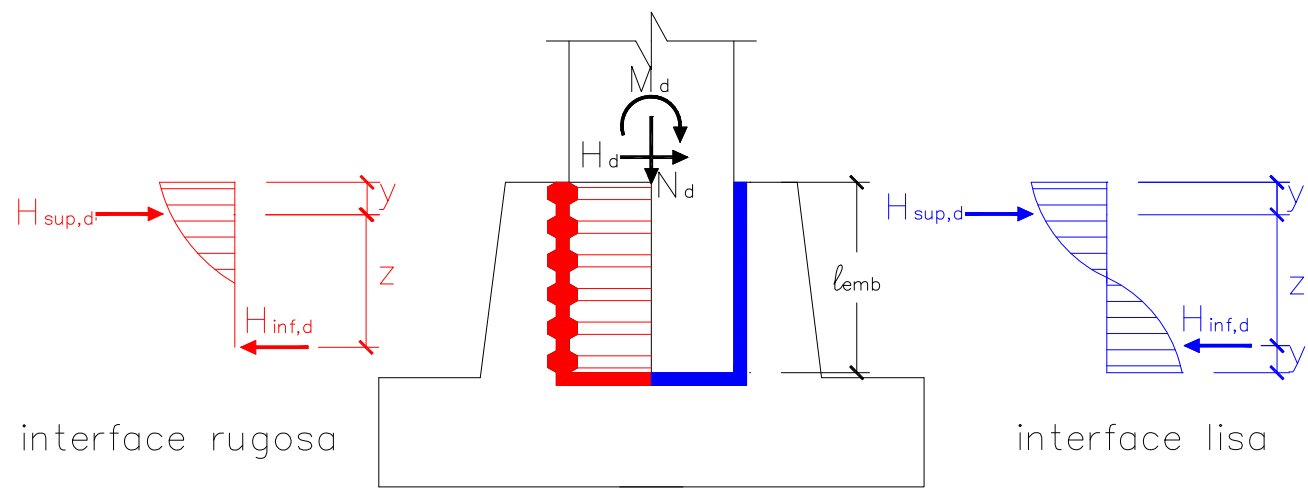

Figura 2. 14 - Forças nas paredes do cálice com interface lisa e rugosa - adaptado de Leonhardt \& Mönnig (1978)

Nesse aspecto, a ABNT NBR 9062:1985 diferencia-se do modelo proposto por Leonhardt \& Mönnig (1978) apenas na situação de interface rugosa, por considerar que a 
força $H_{\text {sup,d }}$ atua na parede 1 à uma distância de $0,15 \cdot \ell_{e m b}$ e não à $0,167 \cdot \ell_{e m b}$ como proposto pelos dois pesquisadores.

Tabela 2.2 - Valores e posições das forças horizontais - adaptados de El Debs (2000)

\begin{tabular}{c|c|c}
\hline \hline Interface & Lisa & Rugosa \\
\hline$H_{\text {sup }, d}$ & $1,5 \cdot \frac{M_{d}}{\ell_{e m b}}+1,25 \cdot V_{d}$ & $1,2 \cdot \frac{M_{d}}{\ell_{e m b}}+1,2 \cdot V_{d}$ \\
\hline$H_{\text {inf,d }}$ & $1,5 \cdot \frac{M_{d}}{\ell_{e m b}}+0,25 \cdot V_{d}$ & $1,2 \cdot \frac{M_{d}}{\ell_{e m b}}+0,2 \cdot V_{d}$ \\
\hline$y$ & $0,167 \cdot \ell_{e m b}$ & $0,150 \cdot \ell_{e m b}$ \\
\hline$z$ & $0,667 \cdot \ell_{e m b}$ & $0,833 \cdot \ell_{e m b}$ \\
\hline \hline
\end{tabular}

A força $H_{\text {sup,d }}$ que solicita a parede 1, é transferida para as paredes longitudinais 3 e 4 que têm o comportamento de consolo engastado na fundação, e portanto, deverão ser dimensionadas como tal. Esse esquema pode ser observado nas Figuras 2.15-a e 2.15-b.
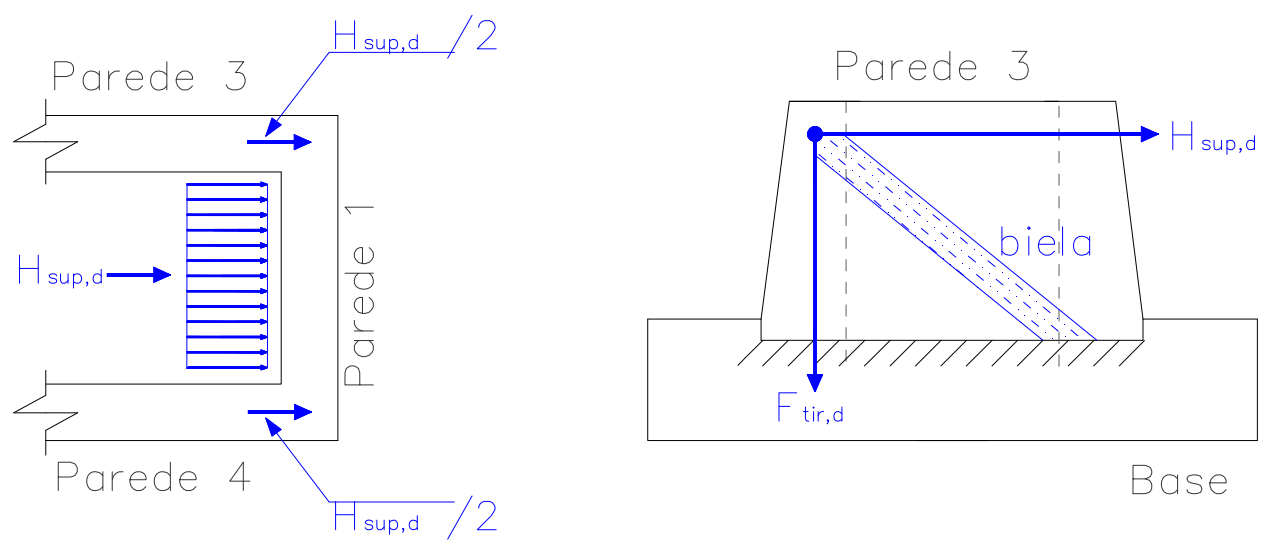

Figura 2. 15 - Transferência de esforços no colarinho segundo Leonhardt \& Mönnig (1978) - adaptado de El Debs (2000) 
Como as paredes longitudinais 3 e 4 possuem uma elevada rigidez a flexão, e admiti-se que a resultante das pressões na parede 2 atua diretamente na base da fundação, apenas a parede 1 estará solicitada à flexão. Esse modelo foi baseado na antiga Norma Italiana CNR10025 (1984), e funciona apenas para cálice com conformação de parede lisa. Recomendações de El Debs (2000) sugerem que a flexão na parede 1 desenvolve-se num trecho de altura igual a um terço de $\ell_{e m b}$ a partir do topo do colarinho. Deve-se dispor de armadura longitudinal para absorver as tensões de tração nesse trecho.

As paredes longitudinais 3 e 4, como dito anteriormente, devem ser dimensionadas como consolo. Além disso, devem dispor de uma armadura horizontal principal $A_{s h p}$ capaz de absorver a força transmitida pela parede 1. Deve-se distribuir essa armadura numa altura de 2.y a partir do topo do colarinho, sendo y a distância entre a força resultante $H_{s u p, d}$ e o topo do colarinho, conforme dito anteriormente. Essa armadura pode ser obtida, a partir da expressão:

$$
A_{s h p}=\frac{H_{\text {sup }, d}}{2 \cdot f_{y d}}
$$

A determinação das demais armaduras: armadura vertical principal $A_{s v p}$, armadura vertical secundária $A_{s v s}$ e armadura horizontal secundária $A_{s h s}$ são obtidas a partir do modelo de consolo mais adequado. Podem-se classificar os consolos em três tipos, de acordo com a inclinação $\beta$ da biela de compressão. São eles:

- Consolo curto $(1 \geq \operatorname{tg} \beta \geq 0,5)$ : Modelo de bielas e tirantes;

- Consolo muito curto ( $\operatorname{tg} \beta \leq 0,5)$ : Modelo de atrito-cisalhamento;

- Consolo longo ( $\operatorname{tg} \beta \geq 1)$ : Modelo da Teoria da Flexão

Como a maioria dos casos recai em consolo curto, será mostrado apenas esse modelo de cálculo, conforme Figura 2.16. Para os demais modelos, recomenda-se leitura do trabalho de Canha (2004). 


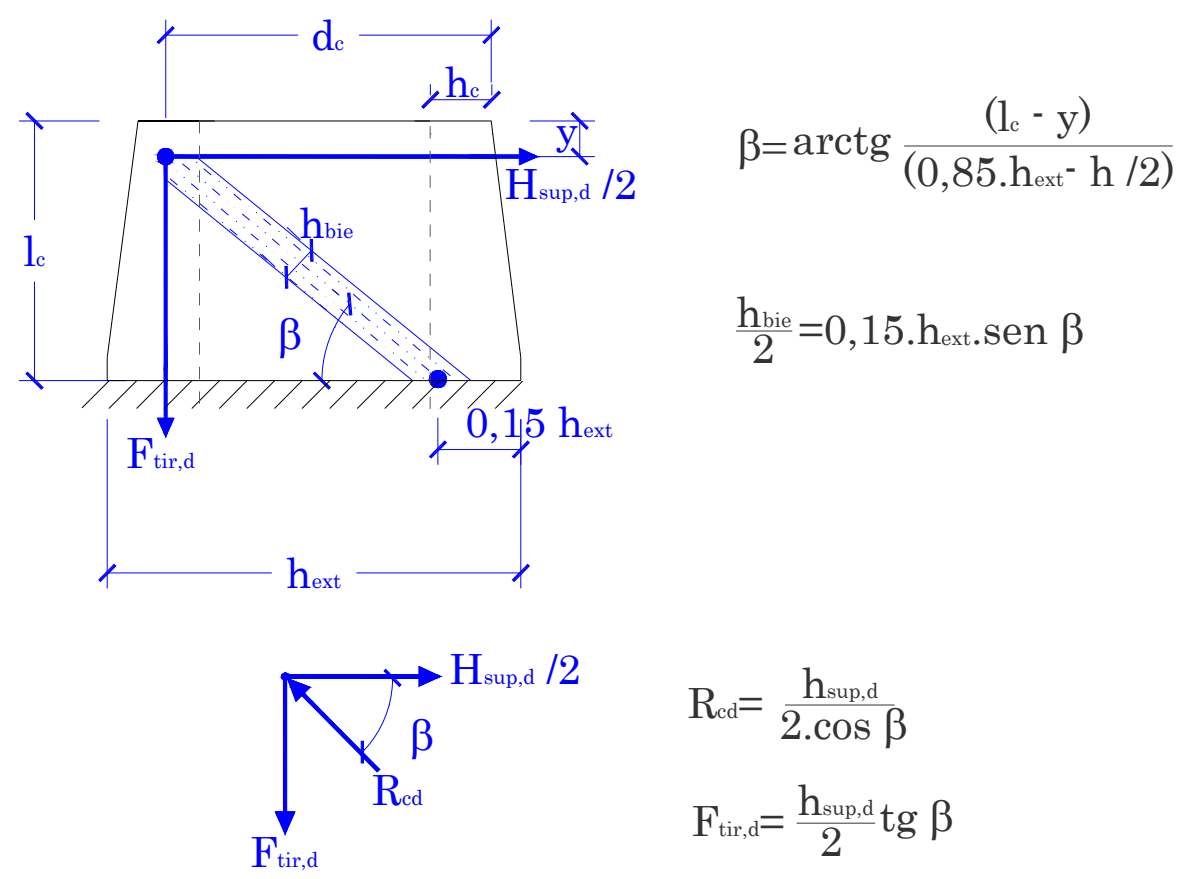

Figura 2. 16 - Indicações de dimensionamento das paredes 3 e 4 como consolo curto - adaptado de El Debs (2000)

Pode-se determinar a armadura vertical principal $A_{s v p}$ bem como a tensão de ruptura da biela comprimida a partir das seguintes expressões:

$$
\begin{gathered}
A_{s v p}=\frac{F_{t i r, d}}{f_{y d}} \\
\sigma_{c d}=\frac{R_{c d}}{h_{b i e} \cdot h_{c}} \leq 0,85 f_{c d}
\end{gathered}
$$

As demais armaduras, vertical e horizontal secundárias funcionam como armaduras de distribuição e de costura, e são obtidas a partir das expressões 2.5 e 2.6:

$$
\begin{aligned}
& A_{s v s}=0,4 \cdot A_{s v p} \\
& A_{s h s} \geq\left\{\begin{array}{l}
0,15 \% \cdot h_{c} \cdot h_{\text {ext }} \\
0,2 \cdot A_{s v p}
\end{array}\right.
\end{aligned}
$$


Essas armaduras também devem ser dispostas nas paredes transversais 1 e 2 . A distribuição das mesmas pode ser vista na Figura 2.17, sugerida por Leonhardt \& Mönnig (1978) e adaptada por El Debs (2000).

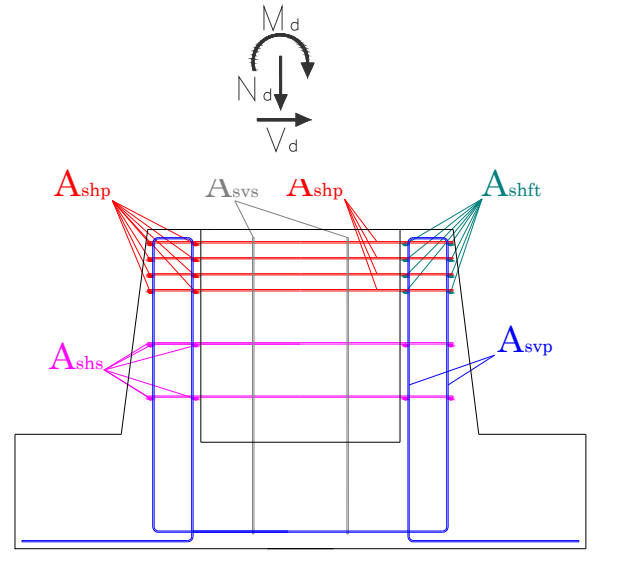

VISTA FRONTAL

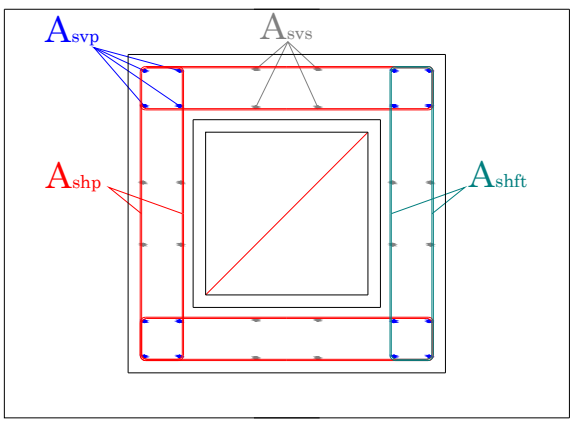

PLANTA
$\mathrm{A}_{\mathrm{svp}}$ - Armadura vertical principal (tirante do consolo)

A shft - Armadura de flexão da parede 1 (cálice de paredes lisas)

Ashp - Armadura horizontal principal (transmitir hsup do consolo)

Asvs - Armadura vertical secundária (costura e distribuição)

Ashs - Armadura horizontal secundária (costura e distribuição)

Figura 2.17 - Esquema das principais armaduras do cálice

Para os cálices com interface lisa e comprimento de embutimento inferiores a $2,00 \cdot h$, permite-se fazer uma redução da força $H_{i n f, d}$ na proporção $\ell_{e m b} / 2,00 \cdot h$ quando do dimensionamento da armadura horizontal secundária. Entretanto, deve-se manter seu valor total na verificação da biela comprimida.

No caso de interface lisa, deve-se garantir a ancoragem das barras da armadura longitudinal do pilar, quando as mesmas estiverem solicitadas à tração. Leonhardt \& Mönnig 
(1978) sugerem que essa ancoragem tenha início a meia altura de $\ell_{e m b}$. Ebeling (2006) sugere que a ancoragem tenha início no ponto de aplicação da força horizontal $H_{\text {sup }, d}$.

Nos casos em que a base da fundação for de pequena espessura, recomenda-se proceder a uma verificação quanto à punção. No cálice de interface lisa, a seção de ruína tem início a partir do pilar, enquanto que no cálice rugoso, admite-se que o conjunto pilar colarinho funciona de forma integrada, estando a superfície de ruína de acordo com as dimensões externas do colarinho.

\subsubsection{Modelo de Willert \& Kesser (1983)}

Willert \& Kesser (1983) ao realizarem pesquisas em cálice de fundação com colarinho externo, propuseram a utilização de um coeficiente de atrito capaz de simular o atrito existente entre as paredes do cálice e do pilar, aprimorando os modelos anteriores. Os autores sugerem a utilização do coeficiente de atrito $\mu=2 / 3$ para o cálice com interface de paredes lisas, entretanto, pode-se calibrar esse fator para a formulação de cálice com a interface rugosa.

As forças de atrito, por sua vez, só se manifestam quando da existência de forças verticais em conjunto com forças horizontais, ou seja, quando o pilar estiver submetido à flexo-compressão.

Quanto ao comprimento de embutimento do pilar $\ell_{e m b}$, os autores recomendam que estejam dentro do intervalo da expressão 2.7:

$1,5 \cdot h \leq \ell_{e m b} \leq 3,0 \cdot h$

Ao contrário da formulação proposta por Leonhardt \& Mönnig (1978), o comprimento de embutimento do pilar $\ell_{\text {emb }}$ não depende da interface da parede do cálice. A Figura 2.18 reproduz o esquema de forças sugerido pelos pesquisadores. 


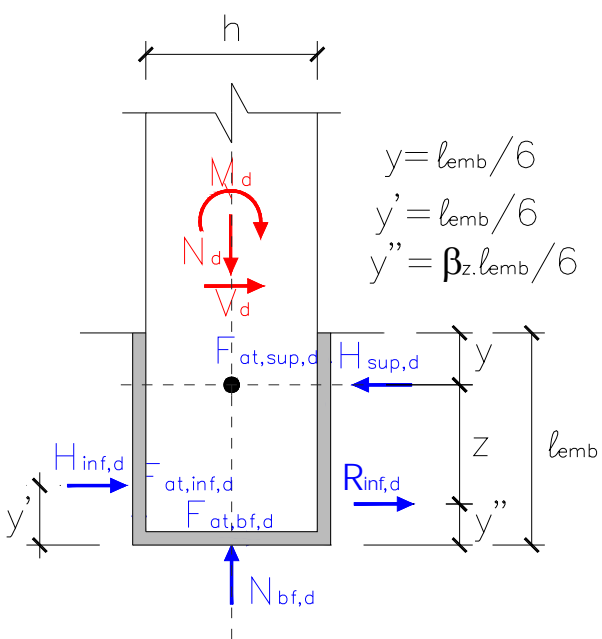

Figura 2. 18 - Esquema de forças segundo Willert \& Kesser (1983)

A partir das condições básicas de equilíbrio, ou seja, forças verticais, horizontais, e dos momentos em torno do ponto $\mathrm{O}$, têm-se as seguintes relações:

$\sum F_{v} \therefore N_{b f, d}+F_{a t, \text { sup }, d}-F_{a t, \text { inf }, d}-N_{d}=0$

$\sum F_{h} \therefore H_{\text {sup }, d}-H_{\text {inf }, d}-F_{a t, b f, d}-V_{d}=0$

$\sum M_{o} \therefore \frac{5 \cdot F_{a t, b f, d} \cdot \ell_{e m b}}{6}+\frac{2 \cdot H_{\mathrm{inf}, d} \cdot \ell_{e m b}}{3}+\frac{\left(F_{a t, \mathrm{sup}, d}+F_{a t, \mathrm{inf}, d}\right) \cdot h}{2}-\frac{V_{d} \cdot \ell_{e m b}}{6}-M_{d}=0$

Como complemento às expressões anteriores, utiliza-se as relações das forças de atrito superior, inferior e na base, com as forças perpendiculares por meio do coeficiente de atrito $\mu$.

$$
\begin{aligned}
& F_{a t, \mathrm{sup}, d}=\mu \cdot R_{\mathrm{inf}, d} \\
& F_{a t, \mathrm{inf}, d}=\mu \cdot H_{\mathrm{inf}, d} \\
& F_{a t, b f, d}=\mu \cdot N_{b f, d}
\end{aligned}
$$

Por fim, têm-se ainda as seguintes condições: 


$$
\begin{aligned}
& R_{\mathrm{inf}, d}=H_{\mathrm{inf}, d}+F_{a t, b f, d} \\
& N_{b f, d} \geq 0
\end{aligned}
$$

A partir da formulação proposta verifica-se que, para pequenas relações $e / h$, isto é, pequenas excentricidades, a força de atrito na base do cálice $F_{a t, b f, d}$ é muito maior do que a força $H_{\text {inf,d }}$ ampliando, portanto, o braço de alavanca entre as forças $H_{s u p, d}$ e $R_{\text {inf,d. }}$.

Quando ocorrer uma situação oposta, isto é, aplicação de forças com grande excentricidade ocorrerá que a força de atrito $F_{a t, b f, d}$ será menor, quando comparada com a força $H_{i n f, d}$ de tal modo que o braço de alavanca entre as forças $H_{s u p, d}$ e $R_{i n f, d}$ diminua.

A partir dessas observações, Willert \& Kesser (1983) desenvolveram uma expressão exponencial que relaciona o braço de alavanca $z$ com a excentricidade $e / h$ a partir do parâmetro $\beta_{z}$. A expressão obtida é a seguinte:

$\beta_{z}=1-e^{\left(\frac{-2 \cdot e}{3 \cdot h}\right)}$

Para pequena excentricidade $(e / h \leq 1 / 6)$ :

$\beta_{z} \approx 0$ e $z \approx \frac{5 \cdot \ell_{e m b}}{6}$

Para média excentricidade $(e / h=1)$ :

$\beta_{z} \approx 0,5$ e $z \approx \frac{3 \cdot \ell_{e m b}}{4}$

Para grande excentricidade $(e / h \geq 6)$ :

$\beta_{z} \approx 1$ e $z \approx \frac{2 \cdot \ell_{e m b}}{3}$ 
Pode-se, portanto, escrever a expressão do braço de alavanca $\mathrm{z}$ em função de $\beta_{z}$ e de $\ell_{e m b}$, resultando na expressão 2.20 .

$$
z=\frac{\ell_{e m b} \cdot\left(5-\beta_{z}\right)}{6}
$$

Assim, da combinação das expressões de equilíbrio, obtêm-se o seguinte resultado para a força cortante resultante $R_{\text {inf,d }}$ na base do pilar:

$$
R_{\mathrm{inf}, d}=\frac{6 \cdot M_{d}+V_{d} \cdot \ell_{e m b}}{\ell_{e m b} \cdot\left(5-\beta_{z}\right)+3 \cdot \mu \cdot h \cdot\left(1+\beta_{z}\right)}
$$

Para pequena excentricidade $\left(e / h \leq 1 / 6\right.$ e $\left.\beta_{z}=0\right)$ a expressão 2.21 resulta em:

$$
R_{\mathrm{inf}, d}=\frac{6 \cdot M_{d}+V_{d} \cdot \ell_{e m b}}{5 \cdot \ell_{e m b}+3 \cdot \mu \cdot h}
$$

Tomando-se o coeficiente de atrito $\mu$ como nulo, obtemos a expressão 2.23 , que é a mesma obtida por Leonhardt \& Mönnig (1978) na formulação de interface rugosa.

$$
R_{\mathrm{inf}, d}=\frac{6 \cdot M_{d}}{5 \cdot \ell_{e m b}}+\frac{V_{d}}{5}
$$

Para a situação de flexão pura $\left(N_{d}=0, e / h=\infty \beta_{z}=1\right)$ a expressão 2.21 se reduz na 2.24.

$$
R_{\mathrm{inf}, d}=\frac{6 \cdot M_{d}+V_{d} \cdot \ell_{e m b}}{4 \cdot \ell_{e m b}+6 \cdot \mu \cdot h}
$$

Tomando-se o coeficiente de atrito $\mu$ como nulo, obtemos a mesma expressão obtida por Leonhardt \& Mönnig (1978) na formulação de interface lisa.

$$
R_{\mathrm{inf}, d}=\frac{3 \cdot M_{d}}{2 \cdot \ell_{e m b}}+\frac{V_{d}}{4}
$$




\subsubsection{Outros estudos relevantes para cálice de fundações}

Olin et al. (1985) propõem um modelo de cálculo diferente para análise da ligação entre o cálice de fundação e o pilar. Segundo os pesquisadores, a capacidade da ligação é amplamente maior do que as referenciadas na literatura técnica até então, em virtude da existência de tensões de aderência entre esses elementos, e pela hipótese da reação vertical na base do pilar se apresentar de forma excêntrica.

De acordo com os pesquisadores, ao atingir o estado limite último, o momento resultante atuante na região do embutimento provoca o deslocamento da reação normal atuante na base do pilar. Esse deslocamento depende de diversos fatores, como a intensidade da ação e das dimensões do cálice. Os autores sugerem utilizar o valor de $h / 6$ para esse deslocamento, sendo $h$ a maior dimensão da seção transversal do pilar.

Olin et al. (1985) não recomendam a existência da força de atrito na região inferior do cálice, pois, segundo os pesquisadores, para que haja força de atrito é necessária a presença de uma força de compressão perpendicular atuando nessa região e, no cálice de fundação, essa força de compressão nem sempre se desenvolve de maneira plena. Os pesquisadores recomendam utilizar o valor de $1,3 \mathrm{~h}$ para o comprimento de embutimento, e no caso das interfaces do cálice, utilizar o coeficiente de atrito $\mu=0,3$ para interface lisa e $\mu=0,6$ para interface rugosa.

Elliott (1996) apresentou dois modelos de cálculo em função dos esforços solicitantes para a ligação pilar fundação por meio de cálice. Ambos os modelos consideram a existência de uma força normal excêntrica atuando no pilar, porém se diferenciam pela existência ou não de uma força horizontal $\mathrm{V}_{\mathrm{d}}$ no topo do colarinho, capaz de provocar força cortante no pilar.

Segundo o pesquisador, existem forças de atrito nas paredes transversais do cálice e na base do pilar, porém essas forças foram desprezadas de tal maneira que a resultante de 
compressão inferior se torna igual a resultante de compressão superior, para a situação sem a força horizontal $\mathrm{V}_{\mathrm{d}}$.

Elliott (1996) recomenda ainda que o comprimento de embutimento do pilar seja maior ou igual a uma vez e meia a maior dimensão da seção transversal do pilar, e que a distância entre o pilar e as paredes do cálice sejam superiores a $75 \mathrm{~mm}$ no topo do colarinho e $50 \mathrm{~mm}$ na base do cálice. A tensão de contato deve ser limitada a $40 \%$ da resistência de cálculo a compressão do concreto utilizado na junta.

Osanai et al. (1996) realizaram ensaio experimental em seis modelos de cálice de fundação variando o comprimento de embutimento $\ell_{e m b}$ entre $1,0 h$ e $1,5 \cdot h$, e a conformação da superfície de contato entre o pilar e as paredes do cálice, rugosa ou lisa. No modelo proposto pelos pesquisadores, surgem forças de atrito nas paredes laterais do cálice, bem como na base do pilar. Além disso, propõem a existência de uma força normal excêntrica atuando na base do pilar. O desenvolvimento do seu modelo se deu baseado no princípio da superposição dos efeitos, na teoria da resistência dos materiais assim como nas hipóteses de dimensionamento de estruturas de concreto armado.

Os pesquisadores concluíram que para o comprimento de embutimento $\ell_{e m b}$ igual a $1,5 \cdot h$ a ligação se comportou como rígida, inclusive para a situação de interface lisa. Melhorando a condição de interface rugosa, esse comprimento pode ser reduzido sem haver perda de rigidez da ligação, de tal modo que os modelos com interface rugosa e $\ell_{e m b}$ igual a $1,0 \cdot h$ apresentaram comportamento semelhante aos cálices com superfície lisa e $\ell_{\text {emb }}$ igual a $1,5 \cdot h$, no qual o pilar rompeu ao atingir sua força última. O cálice com interface lisa não apresentou rigidez suficiente para $\ell_{e m b}$ menor que $1,25 \cdot h$.

Os resultados obtidos nos ensaios experimentais, quando comparados com os valores teóricos, sugerem que os coeficientes de atrito podem ter os seguintes valores: $\mu=1,0$ quando o comprimento de embutimento for maior que $1,25 \cdot h$ para cálice com conformação de parede 
rugosa ou igual a $1,5 \cdot h$ quando da conformação de parece lisa; $\mu=0,5$ para comprimento de embutimento igual a $1,0 \cdot h$ no caso de parede com conformação rugosa. Nesse caso, o cálice de paredes lisas não apresentou rigidez suficiente desde o início dos ensaios.

Os resultados do modelo proposto por Osanai et al. (1996) mostraram-se mais próximos dos valores experimentais, do que os sugeridos pela norma alemã DIN 1045, utilizada na época dos ensaios, considerando os mesmos coeficientes de atrito proposto pelos pesquisadores.

Em Silva (1998), encontra-se um modelo de cálculo para blocos com e sem colarinho. Segundo o autor, o comportamento das forças internas atuantes no pilar é o mesmo para cálice externo ou embutido no bloco. Um dos modelos admite que a reação vertical da força normal atuante no pilar, é transmitida para a sapata sem excentricidade. Essa reação, por sua vez, não é transmitida diretamente à base, mas sim por meio de bielas inclinadas e tirantes horizontais desenvolvidos no interior do pilar, conforme Figura 2.19.

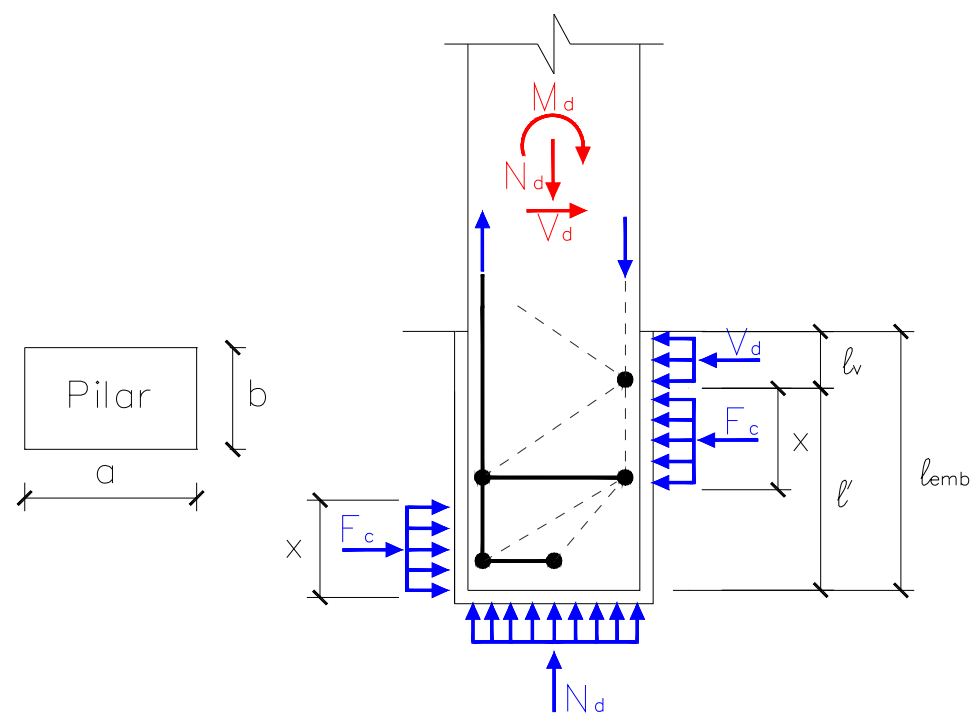

Figura 2. 19 - Esquema de forças atuantes no pilar - Silva (1998) 
A força horizontal $V_{d}$ tem o mesmo valor da força cortante atuante no pilar, e como as tensões de compressão devem ser limitadas a $0,6 \cdot f_{c d}$, pode-se encontrar a altura da região comprimida $\ell_{v}$ a partir da expressão 2.26 .

$$
V_{d}=0,6 \cdot f_{c d} \cdot b \cdot \ell_{v}
$$

Como existe uma excentricidade entre a reação $V_{d}$ e a força cortante atuante no pilar, há um acréscimo no valor do momento, dado pela expressão 2.27 :

$$
M^{\prime}=M+V_{d} \cdot \frac{\ell_{v}}{2}
$$

O momento $M^{\prime}$, por sua vez, é equilibrado pelo binário de forças de compressão $F_{c}$ no topo e na base da parede do cálice, segundo a expressão 2.28:

$$
F_{c}=0,6 \cdot f_{c d} \cdot b \cdot x
$$

Igualando o momento $M^{\prime}$ ao binário das forças de compressão, têm-se:

$$
M^{\prime}=F_{c} \cdot\left(\ell^{\prime}-x\right)=0,6 \cdot f_{c d} \cdot b \cdot x \cdot\left(\ell^{\prime}-x\right)
$$

O valor de $x$ pode ser obtido calculando-se as raízes da seguinte equação do segundo grau:

$$
x^{2}-\ell^{\prime} \cdot x+\frac{M^{\prime}}{0,6 \cdot b \cdot f_{c d}}=0
$$

Na situação de cálice embutido, pode-se utilizar o modelo anterior para comportamento das forças internas do pilar, considerando-se a força normal transmitida à base do bloco sem excentricidade. Outra simplificação é admitir que a reação horizontal do terreno exista a partir do topo do bloco, e que atue de modo colinear com as forças $F_{c}$ e $V_{d}$. Esse procedimento permite à simplificação do modelo, sendo facilmente determinadas as forças de tração nos tirantes em função da geometria do bloco e das cargas atuantes, conforme Figura 2.20. 


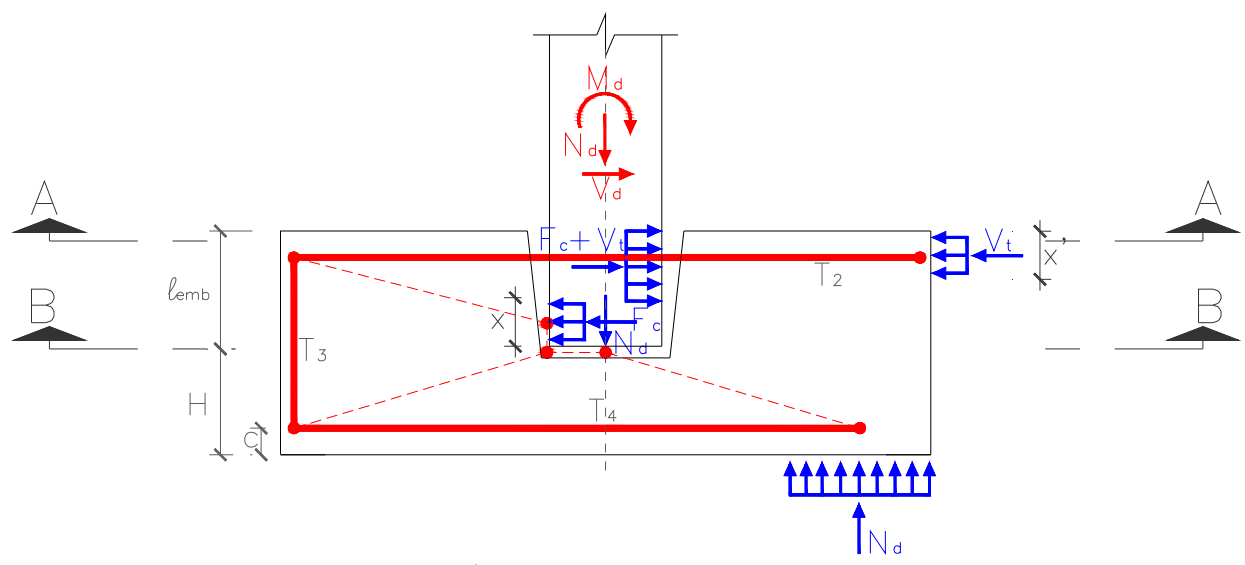

a) corte vertical

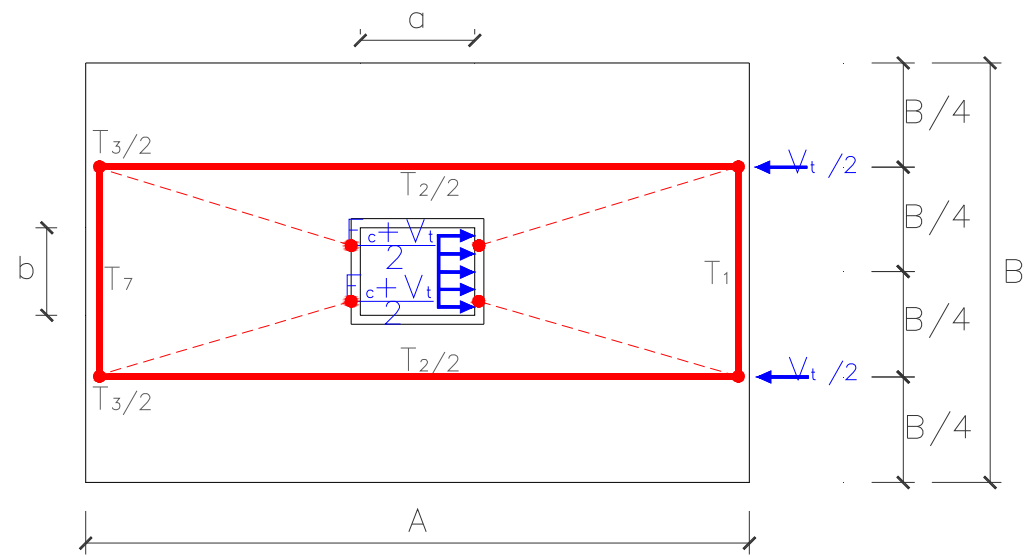

b) $\operatorname{corte} A-A$
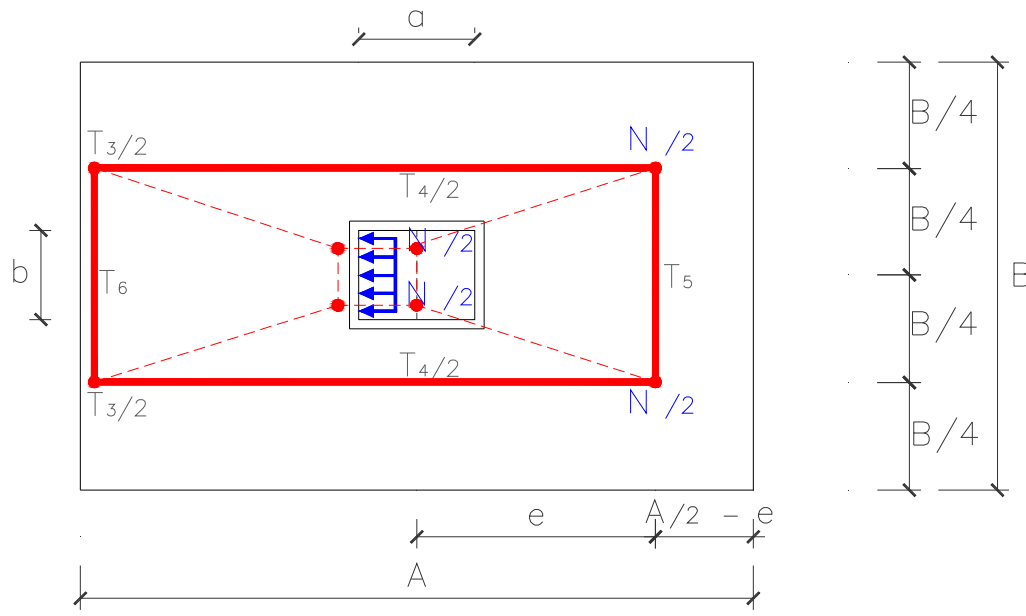

Figura 2. 20 - Modelo de cálculo para bloco com cálice embutido, sem considerar o atrito na junta pilarbloco - Silva (1998) 
A força $F_{c}+V_{d}$ atua numa altura x', dada pela soma dos valores de $l_{v}$ e $x$, calculados com as expressões anteriores. Admite-se que essa força atua em $x^{\prime} / 2$, causando uma excentricidade da reação $N$ na base do bloco, dada pela expressão 2.31:

$$
e=\frac{M+V \cdot \frac{x^{\prime}}{2}}{N}
$$

A força $F_{c}+V_{d}$ é equilibrada pela reação do terreno $V_{t}$, pelo tirante horizontal $\mathrm{T}_{1}$, e pelas forças de tração nos tirantes $T_{2}$. No canto superior esquerdo do bloco, o tirante horizontal $T_{2}$ encontra com o tirante vertical $\mathrm{T}_{3}$ e com uma biela inclinada que sai da face inferior do pilar. $\mathrm{O}$ tirante $\mathrm{T}_{3}$ se liga na face inferior do bloco com dois tirantes horizontais, $\mathrm{T}_{4}$ e $\mathrm{T}_{6}$, e por uma biela inclinada que também sai da extremidade inferior do pilar. A reação do terreno $N$, concentrada a uma distância maior que $0,25 \cdot \mathrm{A}$ do eixo do pilar, equilibra a biela proveniente da face inferior do mesmo, e os tirantes horizontais $\mathrm{T}_{4}$ e $\mathrm{T}_{5}$.

Canha (2004) realizou em sua tese de doutorado uma investigação experimental que é considerada a mais completa no que diz respeito à ligação pilar fundação por meio de cálice externo, com ênfase no colarinho. Foram ensaiados cinco modelos em escala real, variando a conformação das paredes do cálice, sendo três com interface lisa e dois com interface rugosa.

Em apenas um modelo com interface lisa não foi aplicado desmoldante. Nos demais, assim como nos de interface rugosa, o desmoldante serviu para simular melhor a situação de projeto, já que não se pode garantir um perfeito contato entre as interfaces do pilar e do cálice. Também no cálice com interface rugosa, foram testadas diferentes configurações de chave de cisalhamento.

As propriedades geométricas dos modelos foram baseadas nas recomendações da ABNT NBR 9062:1985 e de Leonhardt \& Mönnig (1978). O comprimento de embutimento seguiu as prescrições da ABNT NBR 9062:1985; a espessura das paredes do cálice foi o maior valor 
entre $10 \mathrm{~cm}$ e 1/3 da menor distância interna entre paredes; a espessura utilizada para da base foi de $35 \mathrm{~cm}$, maior que a dimensão mínima de $20 \mathrm{~cm}$ recomendada pela norma; a espessura da junta foi de $5 \mathrm{~cm}$, possibilitando o uso de vibrador quando do adensamento do concreto da junta.

Por fim, baseado nos resultados teóricos e experimentais, Canha (2004) propôs um modelo de projeto para o cálice com interface lisa, na qual é considerada a contribuição das forças de atrito $F_{a t, s u p, d}, F_{a t, i n f, d}$ e $F_{a t, b f, d}$ e a existência da excentricidade $e_{n b}$ da força normal atuante na base do cálice. $\mathrm{O}$ valor sugerido pela pesquisadora para a excentricidade $e_{n b}$ após a aferição do modelo é de $h / 4$, sendo $h$ a menor dimensão da seção transversal do pilar. A distribuição de pressões nas paredes 1 e 2 do cálice assumem uma distribuição triangular. $\mathrm{O}$ valor do coeficiente de atrito $\mu$ indicado é de 0,6. A Figura 2.21 ilustra o esquema de representação das forças atuantes no cálice.

Os resultados para o cálice com conformação das paredes rugosas apresentaram um comportamento próximo de uma ligação monolítica. Em função desse comportamento, Canha (2004) recomenda que a armadura vertical das paredes do colarinho seja dimensionada admitindo a transferência total das ações. Para as paredes longitudinais, podem-se considerar as mesmas como consolos quando do dimensionamento.

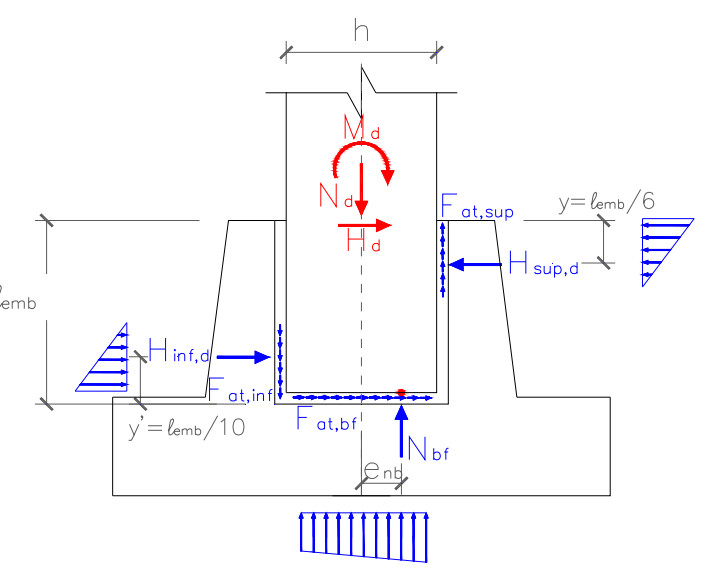

Figura 2. 21 - Forças atuantes no cálice de fundação, Canha (2004) 
Jaguaribe Júnior (2005) prosseguiu com os estudos em ligação pilar fundação por meio de cálice externo, com enfoque no comprimento de embutimento do pilar. Foram estudados dois protótipos, um com interface lisa e outro com interface rugosa, nos quais foi reduzido o comprimento de embutimento. Os resultados experimentais foram comparados com os obtidos por Canha (2004) e com outras recomendações da literatura técnica. O pesquisador concluiu que ao se reduzir o comprimento de embutimento recomendado pela ABNT NBR 9062:1985, há incoerência entre o resultado teórico e experimental.

Ebeling (2006) realizou pesquisa experimental e numérica com o intuito de analisar a base dos pilares na ligação com cálice de fundação. Foram analisados experimentalmente dois modelos de cálice com conformação de paredes lisas. Um fato importante dessa pesquisa, é que houve reaproveitamento de cálices usados em pesquisas anteriormente realizadas por Jaguaribe Júnior (2005) e Canha (2004). Em função desse reaproveitamento, foi necessário proceder a um reforço estrutural com fibra de carbono nas paredes do cálice.

Ebeling (2006) concluiu que a base dos pilares na ligação com cálice de fundação apresenta boa segurança, visto que a ruína dos modelos ocorreu fora da região de embutimento, por escoamento da armadura longitudinal tracionada das paredes do cálice. Esse resultado pode ser confirmado nos modelos experimentais e numéricos. Verificou também que a altura do colarinho influencia diretamente na rigidez do cálice, tendo em vista que os menores deslocamentos no topo do colarinho foram obtidos nos cálices com maior comprimento de embutimento.

Outra observação importante é que a armadura transversal do cálice foi pouco solicitada, provavelmente por conta do reforço em fibras de carbono realizado nos modelos. Por fim, o pesquisador sugeriu um modelo de bielas e tirantes aplicado ao dimensionamento do cálice de fundação. 
Campos \& Marcellino (2008) analisaram o comportamento de blocos de fundação sobre duas estacas para estruturas pré-moldadas, utilizando cálice externo. Foi realizado ensaio em três protótipos de blocos na escala 1:2 variando a altura do colarinho, nos quais o objetivo principal era avaliar a influência que o comprimento de embutimento $\ell_{\mathrm{emb}}$ provoca na base do bloco, bem como na formação da biela comprimida. Os resultados indicaram que o modelo proposto por Melo (2004) é conservador em relação às forças últimas obtidas experimentalmente.

Nunes (2009) realizou pesquisa experimental na ligação pilar-fundação com cálice externo, com ênfase nos esforços nas paredes transversais do cálice. O principal objetivo da pesquisa era avançar no conhecimento desse tipo de ligação, dando prosseguimento aos estudos iniciados por Canha (2004). Nesse aspecto, foram estudados dois protótipos de cálice externo, sendo um com configuração da parede lisa e outro com configuração da parede rugosa, nos quais foi avaliado o comportamento das armaduras verticais principais, situadas no encontro das paredes transversais e longitudinais.

Os resultados obtidos experimentalmente foram comparados com o modelo de cálculo proposto por Canha (2004), e indicaram que a parede transversal está submetida à flexotração, na qual os valores teóricos de $15 \%$ de flexão e $85 \%$ de tração conduzem aos melhores resultados. Constatou-se também que para o protótipo com configuração da parede lisa, as armaduras principais contribuíram efetivamente para a resistência do modelo após o desprendimento dos elementos da junta. 
Delalibera (em fase de elaboração) ${ }^{1}$ realizou simulações numéricas em blocos sobre duas estacas com cálice totalmente embutido. O objetivo da análise era observar quais fatores tinham maior importância no comportamento estrutural dos blocos e, de posse desses parâmetros, proceder experimento em laboratório.

$\mathrm{O}$ pesquisador concluir que os fatores que mais influenciam no comportamento estrutural do bloco com configuração da parede do cálice lisa são o comprimento de embutimento do pilar $\ell_{\mathrm{emb}}$ e a distância entre o fundo do bloco e o fundo do cálice. Para o bloco com configuração da parede rugosa, esses fatores não são relevantes como no bloco com configuração lisa, em virtude da chave de cisalhamento conferir ao bloco um comportamento de ligação monolítica.

Em função dos resultados numéricos, optou-se por realizar ensaio experimental em dois modelos de blocos com cálice embutido, no qual a variável considerada será a configuração das paredes do cálice. Os ensaios estão em andamento. 


\section{Capítulo}

\section{Aspectos de projeto de blocos sobre estacas}

\subsection{Procedimentos gerais}

A utilização de blocos sobre estacas ocorre quando as camadas superficiais do terreno não são suficientemente resistentes para suportar as ações da superestrutura. Estacas são elementos esbeltos cuja finalidade é transmitir as ações provenientes do bloco para as camadas mais profundas do solo. Essa transmissão pode ser feita por meio da resistência de ponta, do atrito lateral, ou da combinação dos dois efeitos.

Tratando de projetos de bloco sobre estacas, a primeira decisão do projetista é definir o tipo de estaca a ser utilizada. Essa escolha é feita baseada na intensidade das ações, bem como no tipo de solo que irá receber a fundação.

Definida o tipo da estaca, obtêm-se a quantidade de estacas a ser utilizada em cada bloco, considerando-se a intensidade das ações: força vertical; força horizontal e momentos, bem como a força resistente de cada estaca. Em situações onde a intensidade da força horizontal for elevada, deve-se prever a utilização de estacas inclinadas, caso as camadas do solo não sejam capazes de impedir o movimento lateral do conjunto estaca-bloco. É preciso considerar também o efeito de grupo entre estacas vizinhas.

Em seguida é feita a distribuição em planta das estacas. Sempre que possível, faz-se coincidir o centro do estaqueamento com o centro geométrico do pilar. A distribuição das estacas deve ser feita de modo a obter o menor volume possível para o bloco. 
A distribuição das estacas segue padrões adotados pelo meio técnico, respeitando-se o espaçamento mínimo entre estacas, distância entre estacas e a face do bloco e altura do bloco. A Figura 3.1 representa o padrão de bloco sobre duas estacas.

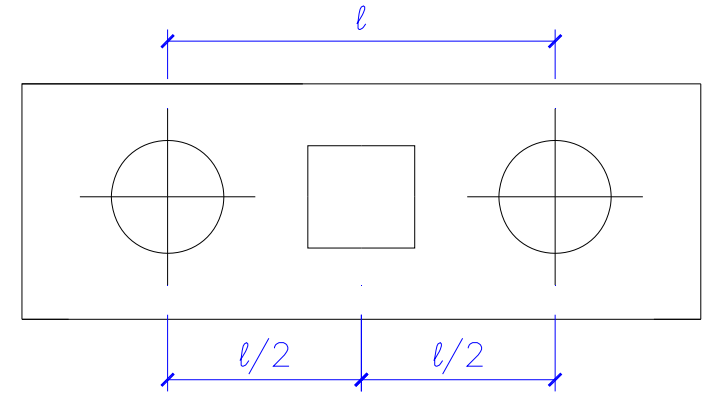

Figura 3. 1 - Bloco padrão sobre duas estacas

\subsection{Critérios de projeto}

\subsubsection{Cálculo das ações nas estacas}

Em Schiel (1957) é encontrado um procedimento para cálculo das reações nas estacas em blocos de fundação submetidos à ação de força centrada e momentos nas duas direções.

Para aplicação desse procedimento, é necessário cumprir algumas condições, entre elas a de que as estacas sejam todas do mesmo tipo, mesmo comprimento e mesmo diâmetro. $\mathrm{O}$ método não é valido caso alguma estaca seja inclinada, e o bloco deve ser necessariamente rígido. A Figura 3.2 indica a posição das ações e dos eixos considerados na expressão 3.1, que devem coincidir com os eixos principais de inércia do bloco. 


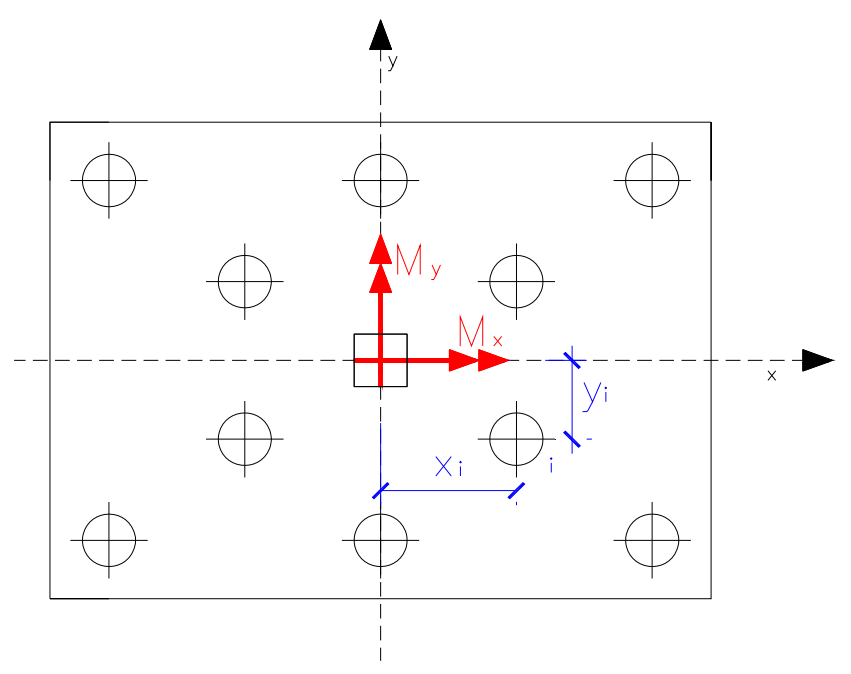

Figura 3. 2 - Método da superposição, Schiel (1957)

$P_{i}=\frac{F}{n} \pm \frac{M_{y} \cdot x_{i}}{\sum x_{i}^{2}} \pm \frac{M_{x} \cdot y_{i}}{\sum y_{i}^{2}}$

sendo que:

$P_{i} \quad$ reação na estaca de coordenadas $x_{i}$ e $y_{i}$;

F força vertical resultante (incluindo o peso próprio do bloco);

$n \quad$ número de estacas;

$M_{x} \quad$ momento fletor em torno do eixo x;

$M_{y} \quad$ momento fletor em torno do eixo y.

A expressão 3.1 nada mais é do que a formulação da flexão composta da Resistência dos Materiais, em que as reações nas estacas são diretamente proporcionais aos seus respectivos deslocamentos, tendo em vista que o bloco é considerado infinitamente rígido.

Quando a parcela do momento fletor estiver comprimindo uma estaca, a sua contribuição é somada a parcela proveniente da força atuante; quando provocar tração, é então subtraída da parcela da força atuante. O estaqueamento é resolvido por tentativa, tendo em 
vista que as reações nas estacas devem obedecer aos valores resistentes de tração e compressão.

\subsubsection{Bloco rígido versus bloco flexível}

Dependendo do valor adotado para altura, o bloco pode ser classificado como rígido ou flexível.

Segundo a ABNT NBR 6118:2003, bloco rígido é aquele que têm comportamento estrutural definido por flexão nas duas direções, mas com trações essencialmente concentradas nas linhas sobre estacas. Além disso, não respeita a hipótese das seções planas. Recomenda ainda que as barras da armadura principal sejam distribuídas em faixas de largura igual a 1,2 vez o diâmetro da estaca. As forças são transmitidas do pilar para as estacas por meio de bielas de compressão, cuja forma e dimensões são complexas. A expressão 3.2 define a altura mínima para bloco rígido.

$$
h \geq \frac{a-a_{p}}{3}
$$

sendo que:

$a$ é a dimensão do bloco em uma determinada direção;

$a_{p} \quad$ é a dimensão do pilar na mesma direção;

$h \quad$ é a altura do bloco.

Blocos flexíveis são aqueles que têm comportamento semelhante ao de vigas, sendo o dimensionamento feito baseado em seções de referência. A norma recomenda realizar uma análise mais completa, desde a distribuição das ações nas estacas, dos tirantes de tração, até a necessidade de verificação à punção.

O boletim 73 do CEB-FIP (1970) classifica o bloco em rígido ou flexível em função do parâmetro $\ell_{c}$, que é a distância entre a face do pilar e o eixo da estaca mais afastada. O bloco é 
dito rígido quando $\ell_{c}$ for menor que uma vez e meia a altura $h$, enquanto que é considerado flexível quando $\ell_{c}$ for maior ou igual a uma vez e meia a altura $h$.

O boletim 73 do CEB-FIP (1970) alerta ainda para que não se utilize blocos com altura superior a duas vezes à distância $\ell_{c}$, evitando que o bloco tenha comportamento semelhante ao de uma viga parede. As expressões 3.3 e 3.4 mostram a relação entre altura $h$ e $\ell_{c}$, para bloco rígido e flexível, respectivamente.

$$
\begin{aligned}
& 2 \cdot \ell_{c}>h>\frac{2 \cdot \ell_{c}}{3} \\
& h \leq \frac{2 \cdot \ell_{c}}{3}
\end{aligned}
$$

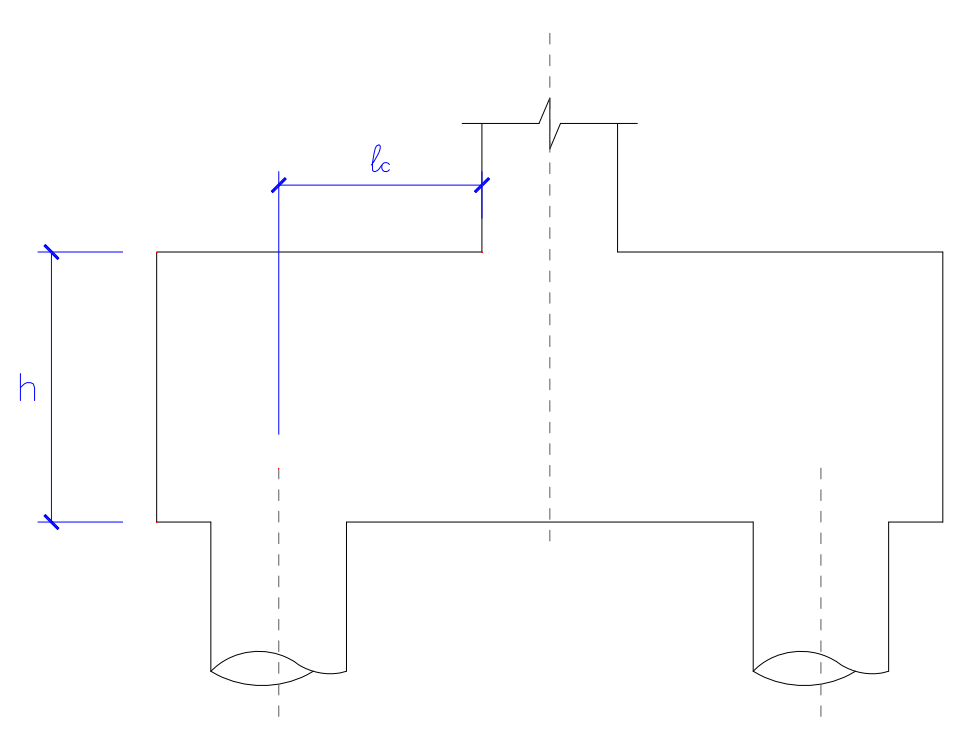

Figura 3. 3 - Parâmetros de classificação do bloco

Guerrin (1955) sugere que o bloco de fundação pode ser calculado tanto pelo método da flexão, como pelo método das bielas. Porém, segundo o autor, naquela época os projetistas não estavam mais utilizando o método da flexão, e ao adotarem altura maior que meia vez a distância entre estacas, obtinham um bloco rígido. 
Calavera (1991), assim como o boletim 73 do CEP-FIP (1970), classifica o bloco como rígido quando a distância $\ell_{c}$ for menor que uma vez e meia a altura $h$, porém difere na altura máxima permitida, sendo esse valor igual a uma vez e meia a distância $\ell_{c}$. O bloco é dito flexível quando atender a expressão 3.4 e rígido quando estiver no seguinte intervalo:

$$
1,5 \cdot \ell_{c}>h>\frac{2 \cdot \ell_{c}}{3}
$$

A norma espanhola EHE (2002), assim como Montoya (2000), recomendam que o bloco seja considerado rígido quando atender a expressão 3.6, caso contrário, o bloco será dito flexível, e deve ser calculado segundo a teoria geral da flexão, ou seja, com distribuição linear das deformações.

$$
h \geq \frac{\ell_{c}}{2}
$$

Silva e Giongo (2000) fazem uma importante observação na análise de um modelo de biela e tirante, constatando que o modelo adotado deve ser função da geometria e das ações atuantes. Um mesmo elemento estrutural submetido a diferentes ações apresenta comportamentos diferentes, ou seja, é inadequado utilizar apenas parâmetros geométricos (relações $\ell_{c} / h$ ) na classificação desses modelos.

\subsubsection{Recomendações a respeito da altura do bloco}

O CEB-FIP (1970), como dito anteriormente, recomenda que os blocos sobre estacas não tenham altura superior a duas vezes à distância $\ell_{c}$.

Calavera (1991) sugere que a altura máxima dos blocos seja igual a uma vez e meia a distância $\ell_{c}$. Em relação à altura mínima recomenda que em hipótese alguma seja inferior a 40 cm ou uma vez e meia o diâmetro da estaca. 
Montoya (2000) recomenda o cálculo da altura útil do bloco por meio da expressão 3.7, em função da força normal atuante e da largura do bloco.

$d=\frac{F_{d}}{500 \cdot b}-0,14>0,34$

sendo que:

$F_{d} \quad$ é a força normal de cálculo no bloco, em $\mathrm{kN}$;

$b \quad$ é a largura do bloco, em metros;

$d \quad$ é a altura útil do bloco.

Essa formulação é recomendada para blocos de duas a seis estacas. Segundo o autor, utilizando essa expressão, a seção transversal de concreto armado torna-se suficiente para resistir à força cortante sem necessidade de armadura específica, tornando o bloco mais econômico.

Munhoz (2004) percebeu que os valores obtidos para altura útil por meio da expressão 3.7 resultam alturas úteis muito grandes, sendo, portanto, necessário constatar se realmente há economia ao não utilizar armadura para resistir à força cortante.

\subsubsection{Distância entre eixos de estacas}

A consideração de uma distância mínima entre eixos de estacas é necessária em virtude do efeito de grupo das estacas. Entende-se por efeito de grupo de estacas o processo de interação das diversas estacas que constituem uma fundação. Essa interação acarreta uma superposição de tensões. O espaçamento mínimo deve ser respeitado não só entre estacas do mesmo bloco, mas também entre estacas de blocos vizinhos.

Alonso (1983) sugere os mesmos valores adotados posteriormente pela ABNT NBR 6118:2003, sendo de duas vezes e meia o diâmetro da estaca para estaca pré-moldada, e de 
três vezes para estacas moldadas in loco. $\mathrm{O}$ autor recomenda que em hipótese alguma seja utilizado espaçamento inferior a $60 \mathrm{~cm}$.

Calavera (1991) indica valores para distância entre eixos de estacas variando entre duas a três vezes o diâmetro das mesmas.

Montoya (2000) sugere adotar o menor valor entre os seguintes: duas vezes o diâmetro da estaca ou $75 \mathrm{~cm}$. Nas situações em que forem adotadas estacas de seção quadrada, a distância entre eixos não deve ser inferior a 1,75 vez a diagonal da seção da estaca.

A ABNT NBR 6118:2003 permite espaçamento entre estacas de duas vezes e meia a três vezes o diâmetro da estaca, admitindo plana a distribuição de forças nas estacas. Ramos (2007) verificou que essa distribuição plana não acontece em blocos sobre muitas estacas, mesmo respeitando o espaçamento mínimo.

\subsubsection{Distância entre eixo da estaca e a face do bloco}

Alonso (1983) recomenda que a distância mínima entre o eixo de qualquer estaca e a face externa do bloco atenda o maior valor dentre os da expressão 3.8.

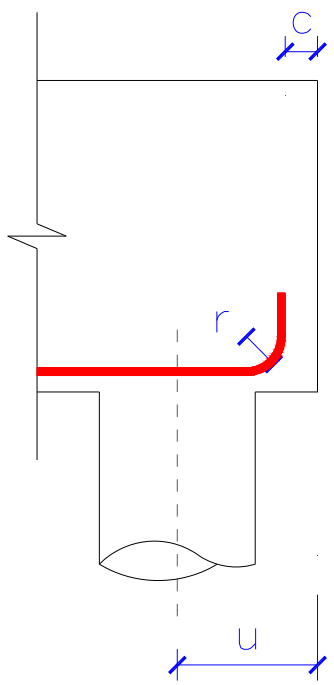

Figura 3. 4 - Distância entre estaca e a face do bloco, Alonso (1983) 


$$
u \geq\left\{\begin{array}{l}
\phi / 2+15 c m \\
r+c+\Phi
\end{array}\right.
$$

sendo que:

$\Phi \quad$ é o diâmetro da armadura longitudinal;

$\phi \quad$ é o diâmetro da estaca;

r é o raio de dobramento da armadura;

c é o cobrimento da armadura.

Calavera (1991) e Montoya (2000) sugerem que a distância entre o perímetro da estaca e a borda do bloco seja superior ao raio da estaca ou $25 \mathrm{~cm}$.

\subsubsection{Ligação estaca-bloco}

Calavera (1991) e Montoya (2000) consideram valores utilizados pelo meio técnico para embutimento da estaca no bloco de fundação. Recomendam ainda que sob o bloco exista um lastro de $10 \mathrm{~cm}$ de concreto. $\mathrm{O}$ topo da estaca, chamado de cota de arrasamento, deve estar situado entre $10 \mathrm{~cm}$ e $15 \mathrm{~cm}$ sobre o lastro de concreto.

De acordo com a ABNT NBR 6122:1996, a ligação estaca bloco varia conforme o tipo de estaca utilizado. Segundo a mesma norma, quando a estaca ficar acima da cota de arrasamento recomendada em projeto, deverá ocorrer a demolição do excedente de tal maneira que a seção resultante permaneça plana e perpendicular à estaca. 


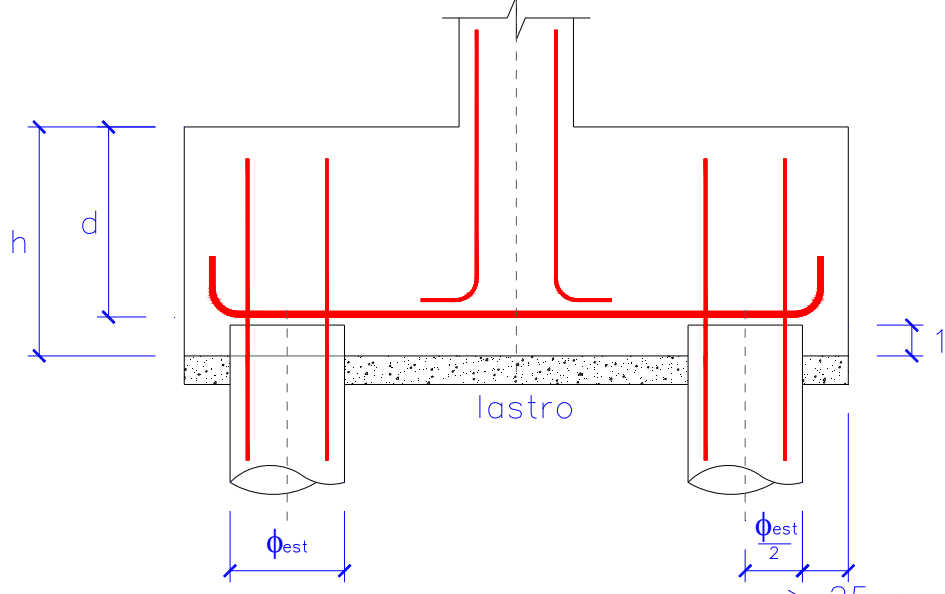

Figura 3. 5 - Ligação estaca-bloco, Calavera (1991)

\subsubsection{Excentricidades acidentais}

Por razões econômicas, em blocos de fundação é comum utilizar diâmetros maiores nas estacas, de modo a diminuir o número de estacas no bloco.

Em blocos com poucas estacas, é recomendado considerar excentricidades acidentais em virtude de possíveis deslocamentos do eixo da estaca durante o processo construtivo. Calavera (1991) faz recomendações importantes para excentricidades acidentais em blocos sobre uma e duas estacas, devendo ser considerada no projeto do bloco. Os valores sugeridos são os seguintes:

$\mathrm{e}=5 \mathrm{~cm} \quad$ em obras com alto controle de execução;

e $=10 \mathrm{~cm} \quad$ em obras com médio controle de execução;

e $=15 \mathrm{~cm} \quad$ em obras com baixo controle de execução.

\subsubsection{Barras da armadura principal}

A ABNT NBR 6118:2003 aceita modelos tridimensionais lineares ou não e modelos de biela e tirante tridimensionais, para definir as forças nos tirantes. No caso de blocos rígidos, recomenda que as barras da armadura principal do bloco estejam concentradas sobre as 
estacas, numa faixa de largura igual a 1,2 vez o diâmetro da estaca. As barras devem se estender de face a face do bloco, e terminar em ganchos nas duas extremidades. No caso de barras com diâmetro maior ou igual a $20 \mathrm{~mm}$, devem ser utilizados ganchos com dobras de $135^{\circ}$ ou $180^{\circ}$.

A ancoragem das barras da armadura deve ser garantida a partir da face da estaca, porém a ABNT NBR 6118:2003 não especifica se é a face interna, externa ou a que engloba o centro geométrico da estaca. Pode-se ainda considerar o efeito favorável sobre as barras da armadura, decorrentes da compressão das bielas. Na expressão 3.9 são apresentados os critérios de verificação de ancoragem das barras da armadura principal.

$$
\ell_{b, \text { nec }}=\alpha \cdot \ell_{b} \frac{A_{s, \text { calc }}}{A_{s, e f}} \geq \ell_{b, \text { min }}
$$

sendo que:

$\ell_{b, \text { nec }} \quad$ é o comprimento de ancoragem necessário;

$\alpha=1 \quad$ para barras sem gancho;

$\alpha=0,7$ para barras tracionadas com gancho, com cobrimento no plano normal ao do gancho maior ou igual a três vezes o diâmetro da barra a ancorar;

$\ell_{b, \min }$ comprimento de ancoragem mínimo, sendo o menor valor entre $\left\{\begin{array}{l}0,3 \cdot \ell_{b} \\ 10 \cdot \phi \\ 100 \mathrm{~mm}\end{array}\right.$

O valor do comprimento de ancoragem básico $\ell_{b}$ pode ser calculado por meio da expressão 3.10:

$$
\ell_{b}=\frac{\phi}{4} \cdot \frac{f_{y d}}{f_{b d}}
$$

sendo que:

$\phi \quad$ é o diâmetro da barra a ser ancorada; 
$f_{y d} \quad$ é a resistência de cálculo ao escoamento da barra a ser ancorada, em MPa;

$f_{b d} \quad$ é a resistência de aderência, calculada pela expressão 3.11.

$$
f_{b d}=\eta_{1} \cdot \eta_{2} \cdot \eta_{3} \cdot \frac{f_{c t k \text { inf }}}{\gamma_{c}}
$$

sendo que:

$\eta_{1}=2,25 \quad$ para barras nervuradas;

$\eta_{2}=1,0 \quad$ para regiões de boa aderência;

$\eta_{3}=1,0 \quad$ para barras com diâmetro inferior a $32 \mathrm{~mm}$;

$\gamma_{c} \quad$ é o coeficiente de segurança do concreto;

$f_{c t k, i n f} \quad$ é a resistência característica a tração direta, com seu valor inferior dado pela expressão 3.12, na qual $f_{c k}$ é a resistência característica do concreto a compressão, expresso em MPa.

$$
f_{c t k, \text { inf }}=0,21 \cdot f_{c k}{ }^{2 / 3}
$$

Delalibera (2006) verificou que os ganchos exigidos pela norma brasileira vigente de estruturas de concreto armado, não apresentaram influência significativa no comportamento estrutural do bloco, apresentando deformações praticamente nulas. Entretanto, faz-se necessário verificar se ocorre comportamento semelhante, quando utilizado barras de armadura com diâmetro inferior a $20 \mathrm{~mm}$.

Calavera (1991) indica que o comprimento de ancoragem deve ser iniciado a partir da seção que contém o eixo da estaca. Permite-se ainda diminuir o comprimento de ancoragem em 20\%, em virtude da boa condição de aderência das barras da armadura principal, provocada pela força de reação das estacas e pelas bielas comprimidas. Conforme a Figura 3.6, caso a ancoragem reta não seja suficiente, permite-se adotar ganchos de acordo com a expressão 3.13, sempre que: 
$\frac{\ell_{1}}{0,7} \geq 0,8 \cdot \ell_{b}$

Ou ainda adotar prolongamento vertical $\ell_{2}$ tal que:

$$
\ell_{2}=0,8 \cdot \ell_{b}-\frac{\ell_{1}}{0,7}
$$

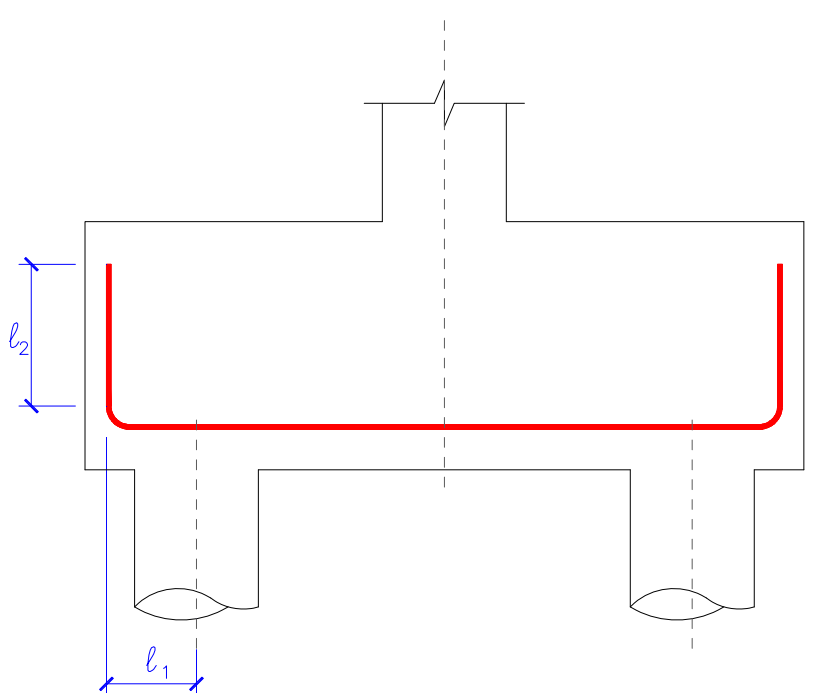

Figura 3. 6 - Comprimento de ancoragem em blocos sobre estacas, Calavera (1991)

Calavera (1991) admite que se reduza o comprimento de ancoragem básico $\ell_{b}$ em função das áreas das barras das armaduras efetivas e necessárias, porém deve-se garantir que as barras cheguem até a face do bloco, descontando o cobrimento. $O$ comprimento $\ell_{1}$ não deve ser em hipótese alguma inferior a um terço de $\ell_{b}, 15 \mathrm{~cm}$ ou dez vezes o diâmetro das barras a ancorar.

Montoya (2000) recomenda que todas as barras da armadura principal sejam ancoradas por prolongamento reto, ângulo reto ou barras soldadas na extremidade. A área das barras não deve sofrer qualquer redução em virtude do efeito benéfico das tensões na biela de compressão, porém, permite-se reduzir o comprimento de ancoragem também em $20 \%$. 


\subsubsection{Armadura secundária}

O boletim 73 do CEB-FIP (1970) recomenda o uso de barras de armadura secundária na forma de estribos na direção transversal e longitudinal em blocos sobre estacas. Essas barras são necessárias principalmente em blocos sobre duas estacas para resistir aos momentos fletores provenientes de excentricidades construtivas, bem como para limitar a abertura de fissuras.

A armadura longitudinal secundária é posicionada na parte superior ao longo de todo o bloco, e deve ter uma área mínima igual a 10\% da área das barras da armadura principal. Nas faces laterais, deve-se considerar uma malha de armadura transversal cujo valor pode ser obtido por meio da expressão 3.15 .

$$
A_{s, w}=0,002 \cdot b \cdot s_{h}
$$

sendo que:

$b \quad$ é a largura do bloco, limitada a metade da altura do mesmo;

$s_{h} \quad$ é o espaçamento das barras da malha.

Alonso (1983) recomenda utilizar armadura secundária nas faces laterais do bloco, e que a área dessas barras não seja inferior a um oitavo da área das barras da armadura principal.

Calavera (1991) admite que o bloco sobre duas estacas possa ser submetido à ação de um momento torçor ocasionado por excentricidades construtivas, de tal maneira que devem ser previstas armaduras secundárias.

Calavera (1991) e Montoya (2000) adotam o mesmo valor de 10\% da área das barras da armadura principal para as barras da armadura longitudinal secundária, posicionada na parte superior do bloco. Entretanto, nas faces laterais, a área das barras deve ser superior a $0,4 \%$ da seção de concreto perpendicular a direção das barras. 
A ABNT NBR 6118:2003 sugere que, para controle do efeito da fissuração, deve ser prevista armadura adicional em malha uniformemente distribuída nas duas direções, considerando esforços solicitantes da ordem de $20 \%$ dos esforços totais. Essa malha deve ser calculada com uma resistência de cálculo de $80 \%$ da resistência à tração de cálculo das barras de aço.

Em alguns casos, a ABNT NBR 6118:2003 recomenda utilizar armadura de suspensão. Se for prevista armadura de distribuição em mais de $25 \%$ dos esforços totais ou se o espaçamento entre estacas for maior do que três vezes o diâmetro das mesmas, deve ser adotado armadura de suspensão. Segundo Leonhardt \& Mönnig (1978), em situações nas quais a armadura principal não estiver distribuída apenas sobre as estacas, existe o risco de ruína prematura em virtude do surgimento de fissuras na região inferior do bloco, portanto, nesses casos devem ser adotadas armaduras de suspensão.

\subsection{Viga de travamento}

A viga de travamento é um elemento estrutural utilizado entre elementos da fundação, sejam blocos ou sapatas, cuja finalidade é absorver os esforços provenientes de recalques e excentricidades construtivas, evitando assim que os mesmos atinjam a superestrutura. Em algumas situações a viga de travamento pode ser utilizada como elemento de apoio para as alvenarias do pavimento térreo de uma edificação, evitando assim a construção do baldrame. Por essa razão, a viga de travamento é também chamada de viga baldrame.

O uso de vigas ou cintas de travamento entre as fundações está sempre presente em debates e discussões no meio técnico. É quase que consenso da comunidade técnica que, dispensar totalmente o uso dessas vigas, é ir contra as práticas da boa engenharia. 
Recentemente em uma lista de discussão eletrônica surgiu o assunto sobre vigas de travamento, na qual diversos engenheiros puderam opinar sobre a utilização de cintamento entre fundações. O resultado dessa discussão gerou uma coletânea com quase quinze páginas de informações técnicas e práticas a respeito da utilização do travamento entre fundações. Algumas informações relevantes são apresentadas a seguir.

De acordo com Carnaúba et al. (2008), numa fundação com várias estacas, cada estaca trabalha sozinha e independente das demais, estando as mesmas apoiadas em terrenos com diferentes características. Dessa forma, cada estaca apresentará sua própria condição de acomodação e deformação após a atuação das ações, que vêm gradualmente se instalando na edificação. Como conseqüência, haverá recalques diferenciais entre as estacas, os quais são difíceis de serem previstos. As vigas de travamento que unem os blocos têm por finalidade absorver essas deformações que poderiam penalizar a superestrutura.

Outra consideração a respeito das estacas que trabalham ao atrito lateral é a de que esse atrito só irá se manifestar a partir do instante em que houver recalque nas estacas. E, como citado anteriormente, é muito provável que o recalque seja diferencial entre as estacas, o que vem a justificar o uso de vigas de travamento entre os blocos.

Carnaúba et al. (2008) sugerem como dimensionar a viga de travamento entre blocos. Alguns projetistas adotam a dimensão mínima para a seção da viga em função do vão $\ell$ da mesma. Para a largura $b_{w}$ adota-se o maior valor entre $20 \mathrm{~cm}$ e $\ell / 25$, enquanto que para a altura adota-se o maior valor entre $35 \mathrm{~cm}$ e $\ell / 12$. A armadura longitudinal da viga é obtida segundo o dimensionamento de um pilar biapoiado submetido à compressão centrada, recebendo uma ação igual a $10 \%$ da ação do pilar mais solicitado entre a viga. Recomenda-se ainda que a face superior da viga de travamento coincida com a face superior do bloco ou da sapata. 


\subsection{Modelo de bielas e tirantes}

O modelo de bielas e tirantes baseia-se na analogia de treliça clássica introduzida no início do século XX por Ritter \& Mörsch, na qual a viga de concreto armado fissurada é comparada a uma treliça de banzos paralelos. Após anos de estudos, o modelo evoluiu obtendo-se então à treliça generalizada de Mörsch, na qual os banzos superior e inferior não são paralelos, nem a inclinação das bielas é constante e igual a $45^{\circ}$ ao longo de toda a viga. Porém, a idéia básica da treliça clássica de que a viga se comporta como uma treliça continua válida.

O método de bielas e tirantes também é conhecido como escoras e tirantes. A diferença entre biela e escora é que a biela precisa necessariamente estar inclinada, enquanto que a escora pode estar inclinada ou não em relação ao tirante.

Durante a fase de projeto, pode-se dividir uma estrutura em duas regiões conhecidas como B e D. Nas regiões B, também chamadas regiões de Bernoulli, são válidas as hipóteses de Bernoulli, isto é, o meio é considerado contínuo e a distribuição de tensões na seção transversal tem comportamento linear. As regiões $\mathrm{D}$, por suas vezes, são regiões de descontinuidade nas quais as tensões obedecem a uma distribuição não-linear, produzidas por descontinuidades estáticas ou geométricas. As descontinuidades estáticas surgem em virtude da existência de forças concentradas, enquanto que as geométricas são conseqüências de variações bruscas na geométrica da estrutura.

A Figura 3.7, encontrada no "Strut-and-Tie Resource Web Site", contempla a distribuição de regiões B e D numa estrutura de ponte. Baseado no princípio de Saint-Venant, a extensão de uma região $\mathrm{D}$ tem valor igual à altura das regiões $\mathrm{B}$ adjacentes, contadas a partir da descontinuidade. 


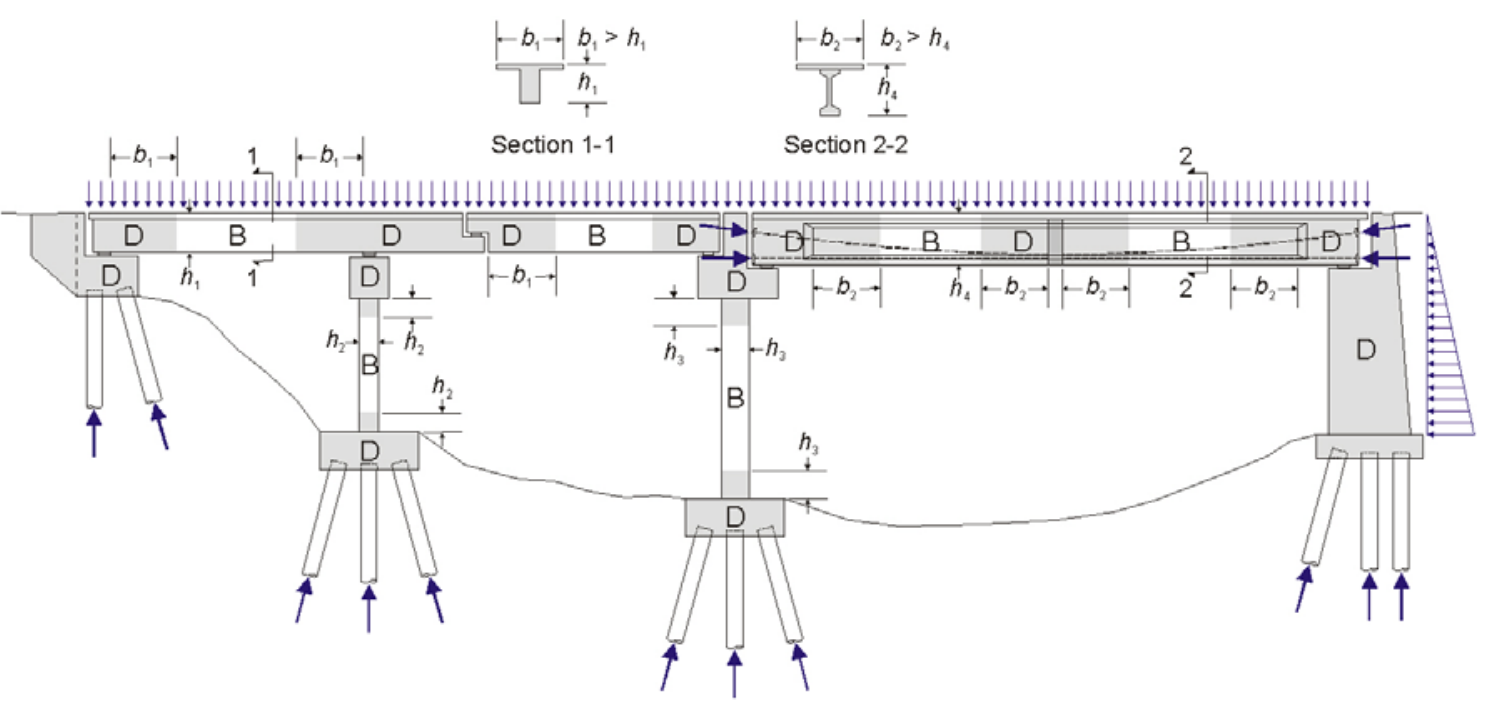

Figura 3. 7 - Divisão de uma estrutura em regiões B e D, "Strut-and-Tie Resource Web Site"

O modelo de bielas e tirantes é uma representação discreta do fluxo de tensões num determinado elemento estrutural. A estrutura inicial é representada por uma estrutura equivalente composta por barras comprimidas e tracionadas, interligadas por meio de nós. As barras comprimidas recebem o nome de biela e devem absorver o fluxo de tensões de compressão, sendo normalmente representadas por linhas contínuas. As barras tracionadas recebem o nome de tirante, e devem absorver o fluxo de tensões de tração existentes no elemento, sendo representadas por linhas tracejadas.

Em elementos de concreto armado, as bielas representam as regiões de concreto que estão submetidas à compressão, enquanto que os tirantes representam as barras de aço submetidas à tração. Eventualmente, podem ser previstos tirantes de concreto em alguns elementos estruturais desde que a tensão máxima não ultrapasse a resistência a tração do material.

Segundo Schlaich \& Schäfer (1991), a biela de compressão pode apresentar diversas configurações de distribuição de tensão. A Figura 3.8-a indica uma distribuição paralela e uniforme das tensões ao longo da biela, sem perturbações. Essa distribuição é típica de 
regiões B. Na Figura 3.8-b percebe-se uma concentração de tensões, com aumento da área da seção da biela. A distribuição dessas tensões provoca compressão biaxial e tração transversal que, combinada com a compressão, pode provocar fissuras longitudinais. Por causa da pequena resistência a tração do concreto, é preciso dispor de barras de aço na direção transversal. A Figura 3.8-c representa uma distribuição radial de tensões, na qual não surgem tensões de tração transversais.

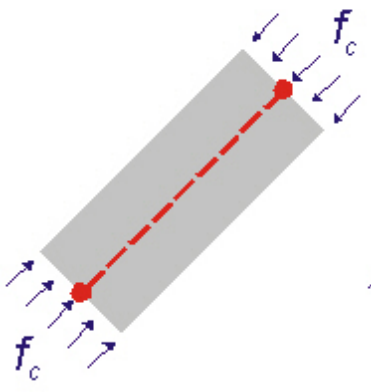

(a)

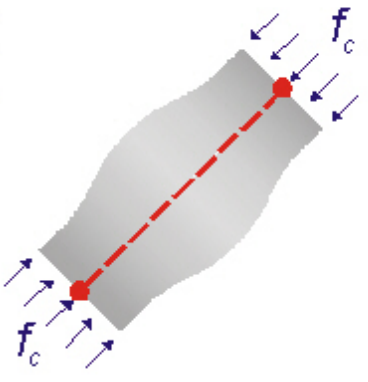

(b)

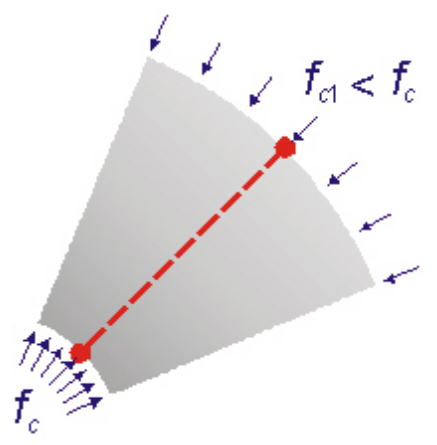

(c)

Figura 3. 8 - Configurações da biela de compressão, "Strut-and-Tie Resource Web Site"

As regiões nodais que interligam as bielas e os tirantes precisam ser verificadas quanto às tensões nelas atuantes. A verificação desses nós é o que diferencia o modelo de bielas e tirantes do modelo de bielas proposto por Blévot \& Frémy (1967).

O código modelo do CEB-FIP (1990) sugere que as regiões nodais tenham geometria bem definida, sendo possível realizar a verificação das tensões nessas regiões. Pesquisadores como Schäfer \& Schlaich (1988), Schlaich \& Schäfer (1991) bem como o código modelo do CEB-FIP (1990), a norma canadense CSA Standard A23.3-04 (2004) e o ACI 318-08 indicam diferentes valores de tensão para as regiões nodais. A Tabela 3.1 mostra um resumo dos valores sugeridos para regiões onde só existam bielas comprimidas, formando estado de tensão biaxial ou triaxial (a), e regiões onde houver barras de armadura ancorada (b). 
Tabela 3.1 - valores de verificação das tensões nas regiões nodais

\begin{tabular}{c|c|c}
\hline \hline Critérios & Situação (a) & Situação (b) \\
\hline Schäfer \& Schlaich (1988) & $0,935 \cdot f_{c d}$ & $0,68 \cdot f_{c d}$ \\
\hline Schlaich \& Schäfer (1991) & $1,1 \cdot f_{c d}$ & $0,8 \cdot f_{c d}$ \\
\hline CEB-FIP (1990) & $0,85 \cdot\left[1-\frac{f_{c k}}{250}\right] \cdot f_{c d}$ & $0,60 \cdot\left[1-\frac{f_{c k}}{250}\right] \cdot f_{c d}$ \\
\hline CSA-A23.3-04 & $0,85 \cdot \phi_{c} \cdot f_{c}^{\prime}$ & $0,75 \cdot \phi_{c} \cdot f_{c}^{\prime}$ \\
\hline ACI 318-08 & $0,8 \cdot f_{c}^{\prime}$ & $0,6 \cdot f_{c}^{\prime}$ \\
\hline \hline
\end{tabular}

sendo que:

$f_{c k} \quad$ resistência característica à compressão do concreto, em $\mathrm{MPa}$;

$f_{c d} \quad$ resistência de cálculo à compressão do concreto;

$\phi_{c} \quad$ fator de segurança do concreto, igual a 0,6 ;

$f_{c}$ resistência característica à compressão do concreto, definida a partir do quantil de $1 \%$.

Nota-se claramente a divergência dos parâmetros de verificação das regiões nodais entre pesquisadores e normas. Silva e Giongo (2000) recomendam utilizar os valores, dentre os apresentados, propostos pelo CEB-FIP (1990). É interessante ressaltar que o ACI 318-08 permite que o ângulo formado entre bielas e tirantes seja igual ou superior a $25^{\circ}$, diferente das recomendações dos demais códigos.

Para uma determinada estrutura existem diversas "estruturas equivalentes" formadas por bielas e tirantes que satisfazem o equilíbrio entre forças externas e internas, de tal maneira 
que a determinação do modelo ideal é de grande dificuldade e requer experiência do projetista.

Schlaich et al. (1987) perceberam que as tensões tendem a utilizar o caminho das mínimas forças e deformações. Matematicamente, pode-se formular esse critério por meio da expressão 3.16.

$\sum_{i}^{n} F_{i} \cdot \ell_{i} \cdot \varepsilon_{m i}$

sendo que:

$i \quad$ é a biela ou tirante do modelo;

$F_{i} \quad$ é a força no tirante ou biela i;

$\ell_{i} \quad$ é o comprimento da biela ou tirante $\mathrm{i}$;

$\varepsilon_{m i} \quad$ é a deformação específica média na biela ou tirante $\mathrm{i}$;

n é o total de bielas e tirantes do modelo.

A formulação acima provém do princípio da energia de deformação mínima para comportamento elástico-linear de bielas e tirantes após a fissuração. A deformação das bielas pode ser omitida uma vez que, quando comparadas aos tirantes, as bielas apresentam deformações muito menores. Sugere-se que, sempre que possível, seja utilizado o modelo com menor número possível de tirantes.

Silva e Giongo (2000) sugerem que o modelo de bielas e tirantes possa ser obtido utilizando o fluxo de tensões na estrutura, utilizando o processo do caminho de carga. Por meio das tensões principais e suas direções obtidas de uma análise elástica, o modelo está pronto para ser resolvido. Tjhin \& Kuchma (2002) concluem que as trajetórias de tensões principais obtidas da análise elásticas satisfazem os estado limites de serviço e último, mas advertem para o fato de serem uma aproximação, uma vez que no estado limite último o fluxo de tensões sofre mudanças significativas. 
Em Munhoz (2004) é apresentada uma rotina de projeto utilizando o método de bielas e tirantes aplicada e blocos de fundação. A seqüência é descrita a seguir.

1-) Definição e limites das regiões D: Nessa etapa divide-se a estrutura em questão em regiões $\mathrm{B}$ e D, bem como são definidas as dimensões dessas regiões. A extensão de uma região $\mathrm{D}$ pode ser tomada como sendo igual à altura das regiões $\mathrm{B}$ adjacentes, de acordo com o princípio de Saint-Venant.

2-) Análise Estrutural: Para realizar a análise estrutural, e necessário separar as regiões B e D. Inicialmente, obtém-se os esforços solicitantes das regiões B e, em seguida, por meio desses esforços, determinam-se as forças atuantes no contorno das regiões D.

3-) Processo do caminho de carga: Após determinação das forças atuantes no contorno, é possível determinar a posição das bielas e tirantes de acordo com o fluxo de tensões no interior da estrutura, substituindo as tensões de compressão por bielas e as de tração por tirantes. O processo de caminho de cargas deve seguir os seguintes passos: Forças distribuídas no contorno devem ser substituídas por cargas concentradas equivalentes; Os caminhos de cargas devem ser desenhados, alinhados e não podem se interceptar; Ações opostas devem ser ligadas por caminhos de cargas os mais curtos possíveis; Linhas curvas devem ser substituídas por linhas retas; Quando for necessário, bielas ou tirantes podem ser adicionados para equilibrar os nós. A Figura 3.9 mostra a seqüência de obtenção de bielas e tirantes para um bloco sobre duas estacas, segundo Munhoz (2004).
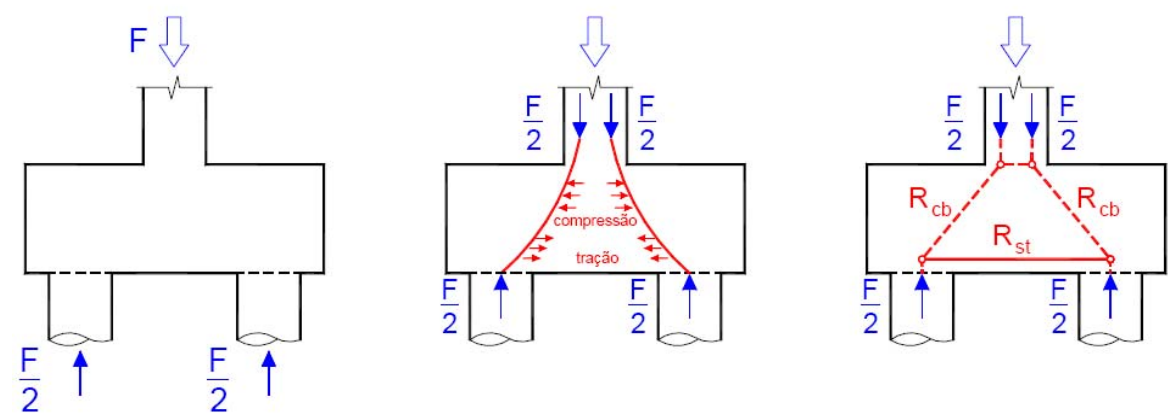

Figura 3.9 - Aplicação do caminho de cargas em blocos sobre duas estacas, Munhoz (2004) 
4-) Escolha do melhor modelo: Como dito anteriormente, existem diversas "estruturas equivalentes" formadas por bielas e tirantes que satisfazem o equilíbrio entre forças externas e internas de uma estrutura. Nesse caso, deve seguir as recomendações de Schlaich et al. (1987) e adotar o modelo cujos tirantes tenham o menor comprimento.

5-) Dimensionamento dos tirantes: As forças nos tirantes normalmente são absorvidas pelas barras de aço, de modo que o eixo das barras das armaduras deve coincidir com o eixo do tirante em questão. A área das barras é dimensionada para o estado limite último, por meio da expressão 3.17:

$$
A_{s}=\frac{\gamma_{f} \cdot R_{s t}}{f_{y d}}
$$

sendo que:

$$
\begin{aligned}
& \gamma_{f} \quad \text { é o fator de majoração das solicitações; } \\
& R_{s t} \quad \text { é a resultante das tensões nas barras da armadura; } \\
& f_{y d} \quad \text { é a resistência de cálculo ao escoamento do aço. }
\end{aligned}
$$

6-) Detalhamento das barras das armaduras: o detalhamento das barras das armaduras requer bastante atenção, principalmente quando da ancoragem das mesmas. A correta definição da ancoragem contribui para verificação das tensões nas bielas e nos nós. A norma canadense CSA Standard A23.3-04 recomenda que seja adotada uma malha de armadura nas faces do elemento estrutural para limitar as aberturas de fissuras. Essa malha não deve ter área das barras inferior a $0,2 \%$ da área de concreto em cada face, e o espaçamento não deve ser maior que $30 \mathrm{~cm}$.

7-) Dimensionamento das bielas: O CEB-FIP (1990) recomenda que a tensão média nas bielas de compressão não ultrapassem os valores das expressões 3.18 e 3.19 
$0,85 \cdot\left[1-\frac{f_{c k}}{250}\right] \cdot f_{c d}$ para zonas não fissuradas

$0,60 \cdot\left[1-\frac{f_{c k}}{250}\right] \cdot f_{c d}$ para zonas fissuradas

É interessante notar que os valores sugeridos pelo CEB-FIP (1990) para verificação da tensão na biela de compressão, são os mesmos adotados pelo referido código, quando da verificação das tensões nodais. As expressões 3.18 e 3.19 são válidas desde que a deformação máxima no concreto não ultrapasse o valor da 3.20. O valor de $f_{c k}$ é dado em MPa.

$\varepsilon_{c u}=0,004-0,002 \cdot \frac{f_{c k}}{100}$

8-) Verificação das regiões nodais: A verificação das regiões nodais deve ser feita com base nos valores da tabela 3.1 anteriormente apresentada. Dentre os valores apresentados, recomendam-se os valores sugeridos pelo CEB-FIP (1990). 


\section{Capítulo}

\section{Avaliação dos modelos numéricos}

\subsection{Considerações iniciais}

As simulações numéricas propostas no presente trabalho foram feitas via Método dos Elementos Finitos, por meio do programa computacional DIANA versão 9.2, registrada para o Departamento de Engenharia de Estruturas da Escola de Engenharia de São Carlos-USP.

Com o intuito de avaliar os modelos numéricos adotados nas simulações utilizando o DIANA, foram feitas as análises de quatro modelos de bloco sobre duas estacas, os quais foram estudados numérica e experimentalmente por Delalibera (2006). Esses quatro blocos serviram de referência aos estudos paramétricos, podendo-se então aferir o modelo numérico de tal maneira que os resultados obtidos fiquem respaldados por ensaios experimentais.

Inicialmente são apresentadas algumas informações pertinentes ao programa DIANA e aos modelos constitutivos disponíveis para simulações de estruturas de concreto armado. Em seguida, é feito um estudo paramétrico dos modelos de referência, a fim de se determinar a influência de vários parâmetros no modelo numérico. Por fim, são apresentados resultados de curvas do tipo força versus deslocamento por meio de comparações dos dados obtidos experimentalmente, e com base nos programas computacionais DIANA 9.2 e ANSYS 9.0, além de um modelo numérico final que servirá de base para as análises dos modelos de blocos com cálice totalmente embutido. 


\subsection{Programa Diana}

\subsubsection{Introdução}

O pacote computacional DIANA é um programa de Elementos Finitos baseado no método dos deslocamentos. Desenvolvido na Holanda desde 1972 por engenheiros civis da TNO Building and Construction Research Company, o DIANA é considerado uma excelente ferramenta para análises tridimensionais e não-lineares.

Outra propriedade desse programa é a possibilidade de considerar em suas análises fenômenos complexos existentes em estruturas de concreto armado. Entre esses fenômenos, podem-se citar: fissuração, plasticidade, fluência, cura, efeitos de temperatura e instabilidade, todos eles aplicados em análises estáticas, não-linear, modal entre outras. Além disso, o referido programa oferece grande variedade de elementos em sua biblioteca, tais como: vigas, sólidos, membranas, placas, cascas, elementos de contato e de interface.

\subsubsection{Modelos constitutivos}

Em estruturas de concreto armado sabe-se que, atingida certa intensidade de solicitação, ocorre uma redução da capacidade resistente com acréscimo significativo de deformação. Esse comportamento existe em virtude de um efeito que ocorre no material, conhecido como "strain softening", também conhecido como amolecimento do material, e ocorre tanto no comportamento à tração como na compressão.

Por causa desse efeito de amolecimento as deformações tendem a se apresentar de maneira mais acentuada em certas regiões da estrutura, de modo que a discretização da malha de elementos finitos nessas regiões passa a ser preponderante na qualidade dos resultados. Uma discretização mais refinada nessas regiões geralmente aumenta o tempo computacional 
da análise em questão. No DIANA um meio de superar essa dificuldade é fazer uso de critérios da Mecânica da Fratura e da Mecânica do Dano.

$\mathrm{Na}$ simulação do efeito de fraturamento nas estruturas de concreto armado, o DIANA dispõe de dois modelos distintos de fissuração: modelo de fissuração discreta (discrete crack model) e o modelo de fissuração distribuída. (smeared crack model).

No modelo de fissuração discreta, a cada incremento de carregamento é gerada uma nova malha de elementos finitos na região de propagação da fissura, de modo a tratar a físsura de maneira mais próxima do real. Essa discretização eleva bastante o tempo computacional das análises, principalmente em modelos tridimensionais. Já o modelo de fissuração distribuída, considera o material danificado pela abertura de fissuras como meio contínuo mantendo, portanto, a discretização original da malha de elementos finitos. Em função dessa consideração, as tensões e deformações podem ser obtidas sem a necessidade de se construir uma nova malha enquanto as fissuras se propagam.

Nas análises feitas no presente trabalho, optou-se por utilizar o modelo de fissuração distribuída. Assim, os parâmetros da mecânica da fratura necessários para representação desse modelo são a energia de fraturamento na tração e na compressão $\left(G_{f}\right.$ e $\left.G_{c}\right)$, as resistências à tração e à compressão, o coeficiente de retenção ao cisalhamento $\beta$, e o comprimento de banda de fissuras (“crack band"). Feenstra \& Borst (1993) apud Souza (2006), indicam que em ensaios experimentais, a energia de fraturamento na compressão, $G_{c}$, apresenta valores entre 50 e 100 vezes superiores à energia de fraturamento na tração, $\mathrm{G}_{\mathrm{f}}$. Esses valores foram confirmados nos ensaios realizados por Farias (2008)

A energia de fraturamento, tanto na tração como na compressão, pode ser entendida como a energia necessária para causar um dano irreverssível no material. Uma maneira de se

${ }^{2}$ FEENSTRA, P. H.; BORST, R. (1993). Aspects of robust computational modeling for plain and reinforced concrete. Heron, v.38, n.04, Delft, Netherlands. 
obter o valor do parâmetro $\mathrm{G}_{\mathrm{f}}$ é realizar um ensaio de deformação controlada e medir a área do diagrama tensão versus abertura de fissuras, como mostra a Figura 4.1

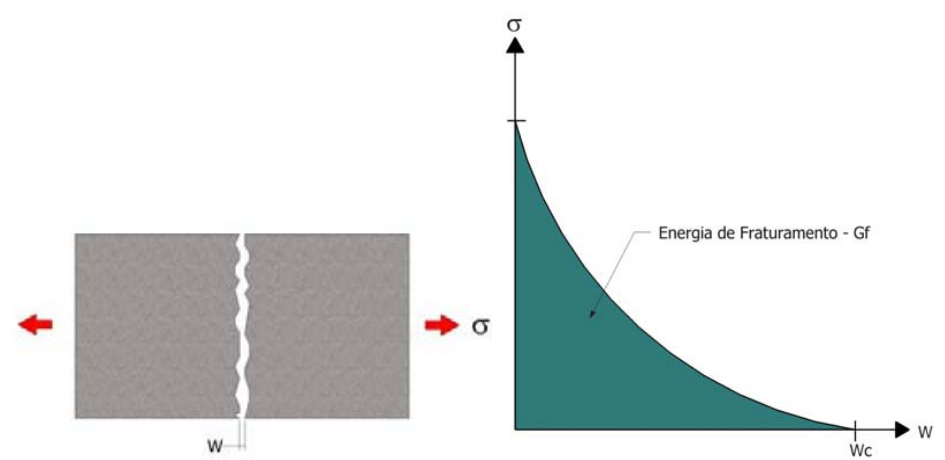

Figura 4. 1 - Energia de fraturamento na tração, Farias (2008)

A energia de fraturamento, por sua vez, pode ser definida como um parâmetro que depende da resistência à compressão e do tamanho máximo do agregado. O CEB-FIP Model Code (1990) permite calcular o valor de $\mathrm{G}_{\mathrm{f}}$ por meio das expressões 4.1 e 4.2:

$$
\begin{aligned}
& \mathrm{G}_{\mathrm{f}}=\mathrm{G}_{\mathrm{F} 0}\left(\mathrm{f}_{\mathrm{cm}} / \mathrm{f}_{\mathrm{cm} 0}\right)^{0,7} \\
& \mathrm{f}_{\mathrm{cm}}=\mathrm{f}_{\mathrm{ck}}+8
\end{aligned}
$$

sendo que:

$\mathrm{G}_{\mathrm{f}} \quad$ é a energia de fraturamento na tração, dada em N.mm $/ \mathrm{mm}^{2}$;

$\mathrm{f}_{\mathrm{cm} 0} \quad$ é igual a $10 \mathrm{~N} / \mathrm{mm}^{2}$;

$\mathrm{f}_{\mathrm{ck}} \quad$ é a resistência característica à compressão do concreto, em N/mm²;

$\mathrm{G}_{\mathrm{f} 0}$ é um parâmetro que depende do tamanho máximo do agregado, conforme apresentado na tabela 4.1.

Tabela 4.1 - Valores de $\mathrm{G}_{\mathrm{F} 0}$ em função de $\mathrm{d}_{\text {máx }}$

\begin{tabular}{c|c}
\hline \hline $\mathbf{G}_{\mathbf{f 0}}\left(\mathbf{N m m} / \mathbf{m m}^{\mathbf{2}}\right)$ & $\mathbf{d}_{\text {máx }}(\mathbf{m m})$ \\
\hline 0,025 & 8 \\
\hline 0,030 & 16 \\
\hline 0,058 & 32 \\
\hline
\end{tabular}


O coeficiente de retenção ao cisalhamento $\beta$, por sua vez, é um parâmetro que permite reduzir o valor do módulo de elasticidade transversal do material, após iniciada a fissuração, sendo que essa redução pode se dar de maneira completa, constante ou variável. De acordo com Farias (2008), a influência desse parâmetro é maior em problemas cuja ruína ocorre por cisalhamento. Ainda nesse capítulo será mostrada a influência do coeficiente de retenção ao cisalhamento nos modelos analisados.

Por fim, o comprimento de banda de fissuras é utilizado para suprir a dependência de malha do modelo. Esse parâmetro pode ser fornecido pelo usuário, bem como calculado pelo programa, em função do tipo de elemento finito utilizado. As expressões 4.3, 4.4 e 4.5 mostram como o comprimento de banda de fissura é calculado no DIANA para elementos bidimensionais de ordem linear, bidimensionais de ordem quadrática e elementos tridimensionais, respectivamente.

$h=\sqrt{A_{e}}$

$$
h=\sqrt{2 \cdot A_{e}}
$$

$h=\sqrt[3]{V_{e}}$

sendo que:

$$
\begin{aligned}
& A_{e} \quad \text { é a área do elemento finito adotado; } \\
& V_{e} \quad \text { é o volume do elemento finito adotado; } \\
& h \quad \text { é o comprimento de banda de fissuras. }
\end{aligned}
$$

Com base nos valores de $\mathrm{G}_{\mathrm{f}}$ e de $\mathrm{h}$, pode-se então calcular um parâmetro denominado $\mathrm{g}_{\mathrm{f}}$ que é o trabalho inelástico do material. Esse parâmetro representa a quantidade de energia necessária a ser dissipada em um elemento da malha de elementos finitos, para que ocorra um dano irreversível no material. 
O modelo de fissuração distribuida descrito anteriormente indica como o programa computacional DIANA trata o efeito da fissuração em um determinado ponto da malha de elementos finitos. Todavia, é preciso compreender como o programa trata a abertura e a orientação dessas fissuras. Isso é feito por meio de dois modelos disponíveis no programa: Modelos incrementais ou plásticos e Modelos "Total Strain".

\subsubsection{Modelos incrementais ou plásticos}

Os modelos incrementais ou plásticos são representados no programa computacional DIANA por meio do "Multi-Directional Crack Model". Esse modelo recorre a conceitos da teoria da plasticidade, e divide a deformação em duas parcelas: uma elástica e outra plástica, sendo essa última irreverssível. A ruptura na tração ocorre quando em algum ponto do material, a máxima tensão principal de tração ultrapassa a resistência do material, enquanto que durante a compressão podem-se utilizar os modelos clássicos de ruptura de Tresca, Von Mises, Mohr-Coulomb e Drucker-Prager.

O "Multi-Directional Crack Model" permite a abertura de várias fissuras em direções diferentes num mesmo ponto da malha de elementos finitos, e apresenta vantagens no tratamento de problemas bidimensionais. Entretanto, esse modelo só deve ser aplicado em problemas que envolvam estado plano de tensão, estado plano de deformação e em elementos axissimétricos, pois a sua formulação não está disponível para elementos sólidos. Na situação de modelagens tridimensionais, o autor recomenda utilizar o "Modified Maekawa Concrete Model", que combina um modelo plástico multi-axial de dano com o efeito de esmagamento e fissuração. Esse modelo não pôde ser utilizado nas análises do presente trabalho, uma vez que o mesmo não está disponível na versão do programa computacional registrado em nome do Departamento de Engenharia de Estruturas da EESC-USP. 


\subsubsection{Modelos "Total Strain"}

Os modelos "Total Strain" descrevem o comportamento do material na tração e na compressão baseados apenas numa relação tensão-deformação. De acordo com DIANA (2005b), esses modelos representam de maneira satisfatória os estado limites último e de serviço de estruturas de concreto armado.

O programa computacional DIANA disponibliza dois modelos total strain: "Rotating Crack Model" e "Fixed Crack Model”. O "Rotating Crack Model”, por sua vez, permite que a abertura da fissura mude de direção enquanto a mesma se propaga no material. Já o "Fixed Crack Model" mantém o mesmo ângulo da abertura da primeira fissura, permitindo que a mesma mude de direção apenas nos casos em que a variação do ângulo da fissura seja igual a $90^{\circ}$ em relação ao ângulo inicial.

A entrada de dados nos modelos "total strain" compreendem duas partes: na primeira são definidos parâmetros básicos como o módulo de elasticidade longitudinal do material, coeficiente de Poisson e resistência à tração e à compressão. Já na segunda etapa, são definidos o comportamento do material na tração, na compressão e ao cisalhamento.

O programa computacional DIANA disponibiliza diversas leis constitutivas para o comportamento dos materiais tanto à tração como à compressão. Essas leis são baseadas na energia de fraturamento, anteriormente detalhada, e podem ser vistas nas Figuras 4.2 e 4.3. 


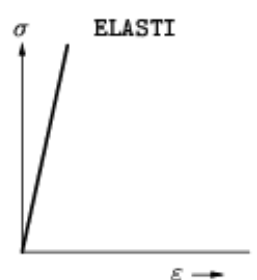

(a) elastic

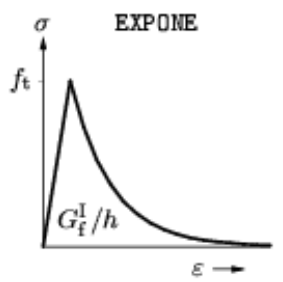

(e) exponential

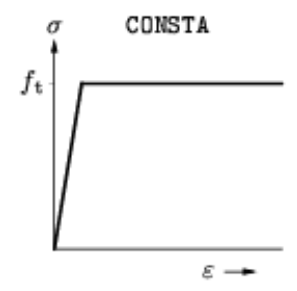

(b) ideal

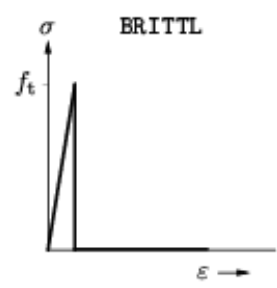

(c) brittle

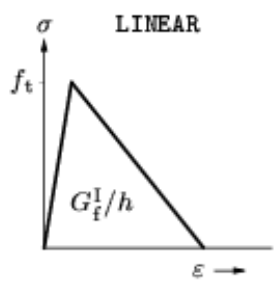

(d) linear

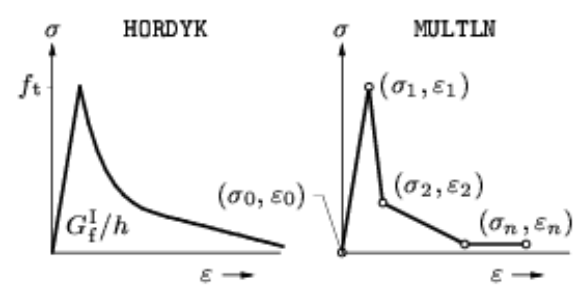

(f) Hordijk

(g) multi-linear

Figura 4. 2 - Modelos Constitutivos à tração pré-definidos, disponíveis em Diana (2005b)

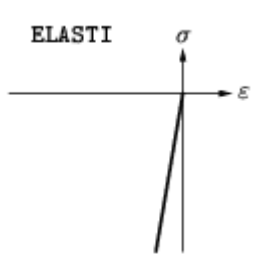

(a) elastic

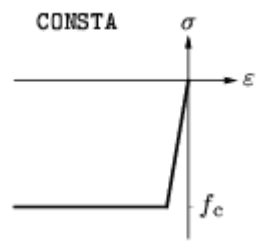

(b) ideal

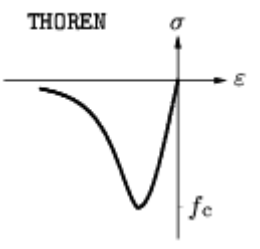

(c) Thorenfeldt

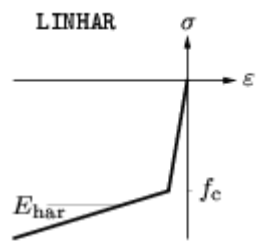

(d) linear

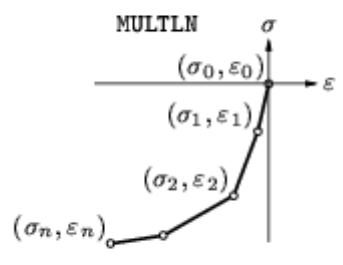

(e) multi-linear

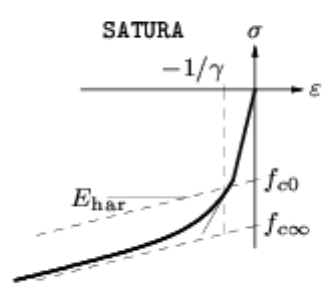

(f) saturation type

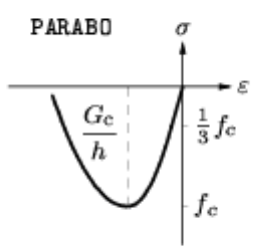

(g) parabolic

Figura 4. 3 - Modelos Constitutivos à compressão pré-definidos, disponíveis em Diana (2005b)

Em relação ao cisalhamento, em virtude do efeito da fissuração pode ocorrer uma redução do módulo de elasticidade transversal do material. Essa redução é considerada por meio do coeficiente de retenção ao cisalhamento, $\beta$. O programa computacional DIANA disponibiliza três modos para consideração desse efeito: retenção completa, retenção constante e retenção variável. 
$\mathrm{Na}$ situação de retenção completa, o módulo de elasticidade transversal não sofre redução alguma. Tratando-se de retenção constante, o usuário define um valor para o parâmetro $\beta$, anteriormente definido, que deve estar no intervalo entre 0 e 1 . Em problemas que o cisalhamento é importante no modo de ruptura da estrutura, o valor de $\beta$ deve ser tomado próximo à zero, quando não, próximo à unidade. Por fim, na retenção variável o parâmetro $\beta$ é calculado como uma função da deformação das fissuras.

O efeito lateral em virtude da fissuração e do confinamento do material também pode ser considerado nos modelos "total strain". Entretanto, não devem ser utilizados quando do uso do diagrama multi-linear para o comportamento do material à compressão. $\mathrm{O}$ programa computacional DIANA disponibiliza duas funções que simulam o comportamento da fissuração lateral e do confinamento do material. São elas: REDCRV e CNFCRV, respectivamente.

A função REDCRV permite que no concreto fissurado, grandes deformações ocasionadas por tração perpendicular às direções principais de compressão, reduzam a resistência à compressão do material. Para tanto, o modelo adotado no DIANA é o proposto por Vecchio e Collins, descrito em DIANA (2005b). A Figura 4.4 mostra como o programa DIANA considera essa redução. Já o aumento da resistência a compressão do material é considerado em virtude do confinamento lateral, por meio da função CNFCRV.

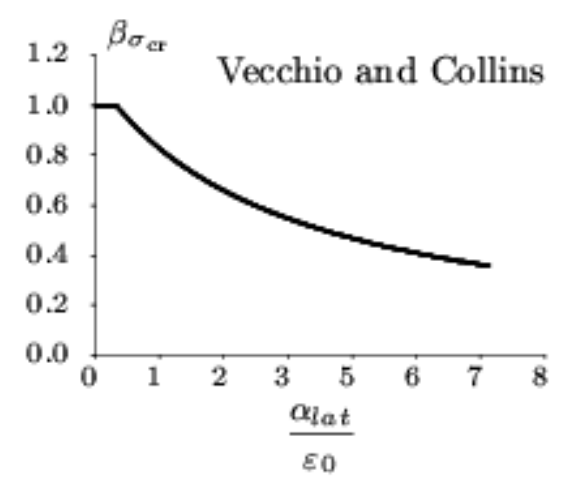

Figura 4. 4 - Fator de redução devido a fissuração lateral, DIANA (2005b) 
É importante destacar que esses efeitos só podem ser ativados via arquivo do tipo DAT antes do processamento, não podendo ser ativado na interface gráfica via pré-processador. Para tanto, para ativar a função REDCRV é preciso utilizar o comando VC1993 na guia referente às propriedades dos materiais, assim como para ativar a função CNFCRV, deve-se utilizar o comando VECCHI.

\subsubsection{Modelagem das barras das armaduras}

Atualmente existem três modos de se modelarem as barras das armaduras nos programas de elementos finitos, são eles: barras de armaduras distribuídas, barras de armaduras embutidas e barras de armaduras discretas.

As barras de armadura do tipo distribuída consideram uma valor de área de aço distribuído numa determinada direção, ao longo dos elementos finitos que existem numa dada região.

As barras de armaduras do tipo embutidas são conhecidas também como embedded ou “incorporadas". Nessa situação, considera-se que o deslocamento na barra da armadura é igual ao do elemento finito na qual a barra se incorpora. Esses elementos são conhecido como mother elements, e considera-se uma aderência perfeita entre as barras das armaduras e o material que representa o concreto.

Já a representação das barras das armaduras do tipo discreta, são introduzidos elementos finitos uniaxiais nas interfaces dos demais elementos, e têm-se a opção de simular a aderência entre o concreto e o aço por meio de elementos de interface.

No programa computacional DIANA, as armaduras podem ser discretizadas dos dois primeiros modos anteriormente descritos. Para tanto, existe no programa um elemento conhecido como reinforcement. Para inserção desses elementos, é preciso conhecer apenas o 
ponto inicial e final da barra da armadura, independente se nesse ponto existe algum nó de um elemento finito.

O modelo constitutivo adotado pelo meio técnico para as barras das armaduras de aço geralmente é o elasto-plástico perfeito com critério de ruptura de Von Mises. As curvas tensão deformação são normalmente obtidas de ensaios uniaxiais e o comportamento adotado é igual tanto na tração quanto na compressão.

\subsubsection{Pré e pós processadores}

Nesse item pretende-se explicar como o programa computacional DIANA funciona desde a geração do modelo, passando por suas análises chegando por fim a interpretação dos resultados. O pacote computacional DIANA conta com um pré-processador, na qual o usuário define a geometria, os carregamentos, condições de contorno e propriedades físicas e mecânicas dos materiais. Esse pré-processador é chamado de iDIANA, e ao iniciar um novo arquivo, o usuário precisa definir as unidades as quais serão utilizadas pelo programa. A interface gráfica do iDIANA pode ser vista na Figura 4.5.

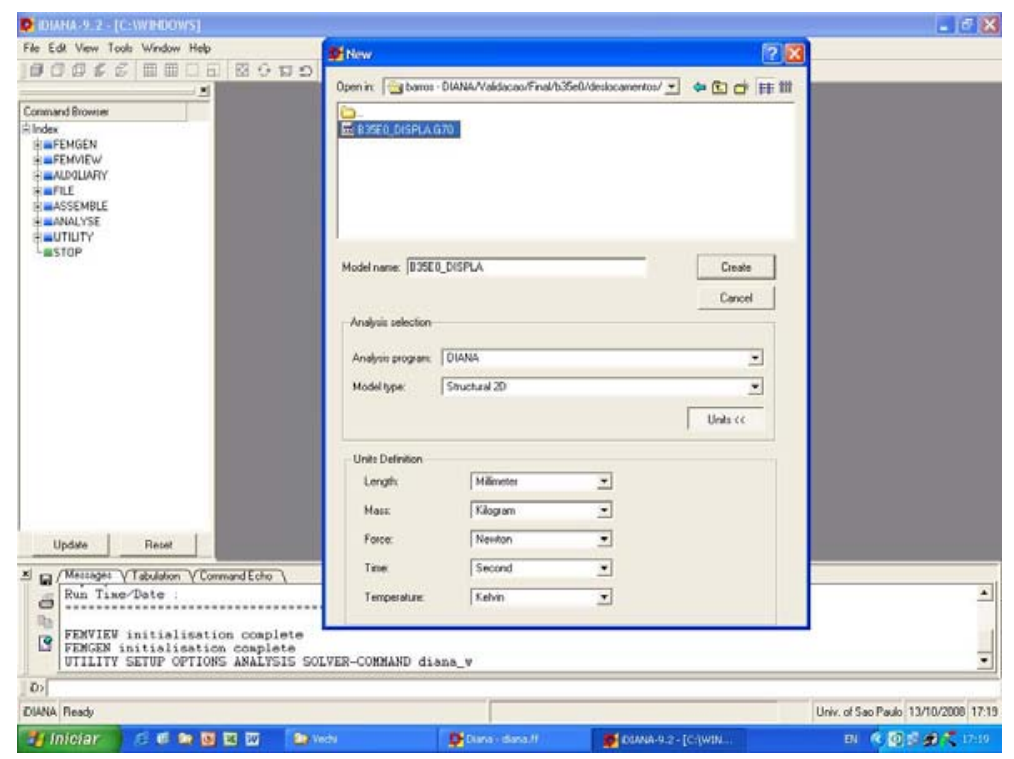

Figura 4. 5 - Interface gráfica do iDIANA 
O iDIANA permite também que o usuário forneça um script contendo todos os comandos necessários para a criação do modelo. O uso de scripts é bastante comum entre usuários de programas de elementos finitos, uma vez que sua utilização acelera a criação do modelo, bem como permite alterações de modo rápido por meio de linhas de comando.

Com o intuito de otimizar a criação dos diversos modelos de blocos sobre duas estacas, foi criada uma rotina na qual o usuário fornece os dados geométricos do bloco, como altura, largura e comprimento, bem como dimensões das estacas e do pilar. O usuário precisa fornecer também dados relativos às propriedades físicas e mecânicas dos materiais, bem como ações e condições de contorno. Por meio dessas informações, é gerado então um script que é lido pelo iDIANA, e em pouco tempo têm-se o modelo pronto para ser processado.

Para elaboração dessa rotina, optou-se por utilizar uma planilha eletrônica por causa das facilidades operacionais e experiência de outros usuários. Outra maneira de elaborar uma rotina é utilizando linguagem de programação, como por exemplo, o FORTRAN. A Figura 4.6 mostra algumas partes dessa rotina. Um exemplo completo é apresentado no Anexo $I^{4}$.

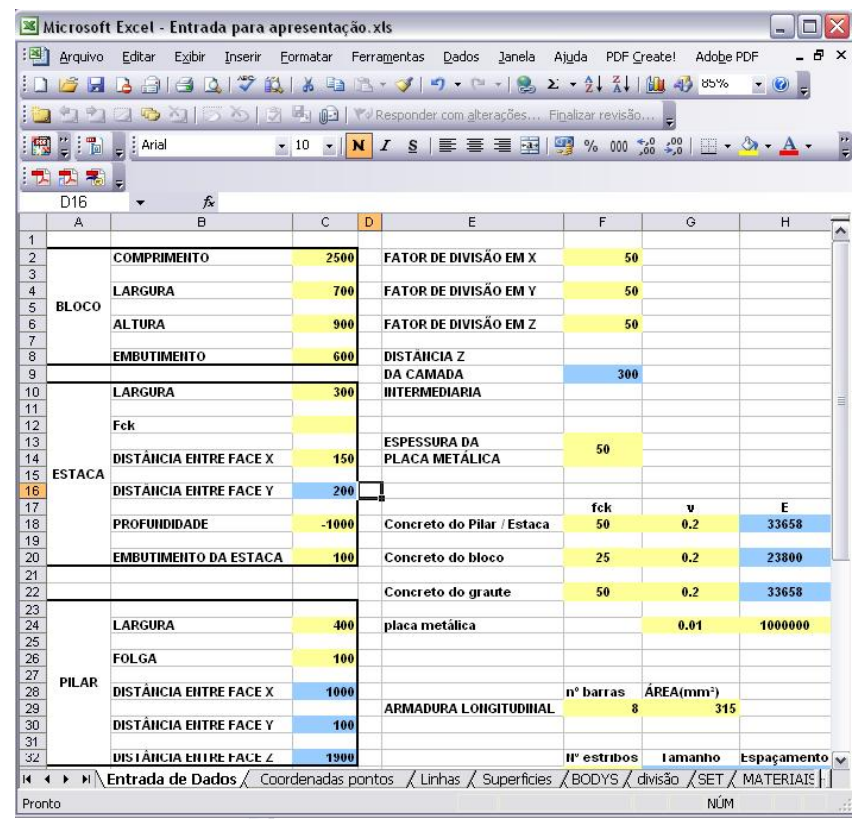

Figura 4. 6 - Entrada de dados via script 
Em seguida, o usuário precisa criar o arquivo com todas as informações relativas ao modelo e que vai ser lido pelo processador, que no caso se chama DIANA. No DIANA o usuário fornece informações relativas ao tipo de análise a ser feito. O DIANA oferece a possibilidade de realizar análises estáticas, análise não-linear física e geométrica, análise modal, análise transiente, entre outras, cada uma dessas análises com suas particularidades. No presente trabalho foi realizada análise estrutural com consideração do efeito de não linearidade física dos materiais.

\subsubsection{Critérios de solução do sistema de equações não-lineares}

Ainda no programa DIANA, o usuário escolhe o método de resolução do sistema de equações não-lineares, o número de incrementos de força, a intensidade máxima de cada incremento bem como o critério de convergência a ser adotado.

O DIANA dispõe de diversos métodos que podem ser aplicados como estratégia na resolução dos sistemas de equações não-lineares, dentre os quais destacam-se o método de Newton-Raphson Regular, Newton-Raphson Modificado, Quasi-Newton (Método Secante) e Método da Rigidez Linear.

A estratégia de Newton-Raphson é uma estratégia incremental-iterativa, na qual se imagina que o resíduo gerado entre duas iterações consecutivas, possa ser considerado contínuo na vizinha da solução. Assim, supõe-se que numa dada iteração $r$ o resíduo em relação à iteração $r$-1 seja nulo e, portanto, possa ser escritos em termos de série de Taylor. Tomando-se a hipótese de que a "função resíduo" tenha uma variação suave, é possível admiti-la até o termo de primeira ordem da série de Taylor. Nota-se que essa condição considera que a força aplicada na estrutura não varia com os deslocamentos, o que é condizente com a condição de forças conservativas. Além do uso de iterações, é comum em uma análise não-linear dividir as ações em várias etapas de carga, de modo que para cada 
etapa são realizadas várias iterações até que haja convergência do problema, definindo, portanto, uma estratégia incremental-iterativa.

A estratégia incremental-iterativa de Newton-Raphson busca calcular um incremento nos deslocamentos em cada etapa de carga. Para tanto, a cada iteração é preciso atualizar a matriz de rigidez, sendo nesse caso, denominada matriz de rigidez tangente. A utilização da matriz tangente em cada iteração é o que define o método de Newton-Raphson Regular. Esse método exige esforço computacional significativo, porém apresenta convergência com poucas iterações.

Já na estratégia incremental-iterativa de Newton-Raphson Modificado, a matriz de rigidez tangente é calculada apenas na primeira iteração de cada incremento de carregamento, e mantida constante nas iterações seguintes. Assim, nos demais passos a matriz de rigidez utilizada passa a ser uma matriz secante. Esse processo demanda um número maior de iterações, e por isso, costuma convergir mais lentamente que o método de Newton-Raphson regular.

O método secante ou Quasi-Newton, por sua vez, não necessita da atualização da matriz de rigidez em cada iteração, utilizando também uma matriz de rigidez secante. Entretanto, baseia-se na solução prévia dos vetores de forças não balanceados, para obter uma melhor aproximação durante a aplicação dos incrementos de carregamento. A utilização do método Quasi-Newton é recomendada quando as estratégias de Newton-Raphson não apresentarem boas soluções. Por fim, o método da rigidez linear é recomendado apenas quando nenhum dos métodos anteriores apresentarem boas soluções.

Na resolução de sistemas de equações não-lineares, é comum a ocorrência de problemas que podem dificultar a convergência de determinadas soluções. Para suprir esse quesito, o programa DIANA dispõe de alguns recursos como o critério de procura de linhas ("line search") e o critério de comprimento de arco ("arc length control"). O critério de "line search" 
busca um multiplicador ótimo para os incrementos de deslocamentos, de modo a acelerar a convergência das soluções. Já o critério de comprimento de arco é extremamente útil na busca do comportamento pós-pico das estruturas. Por meio desse critério, é possível descrever o fenômenos como o snap-through em curvas força versus deslocamento, isto é, descrevem equilíbrios estáveis e instáveis de algumas estruturas, conforme Figura 4.7. Cabe ressaltar que o programa DIANA não permite a utilização do critério de comprimento de arco quando o carregamento aplicado for em controle de deslocamentos.

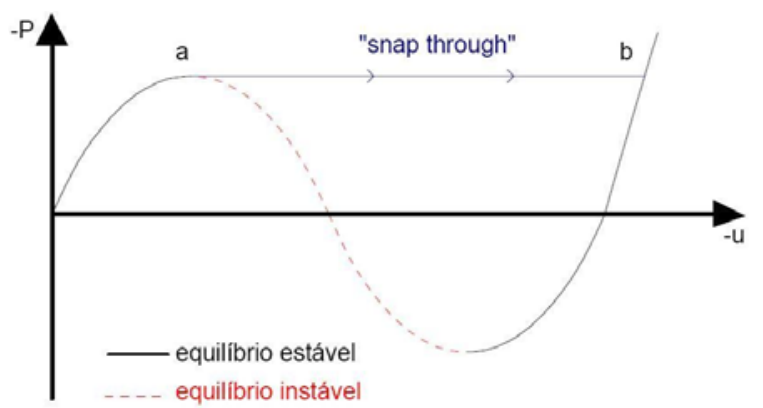

Figura 4. 7 - Curva força versus deslocamento, obtida com critério de comprimento de arco

Ainda no DIANA, é preciso optar pela forma como as ações são aplicadas na estrutura. Para isso, o usuário pode optar em aplicar passos de carga pré-definidos, cuja intensidade do passo é dada por uma porcentagem da carga total aplicada no modelo. Outra maneira de aplicar o carregamento é utilizando um procedimento chamado de "iteration based sizes". Esse procedimento permite que o tamanho dos passos de carga seja variável ao longo da análise, sendo assim, o usuário fornece o valor do passo de carga inicial, e valores para o tamanho máximo e mínimo de cada passo no decorrer da análise. Esse procedimento permite uma análise não-linear mais rápida, porém, ao descrever a trajetória de equilíbrio de uma estrutura, a análise fornece poucos pontos, sendo questionável o comportamento de curvas força versus deslocamento obtidas por meio desse tipo de análise. 
Em relação aos critérios de convergência, o DIANA dispõe de critérios baseados em normas (módulo) de força, deslocamento, energia e resíduos, todos esses comparados com um valor máximo de erro fornecido pelo usuário. Destaca-se nesse quesito o critério de convergência baseado em norma de energia, utilizado nas análises do presente trabalho. Esse critério é baseado no trabalho das forças internas presentes na estrutura, conforme a expressão 4.6.

$E=\left|\frac{\delta u_{i}^{T} \cdot\left(f_{\mathrm{int}, i+1}+f_{\mathrm{int}, i}\right)}{\Delta u_{0}^{T} \cdot\left(f_{\mathrm{int}, 1}+f_{\mathrm{int}, 0}\right)}\right|$

É importante notar que no cálculo da norma em termos energéticos, são utilizadas forças internas, e não forças externas. De acordo com Diana (2005b), o uso de forças externas poderia conduzir a resultados incoerentes, quando do uso do critério de "line search". Segundo Souza (2006), o critério de convergência baseado em energia é mais interessante, pois considera simultaneamente o efeito das forças e dos deslocamentos. O autor conseguiu bons resultados em suas análises adotando tolerância de $10^{-2}$ em termos energéticos. A Figura 4.8 indica o uso de critério de convergência baseado em energia.

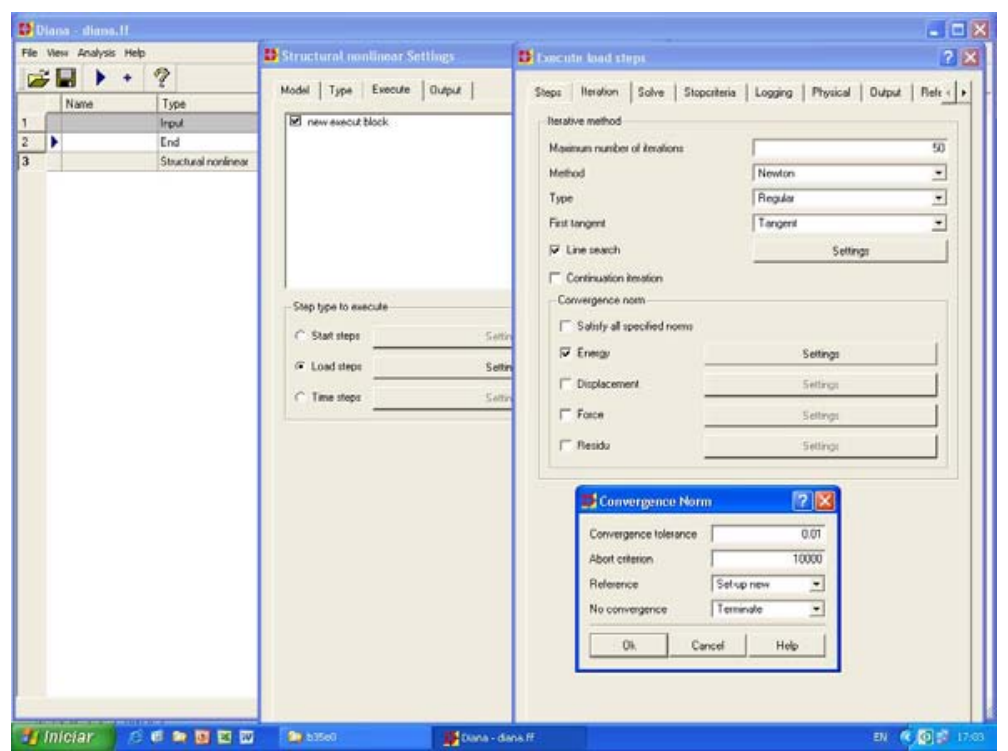

Figura 4. 8 - DIANA, critério de convergência em energia. 
Por fim, o usuário pode configurar a saída de dados do programa, por meio de arquivos tabulados, ou arquivos do tipo femview. Os arquivos tabulados são de grande utilidade, uma vez que com eles podem-se solicitar apenas dados específicos, como por exemplo, deslocamentos ou tensões em determinados pontos da estrutura. Para tanto, é preciso que o usuário defina um set, que nada mais é do que um agrupamento de entidades geométricas, podendo ser composta de pontos, linhas ou bodys. Os resultados de modo tabulado só podem ser fornecidos em relação a determinado set. Já os resultados em modo femview, por suas vezes, podem ser visualizados no iDIANA. É nesse tipo de arquivo que podem ser obtidas imagens dos panoramas de fissuração, distribuição de tensões e deformações, campos de deslocamentos, entre outros.

\subsubsection{Elementos finitos utilizados}

Os elementos finitos utilizados na simulação numérica estão disponíveis na biblioteca de elementos do DIANA. Para a modelagem do concreto das estacas, do pilar e do bloco, foi utilizado elemento sólido. A princípio, optou-se por utilizar o elemento HX24L, que é um elemento finito isoparamétrico com 8 nós e aproximação linear para os deslocamentos. Os graus de liberdade em cada nó desse elemento são os deslocamentos nas direções x, y e z. Por se tratar de um elemento com aproximação linear para os deslocamentos, seria necessária uma maior discretização da malha de elementos finitos. Entretanto, verificou-se em DIANA (2005a) que, em análises não-lineares, não se recomenda a utilização de elementos com função aproximadora linear. Por esse motivo, optou-se por utilizar o elemento CHX60.

O elemento finito CHX60 é um elemento isoparamétrico com 20 nós, e função aproximadora quadrática para os deslocamentos. Cada nó apresenta três graus de liberdade, que são os deslocamentos nas direções x, y e z. A Figura 4.9 apresenta o elemento CHX60 e a função aproximadora para os deslocamentos. 


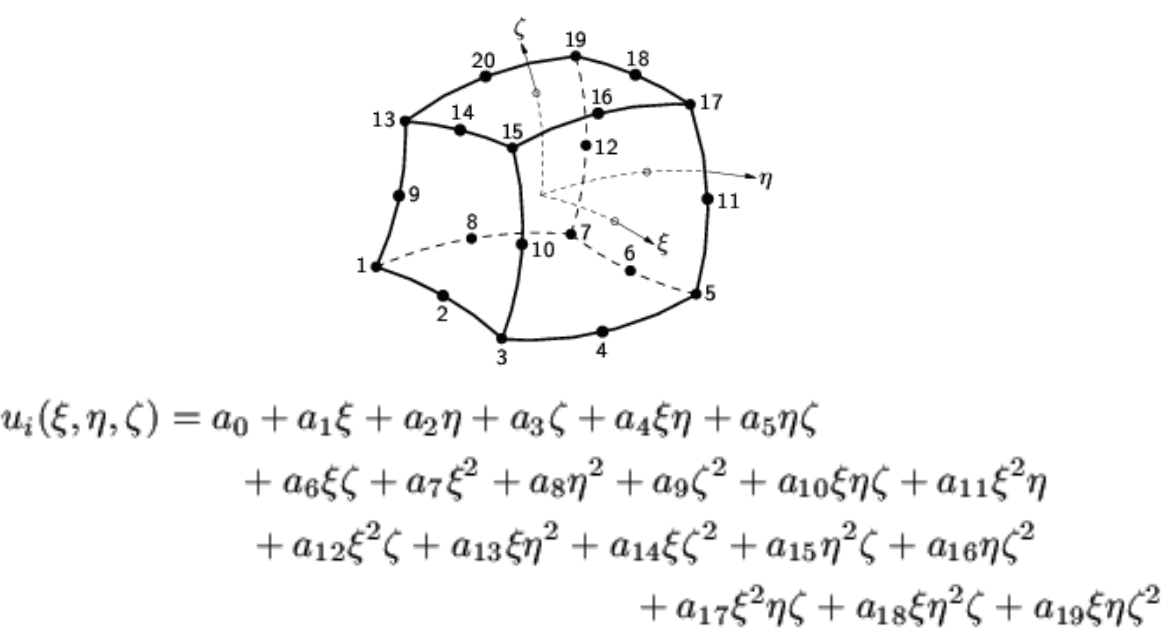

Figura 4. 9 - Elemento CHX60 com função aproximadora em deslocamentos

Para modelagem das barras de aço das armaduras foram utilizados elementos chamados de reinforcements. Esses elementos não possuem nós, e funcionam como enrijecedores dos elementos finitos aos quais estão conectados, também conhecidos como mother elements. Os reinforcements não possuem graus de liberdade, porém têm seu comportamento habilitado na direção axial da barra. Nessa situação, a aderência entre o aço e o concreto é considerada perfeita.

A influência da malha de elementos finitos foi estudada previamente nas análises elásticas, e percebeu-se que, para elementos com aproximação quadrática, melhores resultados foram obtidos com distância máxima entre nós da ordem de $5 \mathrm{~cm}$.

\subsection{Modelos analisados}

Nesse item são apresentados os quatro modelos de blocos sobre duas estacas analisados com o programa computacional DIANA, com o intuito de verificar se o modelo numérico fornece bons resultados. Os elementos finitos adotados foram apresentados em 4.2.8, e as condições de contorno tentaram representar com bom grau de realidade as condições adotadas nos ensaios experimentais. 
Os blocos foram analisados por Delalibera (2006), e os dimensionamentos seguiram as recomendações de Blévot \& Frémy (1967) e da ABNT NBR 6118:2003, no que diz respeito ao arranjo das barras das armaduras. Como o objetivo dos ensaios era estudar a ruína dos modelos por fendilhamento das bielas, as barras das armaduras principais do tirante foram dimensionadas para não escoarem. Além disso, para impedir as ruínas dos pilares ou das estacas dos modelos, utilizaram-se nesses elementos concretos com resistência à compressão maior do que as resistências do concreto dos blocos.

Os modelos escolhidos para análises foram de blocos sobre duas estacas, com força vertical centrada, altura de $35 \mathrm{~cm}$ e $45 \mathrm{~cm}$, com ou sem presença de armadura secundária. A tabela 4.2 apresenta as propriedades geométricas dos modelos analisados, assim como as tabelas 4.3 e 4.4 apresentam os valores das áreas das barras das armaduras principal e secundária dos blocos, bem como as armaduras das estacas e dos pilares.

Tabela 4.2 - Propriedades geométricas dos modelos analisados

\begin{tabular}{c|c|c|c|c|c|c|c|c}
\hline \hline Blocos & $\begin{array}{c}\text { Dimensão } \\
\text { da estaca } \\
(\mathbf{c m})\end{array}$ & $\begin{array}{c}\text { Dimensão } \\
\mathbf{d o} \mathbf{p i l a r} \\
\mathbf{( c m )}\end{array}$ & $\begin{array}{c}\mathbf{B}_{\mathbf{L x}} \\
\mathbf{( c m})\end{array}$ & $\begin{array}{c}\mathbf{B}_{\mathbf{L y}} \\
\mathbf{( c m )}\end{array}$ & $\begin{array}{c}\mathbf{e}_{\mathbf{a d o t}} \\
\mathbf{( c m )}\end{array}$ & $\begin{array}{c}\mathbf{h} \\
(\mathbf{c m})\end{array}$ & $\begin{array}{c}\theta \\
(\mathbf{g r a u s})\end{array}$ & $\mathbf{A}_{\mathbf{s w}}$ \\
\hline B35E0 & $25 \times 25$ & $25 \times 25$ & 117,5 & 25 & 0 & 35 & 45 & $\neq 0$ \\
\hline B35ASW & $25 \times 25$ & $25 \times 25$ & 117,5 & 25 & 0 & 35 & 54,5 & $=0$ \\
\hline B45E0 & $25 \times 25$ & $25 \times 25$ & 117,5 & 25 & 0 & 45 & 45 & $\neq 0$ \\
\hline B45ASW & $25 \times 25$ & $25 \times 25$ & 117,5 & 25 & 0 & 45 & 54,5 & $=0$ \\
\hline \hline
\end{tabular}

Tabela 4.3 - Barras das armaduras dos blocos

\begin{tabular}{c|c|c|c|c}
\hline \hline Blocos & $\begin{array}{c}\text { Armadura } \\
\text { Principal }\end{array}$ & $\begin{array}{c}\text { Armadura } \\
\text { Superior }\end{array}$ & Estribo Vertical & Estribo Horizontal \\
\hline B35E0 & $5 \varnothing 20 \mathrm{~mm}$ & $3 \varnothing 8 \mathrm{~mm}$ & $\varnothing 5 \mathrm{~mm} \mathrm{c} / 30$ & $3 \varnothing 8 \mathrm{~mm}$ \\
\hline B35ASW & $5 \varnothing 20 \mathrm{~mm}$ & - & - & - \\
\hline B45E0 & $5 \varnothing 20 \mathrm{~mm}$ & $3 \varnothing 8 \mathrm{~mm}$ & $\varnothing 5 \mathrm{~mm} \mathrm{c} / 30$ & $3 \varnothing 8 \mathrm{~mm}$ \\
\hline B45ASW & $5 \varnothing 20 \mathrm{~mm}$ & - & - & - \\
\hline \hline
\end{tabular}


Tabela 4.4 - Barras das armaduras dos pilares e estacas

\begin{tabular}{c|c|c|c|c}
\hline \hline Blocos & $\begin{array}{c}\text { Armadura } \\
\text { das Estacas }\end{array}$ & $\begin{array}{c}\text { Estribo das } \\
\text { Estacas }\end{array}$ & $\begin{array}{c}\text { Armadura } \\
\text { do Pilar }\end{array}$ & $\begin{array}{c}\text { Estribo do } \\
\text { Pilar }\end{array}$ \\
\hline B35E0 & $4 \varnothing 10 \mathrm{~mm}$ & $\varnothing 6,3 \mathrm{~mm} \mathrm{c} / 10$ & $8 \varnothing 10 \mathrm{~mm}$ & $\varnothing 6,3 \mathrm{~mm} \mathrm{c} / 2,5$ \\
\hline B35ASW & $4 \varnothing 10 \mathrm{~mm}$ & $\varnothing 6,3 \mathrm{~mm} \mathrm{c} / 10$ & $14 \varnothing 12,5 \mathrm{~mm}$ & $\varnothing 6,3 \mathrm{~mm} \mathrm{c} / 2,5$ \\
\hline B45E0 & $4 \varnothing 12,5 \mathrm{~mm}$ & $\varnothing 6,3 \mathrm{~mm} \mathrm{c} / 10$ & $8 \varnothing 10 \mathrm{~mm}$ & $\varnothing 6,3 \mathrm{~mm} \mathrm{c} / 2,5$ \\
\hline B45ASW & $4 \varnothing 12,5 \mathrm{~mm}$ & $\varnothing 6,3 \mathrm{~mm} \mathrm{c} / 10$ & $14 \varnothing 12,5 \mathrm{~mm}$ & $\varnothing 6,3 \mathrm{~mm} \mathrm{c} / 2,5$ \\
\hline \hline
\end{tabular}

Notas: na tabela 4.2, $B_{\mathrm{Lx}}$ e $\mathrm{B}_{\mathrm{Ly}}$ são os comprimentos dos blocos nas direções x e y, respectivamente, e $A_{\mathrm{sw}}$ é a armadura secundária.

A resistência característica à compressão adotada para os modelos foi de $25 \mathrm{MPa}$ para os blocos e $50 \mathrm{MPa}$ para estacas e pilares. Após a concretagem dos modelos, procederam-se ensaios em laboratório para análise das resistências dos materiais. As tabelas 4.5, 4.6 e 4.7 apresentam os valores médios das resistências à compressão, à tração e do módulo de elasticidade longitudinal para os concretos dos blocos, pilares e estacas, respectivamente, e utilizados na simulação numérica. Outras informações sobre esses ensaios podem ser obtidas em Delalibera (2006).

Tabela 4.5 - Propriedades mecânicas do concreto dos blocos

\begin{tabular}{c|c|c|c}
\hline \hline Blocos & $\begin{array}{c}\mathbf{E}_{\mathbf{c i , m}, \mathbf{e x p}} \\
(\mathbf{M P a})\end{array}$ & $\begin{array}{c}\mathbf{f}_{\mathbf{t m}, \mathbf{e x p}} \\
(\mathbf{M P a})\end{array}$ & $\begin{array}{c}\mathbf{f}_{\mathbf{c m}} \\
\mathbf{( M P a )}\end{array}$ \\
\hline B35E0 & 30203 & 3,2 & 40,6 \\
\hline B35ASW & 37737 & 2,9 & 32,8 \\
\hline B45E0 & 27490 & 2,9 & 31 \\
\hline B45ASW & 27500 & 2,3 & 32,4 \\
\hline \hline
\end{tabular}


Tabela 4.6 - Propriedades mecânicas do concreto dos pilares

\begin{tabular}{c|c|c|c}
\hline \hline Blocos & $\begin{array}{c}\mathbf{E}_{\mathbf{c i , m}, \mathbf{e x p}} \\
(\mathbf{M P a})\end{array}$ & $\begin{array}{c}\mathbf{f}_{\text {tm,exp }} \\
\mathbf{( M P a )}\end{array}$ & $\begin{array}{c}\mathbf{f}_{\mathbf{c m}} \\
(\mathbf{M P a})\end{array}$ \\
\hline B35E0 & 50970 & 3,8 & 72,3 \\
\hline B35ASW & 38250 & 3,9 & 51,8 \\
\hline B45E0 & 36397 & 3 & 55,2 \\
\hline B45ASW & 31003 & 3,3 & 51,2 \\
\hline \hline
\end{tabular}

Tabela 4.7 - Propriedades mecânicas do concreto das estacas

\begin{tabular}{c|c|c|c}
\hline \hline Blocos & $\begin{array}{c}\mathbf{E}_{\mathbf{c i , m}, \mathbf{e x p}} \\
(\mathbf{M P a})\end{array}$ & $\begin{array}{c}\mathbf{f}_{\text {tm,exp }} \\
\mathbf{( M P a )}\end{array}$ & $\begin{array}{c}\mathbf{f}_{\mathbf{c m}} \\
(\mathbf{M P a})\end{array}$ \\
\hline B35E0 & 41060 & 4,6 & 73,3 \\
\hline B35ASW & 42223 & 5,2 & 71,6 \\
\hline B45E0 & 38250 & 3,9 & 51,8 \\
\hline B45ASW & 34937 & 2,9 & 55 \\
\hline \hline
\end{tabular}

As barras de aço das armaduras também foram analisadas por meio de ensaios em laboratório, e foram medidos os valores da resistência ao escoamento, bem como o módulo de elasticidade longitudinal de cada barra. Os ensaios seguiram recomendações da ABNT NBR 6152:1992. Todas as barras apresentaram resistências ao escoamento superiores a $500 \mathrm{MPa}$, e o módulo de elasticidade longitudinal ficou em torno dos $200 \mathrm{GPa}$. A resistência ao escoamento de cada barra está apresentada na tabela 4.8

Os blocos foram ensaiados no Laboratório de Estruturas da Escola de Engenharia de São Carlos, Universidade de São Paulo. A tabela 4.9 apresenta os valores das forças últimas calculadas analiticamente, e comparadas com os resultados dos ensaios em laboratório. Além disso, é apresentado o deslocamento máximo medido na região central da face inferior de 
cada bloco. Esses dados são utilizados na construção da curva força versus deslocamento de cada bloco.

Tabela 4.8 - Resistência ao escoamento das barras de aço

\begin{tabular}{c|c}
\hline $\begin{array}{c}\text { Barra de } \\
\text { Aço }\end{array}$ & $\mathbf{f}_{\mathbf{y}, \mathbf{m}}$ (MPa) \\
\hline$\varnothing 5,0 \mathrm{~mm}$ & 681 \\
\hline$\varnothing 6,3 \mathrm{~mm}$ & 597 \\
\hline$\varnothing 8,0 \mathrm{~mm}$ & 581 \\
\hline$\varnothing 10,0 \mathrm{~mm}$ & 549 \\
\hline$\varnothing 12,5 \mathrm{~mm}$ & 578 \\
\hline$\varnothing 20,0 \mathrm{~mm}$ & 550 \\
\hline \hline
\end{tabular}

Tabela 4.9 - Valores de forças últimas e deslocamentos máximos obtidos nos ensaios

\begin{tabular}{c|c|c|c|c}
\hline \hline Blocos & $\mathbf{F}_{\mathbf{d}}(\mathbf{k N})$ & $\mathbf{F}_{\mathbf{u}}(\mathbf{k N})$ & $\mathbf{F}_{\mathbf{d}} / \mathbf{F}_{\mathbf{u}}$ & $\begin{array}{c}\boldsymbol{\delta}_{\mathbf{T} 1} \\
(\mathbf{m m})\end{array}$ \\
\hline B35E0 & 1776 & 1821 & 0,98 & 3,16 \\
\hline B35ASW & 1435 & 1406 & 1,02 & 2,42 \\
\hline B45E0 & 1796 & 2276 & 0,79 & 3,27 \\
\hline B45ASW & 1877 & 2090 & 0,90 & 2,49 \\
\hline \hline
\end{tabular}

\subsection{Análise paramétrica}

Visando compreender a influência dos diversos parâmetros existentes numa simulação numérica, procedeu-se à várias simulações numéricas a fim de se determinar um modelo capaz de representar de maneira satisfatória os resultados obtidos experimentalmente nos blocos anteriormente apresentados. Em todas as análises, exceto quando da análise desses fatores, foram utilizados o método de Newton-Raphson Regular, coeficiente de retenção ao 
cisalhamento $\beta$ igual a 0,99 , critério de convergência em energia, ação em forma de pressão e modelo de fissuração "total strain" com "Fixed Crack Model". Em todas as análises foram ativados os recurso de "line search" e critério de comprimento de arco, bem como a consideração da influência lateral.

Primeiramente, estudou-se a influência do fator de retenção ao cisalhamento $\beta$. Foram adotados quatro valores para esse coeficiente: 0,$01 ; 0,25 ; 0,50$ e 0,99 . O coeficiente de retenção ao cisalhamento apresentou a mesma tendência de influência nos quatro modelos analisados. Observa-se por meio dos gráficos das Figuras 4.10-a, 4.10-b, 4.10-c e 4.10-d que um valor muito pequeno para $\beta$ faz com que a curva força versus deslocamento apresente comportamento diferente, atingindo um valor de força última muito inferior às demais curvas. Esses resultados diferem dos apresentados em Souza (2006), onde nenhuma diferença foi percebida para um modelo de blocos sobre duas estacas, utilizando-se $\beta$ igual a 0,001 e 0,99 .

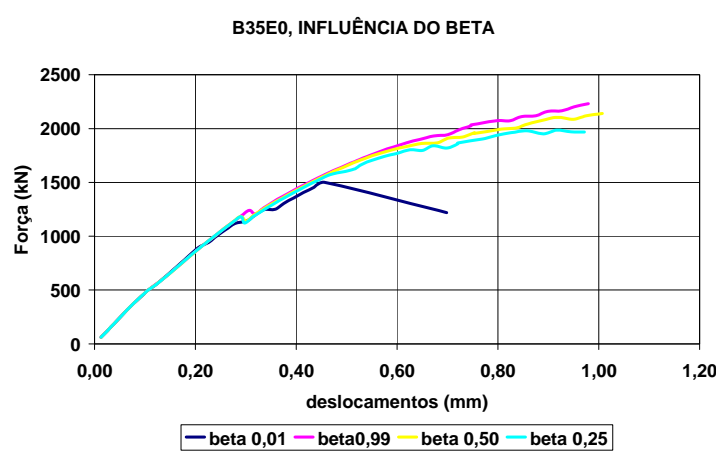

(a)

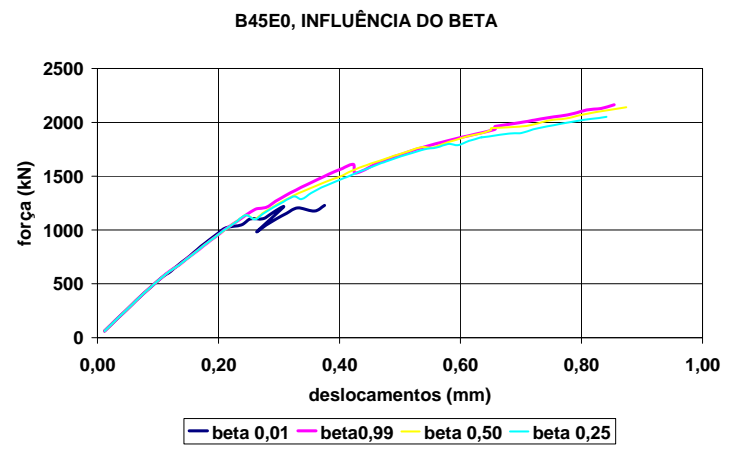

(c)

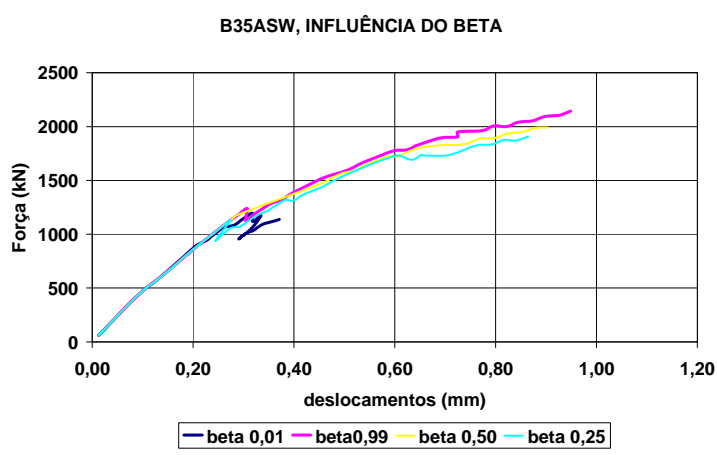

(b)

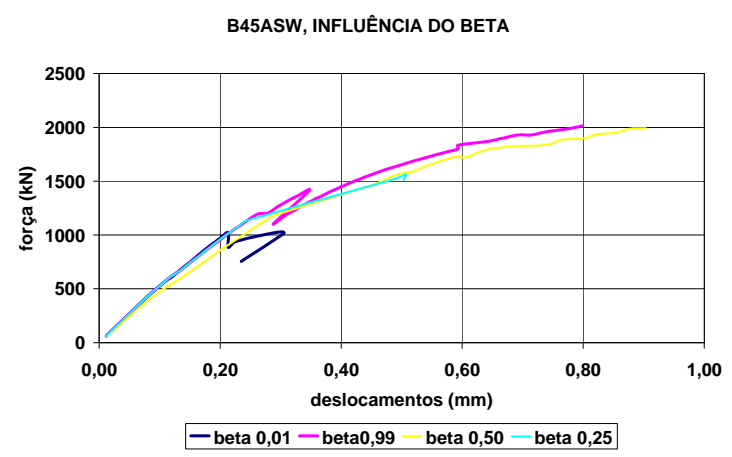

(d)

Figura 4. 10 - Influência do fator de retenção ao cisalhamento $\beta$ 
Em seguida, procurou-se avaliar a influência do tipo de critério de convergência a ser adotado. Para tanto, foi considerado dois tipos de critérios de convergência: critério de convergência em norma de deslocamentos e critério de convergência em norma de energia. Para ambos os casos, foi adotada tolerância de $1 \%$.

Como pode ser observado nos gráficos da Figura 4.11, o critério de convergência em deslocamentos apresentou o comportamento semelhante ao critério em energia para o modelo B35E0, entretanto apresentou problemas nos modelos B35ASW, B45E0 e B45ASW, parando nos passos de carga 19, 24 e 17, respectivamente. Utilizando o critério em energia, o modelo B45ASW apresentou significativa perda de resistência para uma força próxima de $1500 \mathrm{kN}$, na qual percebe-se uma diminuição dos deslocamentos. Entretanto, o bloco voltou a ganhar capacidade resistente e aumentar os deslocamentos. Como esse comportamento não foi observado nos demais modelos, acredita-se que esse comportamento tenha causa numérica.

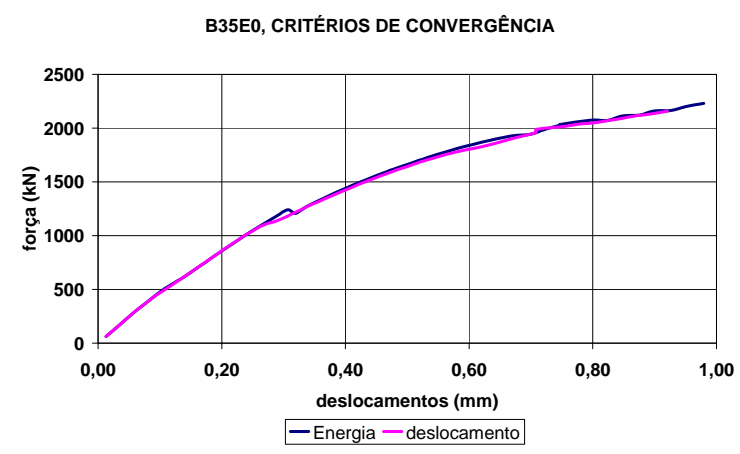

(a)

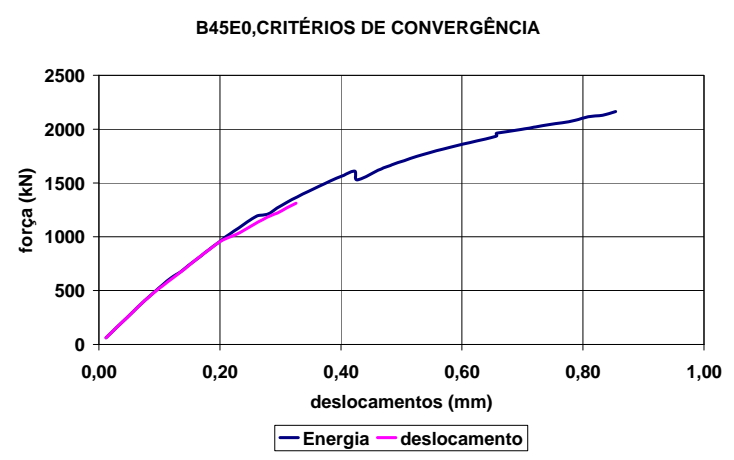

(c)

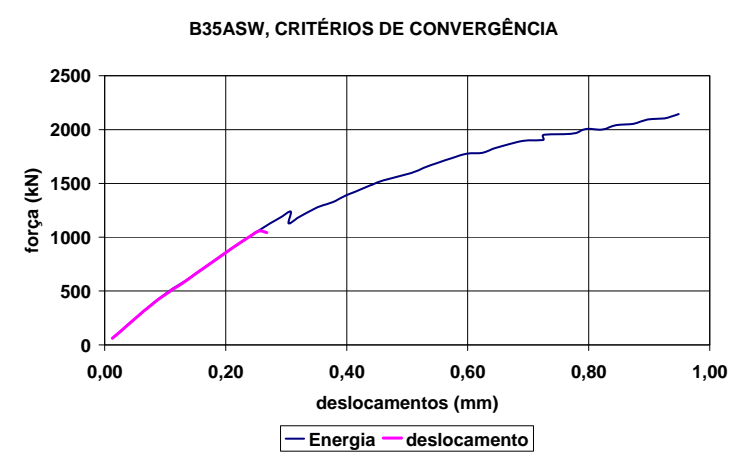

(b)

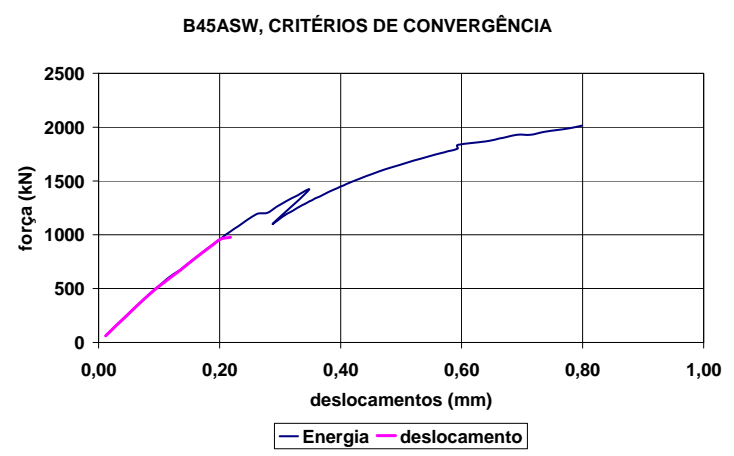

(d)

Figura 4. 11 - Critérios de convergência 
Outra variável analisada foi o modo como a ação pode ser aplicada no modelo. Inicialmente, aplicou-se uma pressão de $1 \mathrm{MPa}$ no topo do Pilar, e ao longo de 50 passos, foi feito um incremento no mesmo valor da pressão, enquanto o modelo permitiu. Quando necessário, o próprio programa corrigia o valor do incremento. Em seguida, aplicou-se num novo modelo uma pressão cujo valor é igual ao registrado na última etapa de carregamento da primeira análise, de tal maneira que cada etapa de carregamento corresponderia a $2 \%$ da carga total aplicada, completando assim os $100 \%$ do carregamento. A primeira análise recebeu o nome de "carga crescente", enquanto que a segunda foi chamada de "\% de carga".

A princípio, era esperado que os resultados das análises fossem semelhantes, entretanto verificou-se nos quatro modelos um comportamento diferente do esperado. Nos modelos analisados, a curva "\% de carga" apresentou carga última inferior quando comparada à curva "carga crescente". Essa tendência de comportamento foi verificada nos quatro modelos, e pode ser observada nas Figuras 4.12-a, 4.12-b, 4.12-c e 4.12-d.

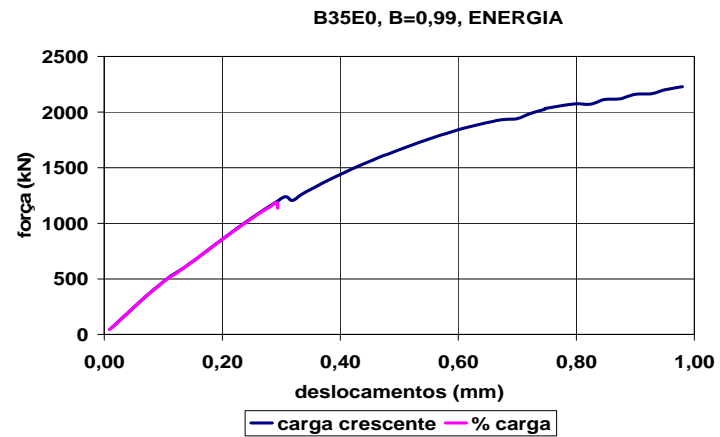

(a)

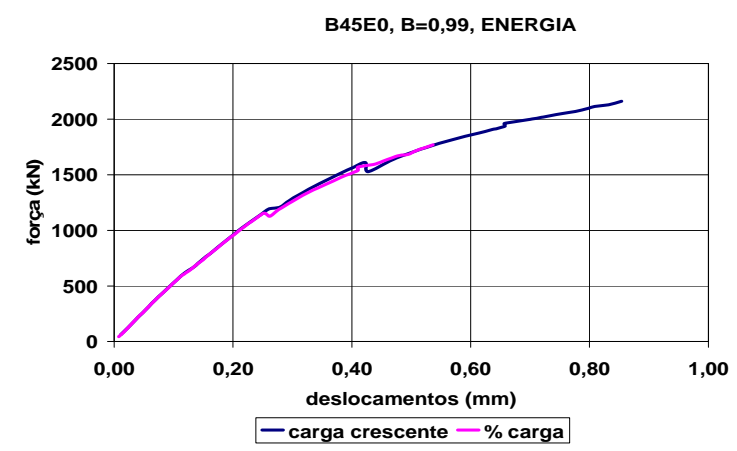

(c)

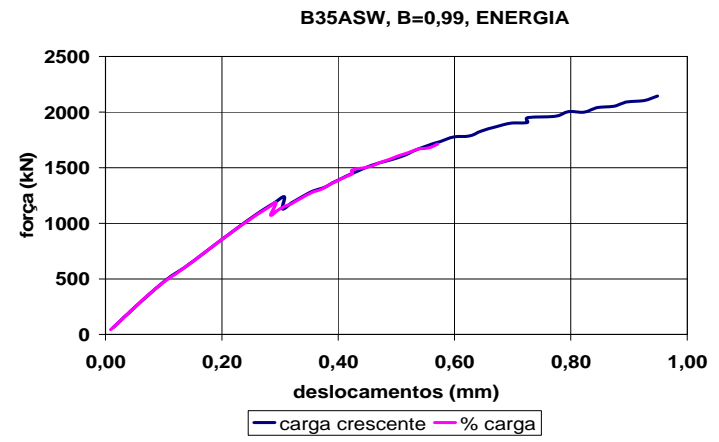

(b)

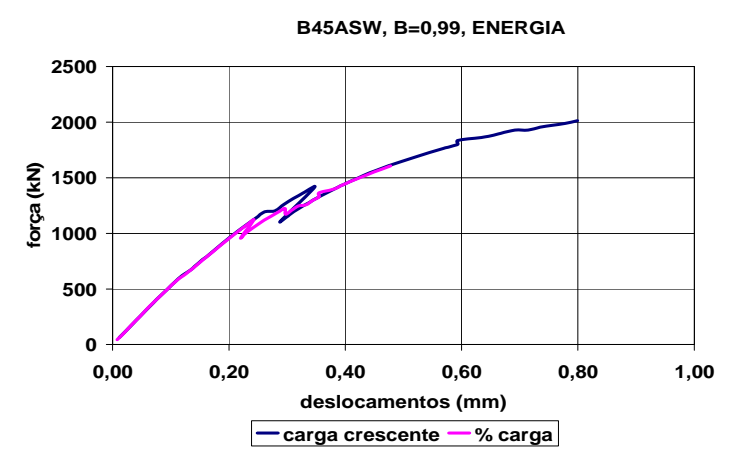

(d)

Figura 4. 12 - Modo de aplicação do carregamento 
Desta forma, entende-se que o melhor modo de aplicar o carregamento é partindo de uma pressão inicial de $1 \mathrm{MPa}$, aumentando esse valor por meio de incrementos de carregamento, e não partindo do valor máximo suportado pelo modelo.

Outra verificação feita foi em relação ao modelo de fissuração adotado para o concreto. Foram estudados dois modelos "total strain", sendo eles o "Fixed Crack Model" e o "Rotating Crack Model". O modelo "Fixed Crack Model" apresentou um comportamento mais rígido do que o "Rotating Crack Model", que por sua vez não teve uma boa representação do modelo B35E0, conforme Figura 4.13.

Esse resultado era esperado, uma vez que a própria descrição do modelo relata que seu uso conduz a cargas últimas menores do que as reais. Apesar do conhecimento dessa informação, optou-se por realizar esse teste, pois Souza (2006), analisando bloco sobre duas estacas, encontrou força última maior utilizando o "Rotating Crack Model".

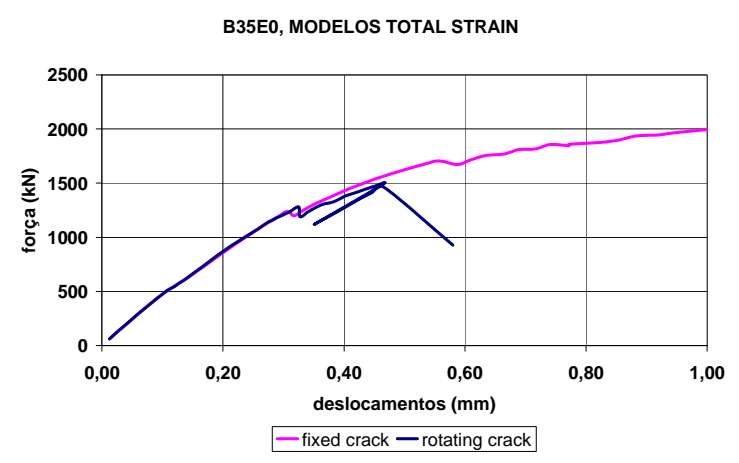

Figura 4. 13 - "Fixed crack model " versus "Rotating crack model"

Outro parâmetro avaliado foi o tipo de ação aplicada. No modelo B35E0, aplicou-se no topo do pilar de concreto armado ação em forma de pressão, e em outro modelo aplicou-se deslocamento imposto. Para essa análise, variou-se também o tipo de critério de convergência. Observa-se por meio da Figura 4.14-a que o modelo com ação em forma de deslocamento imposto apresenta-se mais rígido quando comparado ao modelo com ação em forma de pressão, para critério de convergência em deslocamentos. Entretanto, a ação em forma de 
deslocamento imposto apresentou problemas de convergência, e parou no $15^{\circ}$ incremento de carga.

Visando esclarecer um pouco mais a diferença entre deslocamento imposto e pressão, foi analisado novamente o modelo B35E0, porém com critério de convergência em energia. Nessa situação, observa-se que a ação em forma de deslocamento imposto apresentou uma força última muito superior a obtida em laboratório. Observa-se que para um deslocamento no meio do bloco em torno de $0,4 \mathrm{~mm}$ a força se mantém constante em torno de $2400 \mathrm{kN}$, porém logo em seguida o bloco volta a ganhar resistência, e atinge seu pico próximo aos $3600 \mathrm{kN}$, com deslocamento de $0,95 \mathrm{~mm}$. Entende-se, portanto, que para o modelo analisado, a ação em forma de pressão resulta num comportamento mais próximo do real.

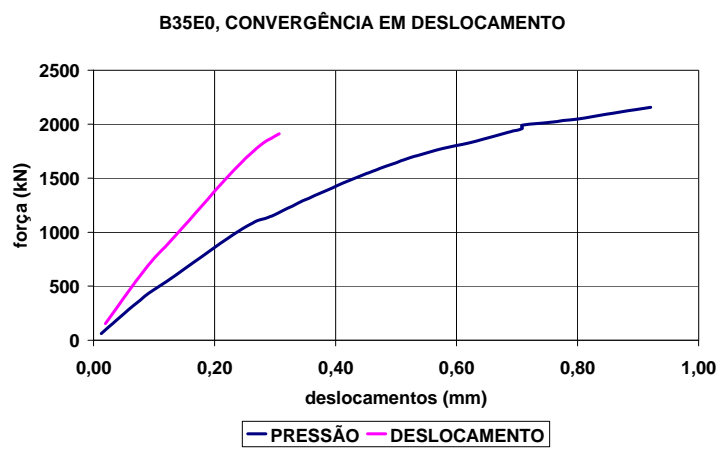

(a)

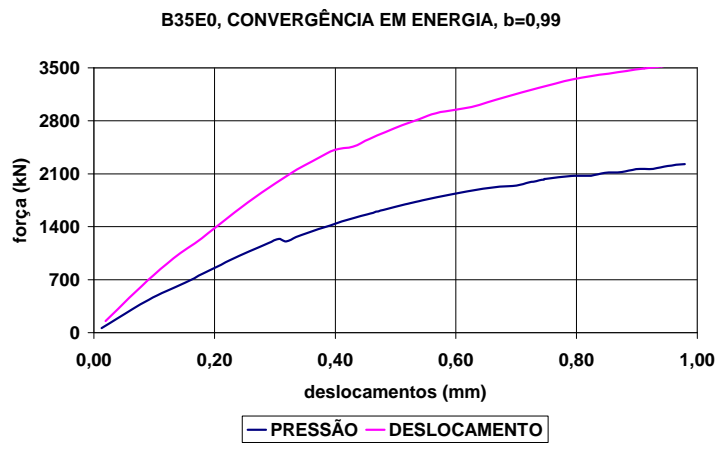

(b)

Figura 4. 14 - Ação em forma de pressão e deslocamento imposto

Finalmente, decidiu-se verificar a influência dos métodos de resolução do sistema de equações não-lineares disponíveis no DIANA. Foram analisados os métodos de NewtonRaphson Regular, Newton-Raphson Modificado, Método da Rigidez Linear e Método Secante.

Observa-se para o modelo B35E0 que os diversos métodos de resolução apresentaram praticamente o mesmo comportamento na determinação da curva força versus deslocamento. No modelo B35ASW o método da Rigidez Linear apresentou vários pontos com diminuição 
da capacidade resistente do bloco. Para os modelos B45E0 e B45ASW os diversos métodos apresentaram uma divergência mais acentuada, principalmente no último modelo, na qual o Método Secante apresentou problemas de convergência no $22^{\circ}$ incremento de carga.

Os métodos de Newton-Raphson Regular e Newton-Raphson Modificado apresentaram a mesma tendência de comportamento nos quatro modelos estudados, a menos do modelo B45ASW, na qual o método de Newton-Raphson Regular mostrou-se mais rígido, como pode ser observado nos gráficos da Figura 4.15.

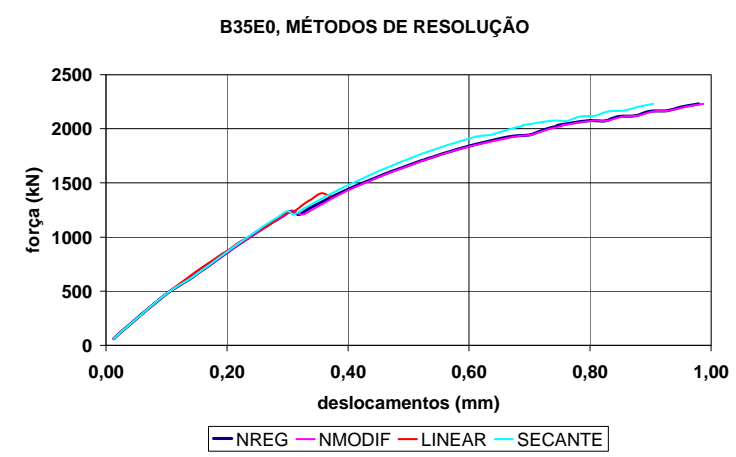

(a)

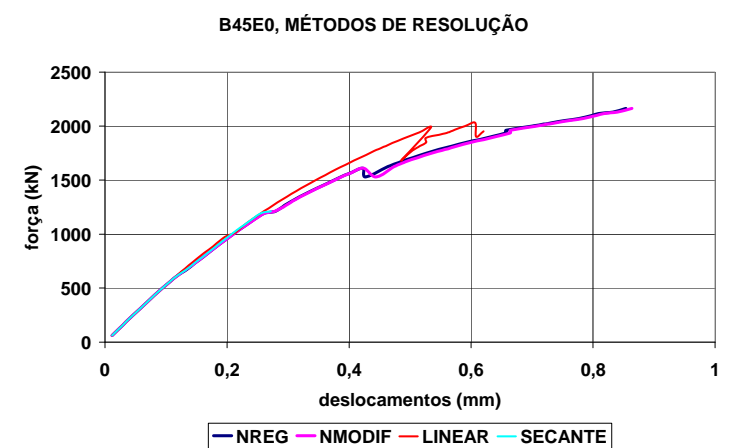

(c)

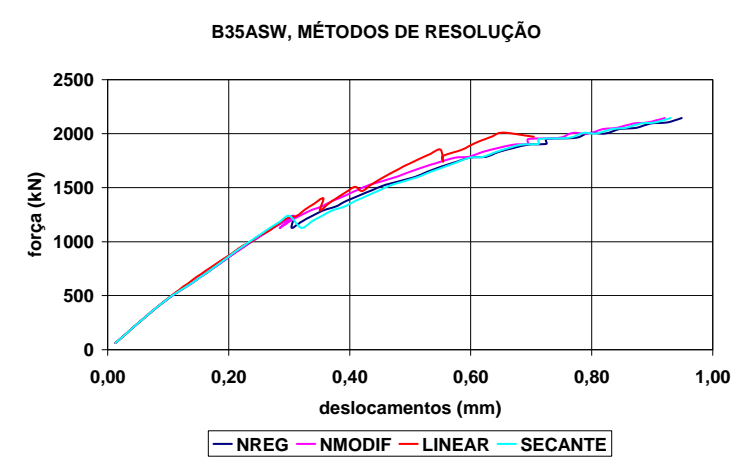

(b)

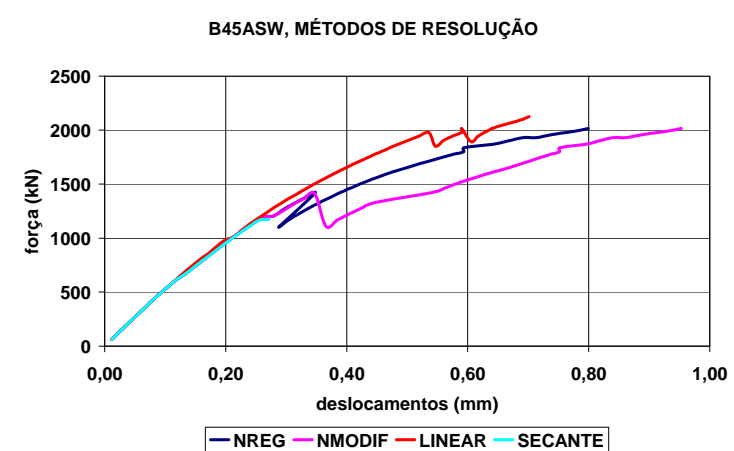

(d)

Figura 4. 15 - Métodos de resolução do sistema de equações não-lineares

Conforme dito anteriormente, o DIANA apresenta um procedimento chamado "iteration based sizes", que permite que o tamanho dos incrementos de pressão sejam variados ao longo da análise, mediante fornecimento dos valores inicial, máximo e mínimo de incrementos no decorrer da análise. 
Inicialmente, foram verificados diversos valores de incremento máximo de pressão, variando-se também o valor do coeficiente de retenção ao cisalhamento para o modelo B35E0. Por meio da Figura 4.16-a e 4.16-b percebe-se como o tamanho máximo do incremento de pressão modifica completamente o comportamento da curva força versus deslocamento. Entre todos os valores testados, a curva que mais se aproximou do resultado experimental foi aquela cujo valor máximo do incremento é igual a $50 \mathrm{~N} / \mathrm{mm}^{2}$. Em relação ao coeficiente de retenção ao cisalhamento, mais uma vez o valor de 0,99 apresentou um melhor resultado quando comparado ao valor de 0,01. Nas Figuras 4.16-c e 4.16-d variaram-se os métodos de resolução do sistema de equações não lineares, para o modelo B35E0 com incremento máximo de $50 \mathrm{~N} / \mathrm{mm}^{2}$ e critério de convergência em energia. Observa-se, portanto, que a curva força versus deslocamento com comportamento mais próximo do modelo experimental foi a que utilizou o método de Newton-Raphson Regular.

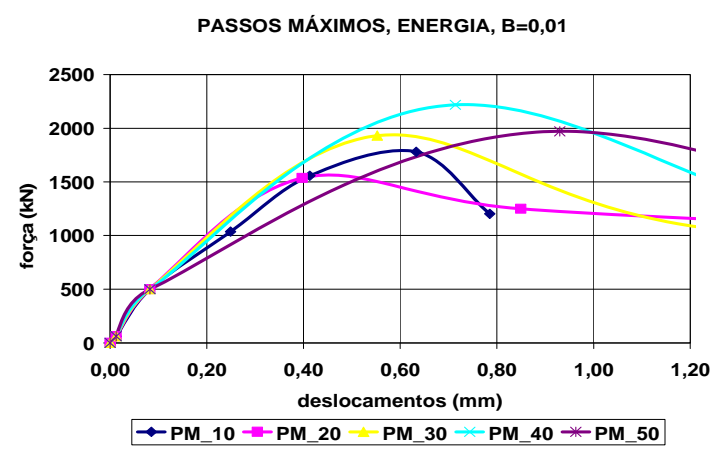

(a)

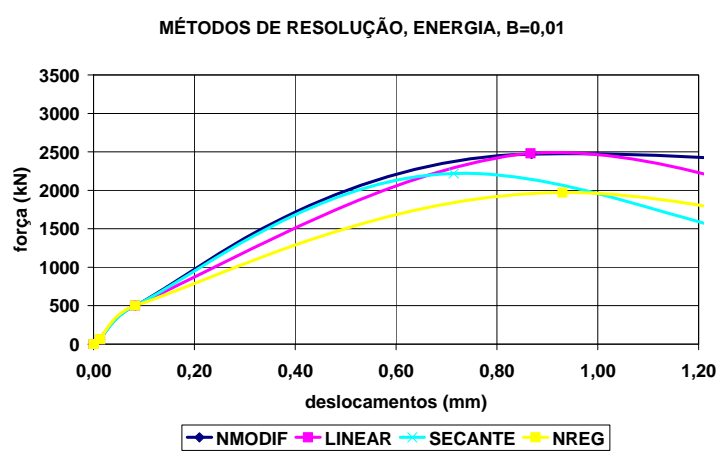

(c)

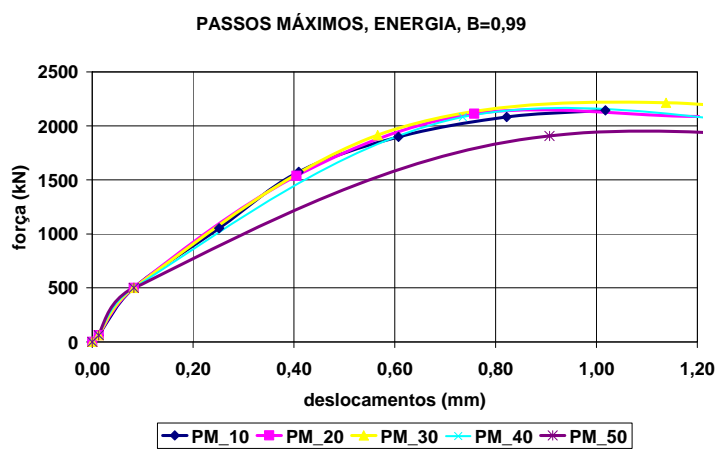

(b)

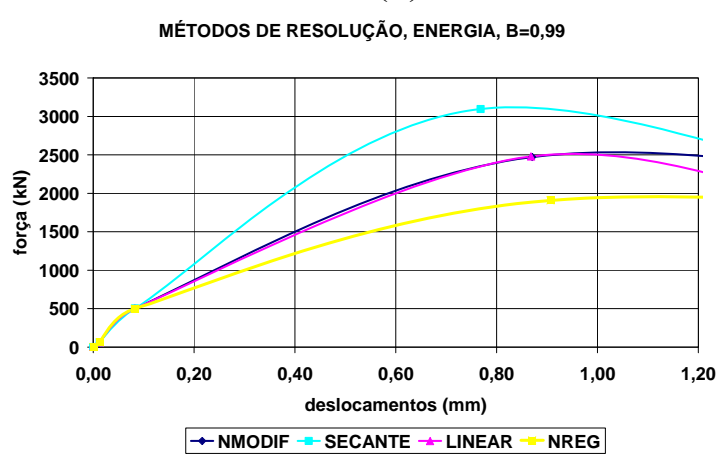

(d)

Figura 4. 16 - Modelo B35e0 calculado via "iteration based sizes" 
Outra análise feita foi em relação ao número total de incrementos de força utilizado. É comum em análises numéricas utilizar um número muito grande de incrementos de carga. Utilizando o programa computacional DIANA, observou-se que nem sempre um número grande de incrementos fornece melhores resultados. Em algumas análises, verificou-se que à medida que se amplia o número de incrementos, o modelo não atende aos critérios de convergência para um valor de força inferior ao da força última obtida em laboratório.

Em outros modelos, nota-se pouca diferença no comportamento da curva força versus deslocamento, independente do número de incrementos aplicado no modelo, como ocorreu com o modelo B35E0. A Figura 4.17 mostra a curva força versus deslocamento para a aplicação de 50 e de 300 incrementos de força. Observa-se que as curvas ficaram praticamente sobrepostas uma em relação à outra.

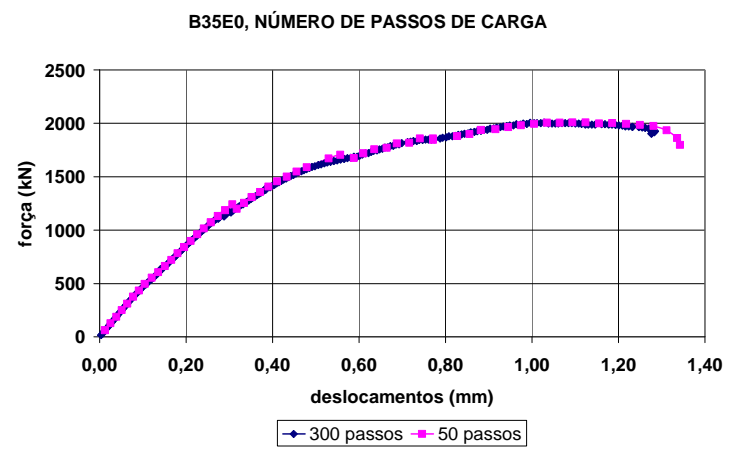

Figura 4. 17 - B35E0, Influência do número de passos de carga

Com base nos resultados apresentados anteriormente, foram feitas algumas análises de modo a se obter os parâmetros necessários para uma simulação eficiente de blocos sobre duas estacas, utilizando o programa computacional DIANA.

Em virtude da grande variabilidade dos resultados, optou-se por não utilizar o procedimento "iteration based sizes". Utilizando esse procedimento, o tempo de processamento foi reduzido consideravelmente, entretanto, o traçado da curva força versus deslocamento ficou comprometido por causa da pequena quantidade de pontos obtidos na 
análise. Reduzindo o tamanho do incremento máximo de carga, observou-se que a força última ficou muito distante do valor obtido experimentalmente.

Em relação aos métodos de resolução do sistema de equações não-lineares, optou-se por utilizar o método de Newton-Raphson Regular, pois este método apresentou melhor resultado para os modelos analisados.

Verificou-se também que em relação ao modo de aplicação da ação, os melhores resultados foram obtidos com ação em forma de pressão, e não em forma de deslocamento imposto. Para o critério de convergência, será utilizado o critério em norma de energia, por causa dos diversos problemas encontrados utilizando o critério de convergência em deslocamentos.

Quanto ao modelo de fissuração do concreto, verificou-se que o "Fixed Crack Model" apresentou melhores resultados, quando comparados com o "Rotating Crack Model". Em relação ao coeficiente de retenção ao cisalhamento, os melhores resultados foram obtidos para o valor de $\beta$ igual a 0,99 .

\subsection{Análise dos resultados}

Com base nos parâmetros estudados anteriormente, procedeu-se à simulação numérica de quatro modelos de blocos sobre duas estacas, descritos detalhadamente no item 4.3. Os resultados obtidos com o programa computacional DIANA são comparados com os resultados de ensaios experimentais e numéricos, sendo que na análise numérica foi utilizado o programa computacional ANSYS 9.0. As Figuras 4.18; 4.19; 4.20 e 4.21 apresentam a malha de elementos finitos com o carregamento e as condições de contorno, bem como a discretização das barras das armaduras no DIANA para os quatro modelos analisados. 


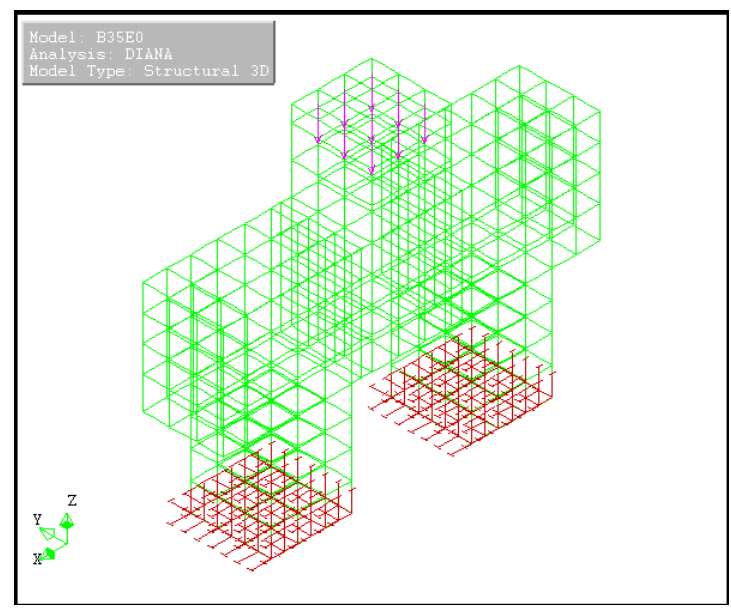

(a)

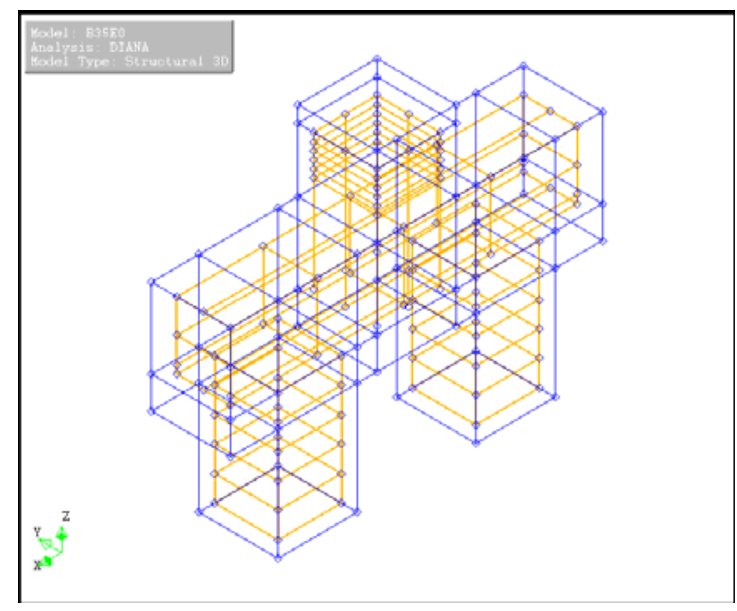

(b)

Figura 4. 18 - Modelo B35E0

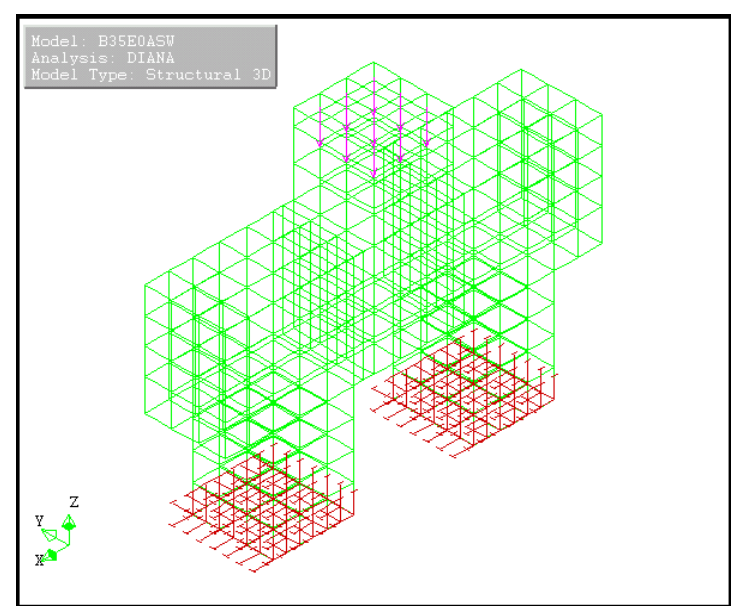

(a)

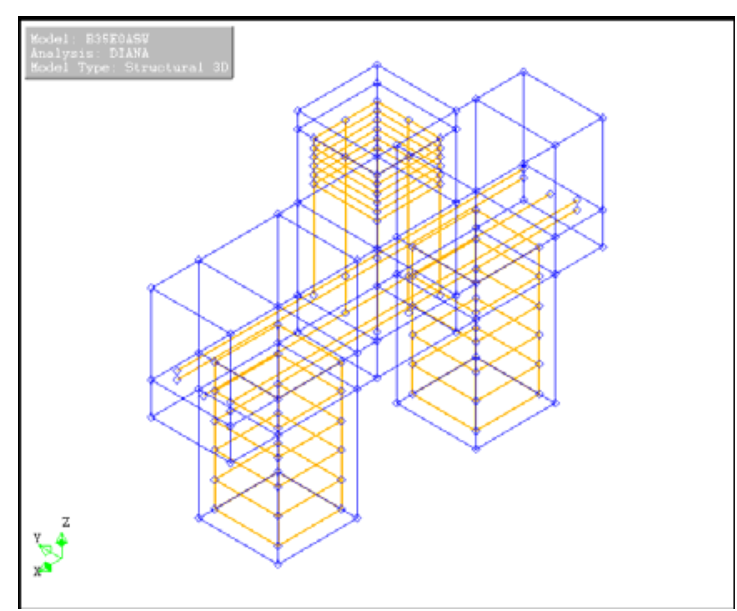

(b)

Figura 4. 19 - Modelo B35ASW

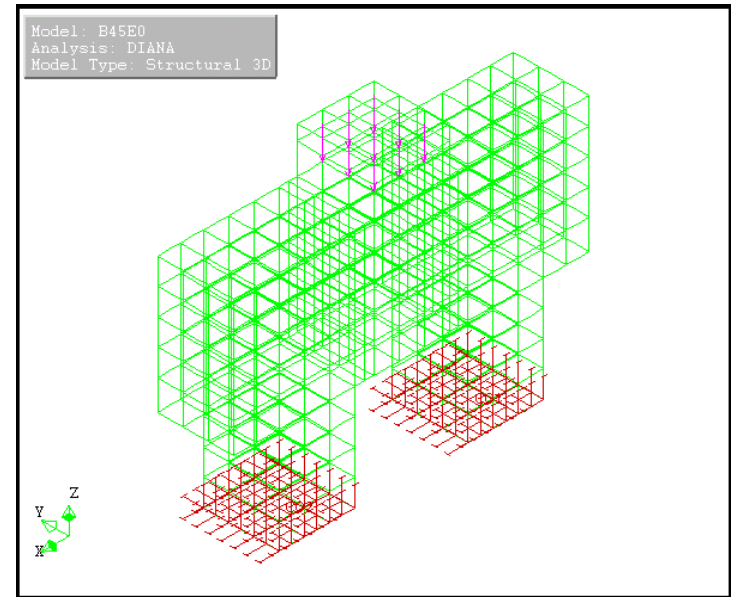

(a)

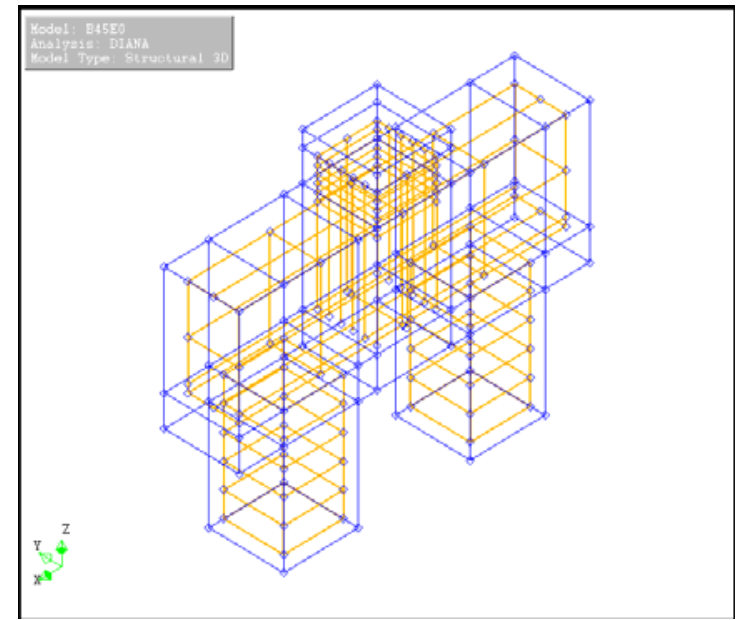

(b)

Figura 4. 20 - Modelo B45E0 


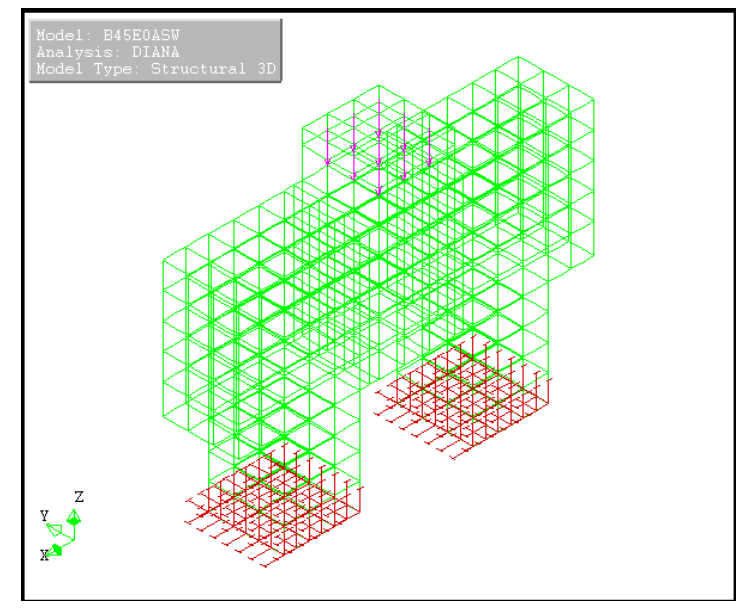

(a)

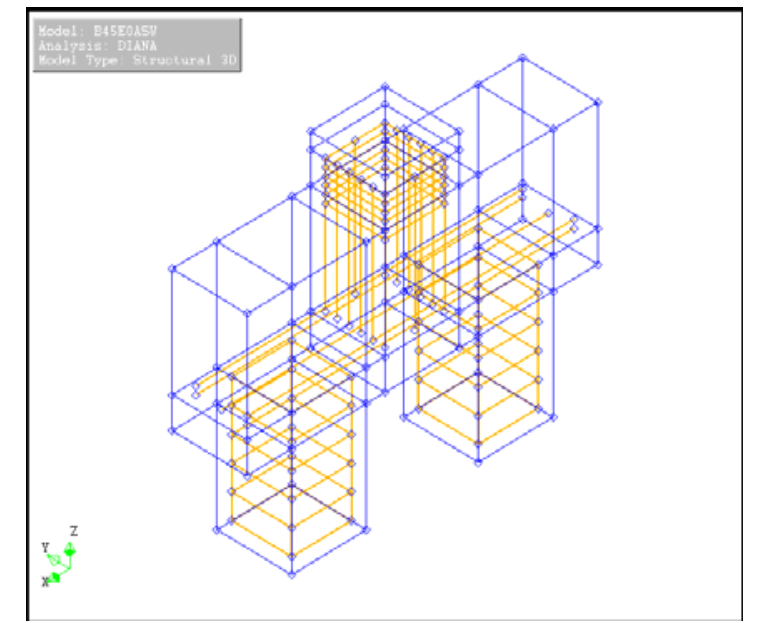

(b)

Figura 4. 21 - ModeloB45ASW

\subsubsection{Modelo B35E0}

O modelo B35E0 possuía $35 \mathrm{~cm}$ de altura, e as seções das estacas e do pilar eram quadradas com largura de $25 \mathrm{~cm}$. No ensaio experimental, o bloco apresentou força última igual a $1821 \mathrm{kN}$, e a tensão máxima registrada nas barras da armadura longitudinal foi de 392 MPa. Na simulação numérica, por sua vez, a força última obtida foi de $2009 \mathrm{kN}$, e a tensão nas barras da armadura longitudinal foi de $397 \mathrm{MPa}$.

Observa-se também que o processo de fissuração do concreto teve início na região inferior do bloco, e que as tensões máximas de tração estavam limitadas ao valor de $\mathrm{f}_{\text {tm }}$ apresentados na tabela 4.5. Na Figura 4.22 pode-se acompanhar o panorama de fissuração para $25 \%, 50 \%, 75 \%$ e $100 \%$ da força última. Observa-se que com $75 \%$ da carga última, a estaca encontra-se fissurada na região interna dos apoios, indicando que a distribuição de tensões não é constante na seção das estacas. Essa distribuição de tensões também foi observada por Delalibera (2006).

Na Figura 4.23 observa-se a distribuição de tensões principais de compressão e tração no bloco B35E0, na qual é possível perceber a configuração das bielas. 

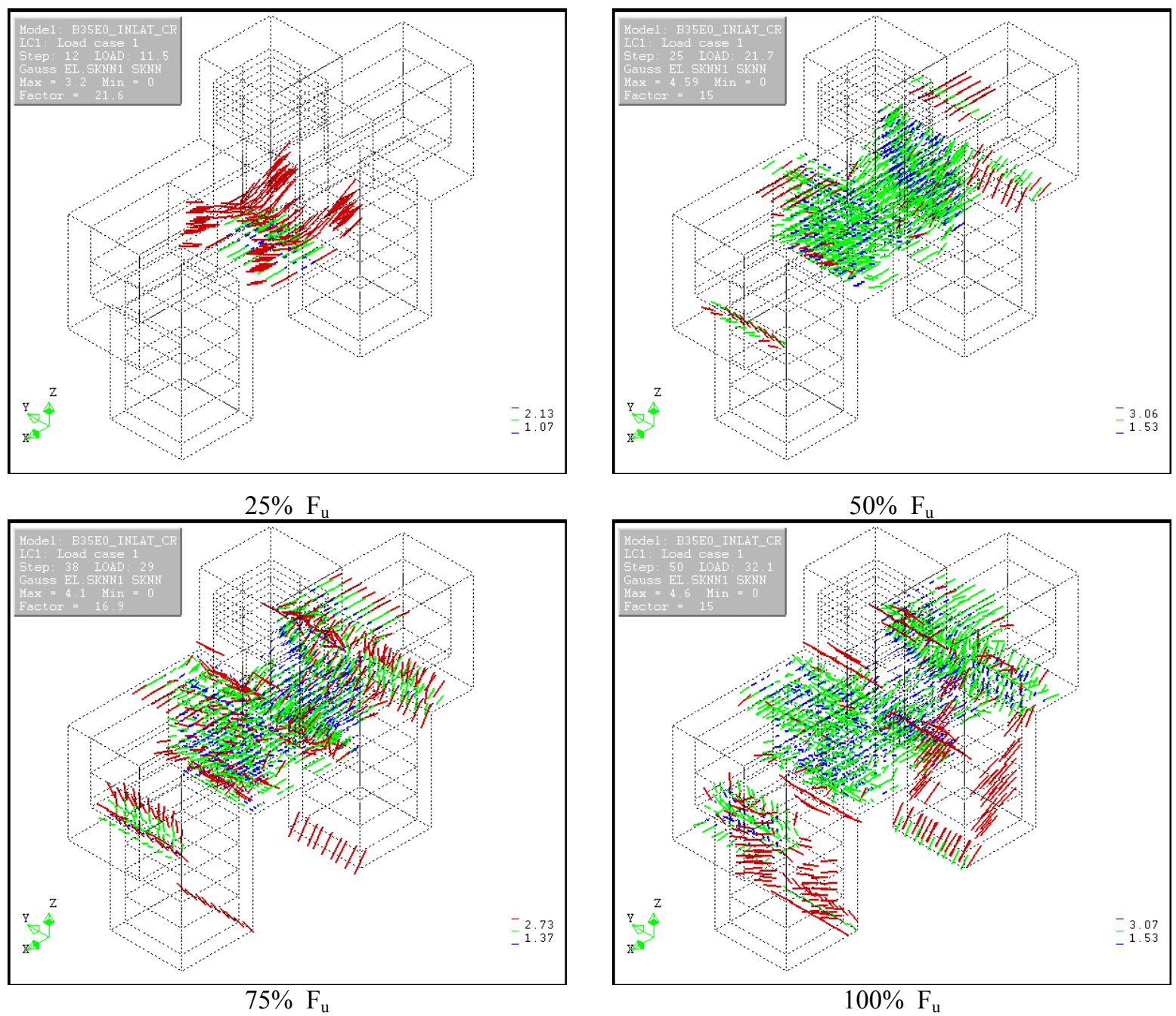

Figura 4. 22 - Panorama de fissuração do bloco B35E0

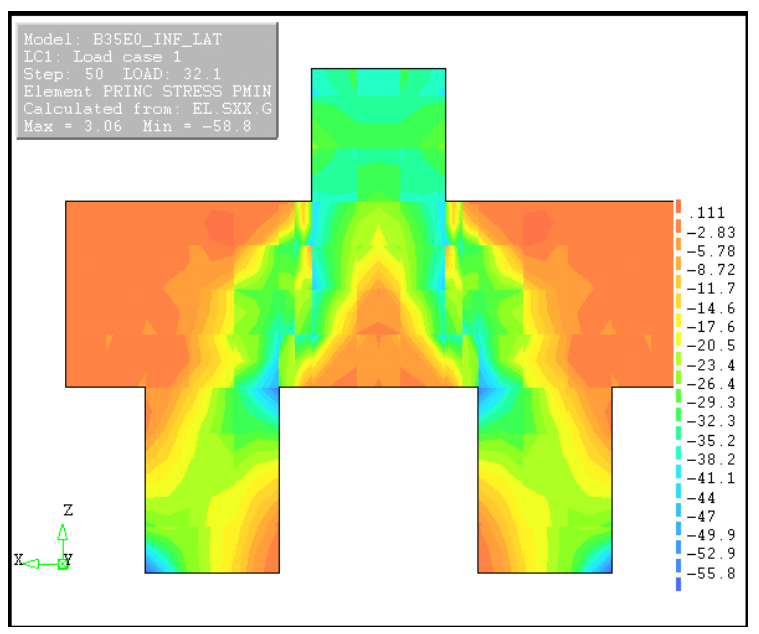

(a)

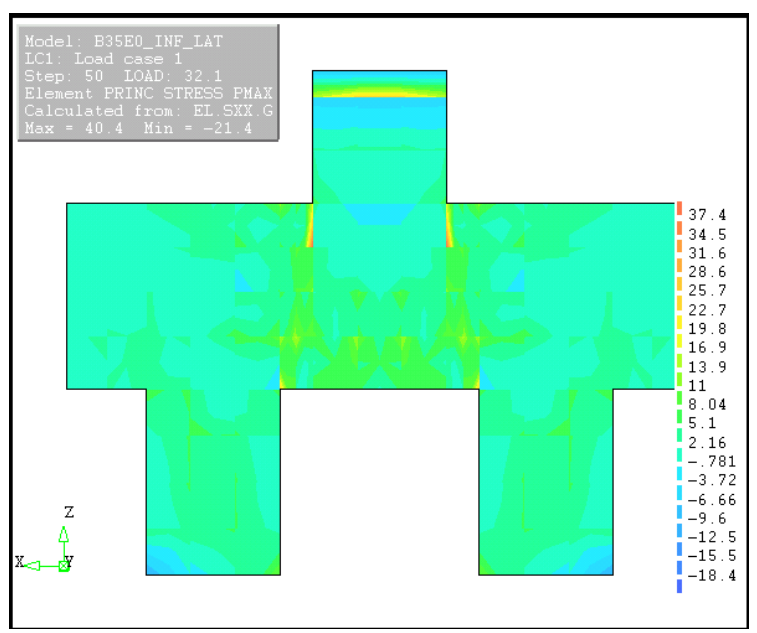

(b)

Figura 4. 23 - Tensões principais de compressão e tração no bloco B35E0 


\subsubsection{Modelo B35ASW}

O Modelo B35ASW também possuía $35 \mathrm{~cm}$ de altura, e as seções das estacas e pilares eram quadradas com largura de $25 \mathrm{~cm}$, porém não apresentava armadura secundária. No ensaio experimental, o bloco apresentou força última de $1406 \mathrm{kN}$ e a tensão máxima nas barras da armadura longitudinal foi de $340 \mathrm{MPa}$. Na simulação numérica a força última foi de $1684 \mathrm{kN}$ e a tensão máxima nas barras da armadura longitudinal foi de $456 \mathrm{MPa}$. A Figura 4.24 apresenta o panorama de fissuração do concreto enquanto que na Figura 4.25 pode-se observar a distribuição das tensões principais nesse modelo.
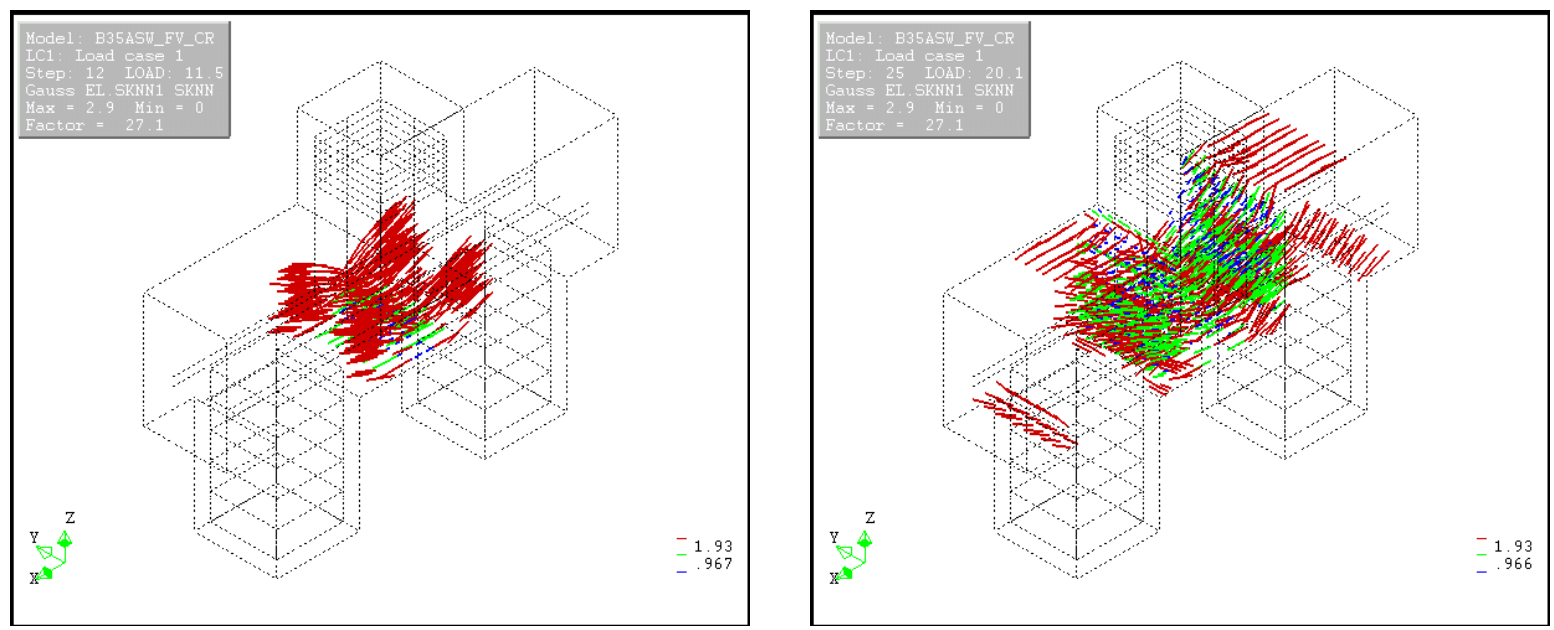

$25 \% \mathrm{~F}_{\mathrm{u}}$
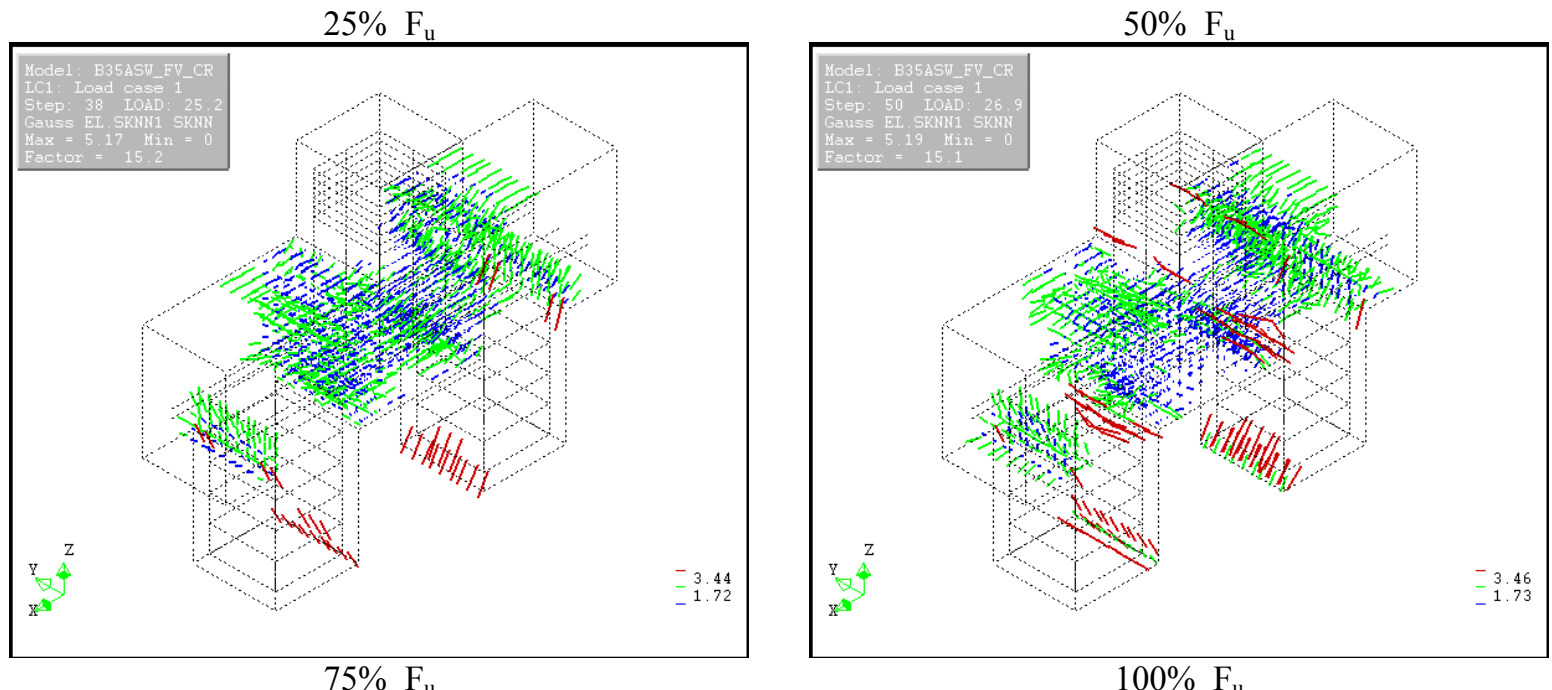

Figura 4. 24 - Panorama de fissuração do bloco B35ASW 


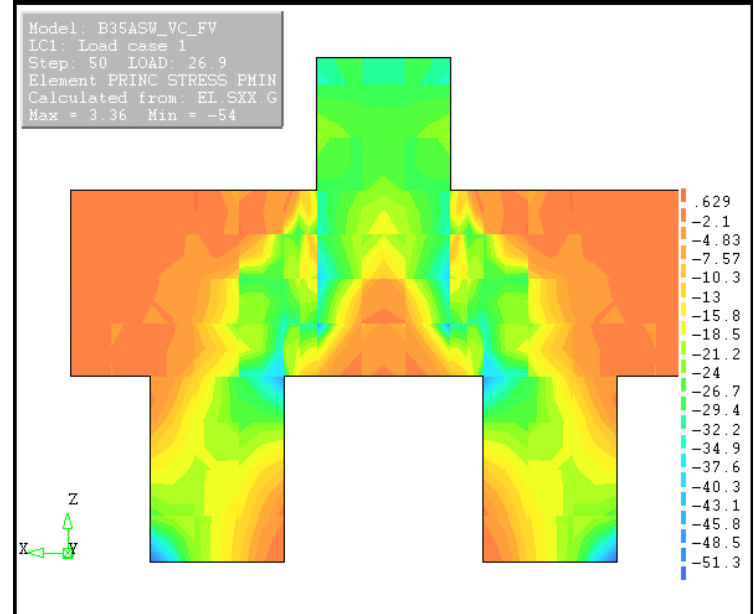

(a)

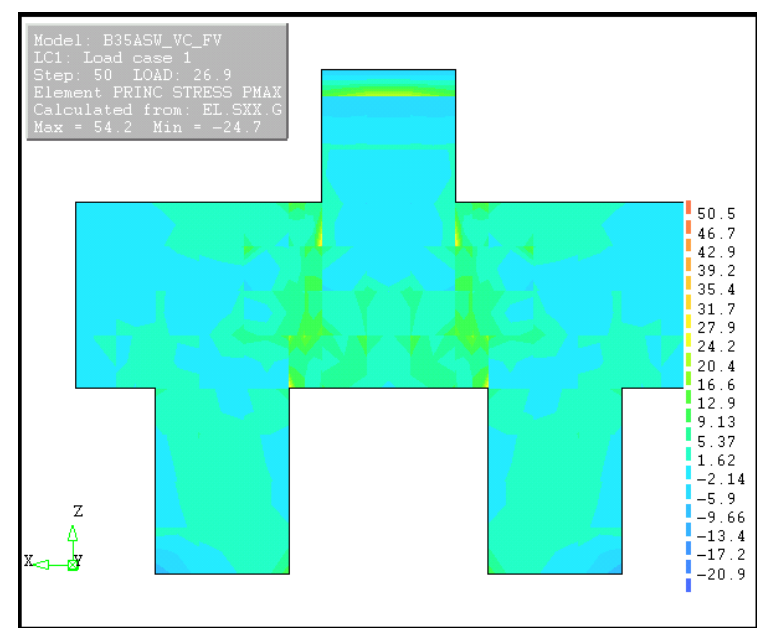

(b)

Figura 4. 25 - Tensões principais de compressão e tração no bloco B35ASW

\subsubsection{Modelo B45E0}

O Modelo B45E0 tinha $45 \mathrm{~cm}$ de altura, e as seções das estacas e pilares eram quadradas com largura de $25 \mathrm{~cm}$. No ensaio experimental, o bloco apresentou força última de $2276 \mathrm{kN}$ e a tensão máxima nas barras da armadura longitudinal foi de $590 \mathrm{MPa}$. Na simulação numérica a força última obtida foi de $2120 \mathrm{kN}$ e a tensão máxima nas barras da armadura longitudinal foi de $462 \mathrm{MPa}$.. A Figura 4.26 apresenta o panorama de fissuração do concreto enquanto que na Figura 4.27 pode-se observar a distribuição das tensões principais nesse modelo.

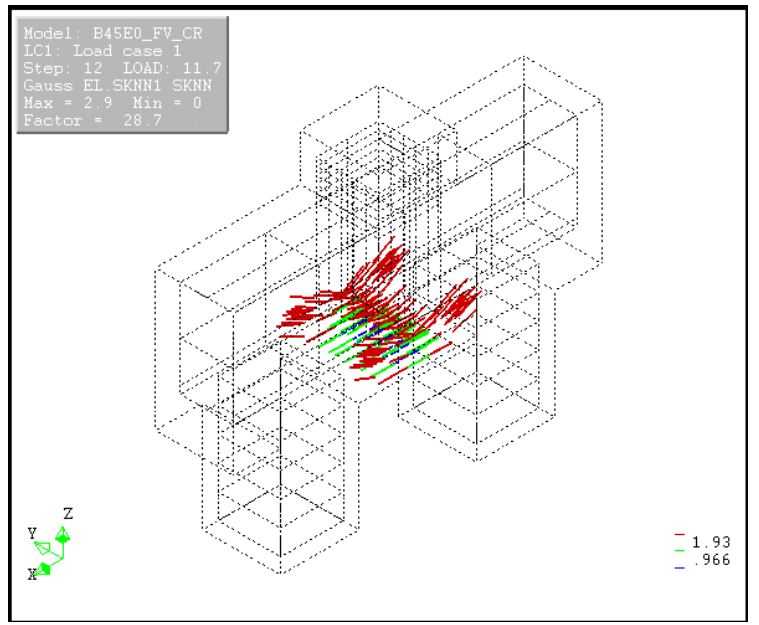

$25 \% \quad \mathrm{~F}_{\mathrm{u}}$

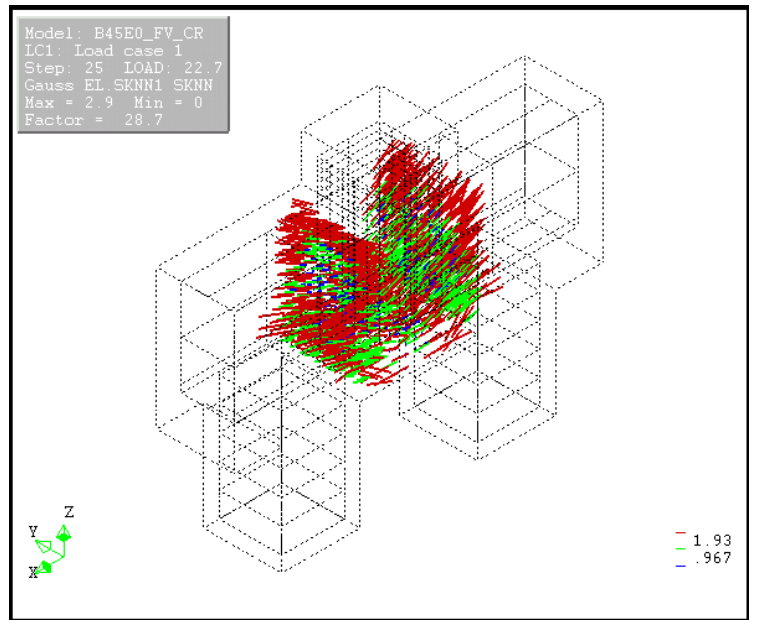

$50 \% \quad \mathrm{~F}_{\mathrm{u}}$ 


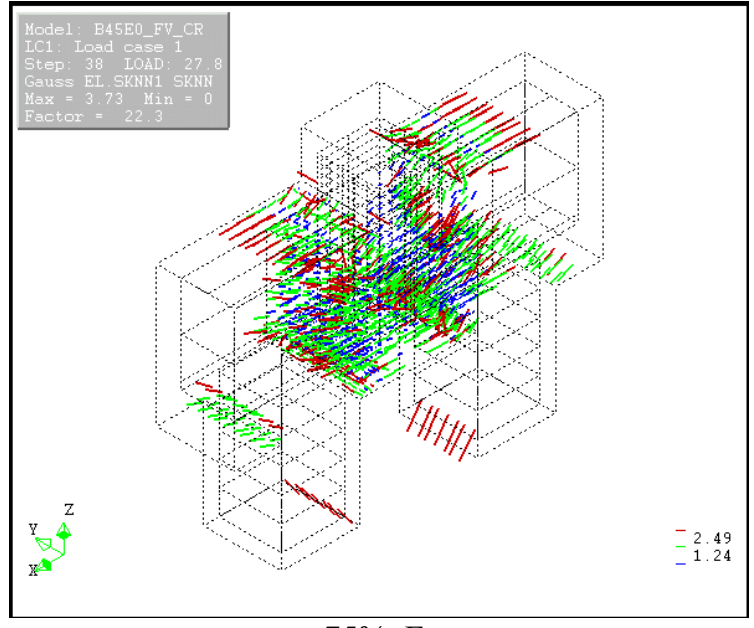

$75 \% \mathrm{~F}_{\mathrm{u}}$

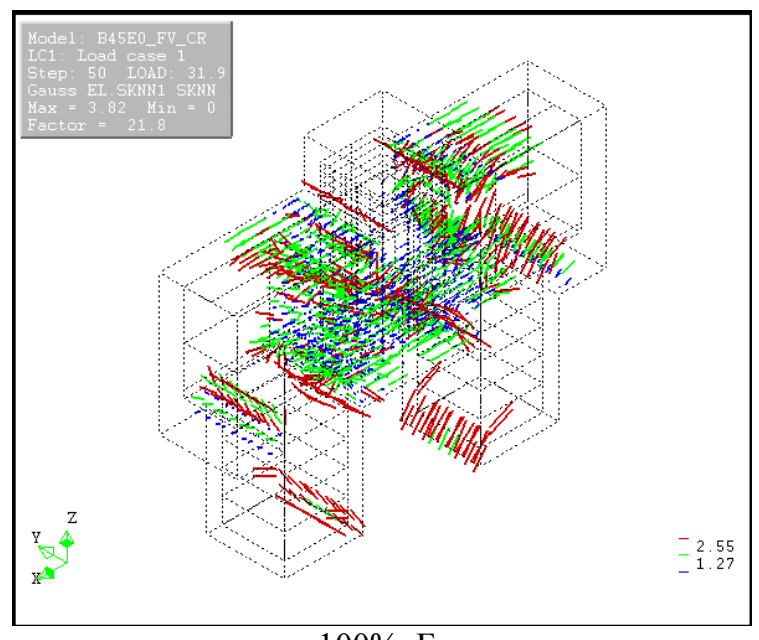

Figura 4. 26 - Panorama de fissuração do bloco B45E0

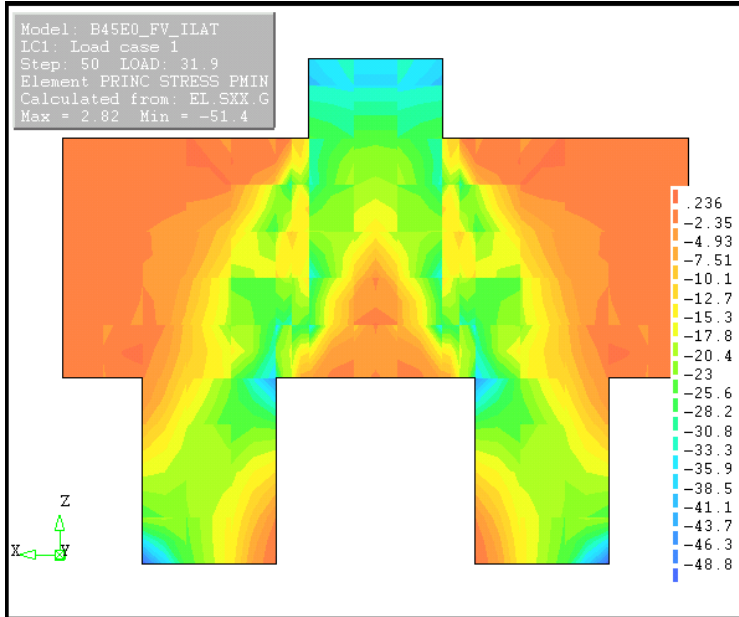

(a)

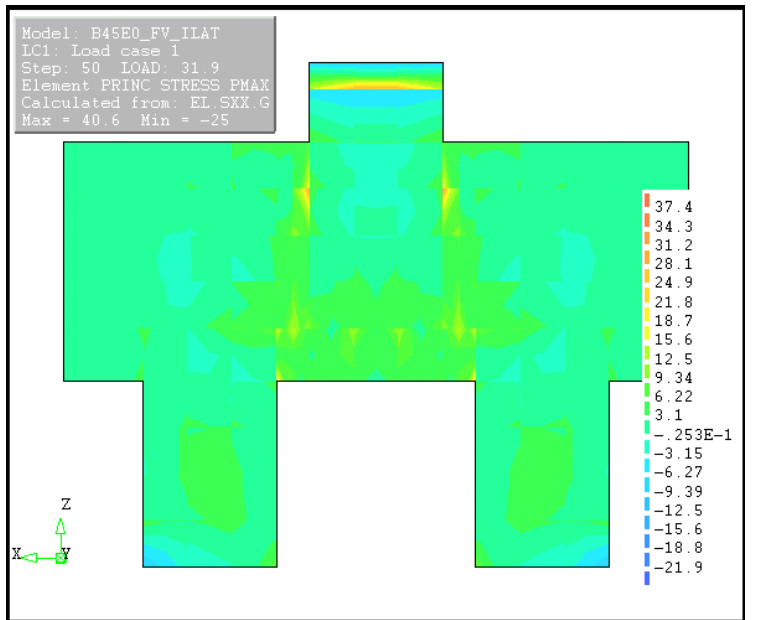

(b)

Figura 4. 27 - Tensões principais de compressão e tração no bloco B45E0

\subsubsection{Modelo B45ASW}

O Modelo B45ASW também tinha $45 \mathrm{~cm}$ de altura, e as seções das estacas e pilares eram quadradas com largura de $25 \mathrm{~cm}$, porém não apresentava armadura secundária. No ensaio experimental, o bloco apresentou força última de $2090 \mathrm{kN}$ e a tensão máxima nas barras da armadura longitudinal foi de $380 \mathrm{MPa}$. Na simulação numérica a força última obtida foi de $2146 \mathrm{kN}$ e a tensão máxima nas barras da armadura longitudinal foi de $598 \mathrm{MPa}$. A Figura 4.28 apresenta o panorama de fissuração do concreto enquanto que na Figura 4.29 pode-se observar a distribuição das tensões principais nesse modelo. 

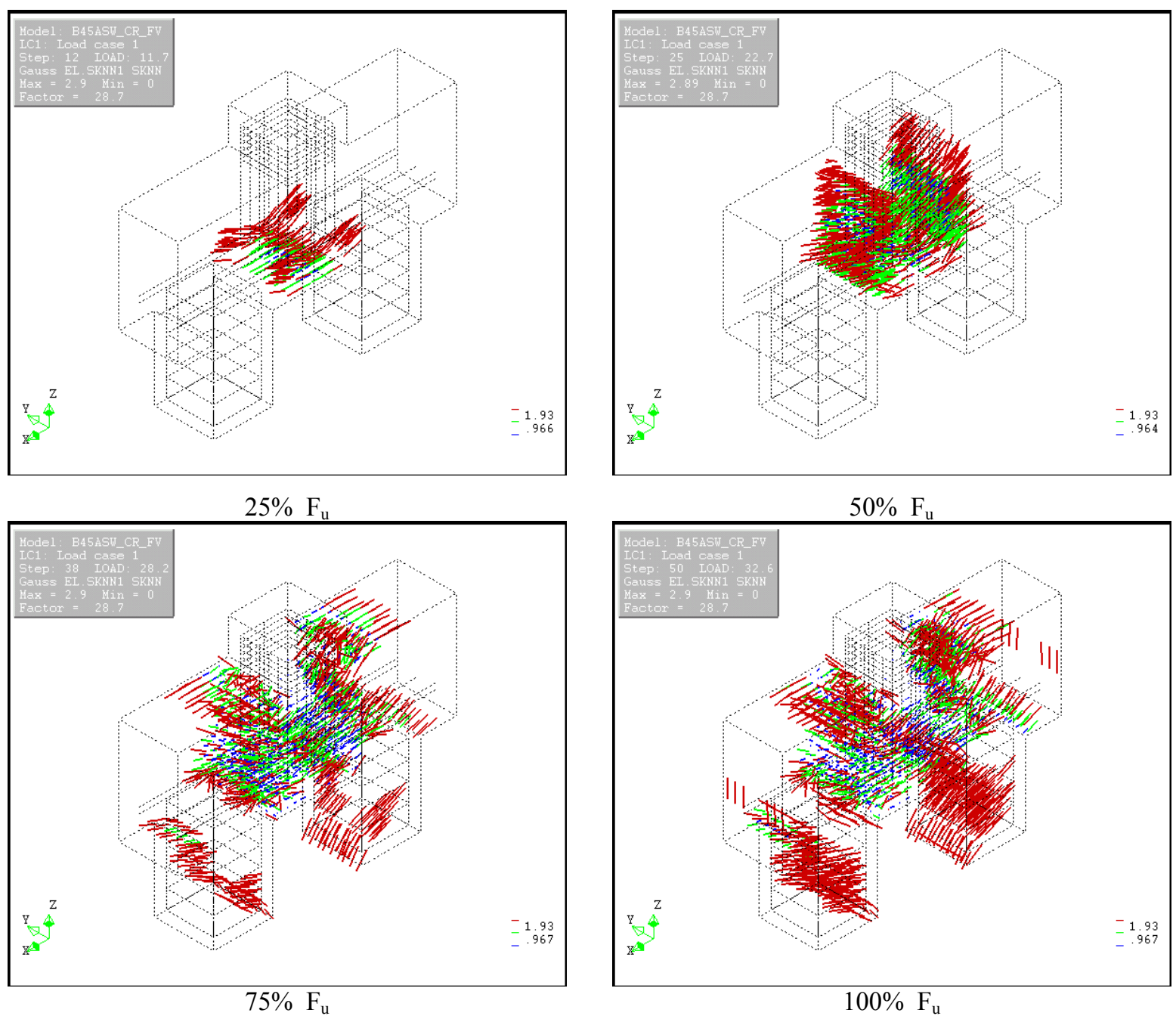

Figura 4. 28 - Panorama de fissuração do bloco B45ASW

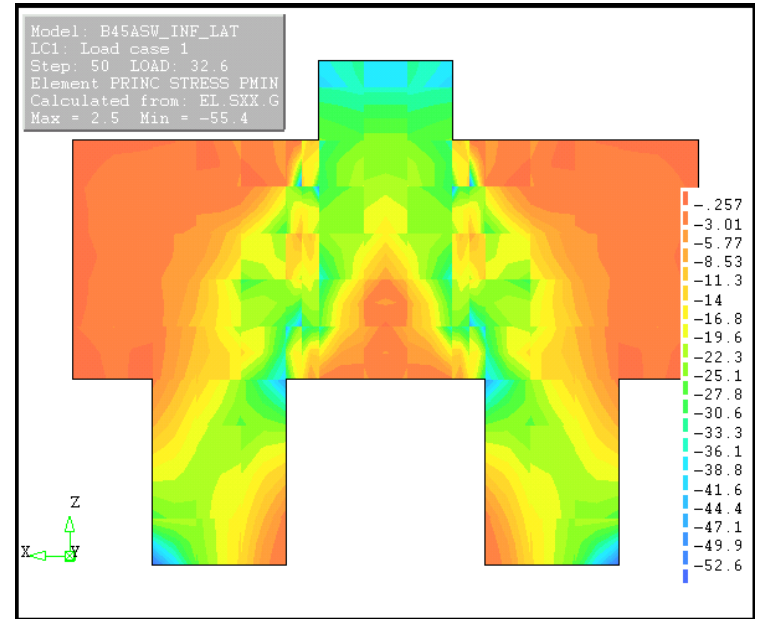

(a)

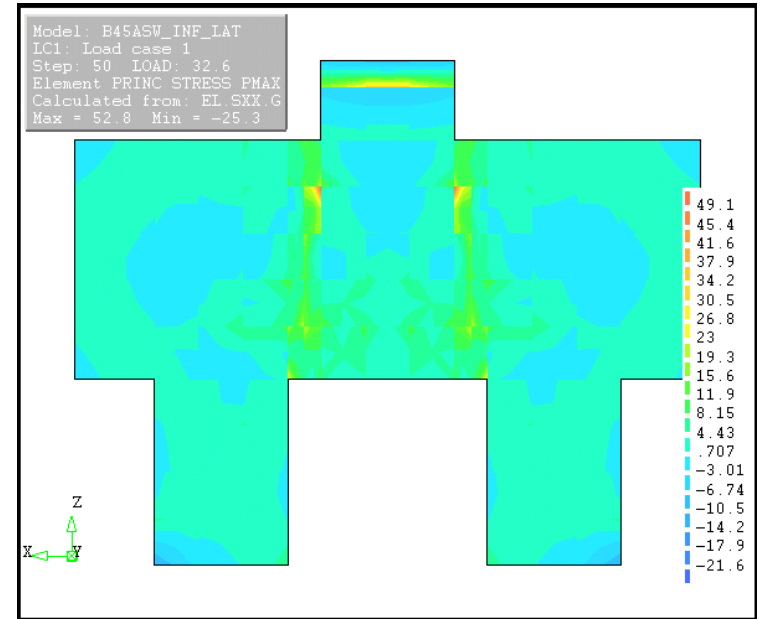

(b)

Figura 4. 29 - Tensões principais de compressão e tração no bloco B45E0 
Observa-se nos quatro modelos estudados que o valor encontrado para a tensão máxima nas barras da armadura longitudinal não apresentou bons resultados, a menos do modelo B45E0. Acredita-se que esse resultado seja proveniente do modo como o programa computacional DIANA considera os elementos do tipo reinforcements. As Figuras 4.30-a, 4.30-b, 4.30-c e 4.30-d mostram a distribuição de tensões nas barras da armadura longitudinal dos quatro modelos analisados, e a tabela 4.10 os resultados das tensões máximas obtidas experimentalmente, e com dois pacotes computacionais, DIANA e ANSYS. Verifica-se que os melhores resultados foram obtidos para as tensões nas barras da armadura longitudinal utilizando o ANSYS, uma vez que nesse programa as barras das armaduras são modeladas com um elemento finito diferente dos embedded reinforcements utilizados no DIANA.

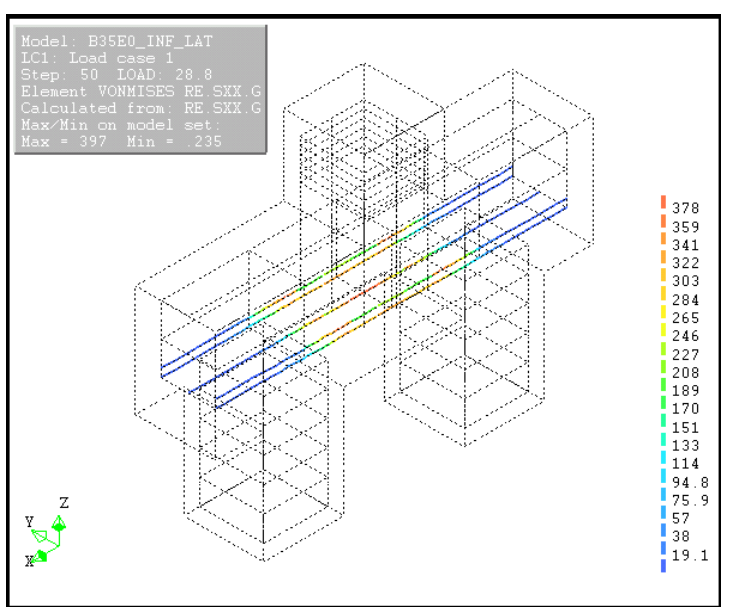

(a)

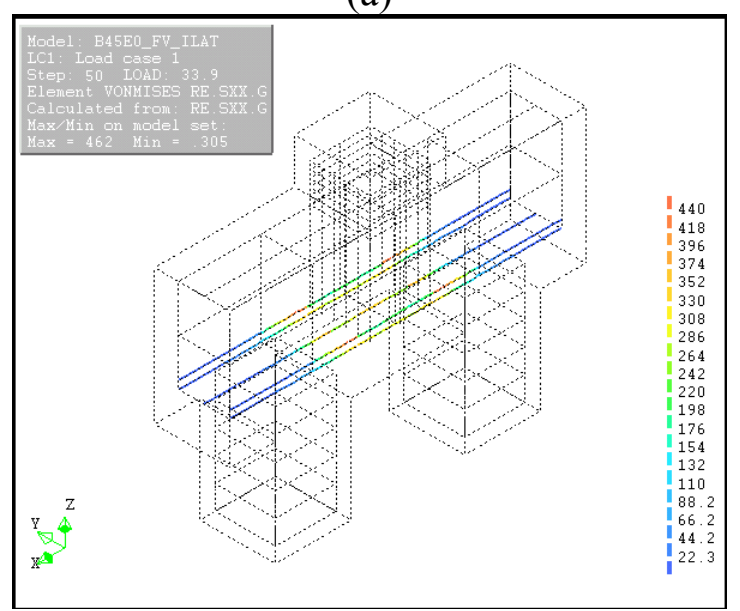

(c)

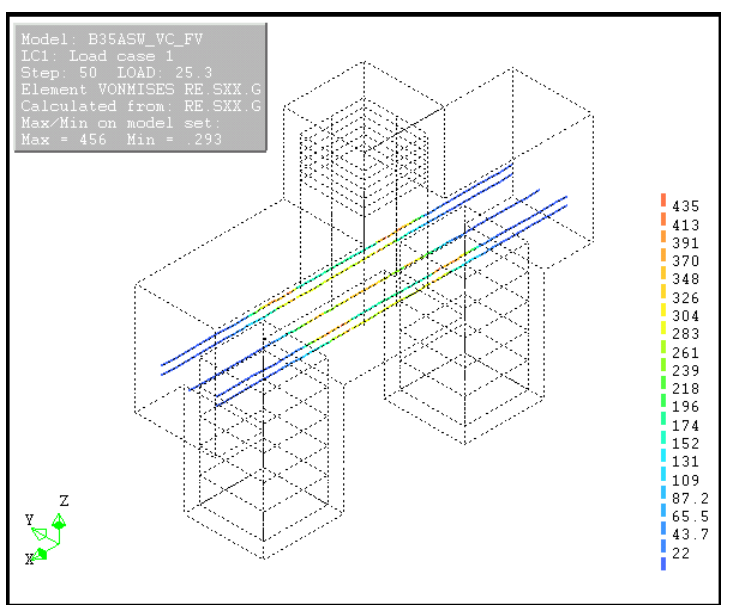

(b)

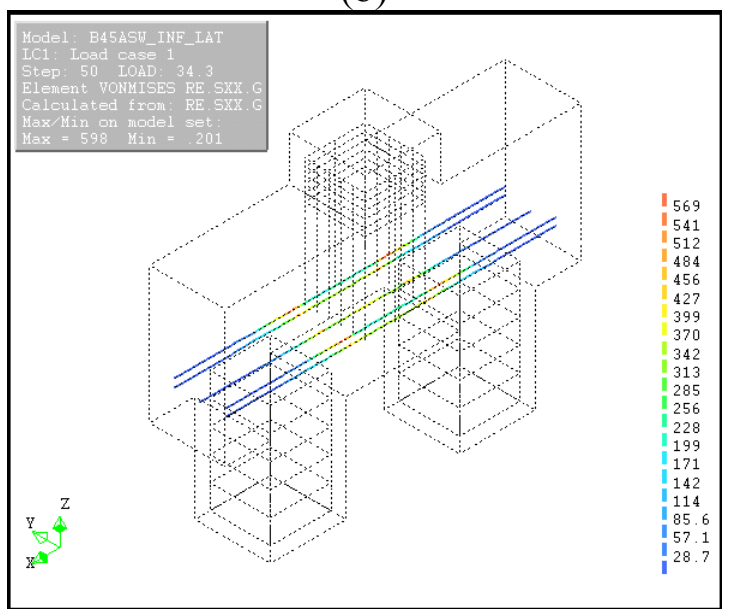

(d)

Figura 4. 30 - Tensões nas barras da armadura longitudinal dos modelos B35E0, B35ASW, B45E0 e B45ASW, respectivamente 
Tabela 4.10 - Tensão máxima nas barras da armadura longitudinal

\begin{tabular}{|c|c|c|c|c|c|}
\hline Blocos & $\begin{array}{c}\sigma_{\mathrm{y}, \exp } \\
(\mathrm{MPa})\end{array}$ & $\begin{array}{c}\sigma_{\mathbf{y}, \text { num }} \\
\text { (DIANA) } \\
\text { (MPa) }\end{array}$ & $\begin{array}{c}\sigma_{\mathrm{y}, \text { num }} \\
\text { (ANSYS) } \\
(\mathrm{MPa})\end{array}$ & $\begin{array}{c}\sigma_{\mathbf{y}, \exp } / \sigma_{\mathbf{y}, \text { num }} \\
\text { (DIANA) }\end{array}$ & $\begin{array}{c}\sigma_{\mathbf{y}, \text { exp }} / \sigma_{y, \text { num }} \\
\text { (ANSYS) }\end{array}$ \\
\hline B35E0 & 392 & 397 & 413 & 0,99 & 0,96 \\
\hline B35ASW & 340 & 456 & 390 & 0,75 & 0,87 \\
\hline B45E0 & 590 & 462 & 505 & 1,28 & 1,17 \\
\hline B45ASW & 380 & 598 & 353 & 0,65 & 1,08 \\
\hline
\end{tabular}

A relação força versus deslocamentos também foi analisada para os quatro modelos em questão. O deslocamento analisado foi medido na parte inferior do bloco, e os resultados encontram-se nos gráficos da Figura 4.31. De uma maneira geral, os modelos numéricos apresentam-se mais rígidos do que os modelos experimentais, e pode-se afirmar que os modelos analisados por meio dos programas computacionais DIANA e ANSYS apresentaram comportamentos semelhantes.

Apesar da diferença entre os modelos experimentais e numéricos, pode-se afirmar que os resultados são proveitosos. Uma vez fundamentado na teoria da análise limite, que diz que "para fins de determinação da capacidade limite de carga de uma estrutura, é possível dispensar uma análise evolutiva das tensões e das deformações, admitindo-se, simplificadamente, que o material tenha comportamento elasto-plástico perfeito". Como o modelo de bielas e tirantes é garantido pelo Teorema do Limite Inferior considera-se que, para obtenção da distribuição do fluxo de tensões na iminência da ruína, os resultados são válidos. 


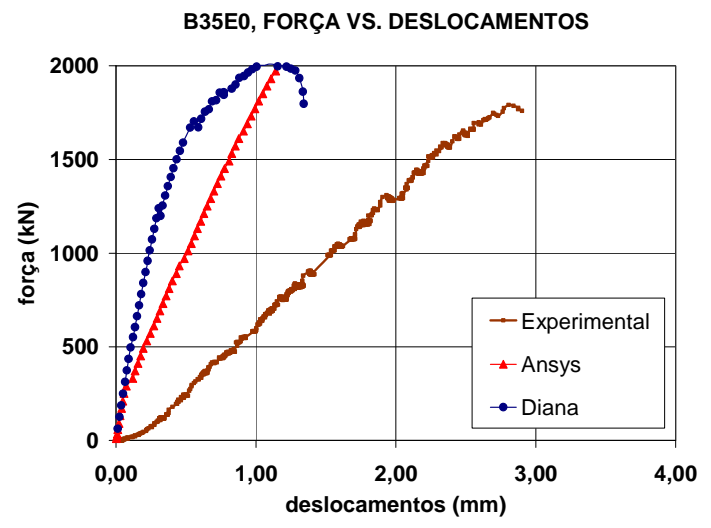

(a)

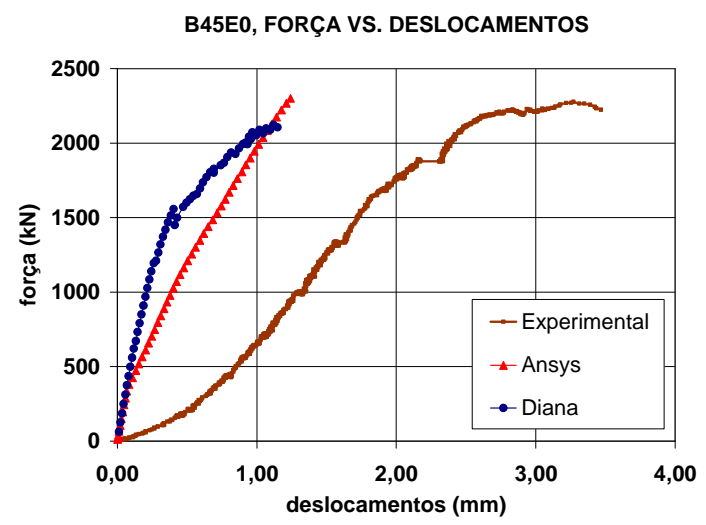

(c)

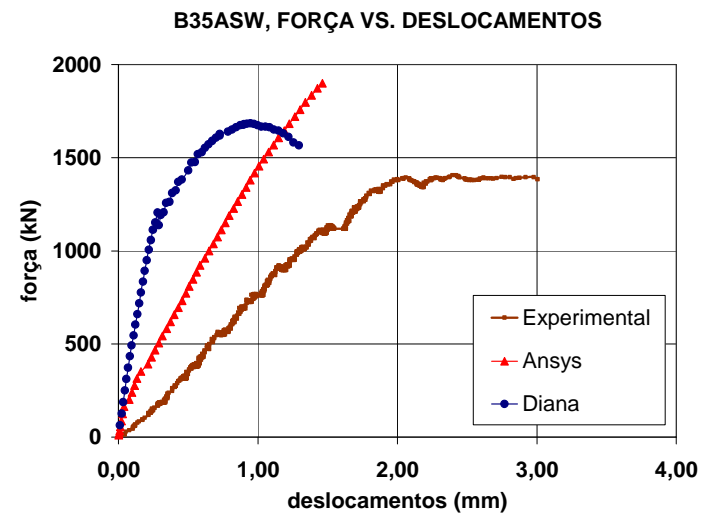

(b)

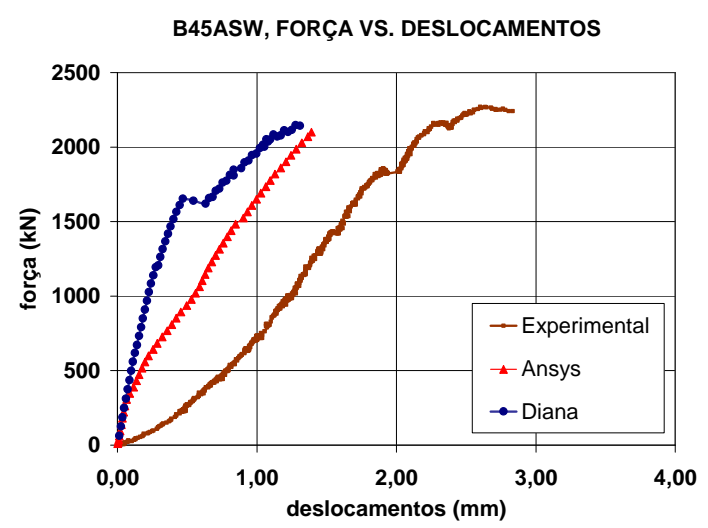

(d)

Figura 4. 31 - Curva força vs. deslocamentos dos modelos B35E0, B35ASW, B45E0 e B45ASW, respectivamente

Tabela 4.11 - Força última obtida nos modelos

\begin{tabular}{c|c|c|c|c|c}
\hline \hline Blocos & $\begin{array}{c}\mathbf{F}_{\mathbf{u}, \mathbf{e x p}} \\
(\mathbf{k N )}\end{array}$ & $\begin{array}{c}\mathbf{F}_{\mathbf{u}, \mathbf{n u m}} \\
(\mathbf{D I A N A}) \\
(\mathbf{k N})\end{array}$ & $\begin{array}{c}\mathbf{F}_{\mathbf{u}, \mathbf{n u m}} \\
(\mathbf{A N S Y S )} \\
(\mathbf{k N})\end{array}$ & $\begin{array}{c}\mathbf{F}_{\mathbf{u}, \mathbf{e x p}} / \mathbf{F}_{\mathbf{u}, \mathbf{n u m}} \\
(\mathbf{D I A N A})\end{array}$ & $\begin{array}{c}\mathbf{F}_{\mathbf{u}, \mathbf{e x p}} / \mathbf{F}_{\mathbf{u}, \mathbf{n u m}} \\
(\mathbf{A N S Y S})\end{array}$ \\
\hline B35E0 & 1821 & 2009 & 1971 & 0,91 & 0,92 \\
\hline B35ASW & 1406 & 1684 & 1616 & 0,84 & 0,87 \\
\hline B45E0 & 2276 & 2120 & 2267 & 1,07 & 1,01 \\
\hline B45ASW & 2090 & 2146 & 2100 & 0,97 & 0,99 \\
\hline \multicolumn{7}{c}{ Valores médios } & 0,9475 & 0,9475 \\
\hline
\end{tabular}

De um modo geral, os modelos numéricos apresentaram-se mais rígidos do que os modelos experimentais, e pode-se afirmar que, enquanto os resultados provenientes do 
programa Ansys apresentaram uma tendência de comportamento dividida em trechos lineares, os resultados do programa Diana apresentam uma não-linearidade mais acentuada.

Em termos de deslocamento, observa-se que tanto o Ansys como o Diana, apresentam resultados distantes do obtido experimentalmente. Todavia, essa diferença se justifica pela dificuldade de simular numericamente o comportamento real do concreto. Desenvolver um modelo capaz de representar o comportamento do concreto o mais próximo do real é um desafio. O concreto armado é um material quase-frágil e tem diferentes comportamentos na compressão e na tração. Verifica-se, portanto, a necessidade de melhorar os modelos constitutivos para representação do material concreto nesses tipos de programa.

Outra dificuldade é captar diversos fatores que ocorrem nos ensaios laboratoriais, como por exemplo a presença de pequena excentricidade na aplicação do carregamento, temperatura e umidade ambiente, entre outros.

\subsection{Comentários finais}

Neste capítulo buscou-se aferir um modelo numérico utilizando o programa computacional DIANA, procedendo a uma analise comparativa de quatro modelos de blocos sobre duas estacas, estudados experimentalmente no Laboratório de Estruturas da Escola de Engenharia de São Carlos, Universidade de São Paulo.

Por meio da análise paramétrica, verificou-se a influência dos diversos parâmetros envolvidos na simulação numérica. Após varias análises, foi obtido um modelo numérico capaz de representar de maneira satisfatória, em termos de força última, os quatro modelos ensaiados experimentalmente, e que pode então ser estendido às análises propostas inicialmente nesse trabalho. 
Capítulo

\section{Blocos sobre duas estacas com cálice embutido}

\subsection{Considerações iniciais}

Conforme foi apresentado no capítulo 4, as simulações numéricas foram feitas via método dos elementos finitos, por meio do programa computacional DIANA, versão 9.2, registrada para o Departamento de Engenharia de Estruturas da Escola de Engenharia de São Carlos - USP.

Foram estudados blocos sobre duas estacas com cálice totalmente embutido, utilizado na ligação com pilar pré-moldado. As condições de contorno bem como as ações que incidem sobre o bloco procuraram reproduzir uma situação próxima da real existente em projetos. As propriedades mecânicas dos materiais utilizados nos modelos foram obtidas por meio das normas ABNT NBR 6118:2003 e ABNT NBR 7480:2007.

A análise numérica teve por objetivo avaliar o comportamento do bloco sobre duas estacas com cálice embutido, no que diz respeito à distribuição e fluxo de tensões principais, tensões nas barras das armaduras dos tirantes e curvas do tipo força versus deslocamentos. 


\subsection{Modelos analisados numericamente}

\subsubsection{Parâmetros analisados}

Os parâmetros escolhidos para serem analisados nas simulações numéricas foram os seguintes: o ângulo de inclinação da biela comprimida, a espessura da parede lateral do cálice, a conformação das paredes do cálice (lisa ou rugosa) e a presença ou não da viga de travamento.

Os ângulos adotados para a biela de compressão foram iguais a $45^{\circ}$ e $55^{\circ}$. A escolha desses valores se deu em função das recomendações de Blévot \& Frémy (1967).

Tratando da espessura das paredes laterais do cálice, foram adotados os valores de 15 cm e $20 \mathrm{~cm}$. Por causa da ausência de bibliografia específica a respeito de cálice embutido, optou-se por utilizar as recomendações de Leonhardt \& Mönnig (1978) e da ABNT NBR 9062:1985 para cálice externo.

A conformação das paredes internas do cálice também foi considerada, sendo avaliados cálices com paredes rugosas e lisas.

Em relação à viga de travamento, foi estudado o bloco com e sem a presença da viga. Quando da presença da viga, foram utilizados dois valores distintos de ações, a fim de verificar a sua influência no comportamento do bloco sobre duas estacas. No total foram estudados vinte e quatro modelos de blocos sobre duas estacas com cálice totalmente embutido.

\subsubsection{Nomenclatura dos modelos}

A nomenclatura adotada para os modelos foi idealizada a partir dos seguintes parâmetros: conformação das paredes do cálice; altura total do bloco (função do comprimento 
de embutimento, $\ell_{\text {emb}}$ ); ângulo de inclinação da biela comprimida; espessura da parede lateral do cálice e tipo de solicitação na viga de travamento.

Para compreender melhor a nomenclatura adotada, utilizam-se os exemplos a seguir. $\mathrm{O}$ modelo BLH75A45_15 representa o bloco com conformação das paredes lisa, altura do bloco de $75 \mathrm{~cm}$, ângulo de inclinação da biela igual a $45^{\circ}$, espessura da parede igual a $15 \mathrm{~cm}$ e sem viga de travamento. Já o modelo BRH65A55_20_cv1 representa o bloco com conformação das paredes rugosas, altura do bloco de $65 \mathrm{~cm}$, ângulo de inclinação da biela igual a $55^{\circ}$, espessura da parede igual a $20 \mathrm{~cm}$ e com ação do tipo 1 na viga de travamento.

\subsubsection{Apresentação dos modelos}

Os modelos estudados numericamente visaram simular uma situação bastante comum em projetos de galpões pré-moldados. Uma seqüência de pilares pré-moldados alinhados e conectados por meio de vigas de travamento. Sobre essas vigas, é possível ainda a construção de paredes em alvenaria ou bloco, servindo, portanto, como viga baldrame. A Figura 5.1 reproduz a situação anteriormente descrita.

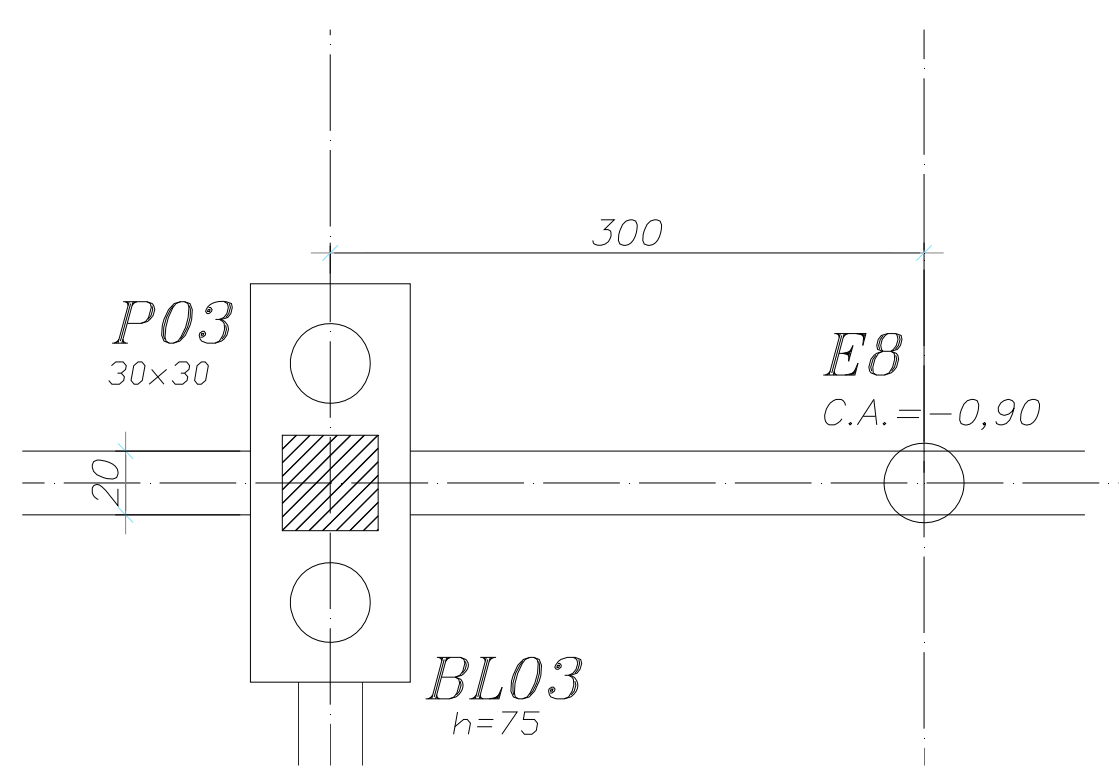

Figura 5. 1 - Situação de projeto analisada 
Para determinar os valores das ações nas vigas de travamento, foram idealizadas duas situações. Na primeira delas, imaginou-se uma parede feita em blocos de argamassa, com dimensões em centímetros de 14 × 19 × 29, revestimento em argamassa de cimento e areia e 5,00 m de altura. Na segunda situação, os blocos passaram a ter dimensões de 19x19x39, e parede com altura de $6,00 \mathrm{~m}$. A primeira situação, a qual será tratada como carregamento do tipo 1 (cv1) resultou numa ação de $18,5 \mathrm{kN} / \mathrm{m}$, enquanto que a segunda, chamada de carregamento do tipo 2 (cv2) resultou em $29,4 \mathrm{kN} / \mathrm{m}$. A Figura 5.2 reproduz a geometria dos blocos em argamassa. Apresentados os parâmetros que foram estudados nas simulações numéricas, obtemos um total de vinte e quatro modelos apresentados na tabela 5.1.

Tabela 5.1 - Modelos analisados numericamente

\begin{tabular}{|c|c|c|c|c|c|}
\hline Bloco & Interface & Ângulo & Espessura & Viga & Solicitação \\
\hline \multirow{12}{*}{ BLH75 } & \multirow{12}{*}{ LISA } & \multirow{6}{*}{$45^{\circ}$} & \multirow{3}{*}{15} & SEM & - \\
\hline & & & & $\mathrm{COM}$ & $\mathrm{cv} 1$ \\
\hline & & & & $\mathrm{COM}$ & cv2 \\
\hline & & & \multirow{3}{*}{20} & SEM & - \\
\hline & & & & $\mathrm{COM}$ & cv1 \\
\hline & & & & $\mathrm{COM}$ & $\mathrm{cv} 2$ \\
\hline & & \multirow{6}{*}{$55^{\circ}$} & \multirow{3}{*}{15} & SEM & - \\
\hline & & & & $\mathrm{COM}$ & $\mathrm{cv1}$ \\
\hline & & & & $\mathrm{COM}$ & $\mathrm{cv} 2$ \\
\hline & & & \multirow{3}{*}{20} & SEM & - \\
\hline & & & & $\mathrm{COM}$ & cv1 \\
\hline & & & & $\mathrm{COM}$ & $\mathrm{cv} 2$ \\
\hline BRH65 & RUGOSA & $45^{\circ}$ & 15 & $\begin{array}{l}\text { SEM } \\
\text { COM } \\
\text { COM }\end{array}$ & $\begin{array}{c} \\
\mathrm{cv} 1 \\
\mathrm{cv} 2\end{array}$ \\
\hline
\end{tabular}


Tabela 5.1 - Modelos analisados numericamente.(continuação)

\begin{tabular}{|c|c|c|c|c|c|}
\hline Bloco & Interface & Ângulo & Espessura & Viga & Solicitação \\
\hline \multirow{9}{*}{ BRH65 } & \multirow{9}{*}{ RUGOSA } & \multirow{3}{*}{$45^{\circ}$} & \multirow{3}{*}{20} & SEM & - \\
\hline & & & & $\mathrm{COM}$ & cv1 \\
\hline & & & & $\mathrm{COM}$ & cv2 \\
\hline & & \multirow{6}{*}{$55^{\circ}$} & \multirow{3}{*}{15} & SEM & - \\
\hline & & & & $\mathrm{COM}$ & cv1 \\
\hline & & & & $\mathrm{COM}$ & cv2 \\
\hline & & & \multirow{3}{*}{20} & SEM & - \\
\hline & & & & $\mathrm{COM}$ & cv1 \\
\hline & & & & $\mathrm{COM}$ & cv2 \\
\hline
\end{tabular}
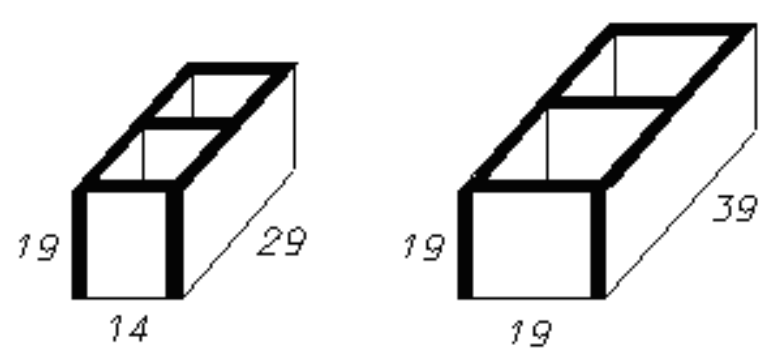

Figura 5. 2 - Blocos em argamassa utilizados sobre a viga de travamento

\subsubsection{Geometria dos modelos e propriedades mecânicas}

Nesse item é apresentada a geometria dos modelos de blocos sobre duas estacas com cálice embutido analisados numericamente por meio do programa DIANA, versão 9.2.

Os blocos foram dimensionados segundo recomendações de Blévot \& Frémy (1967), da ABNT NBR 9062:1985 e da ABNT NBR 6118:2003 na determinação do arranjo das barras das armaduras. Como o objetivo da analise em questão é estudar o comportamento do bloco com cálice embutido quando da presença da viga de travamento, optou-se em não variar a geometria dos pilares, estacas e vigas nos modelos analisados. 
A tabela 5.2 apresenta as propriedades geométricas dos quatro grupos de blocos analisados. Os pilares e estacas são de seção quadrada com medida dos lados igual a $30 \mathrm{~cm}$. As paredes laterais possuem dois valores de espessura, $15 \mathrm{~cm}$ e $20 \mathrm{~cm}$. Além disso, há uma folga entre o pilar e o cálice de $5 \mathrm{~cm}$ em cada face, que posteriormente é ocupado pelo graute, resultando assim nos valores de $B_{\text {Ly }}$. A tabela 5.3 apresenta as propriedades mecânicas dos concretos utilizados nos modelos.

Tabela 5.2 - Propriedades geométricas dos modelos analisados

\begin{tabular}{c|c|c|c|c|c|c|c}
\hline \hline Blocos & $\begin{array}{c}\text { Dimensão } \\
\text { da estaca } \\
(\mathbf{c m})\end{array}$ & $\begin{array}{c}\text { Dimensão } \\
\mathbf{d o} \text { pilar } \\
(\mathbf{c m})\end{array}$ & $\begin{array}{c}\text { Dimensão } \\
\mathbf{d a} \text { viga } \\
(\mathbf{c m})\end{array}$ & $\begin{array}{c}\mathbf{B}_{\mathbf{L x}} \\
(\mathbf{c m})\end{array}$ & $\begin{array}{c}\mathbf{B}_{\mathbf{L y}} \\
(\mathbf{c m})\end{array}$ & $\begin{array}{c}\boldsymbol{\ell}_{\mathbf{e m b}} \\
(\mathbf{c m})\end{array}$ & $\begin{array}{c}\text { Altura } \\
(\mathbf{c m})\end{array}$ \\
\hline BLH75A45 & $30 \times 30$ & $30 \times 30$ & $20 \times 40$ & 205 & $70 / 80$ & 45 & 75 \\
\hline BLH75A55 & $30 \times 30$ & $30 \times 30$ & $20 \times 40$ & 165 & $70 / 80$ & 45 & 75 \\
\hline BRH65A45 & $30 \times 30$ & $30 \times 30$ & $20 \times 40$ & 185 & $70 / 80$ & 35 & 65 \\
\hline BRH65A55 & $30 \times 30$ & $30 \times 30$ & $20 \times 40$ & 150 & $70 / 80$ & 35 & 65 \\
\hline \hline
\end{tabular}

Tabela 5.3 - Propriedades mecânicas dos concretos

\begin{tabular}{c|c|c|c}
\hline \hline Propriedades & $\begin{array}{c}\mathbf{f}_{\text {ck }} \\
(\mathbf{M P a})\end{array}$ & $\begin{array}{c}\mathbf{f}_{\text {ct,m }} \\
(\mathbf{M P a})\end{array}$ & $\begin{array}{c}\mathbf{E}_{\mathbf{c s}} \\
(\mathbf{M P a})\end{array}$ \\
\hline Bloco & 25 & 2,56 & 23800 \\
\hline Pilar & 50 & 4,07 & 33658 \\
\hline Estaca & 50 & 4,07 & 33658 \\
\hline Viga & 25 & 2,56 & 23800 \\
\hline Graute & 50 & 4,07 & 33658 \\
\hline \hline
\end{tabular}

Seguindo os mesmos princípios das análises feitas no capitulo 4, as barras das armaduras principais do tirante foram dimensionadas para não escoarem, assim como os pilares e estacas tiveram concretos com resistência a compressão maior do que as resistências do concreto dos blocos e das vigas. Apesar de não ser um modo de dimensionamento dos 
blocos, esse procedimento foi feito com o intuito de evitar a ruína dos modelos no pilar ou na estaca. A tabela 5.4 apresenta a configuração das barras das armaduras adotadas nos modelos. O valor da resistência ao escoamento utilizado foi igual a $500 \mathrm{MPa}$, enquanto que o módulo de elasticidade foi igual a $210 \mathrm{GPa}$.

Tabela 5.4 - Barras de aço das armaduras dos modelos analisados.

\begin{tabular}{c|c|c|c|c}
\hline \hline Blocos & BLH75A45 & BLH75A55 & BRH65A45 & BRH65A55 \\
\hline Armadura Longitudinal & $6 \varnothing 20 \mathrm{~mm}$ & $6 \varnothing 20 \mathrm{~mm}$ & $6 \varnothing 20 \mathrm{~mm}$ & $6 \varnothing 20 \mathrm{~mm}$ \\
\hline Estribo Vertical & $6 \varnothing 6,3 \mathrm{c} / 10$ & $6 \varnothing 6,3 \mathrm{c} / 11,5$ & $6 \varnothing 6,3 \mathrm{c} / 13,5$ & $6 \varnothing 6,3 \mathrm{c} / 15,5$ \\
\hline Estribo Horizontal & $4 \varnothing 6,3 \mathrm{c} / 15$ & $4 \varnothing 6,3 \mathrm{c} / 15$ & $4 \varnothing 6,3 \mathrm{c} / 15$ & $4 \varnothing 6,3 \mathrm{c} / 15$ \\
\hline Ashp & $3 \varnothing 6,3 \mathrm{c} / 6$ & $3 \varnothing 6,3 \mathrm{c} / 6$ & $3 \varnothing 6,3 \mathrm{c} / 6$ & $3 \varnothing 6,3 \mathrm{c} / 6$ \\
\hline Ashs & $4 \varnothing 6,3 \mathrm{c} / 10$ & $4 \varnothing 6,3 \mathrm{c} / 10$ & $4 \varnothing 6,3 \mathrm{c} / 10$ & $4 \varnothing 6,3 \mathrm{c} / 10$ \\
\hline Asvp & $2 \varnothing 6,3 \mathrm{c} / 10$ & $2 \varnothing 6,3 \mathrm{c} / 10$ & $2 \varnothing 6,3 \mathrm{c} / 10$ & $2 \varnothing 6,3 \mathrm{c} / 10$ \\
\hline Asvs & $4 \varnothing 6,3 \mathrm{c} / 8$ & $4 \varnothing 6,3 \mathrm{c} / 8$ & $4 \varnothing 6,3 \mathrm{c} / 8$ & $4 \varnothing 6,3 \mathrm{c} / 8$ \\
\hline Armadura de Punção & $4 \varnothing 6,3 \mathrm{c} / 8$ & $4 \varnothing 6,3 \mathrm{c} / 8$ & $4 \varnothing 6,3 \mathrm{c} / 8$ & $4 \varnothing 6,3 \mathrm{c} / 8$ \\
\hline Armadura de Costura & $6 \varnothing 6,3 \mathrm{c} / 10$ & $6 \varnothing 6,3 \mathrm{c} / 11,5$ & $6 \varnothing 6,3 \mathrm{c} / 13,5$ & $6 \varnothing 6,3 \mathrm{c} / 15,5$ \\
\hline Armadura do Pilar & $12 \varnothing 12,5 \mathrm{~mm}$ & $12 \varnothing 12,5 \mathrm{~mm}$ & $12 \varnothing 12,5 \mathrm{~mm}$ & $12 \varnothing 12,5 \mathrm{~mm}$ \\
\hline Armadura da Estaca & $8 \varnothing 12,5 \mathrm{~mm}$ & $8 \varnothing 12,5 \mathrm{~mm}$ & $8 \varnothing 12,5 \mathrm{~mm}$ & $8 \varnothing 12,5 \mathrm{~mm}$ \\
\hline \hline
\end{tabular}

\subsubsection{Elementos finitos utilizados}

Os elementos finitos utilizados na simulação numérica foram os mesmos apresentados no capítulo 4, descritos detalhadamente no item 4.2.8 e disponíveis na biblioteca de elementos do DIANA. Para a representação do concreto, bloco, pilar, estaca e viga foi utilizado o elemento CHX60, enquanto que para a representação das barras das armaduras foram utilizados elementos do tipo reinforcement. As Figuras 5.3-a e 5.3-b apresentam os modelos BLH75A45_15_cv1 e BRH65A55_15, respectivamente. 


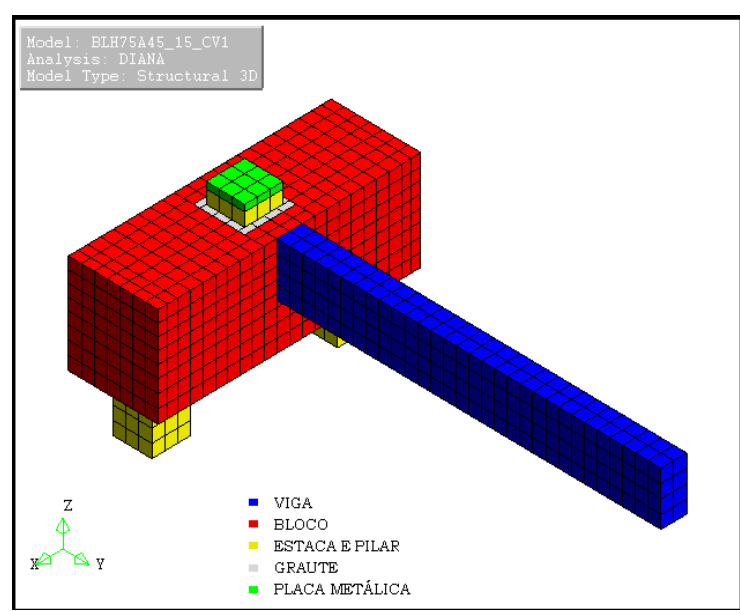

(a)

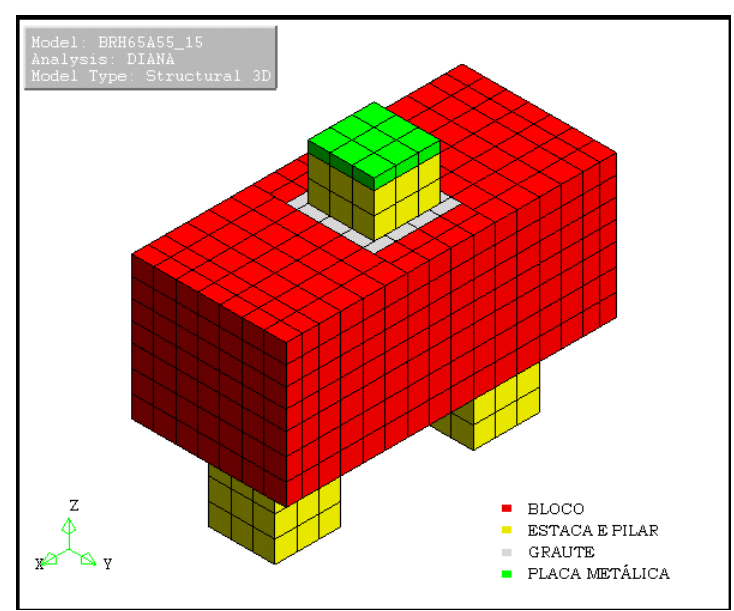

(b)

Figura 5. 3 - Malha de elementos finitos dos BLH75A45_15_CV1 e BRH65A55_15

Observa-se na figura anterior a presença de uma placa metálica sobre o pilar. Essa placa apresenta rigidez elevada e foi utilizada com o intuito de evitar concentração de tensão no topo do pilar.

As ações foram aplicadas no modelo por meio de pressão. As condições de contorno adotadas nos modelos restringiam os deslocamentos das estacas nas direções x, y e z. Quando da presença da viga de travamento, foi restringido os deslocamentos e as rotações na extremidade da viga, simulando um engaste perfeito da viga com a estaca. As Figuras 5.4-a e 5.4-b apresentam o modelo BLH75A45_15_cv1 com as ações e as condições de contorno, respectivamente.

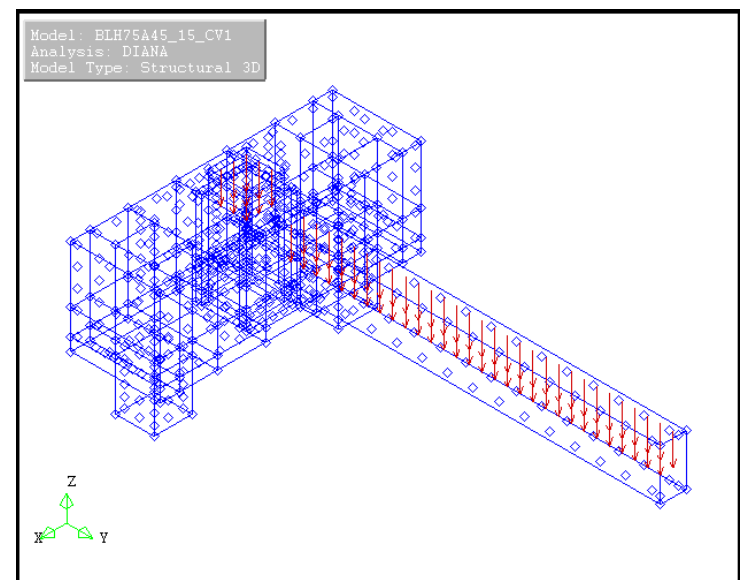

(a)

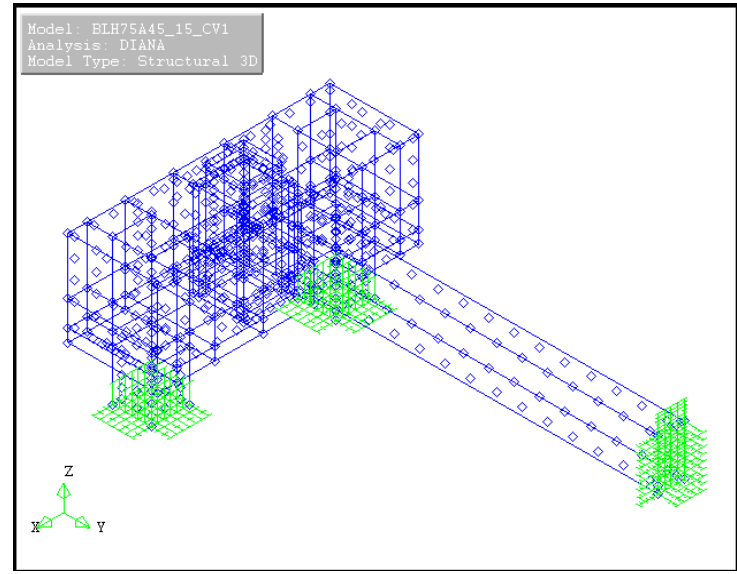

(b)

Figura 5. 4 - Modelo BLH75A45_15_cv1 com ações e condições de contorno 
O uso de reinforcements para representação das barras das armaduras permitiu a discretização de todas as armaduras presentes no bloco e no cálice. No bloco de fundação foi utilizada armadura longitudinal principal, estribos horizontais e verticais, e armadura de costura. No cálice propriamente dito, foi utilizada armadura vertical principal e secundária, e armadura horizontal principal e secundária, sugerida por Leonhardt \& Mönnig (1978) e adaptada por El Debs (2000). Foi utilizada sob o cálice embutido uma armadura a fim de evitar punção. Também foram modeladas as barras das armaduras inferior, superior e dos estribos da viga, bem como as armaduras do pilar e das estacas.

As barras das armaduras anteriormente descritas foram dimensionadas e apresentadas na tabela 5.4 As Figuras 5.5-a; 5.5-b; 5.6-a; 5.6-b; 5.7-a e 5.7-b mostram separadamente como as barras das armaduras foram utilizadas nos modelos, tomando como exemplo o modelo BLH75A45_15_cv1.

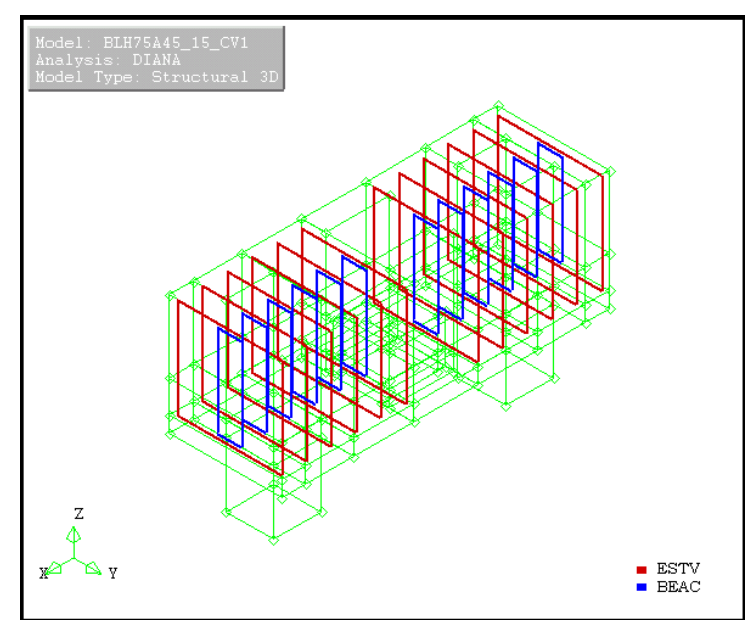

(a)

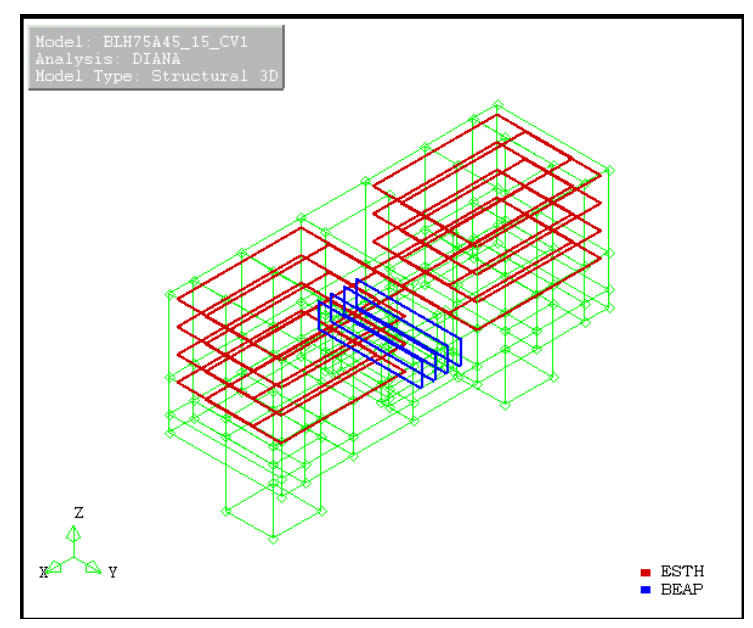

(b)

Figura 5. 5 - Barras dos estribos verticais e armadura de costura; barras dos estribos horizontais e armadura de punção, respectivamente 


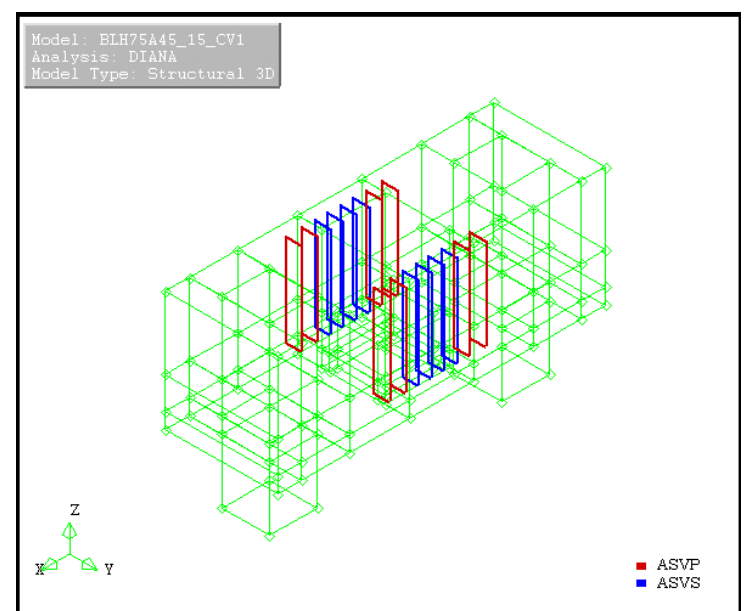

(a)

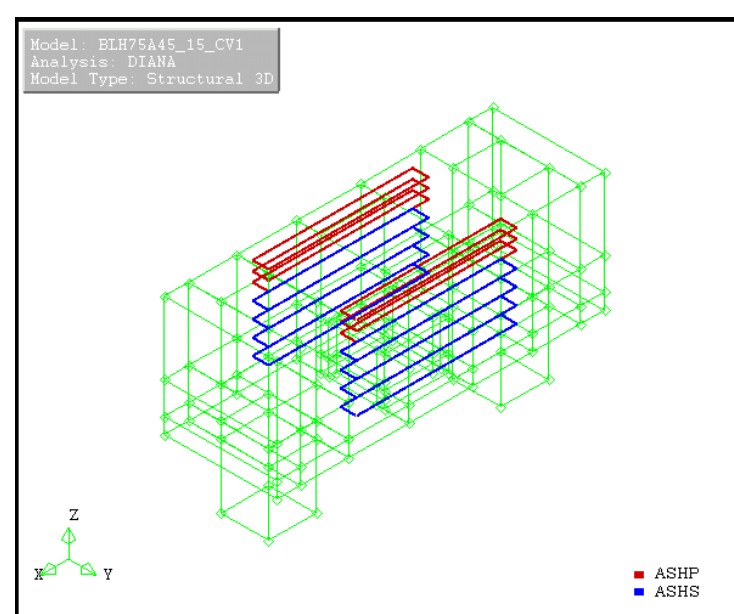

(b)

Figura 5. 6 - Barras da armadura vertical principal e secundária; barras da armadura horizontal principal e secundária, respectivamente

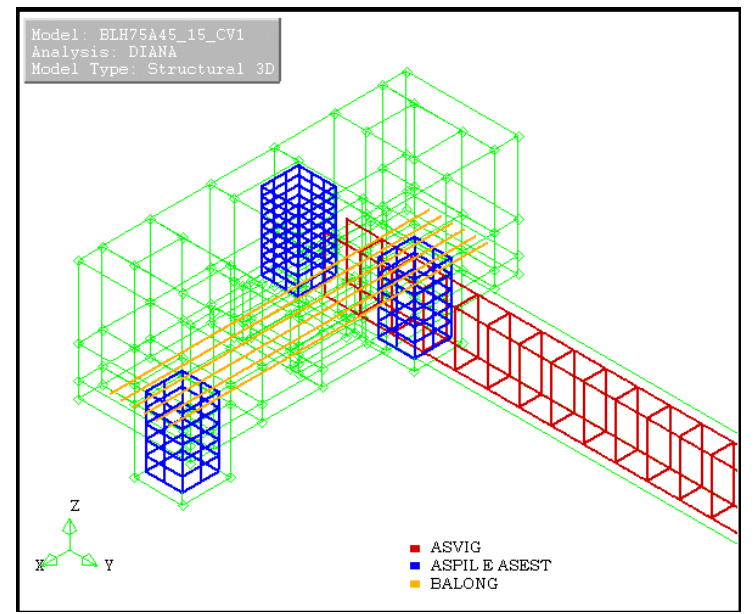

(a)

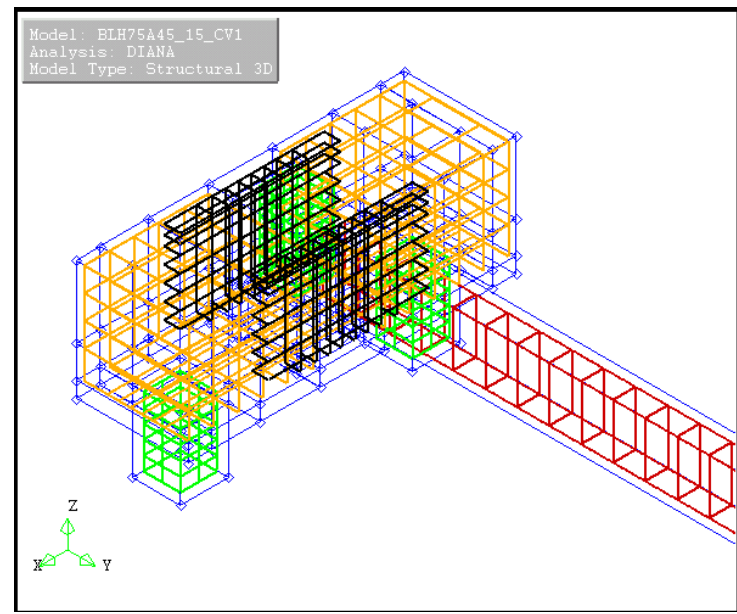

(b)

Figura 5. 7 - Barras da armadura da viga, pilar, estacas e armadura longitudinal; modelo com barras das armaduras completas

$\mathrm{Na}$ simulação do contato existente entre o pilar e o graute e o graute e o bloco, primeiramente foi utilizado elementos de contato disponíveis na biblioteca do programa DIANA. Entretanto, a utilização desses elementos não foi satisfatória, uma vez que os resultados obtidos para dois modelos de blocos, sendo que em apenas um deles havia elementos de contato, foram idênticos. O autor considera que os elementos de contato disponíveis no programa DIANA devem ser utilizados para simular a não-linearidade de contato, por exemplo, quando há alteração das condições de contorno de um modelo. 
Diante dos resultados obtidos com o uso dos elementos de contato, optou-se por utilizar novas estratégias para simular o comportamento existente entre o pilar e o graute e o graute e o bloco, dentre as quais está o uso de elementos de interface.

Na maioria dos trabalhos consultados durante a revisão bibliográfica, constatou-se que o uso de elementos de contato é mais utilizado do que os elementos de interface. Entretanto, o elemento de interface é perfeitamente capaz de representar o comportamento existente entre duas superfícies sujeitas a atrito. Bangash (2001) considera que os elementos de interface apresentam um grande potencial nos problemas de interação solo-estrutura, discretização do concreto com armadura, atrito em ligações de estruturas de concreto pré-moldado, entre outras situações.

O elemento finito de interface utilizado foi o CQ48I, que é um elemento plano, quadrilateral com função aproximadora quadrática em deslocamentos, recomendado em análises tridimensionais. A escolha desse elemento se deu em função do elemento finito CHX60 utilizado na modelagem do concreto, já que ambos possuem oito nós em cada face. A

Figura 5.8 apresenta o elemento CQ48I.

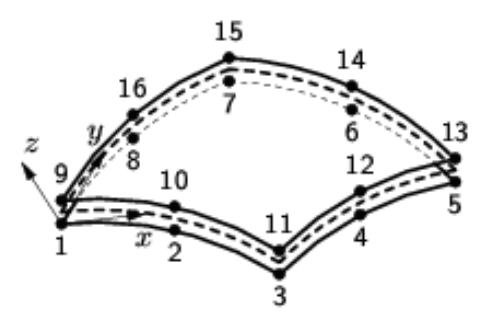

(a) topology

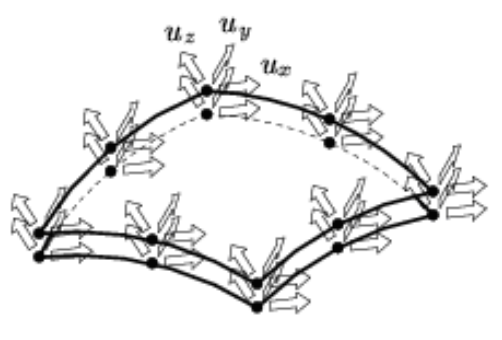

(b) displacements

Figura 5. 8 - Elemento CQ48I, DIANA (2005a)

A utilização dos elementos de interface foi feita apenas nos blocos cujas paredes do cálice apresentavam configuração lisa. Na situação de paredes rugosas, alguns pesquisadores 
como Canha (2004) e Delalibera (2008) verificaram que, quando da ocorrência de chave de cisalhamento, pode-se considerar que essa ligação apresente comportamento monolítico.

Nos cálices com parede lisa, há atrito entre o pilar e o graute e entre o graute e o bloco, sendo necessária a utilização de duas superfícies de interface. Entretanto, nas primeiras simulações, o programa DIANA não encontrava solução para o sistema de equações nãolineares, acusando que o mesmo era singular e que as condições de apoio deveriam ser checadas. Esse tipo de erro ocorre quando não existem condições de contorno do problema, estando, portanto, em desacordo com a situação em questão.

Após entrar em contato com o suporte da TNO DIANA e enviar o script do modelo com duas superfícies de interface, não foi possível identificar a causa da mensagem de erro. Como sugestão, os técnicos recomendaram modelar todo o graute como uma única superfície de interface, com espessura equivalente a do graute. Seguindo essa sugestão, constatou-se um aumento significativo no tempo de processamento do modelo, porém os resultados foram idênticos ao de um modelo que apresentava apenas uma superfície de interface, no caso entre o pilar e o graute, com espessura mínima entre as superfícies. Como esse último modelo apresentou um tempo de processamento menor do que o do modelo sugerido pelo suporte, optou-se por utilizar apenas uma superfície de interface nos modelos de blocos cujas paredes do cálice apresentam configuração lisa. As Figuras 5.9-a e 5.9-b mostram a região onde foi utilizado os elementos de interface, bem como o tipo de material utilizado.

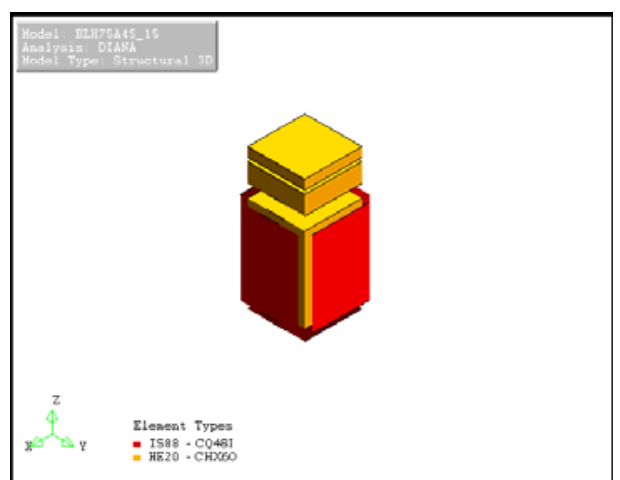

(a)

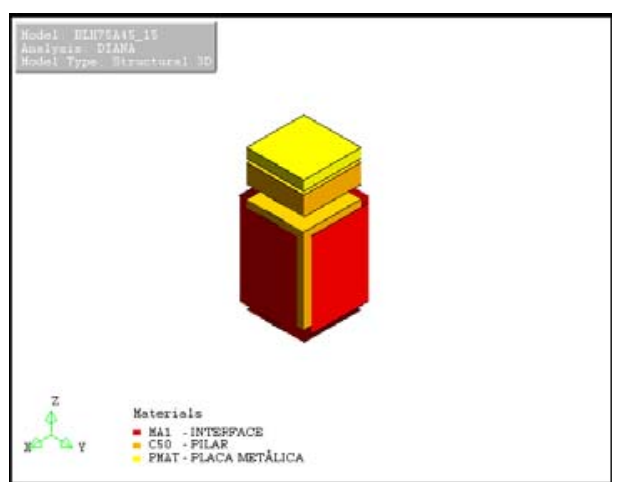

(b)

Figura 5.9 - Configuração da região de interface entre o pilar e o graute 


\subsubsection{Modelos especiais}

O programa DIANA dispõe de modelos especiais que simulam o comportamento do material, quando da utilização de elementos de interface. Entre eles destacam-se os seguintes modelos: Elasticity, Cracking, Bond-slip, Friction e Combined Cracking-Shearing-Crushing. O modelo escolhido para ser utilizado nas simulações do presente trabalho foi o modelo de Fricção.

De acordo com o manual do DIANA, a interação entre duas interfaces de uma estrutura pode ser descrito por um comportamento de fricção entre essas partes. O modelo de fricção de Coulomb, semelhante ao modelo modificado de Mohr-Coulomb descrito em Chen (1982), pode ser utilizado para descrever esse comportamento.

Segundo Chen (1982), o círculo de Mohr para um elemento submetido à compressão simples e à tração simples é envolvido por dois segmentos de reta, conforme Figura 5.10. Os círculos interceptam horizontalmente a partir da origem os valores de resistência à compressão e à tração do material. O critério de ruptura de Mohr-Coulomb modificado pode ser dividido em duas partes: critério de deslizamento (sliding criterion) e critério de separação (separation criterion), definidos pelas expressões 5.1 e 5.2, respectivamente.

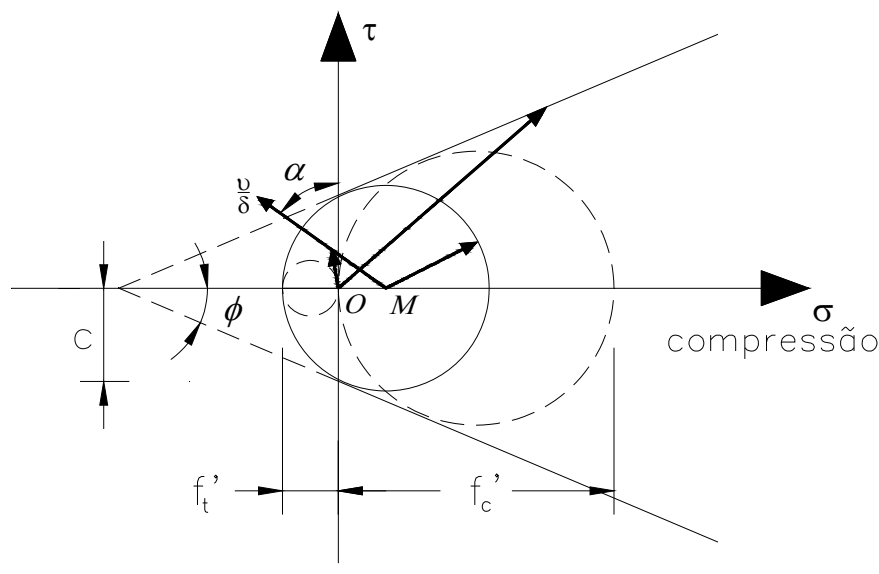

Figura 5. 10 - Modelo modificado de Mohr-Coulomb - Chen (1982) 
$|\tau|=c-\sigma \cdot \tan \phi$

$\sigma=f_{t}^{\prime}$

sendo que:

c $\quad$ é a coesão do material;

$\sigma \quad$ é a tensão normal;

$\tau \quad$ é a tensão de cisalhamento;

$\phi \quad$ é o ângulo interno de atrito;

$f_{t}^{\prime} \quad$ é a resistência à tração do material;

$f_{c}$ ' é a resistência à compressão do material

Pode-se ainda escrever o critério de deslizamento em termos das tensões principais, de tal modo que a expressão 5.1 divide-se em 5.3, 5.4, 5.5 e 5.6.

$\frac{1}{2} \cdot \sigma_{1} \cdot(1+\operatorname{sen} \phi)-\frac{1}{2} \cdot \sigma_{3} \cdot(1-\operatorname{sen} \phi)-c \cdot \cos \phi=0$

$m \cdot \sigma_{1}-\sigma_{3}=2 \cdot c \cdot \sqrt{m}=f_{c}^{\prime}$

$m=\frac{(1+\operatorname{sen} \phi)}{(1-\operatorname{sen} \phi)}=\frac{f_{c}^{\prime}}{f_{t}^{\prime}}$

$c=\frac{f_{c}^{\prime} \cdot(1-\operatorname{sen} \phi)}{2 \cdot \cos \phi}$

De acordo com Chen (1982), valores usuais para $\phi$ estão em torno de $37^{\circ}$, correspondente à $m=4$. Entretanto, utilizar valores de $\mathrm{m}=4$ resulta em resistência à tração em torno de $25 \%$ do valor da resistência à compressão, valor esse comprovadamente alto para os concretos atuais. Dessa maneira, adotou-se um ângulo interno de atrito $\phi$ igual a $31^{\circ}$, cuja 
tangente resulta em 0,6 e o valor de $f_{t}^{\prime}$ foi considerado de acordo com as recomendações da ABNT NBR 6118:2003 para resistência à tração do concreto. O valor da coesão foi calculado pela expressão 5.6.

\subsection{Apresentação e análise dos resultados.}

Neste item são apresentadas as curvas força versus deslocamento para os modelos analisados numericamente. Os resultados encontram-se divididos em blocos sem viga de travamento e blocos com viga de travamento.

\subsubsection{Blocos sem viga de travamento}

Como esperado, os blocos com ângulo de inclinação das bielas igual a $55^{\circ}$ apresentaram maior rigidez quando comparados aos blocos com inclinação de $45^{\circ}$. Constatouse também que, de um modo geral, os blocos com inclinação igual a $55^{\circ}$ apresentaram valor de força última superior aos blocos de $45^{\circ}$, que por sua vez, apresentaram deslocamentos maiores. Essa tendência de comportamento foi verificada tanto para os blocos com conformação das paredes do cálice rugosa, como para os blocos com conformação das paredes lisa, e pode ser verificado nas Figuras 5.11 e 5.12 por meio das curvas força versus deslocamento. Os deslocamentos máximos foram obtidos na região central da face inferior do bloco. 

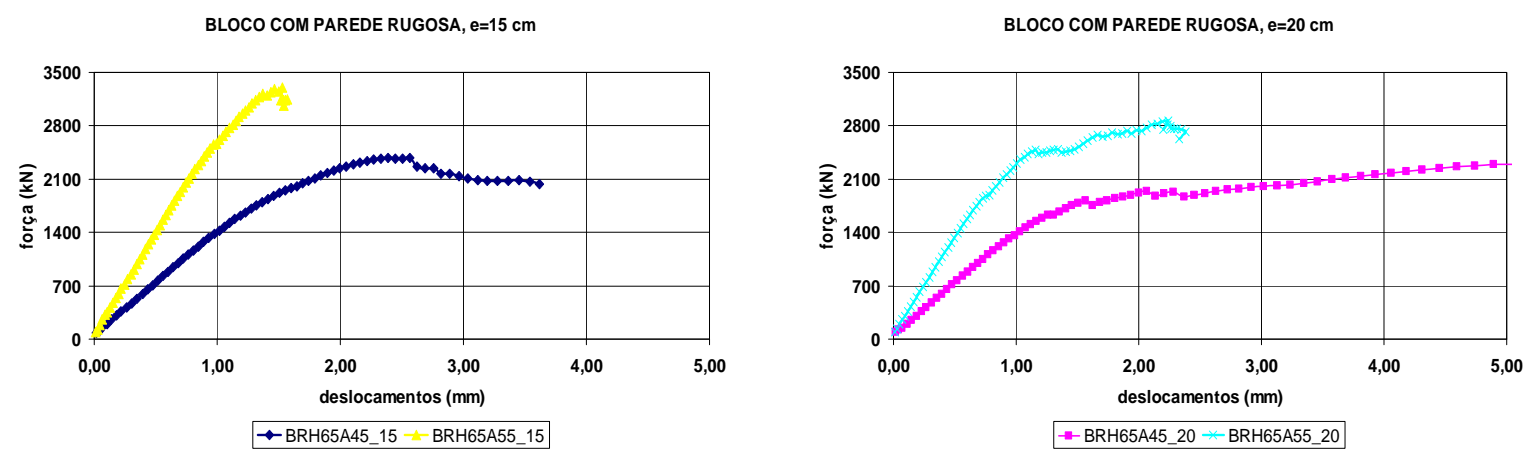

Figura 5. 11 - Bloco com parede rugosa
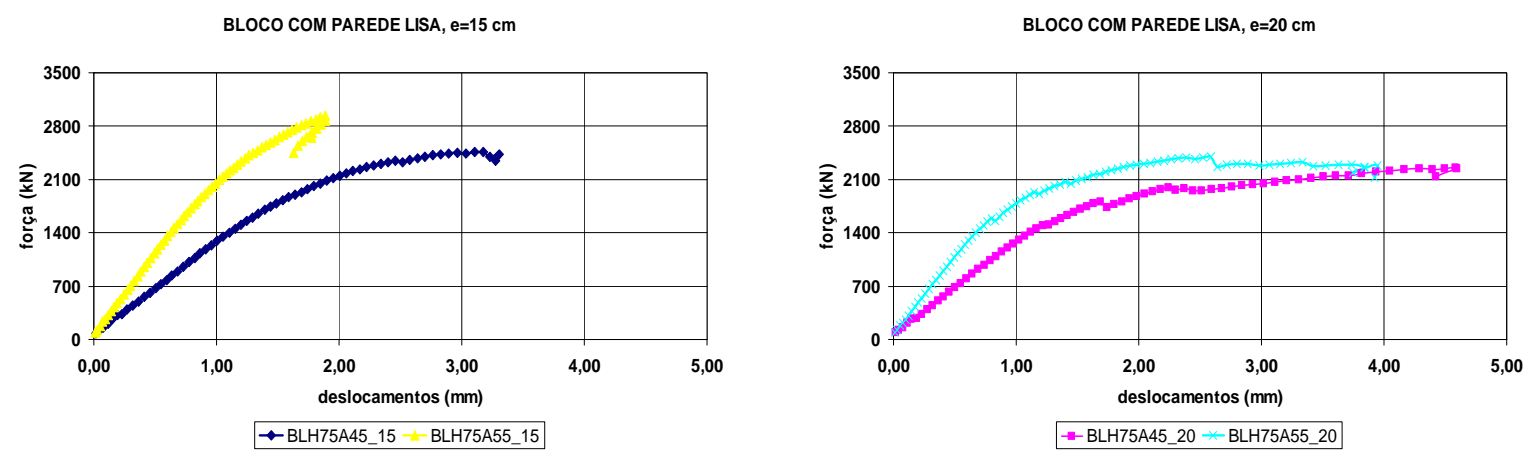

Figura 5. 12 - Bloco com parede lisa

Observa-se ainda que, independente da conformação das paredes do cálice e sem presença de viga de travamento, a força última foi superior nos blocos com espessura da parede igual a $15 \mathrm{~cm}$ quando comparados aos blocos cuja espessura da parede era igual a 20 $\mathrm{cm}$. Esse resultado mostra que nem sempre blocos com grandes dimensões implicam em blocos com maior capacidade resistente, e podem ser visto na Figura 5.13

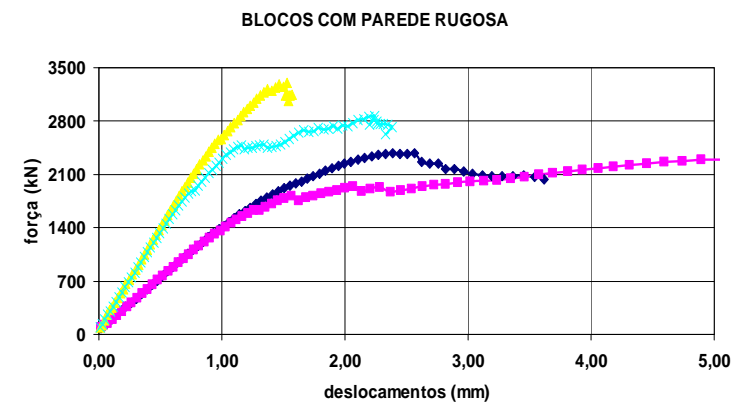

$\rightarrow$ BRH65A45_15 -BRH65A45_20 - BRH65A55_15 * BRH65A55_20

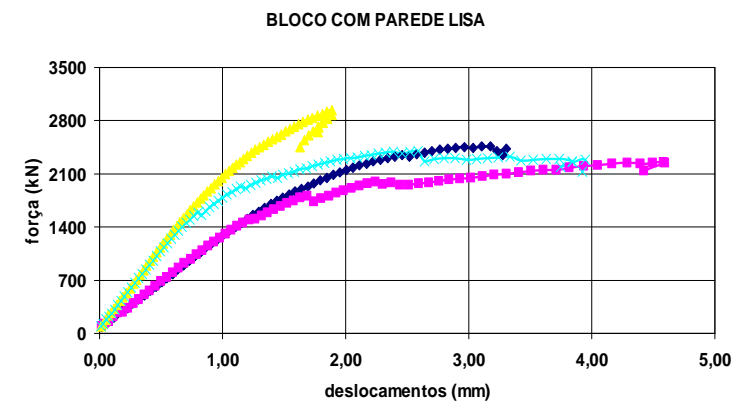

$\rightarrow$ BLH75A45_15 $\rightarrow$ BLH75A45_20 $\div$ BLH75A55_15 $\div$ BLH75A55_20

Figura 5. 13 - Blocos com espessura igual a $15 \mathrm{~cm}$ e $20 \mathrm{~cm}$ 
É possível ainda se obter algumas informações dos blocos sem a presença de viga de travamento, comparando-se valores de força última para diferentes inclinações da biela.

Por meio da Figura 5.14, é possível observar que, para o ângulo da biela igual a $45^{\circ}$, a curva força versus deslocamento do bloco com conformação da parede lisa apresenta a mesma tendência de comportamento do bloco com conformação da parede rugosa. Comportamento semelhante é observado nos blocos com espessura da parede igual a $15 \mathrm{~cm}$ e $20 \mathrm{~cm}$. .

Quando a biela possui inclinação igual à $55^{\circ}$, observa-se que os blocos com conformação da parede rugosa apresentam valores de força última superior aos blocos com conformação da parede lisa, diferentemente do comportamento apresentado anteriormente nos blocos com inclinação da biela igual a $45^{\circ}$. Esse comportamento também se repete independente da espessura da parede do cálice, como pode ser observado na Figura 5.15
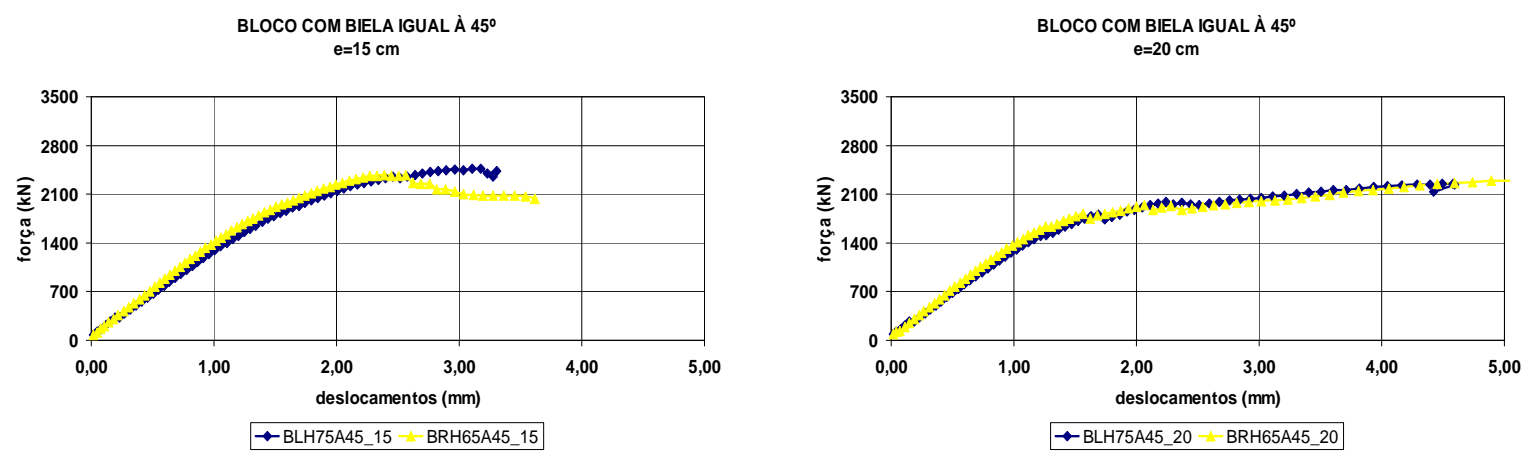

Figura 5. 14 - Bloco com inclinação igual a $45^{\circ}$
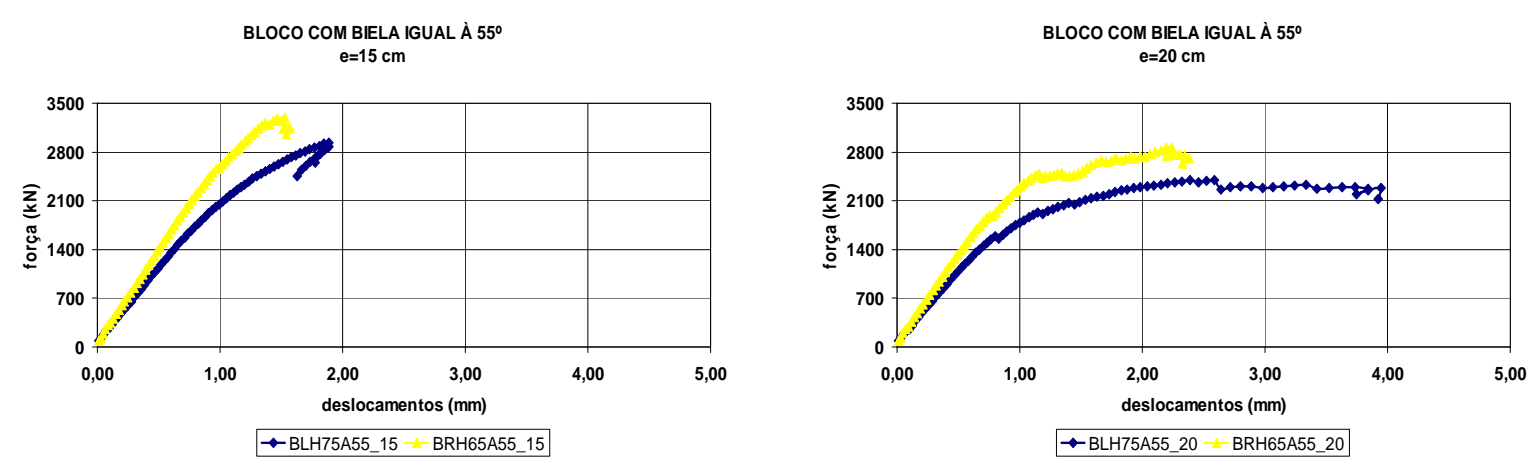

Figura 5. 15 - Bloco com inclinação igual a $55^{\circ}$ 


\subsubsection{Blocos com viga de travamento}

\subsubsection{Blocos com parede rugosa, $\theta=4^{\circ}$}

Nos modelos de blocos de parede rugosa com presença de viga de travamento, as curvas força versus deslocamento apresentaram comportamento semelhante aos blocos sem presença de viga. Constatou-se que a presença da viga de travamento não contribui de maneira significativa na ruína dos blocos, já que a parede do cálice consegue transmitir de modo satisfatório a força proveniente da viga em direção as estacas.

A Figura 5.16-a apresenta as curvas força versus deslocamento de três modelos de blocos com parede rugosa, espessura da parede igual a $15 \mathrm{~cm}$ e com dois tipos de solicitação na viga de travamento. São eles: BRH65A45_15, BRH65A45_15_cv1 e BRH65A45_15_cv2. A Figura 5.16-b, por sua vez, apresenta a curva força versus deslocamento de modelos semelhantes aos citados anteriormente, porém com espessura da parede do cálice igual a 20 $\mathrm{cm}$.

Comparando os modelos com espessura da parede igual a $15 \mathrm{~cm}$ e $20 \mathrm{~cm}$, observa-se que, para uma mesma intensidade de solicitação na viga de travamento, os blocos com espessura igual a $15 \mathrm{~cm}$ apresentaram força última superior aos blocos com espessura de 20 cm. As Figuras 5.17-a e 5.17-b mostram as curvas força versus deslocamento para os modelos com solicitação do tipo cv1 e cv2, respectivamente. 


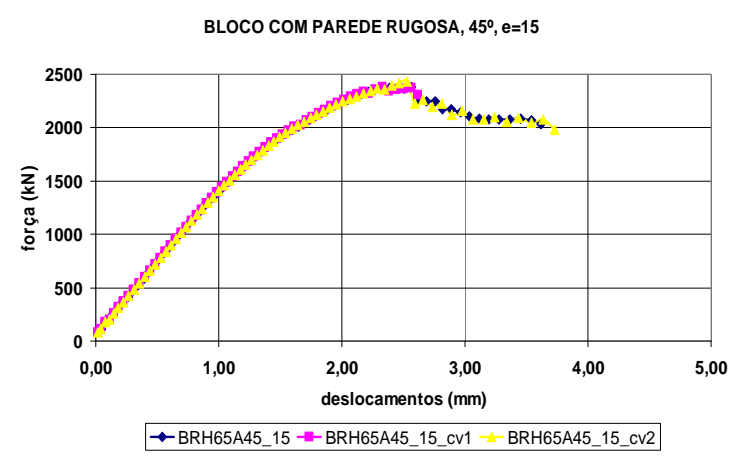

(a)

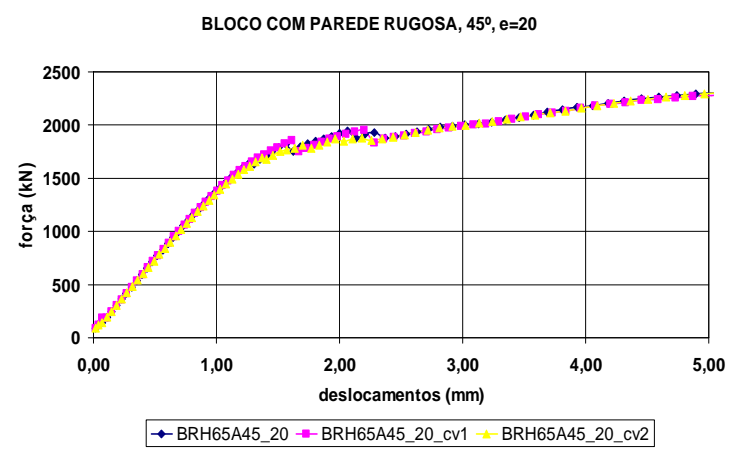

(b)

Figura 5. 16 - Comparação de blocos com e sem viga de travamento

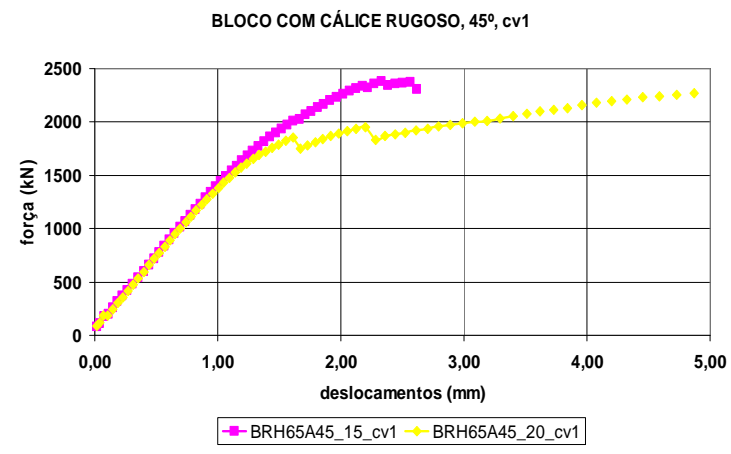

(a)

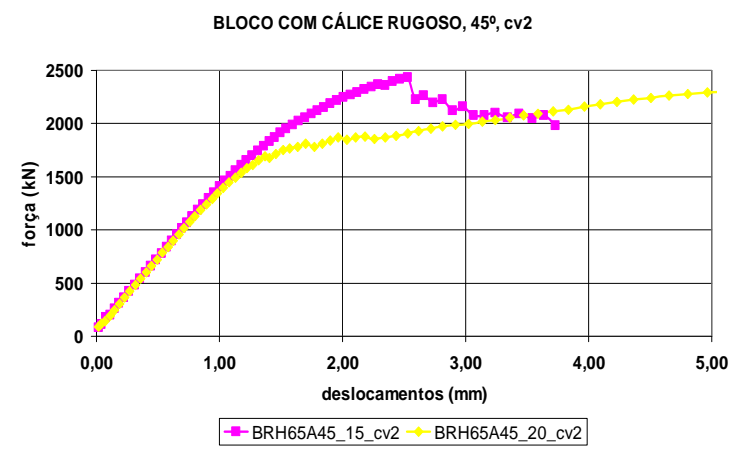

(b)

Figura 5. 17 - Blocos de parede rugosa com viga de travamento

\subsubsection{Blocos com parede lisa, $\theta=\mathbf{4 5}^{\circ}$}

Assim como nos modelos de parede rugosa, a presença de viga de travamento não influenciou no comportamento do bloco com conformação da parede lisa. Os resultados obtidos para os modelos BLH75A45_15, BLH75A45_15_cv1 e BLH75A45_15_cv2 foram semelhantes aos apresentados em 5.3.2.1, ou seja, independente da intensidade de solicitação na viga, a curva força versus deslocamento apresentou a mesma tendência de comportamento para os blocos com e sem viga de travamento, conforme Figura 5.18-a e 5.18-b.

No que diz respeito ao comportamento dos blocos relativos à espessura da parede do cálice, mais uma vez os blocos com espessura da parede igual a $15 \mathrm{~cm}$ apresentaram valor de força última superior aos blocos com espessura igual a $20 \mathrm{~cm}$. Esses resultados podem ser observados nos gráficos das Figuras 5.19-a e 5.19-b. 


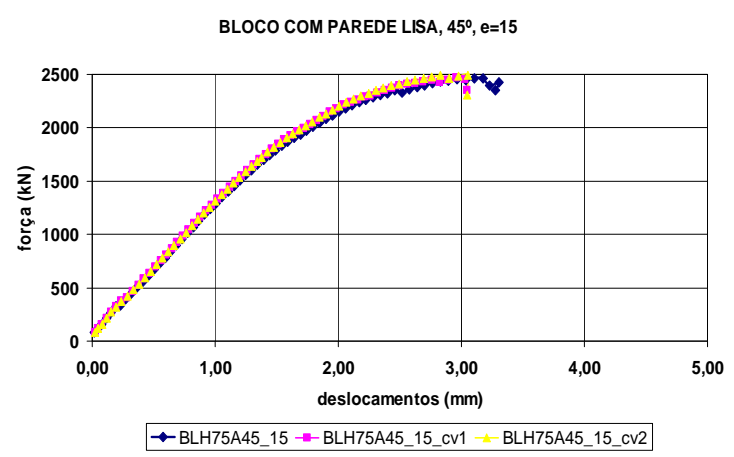

(a)

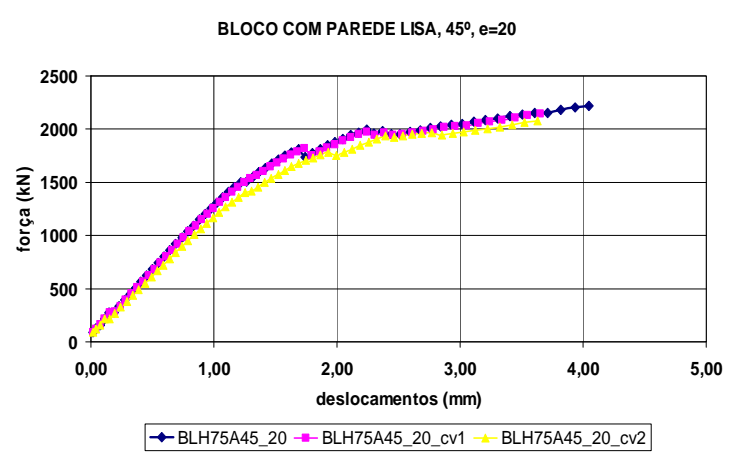

(b)

Figura 5. 18 - Comparação de blocos com e sem viga de travamento

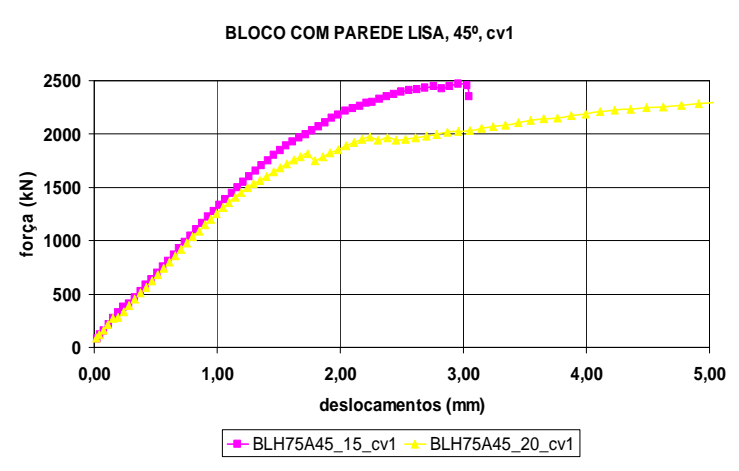

(a)

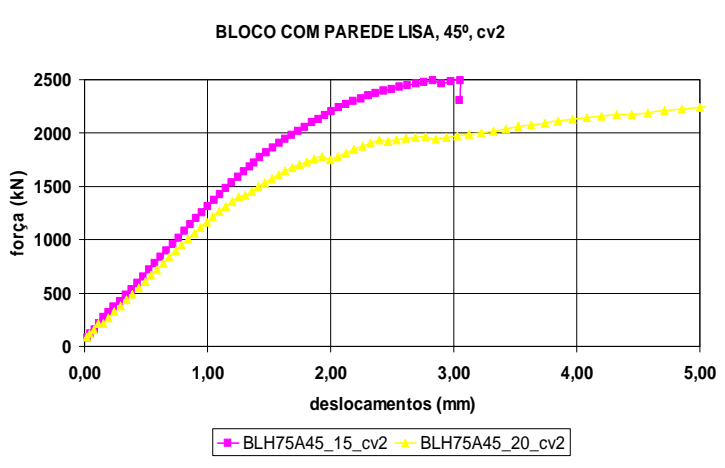

(b)

Figura 5. 19 - Blocos de parede lisa com viga de travamento

\subsubsection{Blocos com parede rugosa, $\theta=\mathbf{5 5}^{\circ}$}

Diferente do que ocorreu nos blocos de parede rugosa com ângulo de inclinação das bielas igual a $45^{\circ}$, os modelos com inclinação de $55^{\circ}$ apresentaram diminuição na força última mediante presença da viga de travamento.

Nessa ocasião, verifica-se que para os modelos com espessura da parede igual a $15 \mathrm{~cm}$, houve redução da carga última da ordem de $7 \%$ comparados com o modelo sem viga de travamento, enquanto para os modelos com espessura da parede igual a $20 \mathrm{~cm}$, a redução foi da ordem de $14 \%$.

Ainda no caso de paredes com espessura de $20 \mathrm{~cm}$, verifica-se que a curva força versus deslocamento do modelo BRH65A55_20 apresenta uma acomodação ao atingir uma força próxima dos $2450 \mathrm{kN}$ para um deslocamento de $1,2 \mathrm{~mm}$. A partir de então a força mantém-se próxima desse valor, e os deslocamentos seguem aumentando até atingir 1,5 $\mathrm{mm}$, quando 
então o modelo volta a ganhar capacidade resistente, atingindo o valor de força última próximo dos $2800 \mathrm{kN}$.

A curva força versus deslocamento dos modelos com espessura da parede igual a $15 \mathrm{~cm}$ podem ser observados na Figura 5.20-a, enquanto que as do modelo com espessura igual a 20 $\mathrm{cm}$ aparecem na Figura 5.20-b. Comparando apenas os modelos com a presença de viga, mais uma vez os modelos com espessura da parede igual a $15 \mathrm{~cm}$ apresentaram valor de força última superior aos modelos com espessura igual a $20 \mathrm{~cm}$, e podem ser observados nas Figuras 5.21-a e 5.21-b.

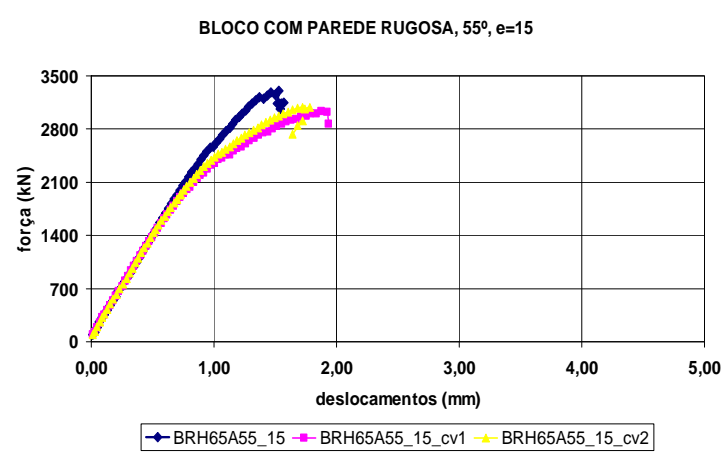

(a)

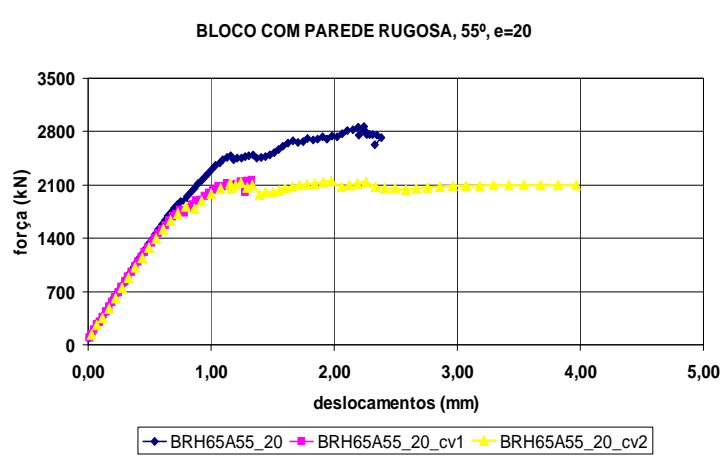

(b)

Figura 5. 20 - Comparação de blocos com e sem viga de travamento

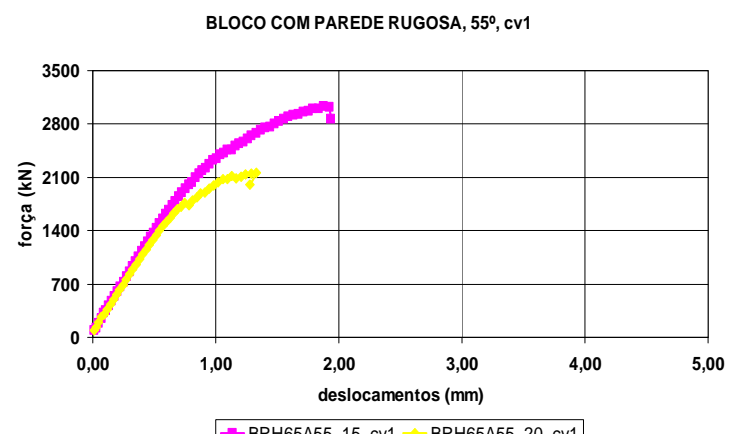

- -BRH65A55_15_cv1 - BRH65A55_20_cv1

(a)

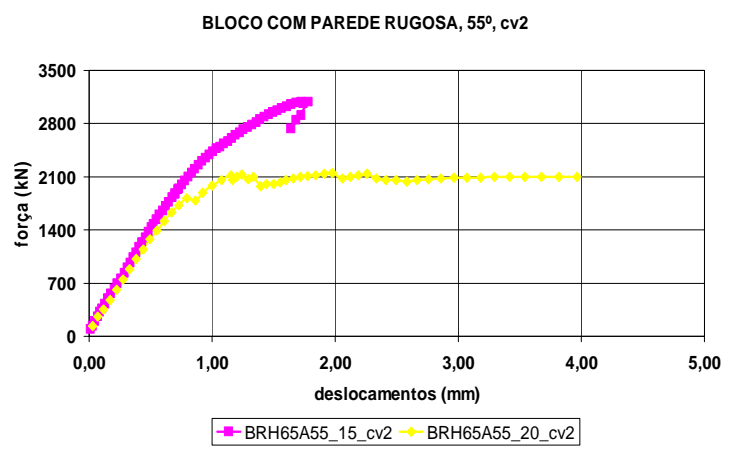

(b)

Figura 5. 21 - Blocos de parede rugosa com viga de travamento 


\subsubsection{Blocos com parede lisa, $\theta=\mathbf{5 5}^{\circ}$}

Os resultados dos modelos de blocos com parede lisa e ângulo de inclinação da biela igual a $55^{\circ}$ foram idênticos aos resultados obtidos para os modelos com inclinação da biela de $45^{\circ}$, e anteriormente apresentados em 5.3.2.2.

Os modelos BLH75A55_15, BLH75A55_15_cv1 e BLH75A55_15_cv2, assim como os modelos BLH75A55_20, BLH75A55_20_cv1 e BLH75A55_20_cv2 apresentaram a mesma tendência de comportamento na obtenção da curva força versus deslocamento. Ou seja, a viga de travamento não alterou de modo significativo o comportamento do bloco sobre duas estacas, conforme Figuras 5.22-a e 5.22-b.

Em relação ao comportamento dos blocos mediante a presença da viga de travamento, os modelos com espessura da parede igual a $15 \mathrm{~cm}$ apresentaram valor de força última superior ao apresentado pelos modelos com espessura da parede igual a $20 \mathrm{~cm}$. Esse comportamento foi verificado em todas as situações estudadas em que houve a presença da viga de travamento, e pode ser observado nas Figuras 5.23-a e 5.23-b.

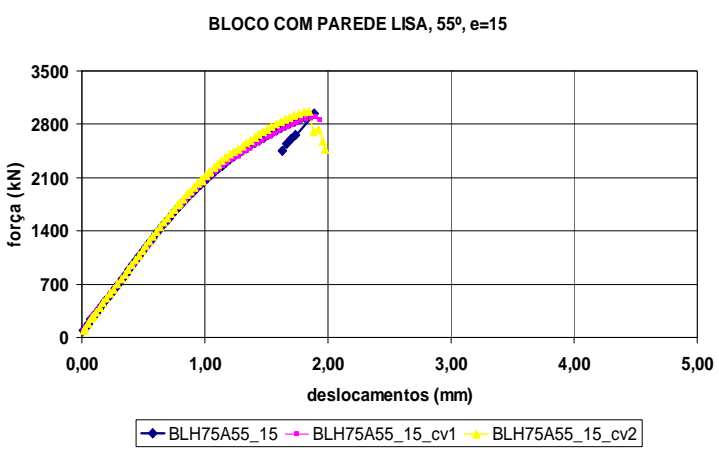

(a)

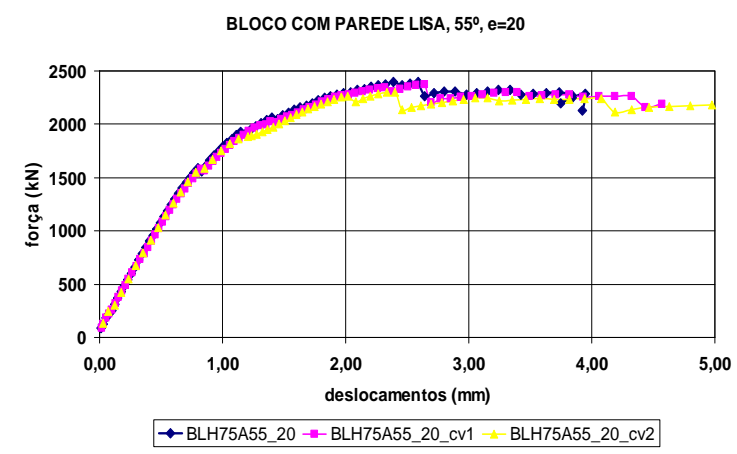

(b)

Figura 5. 22 - Comparação de blocos com e sem viga de travamento 


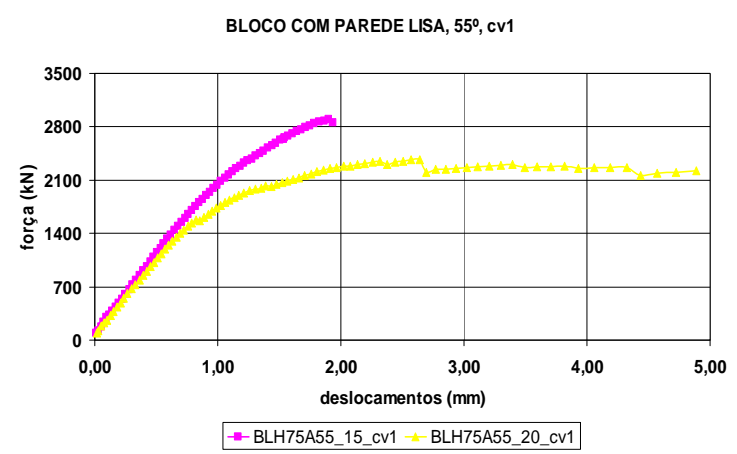

(a)

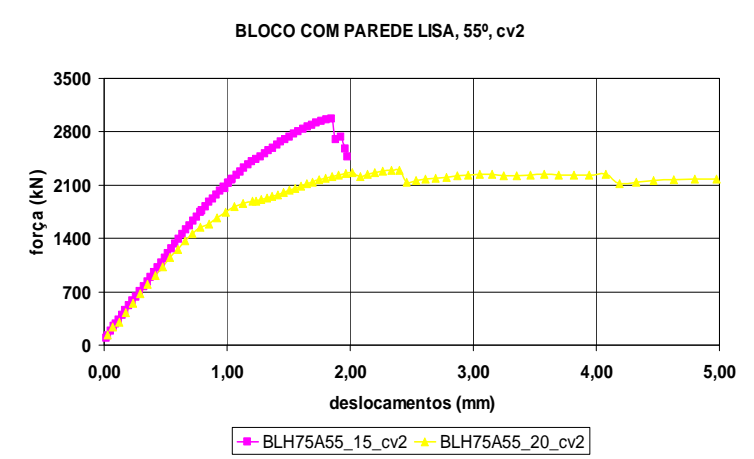

(b)

Figura 5. 23 - Blocos de parede lisa com viga de travamento

\subsection{Fluxo de tensões nas bielas}

A distribuição do fluxo de tensões permitiu observar a geometria das bielas de compressão. Constatou-se que nos blocos com configuração da parede lisa, assim como nos blocos com parede rugosa, a formação da biela ocorre a partir do início do comprimento de embutimento do pilar no bloco, sendo que nos modelos com parede rugosa, houve uma maior distribuição das tensões de compressão na face superior do bloco. Essa diferença pode ser atribuída ao uso dos elementos de interface apenas nos blocos com parede lisa.

Apesar de o resultado ter se repetido em todos os modelos avaliados, ainda é necessário avançar nesse estudo. O ponto de início da biela existente entre o pilar e a estaca é ponto chave no dimensionamento de blocos com cálice embutido. Recomenda-se em pesquisas futuras a confirmação desses resultados por meio de ensaios em laboratório.

Outro aspecto constatado nas análises é que existe um grande fluxo de tensões de compressão na região inferior do bloco em contato com o pilar. Esse fluxo comprova que essa região está sujeita a ocorrência de punção, que por sua vez pode ocorrer caso não seja prevista no dimensionamento do bloco, principalmente quando a distância entre o fundo do pilar e do bloco for pequena. No presente trabalho essa distância foi mantida constante em todos os 
modelos, e por isso a região não foi alvo de estudo minucioso, merecendo ser estudada com mais atenção.

As Figuras 5.24 à 5.27 mostram o fluxo de tensões de compressão nos modelos com parede lisa, enquanto que as Figuras 5.28 à 5.31 mostram o fluxo para os modelos com parede rugosa. Os modelos estão apresentados na seguinte ordem: modelo sem viga de travamento, com viga de travamento e ação do tipo cvle com viga de travamento e ação do tipo cv2.
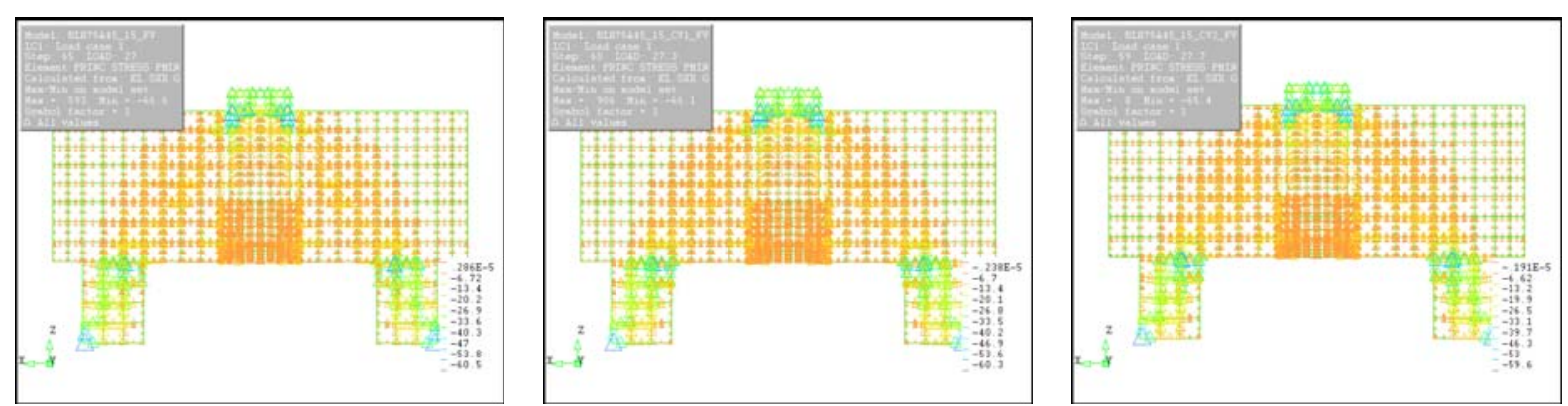

Figura 5. 24 - Fluxo de tensões nos modelos BLH75A45_15
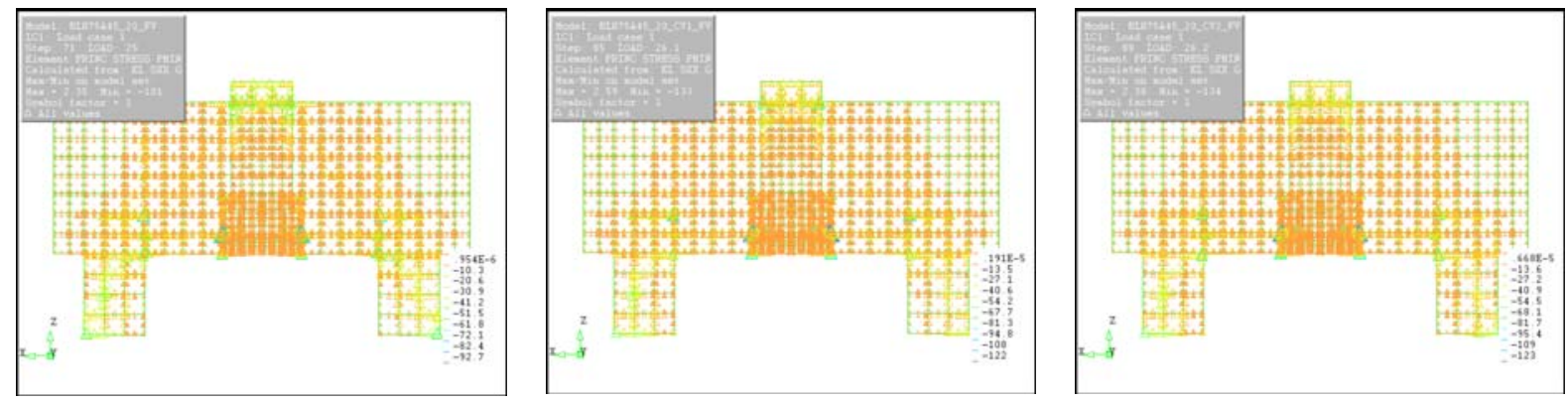

Figura 5. 25 - Fluxo de tensões nos modelos BLH75A45_20
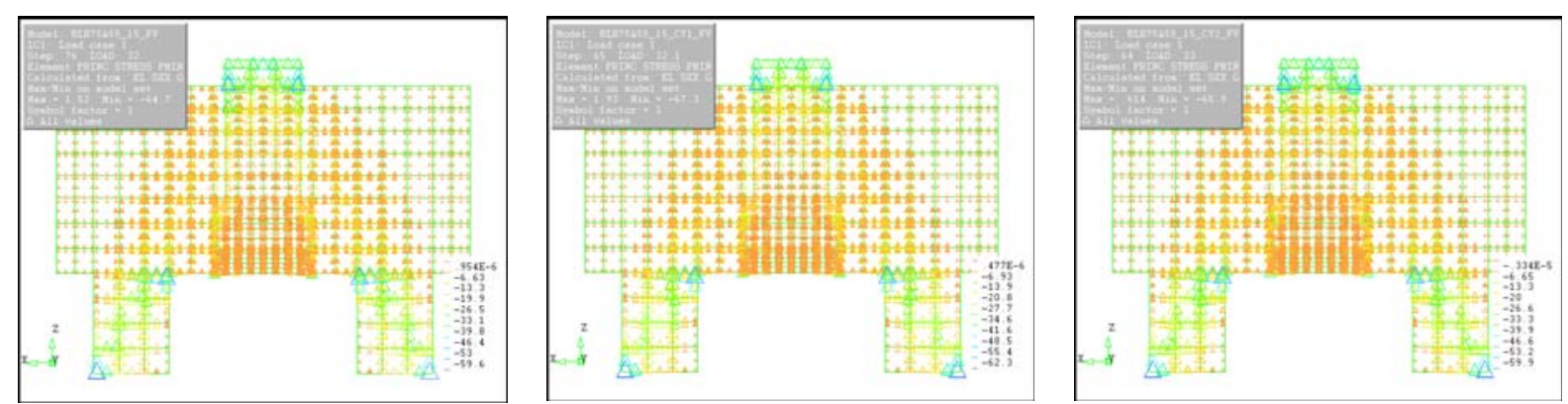

Figura 5. 26 - Fluxo de tensões nos modelos BLH75A55_15 

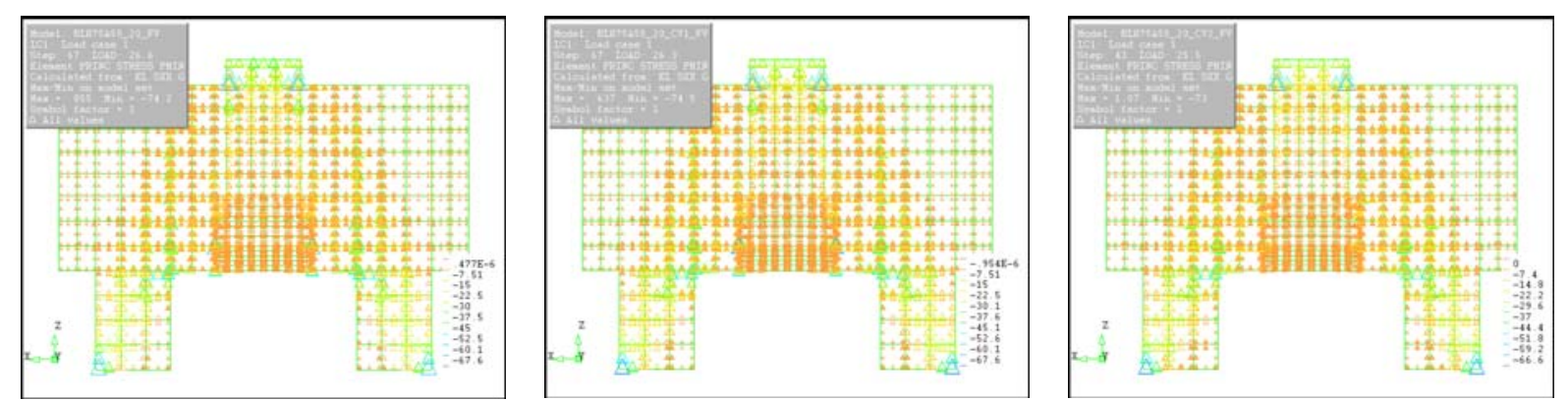

Figura 5. 27 - Fluxo de tensões nos modelos BLH75A55_20
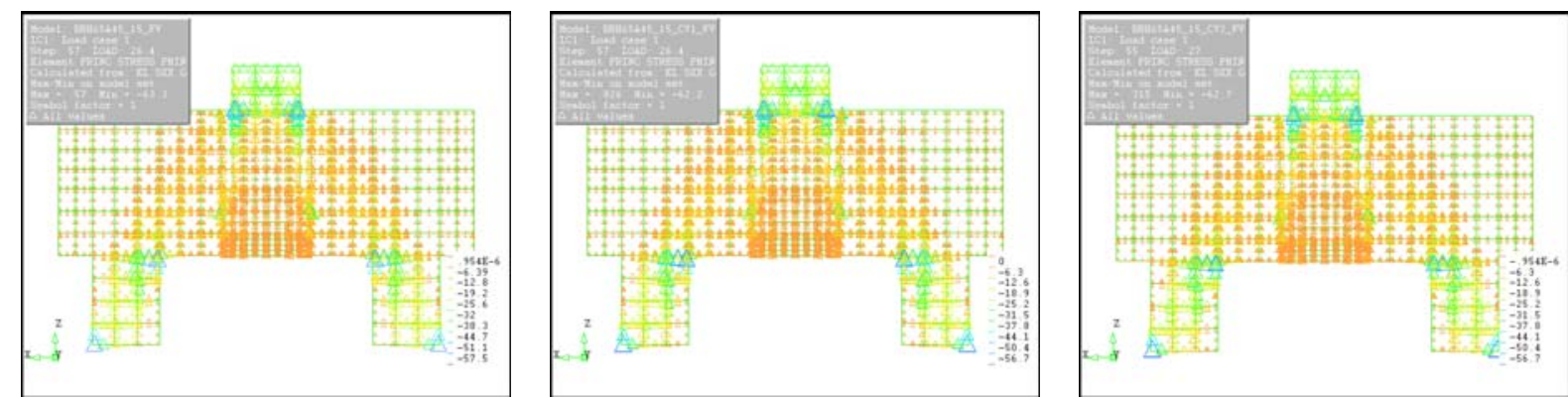

Figura 5. 28 - Fluxo de tensões nos modelos BRH65A45_15
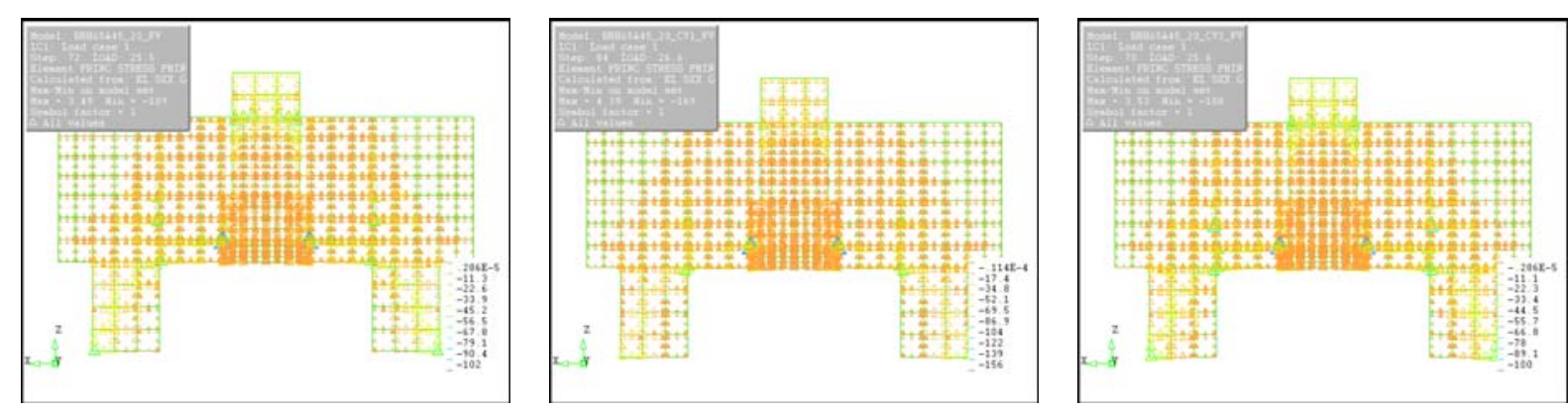

Figura 5. 29 - Fluxo de tensões nos modelos BRH65A45_20
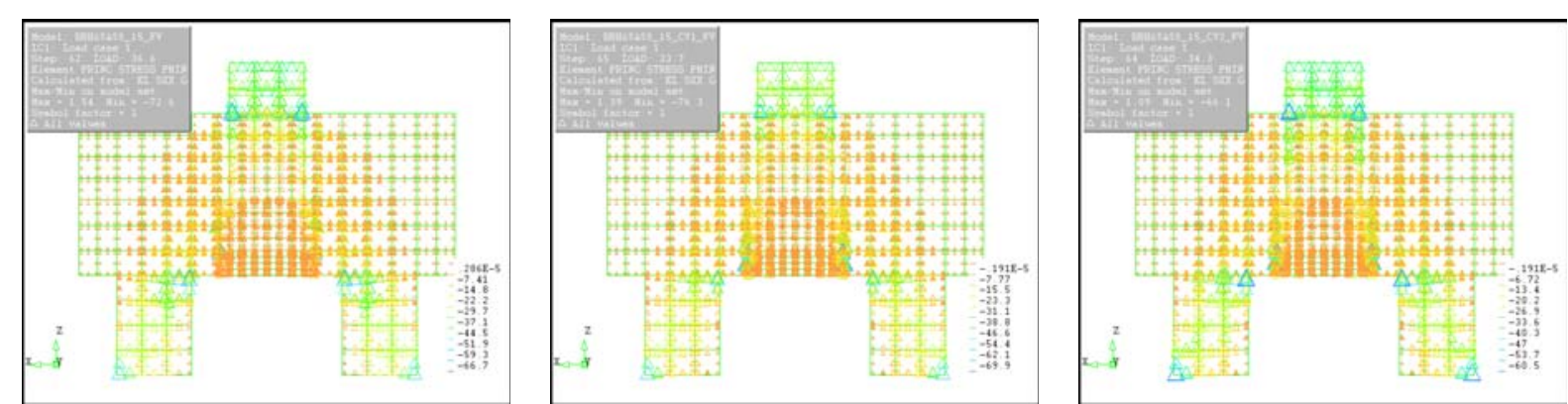

Figura 5. 30 - Fluxo de tensões nos modelos BRH65A55_15 

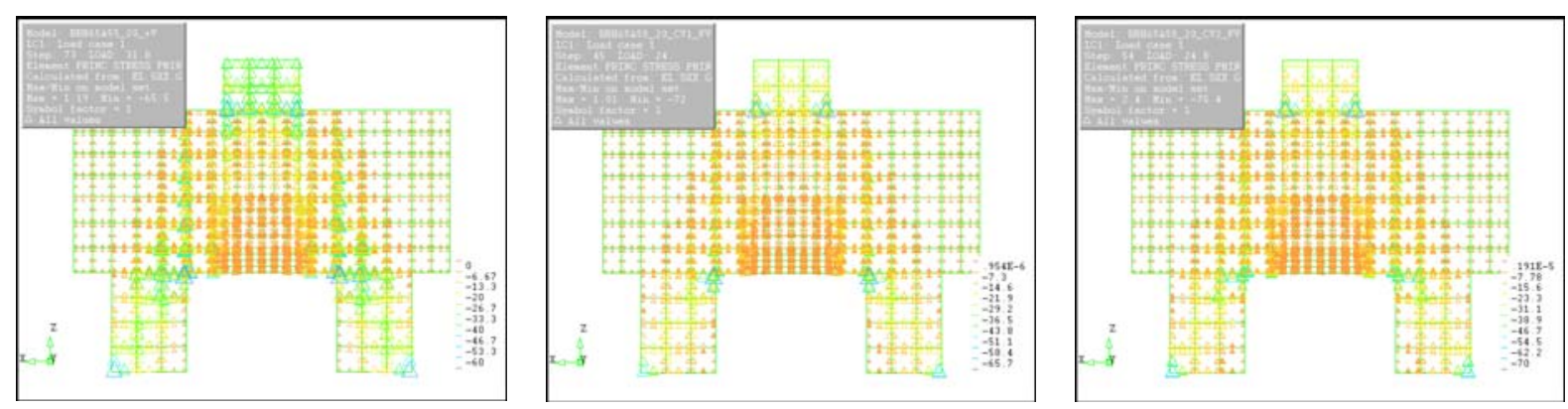

Figura 5. 31 - Fluxo de tensões nos modelos BRH65A55_20

\subsection{Tensões principais}

Neste item é apresentada a distribuição das tensões principais de tração e compressão nos blocos estudados, obtidas por meio da análise numérica. Nos diversos modelos analisados, é possível perceber a formação da biela de compressão a partir do encontro do pilar com o bloco. Observa-se por meio das Figuras 5.32 à 5.39 que a distribuição de tensões nas estacas não é uniforme, estando a biela localizada no meio da seção e atravessando a estaca em direção a face mais externa da mesma.

Essa distribuição de tensões difere da observada por Delalibera (2006) em resultados numéricos, na qual o autor constatou que os maiores valores de tensão de compressão encontram-se na face interna da estaca, confirmando a hipóteses de que a força de reação não está posicionada no centro geométrico da estaca. Naquela ocasião, o autor propôs que a força na estaca seja aplicada a uma distância equivalente a um quarto de uma das faces da estaca.

Atribui-se a diferença encontrada na distribuição de tensões nas estacas às condições de contorno adotadas nos modelos. Delalibera (2006) restringiu apenas as translações na direção vertical do bloco. Em pesquisa de pós-doutorado, Delalibera (2009) passou a restringir as translações nas direções x, y e z, restrições essas adotadas no presente trabalho. A unidade das tensões das figuras a seguir é o Megapascal. 

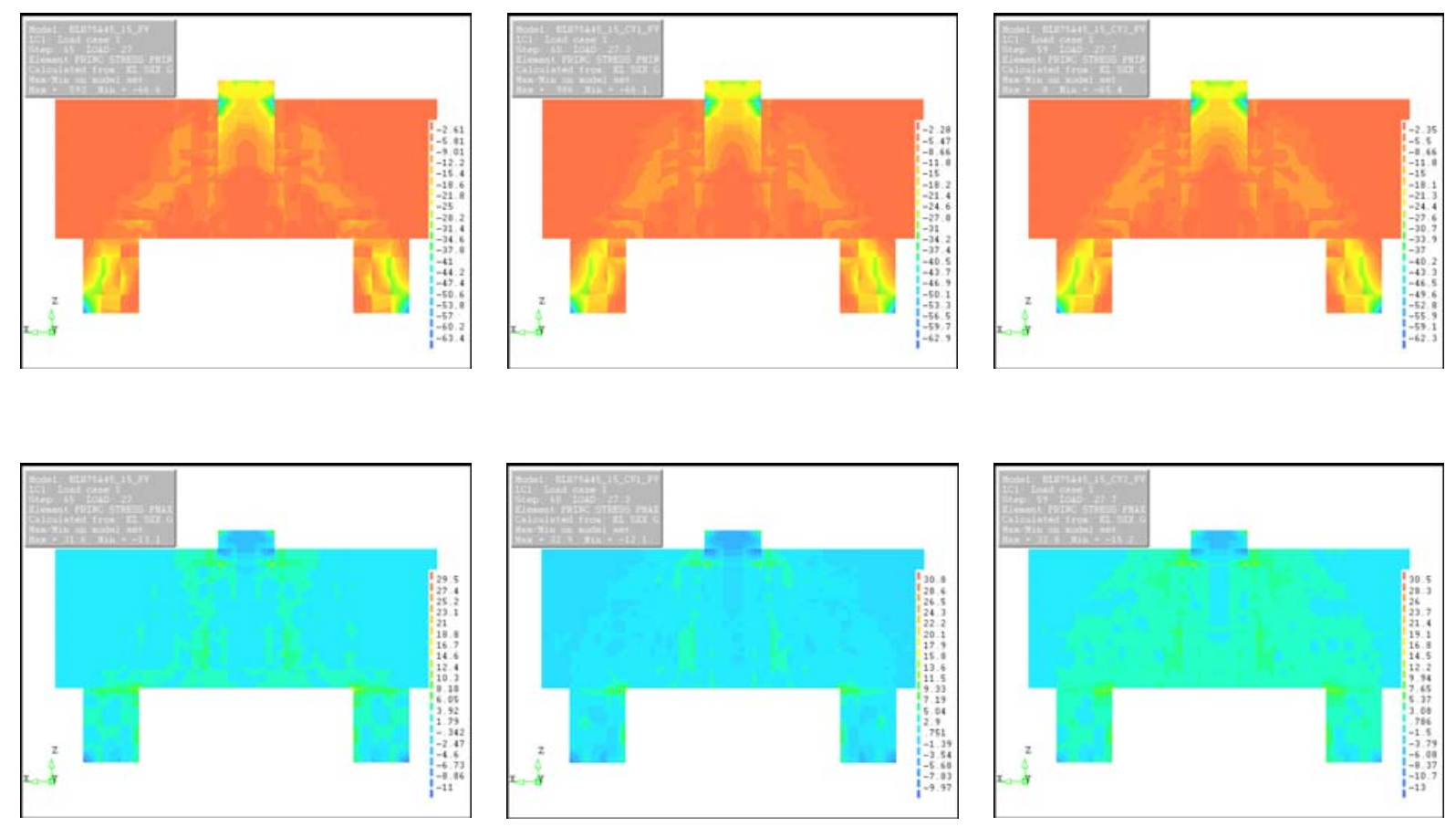

Figura 5. 32 - Tensões principais de compressão e tração nos modelos BLH75A45_15
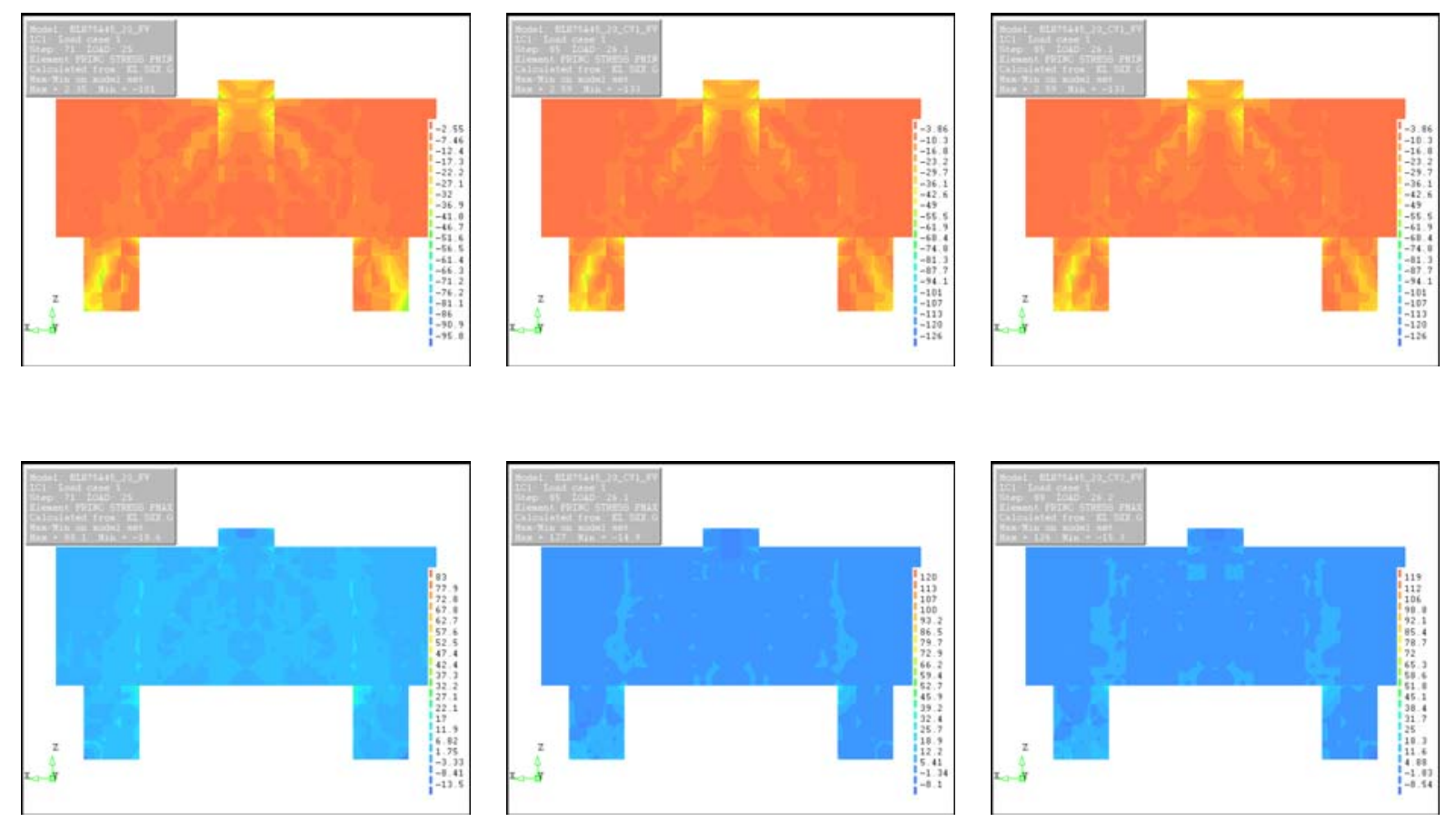

Figura 5. 33 - Tensões principais de compressão e tração nos modelos BLH75A45_20 

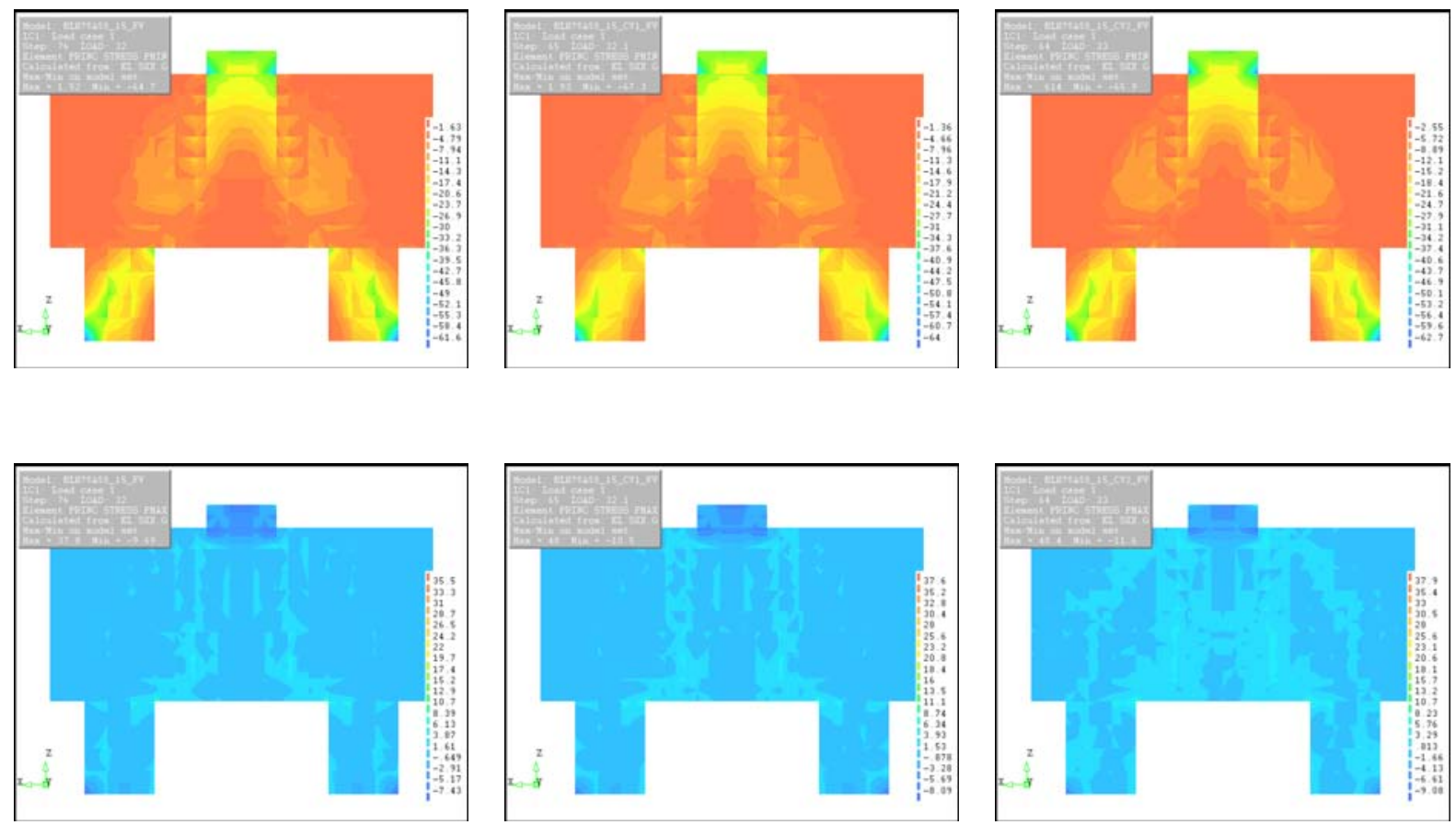

Figura 5.34 - Tensões principais de compressão e tração nos modelos BLH75A55_15
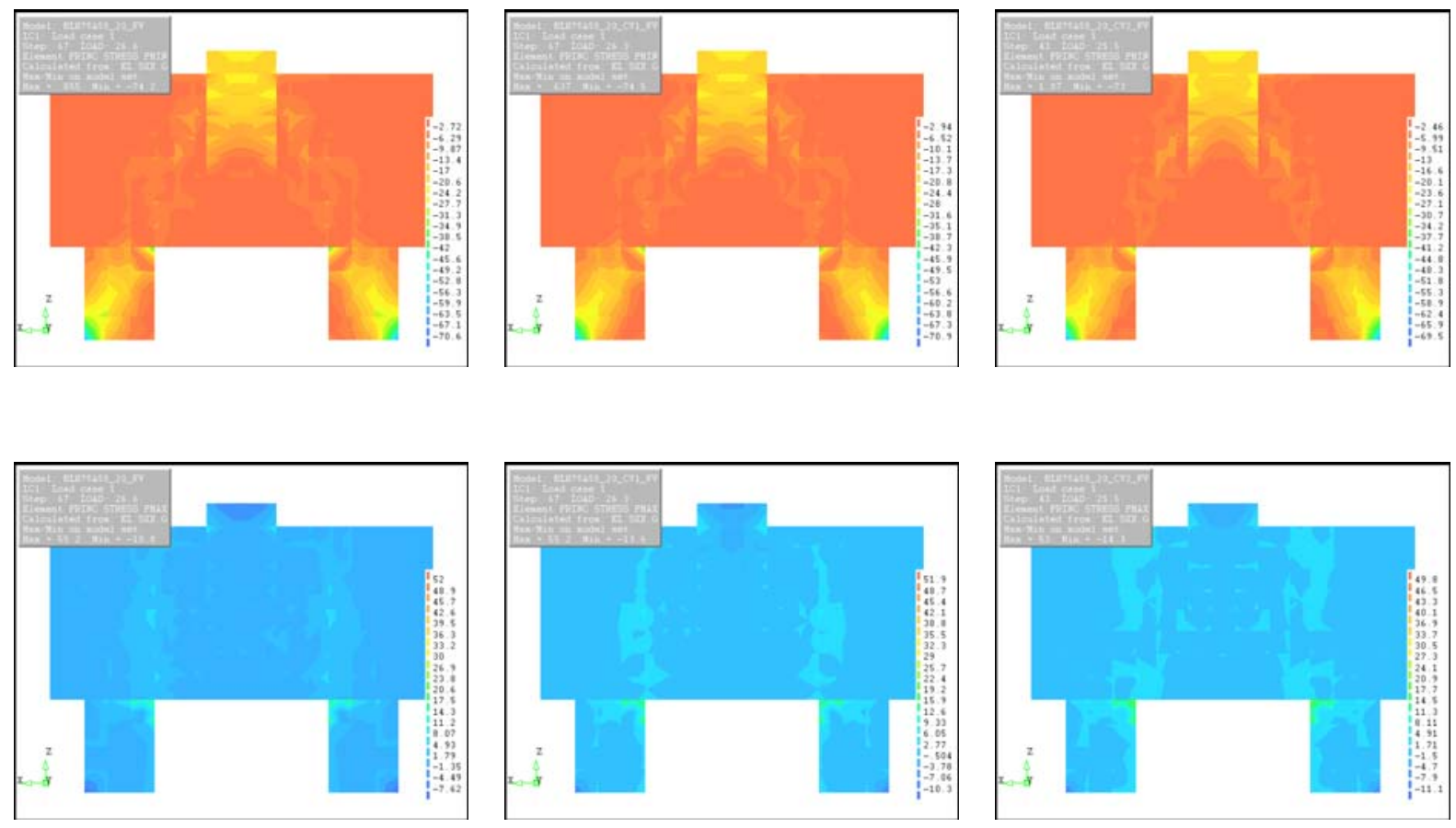

Figura 5. 35 - Tensões principais de compressão e tração nos modelos BLH75A55 20 

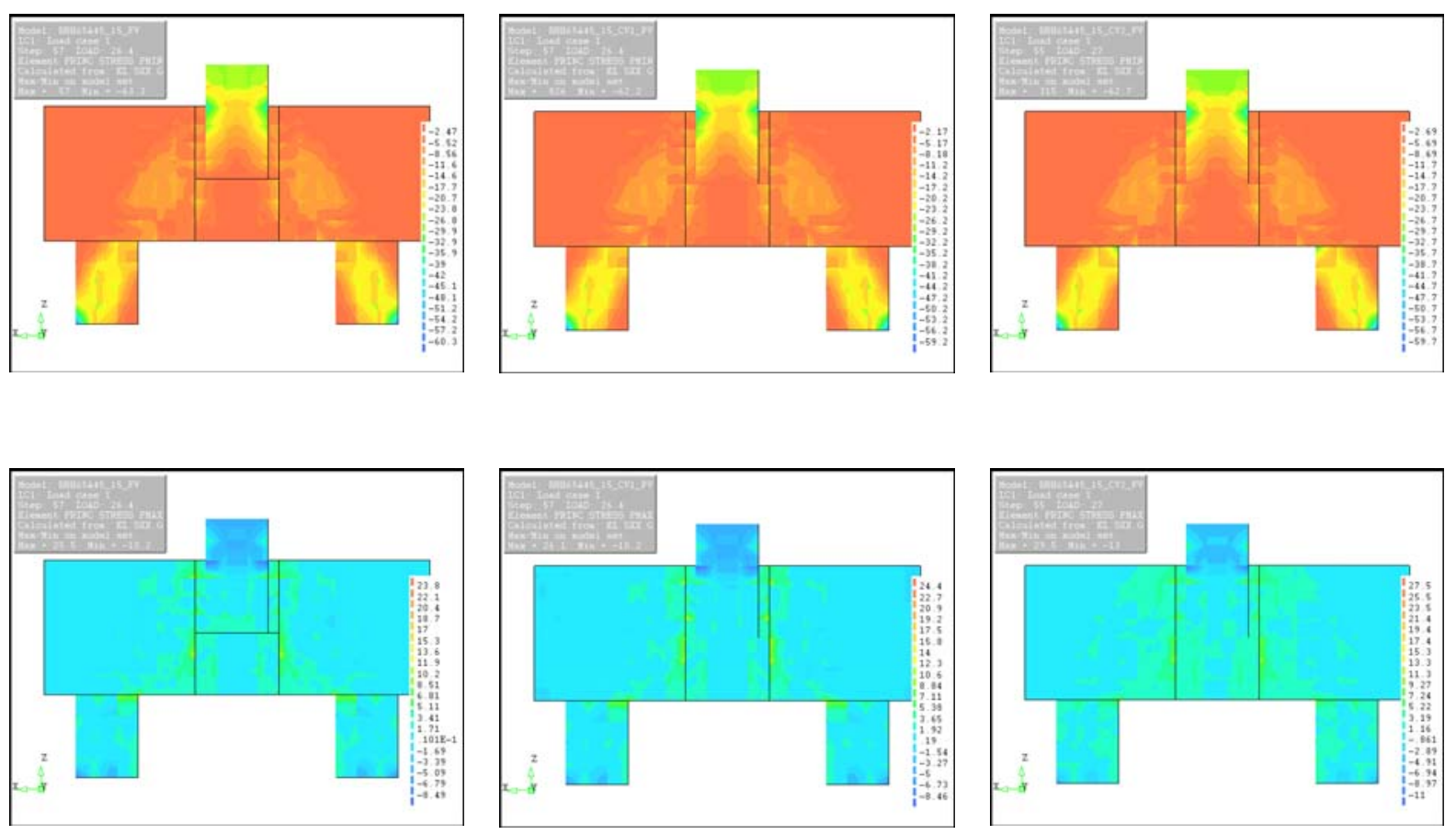

Figura 5.36 - Tensões principais de compressão e tração nos modelos BRH65A45_15
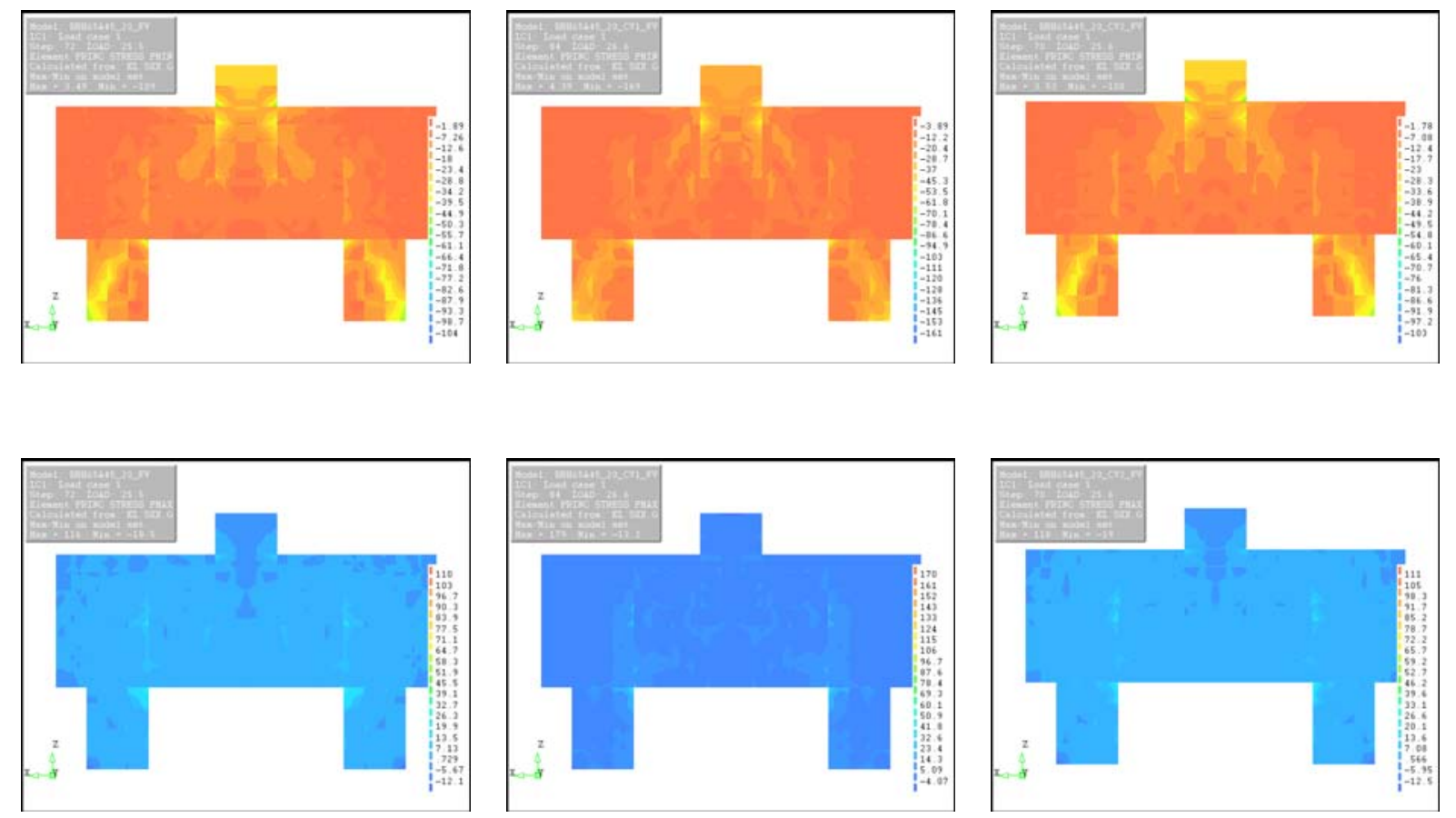

Figura 5.37 -Tensões principais de compressão e tração nos modelos BRH65A45_20 

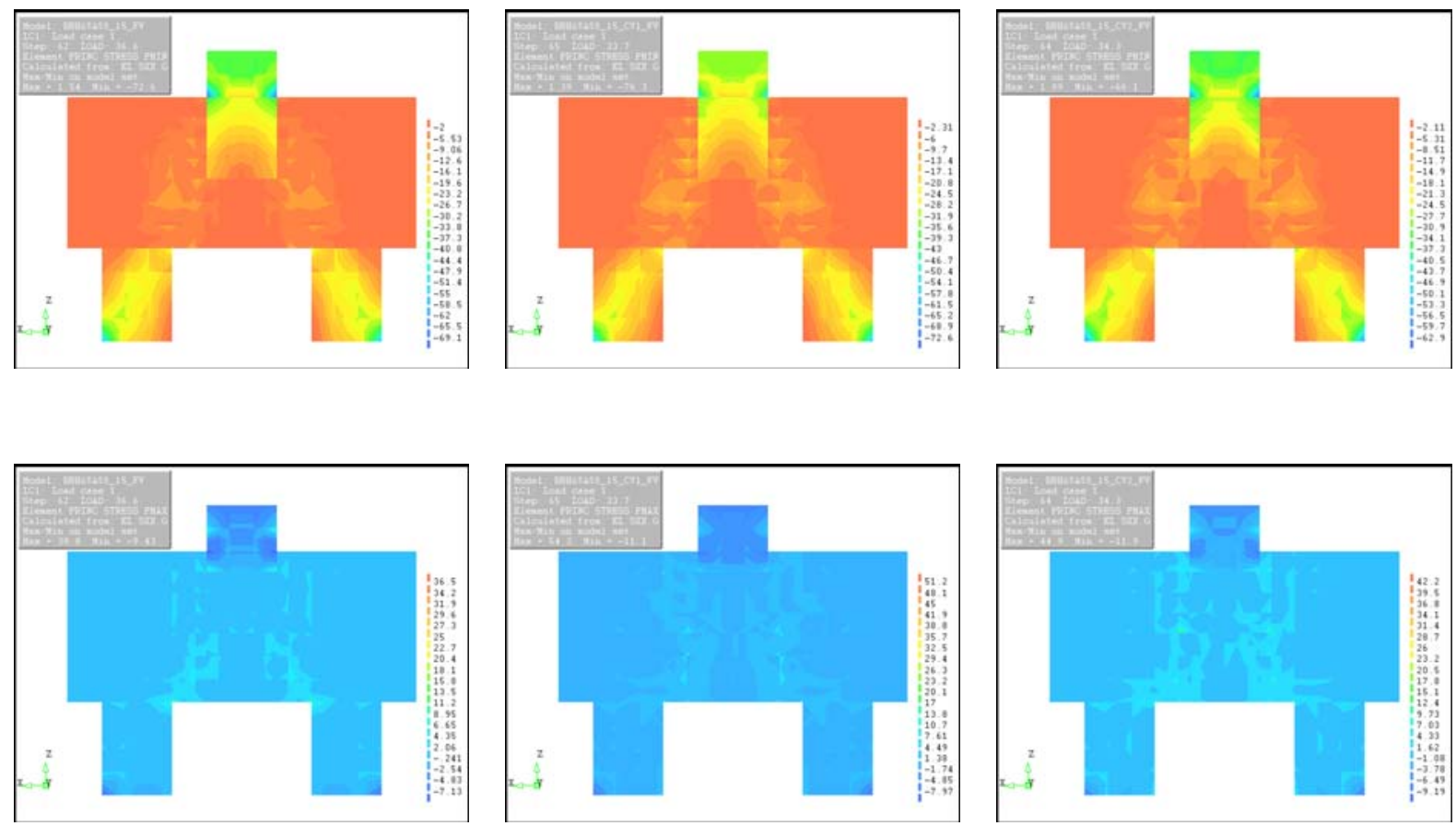

Figura 5. 38 -Tensões principais de compressão e tração nos modelos BRH65A55_15
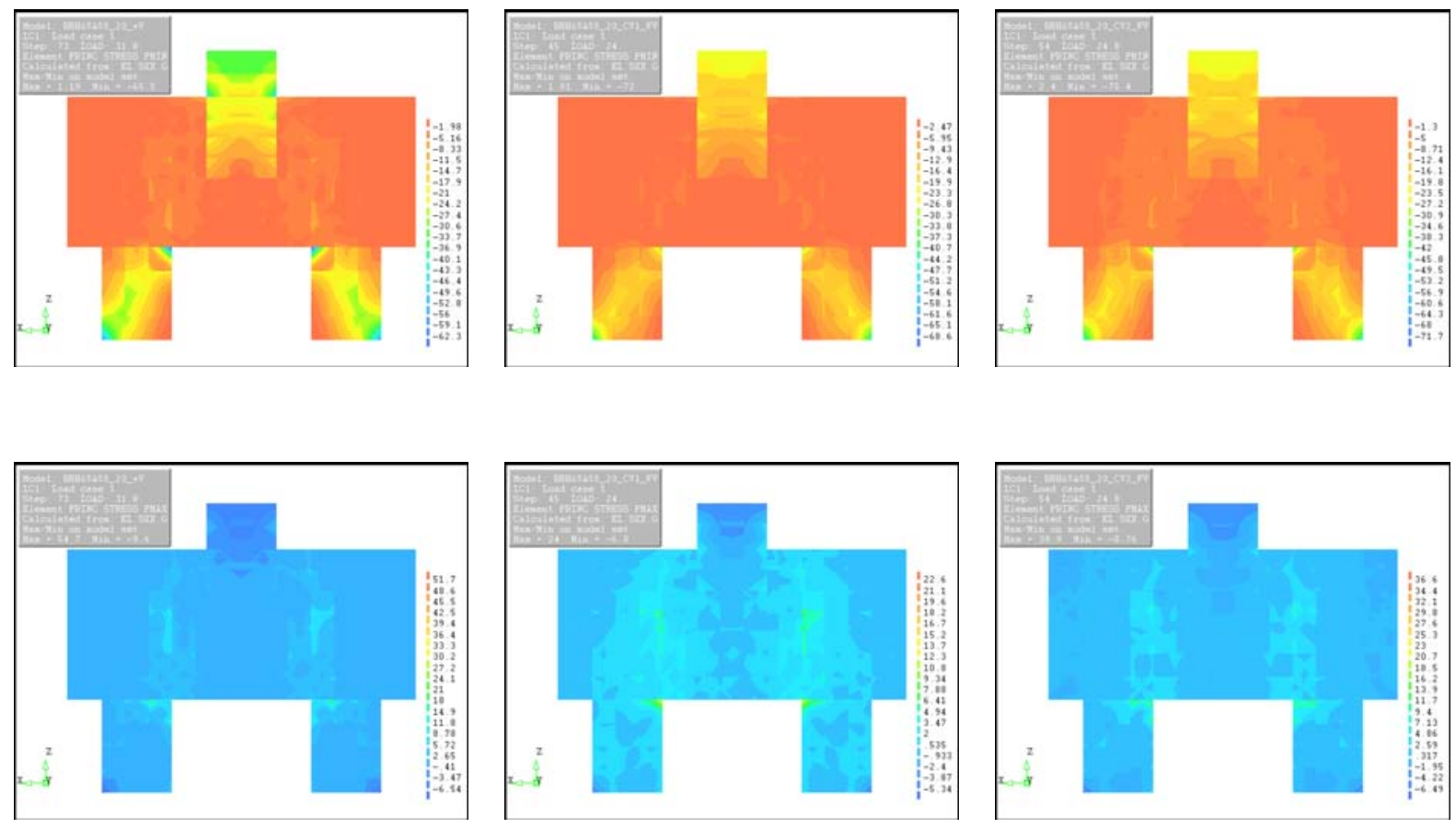

Figura 5. 39 -Tensões principais de compressão e tração nos modelos BRH65A55_20 


\subsection{Tensões nas barras das armaduras}

Neste item são apresentados os resultados de tensões em algumas barras das armaduras dos modelos analisados. De um modo geral, os valores de tensões nas barras das armaduras foram coerentes com os valores obtidos analiticamente. Observa-se também que algumas barras apresentaram valor de tensão superior ao valor adotado para a resistência ao escoamento do aço. Mesmo com inúmeras tentativas de solucionar esse problema, não foi possível encontrar um modelo em que não houvesse pontos localizados com valor de tensão

superior à resistência ao escoamento. É possível que esse problema tenha ocorrido em virtude do modo como o programa Diana trata os elementos do tipo reinforcements.

Analisando as barras da armadura principal do tirante, observa-se que os maiores valores de tensão ocorreram na seção do meio do bloco. Constata-se também que nas seções próximas da estaca, houve uma redução significativa dos valores de tensão, fato provocado pelo efeito benéfico da biela de compressão existente nessa região. Ainda em relação às barras da armadura principal do tirante, observa-se que os valores de deformação foram relativamente pequenos nas seções entre a face mais afastada da estaca e a face do bloco, justificando assim a ausência dos ganchos nos modelos analisados. Resultados semelhantes para as barras da armadura principal do tirante foram obtidos por Delalibera (2006).

Em relação à armadura de costura adotada no meio do bloco, observam-se valores de tensões maiores na região que atravessa a biela comprimida. O mesmo ocorreu com os estribos horizontais do bloco presente nessa região.

Em relação ao cálice, percebeu-se que as barras das armaduras horizontais principais e secundárias foram bastante solicitadas, principalmente as secundárias quando da existência da viga de travamento. Tratando das barras das armaduras verticais, observa-se que as barras das 
armaduras secundárias auxiliaram na ancoragem da armadura da viga de travamento no bloco, absorvendo boa parte das tensões provenientes da viga.

As Figuras $\mathbf{5 . 4 0}$ a $\mathbf{5 . 5 5}$ mostram as tensões nas barras das armaduras no último incremento de força dos modelos com presença de viga de travamento: BLH75A45_15, BLH75A45_20, BLH75A55_15, BLH75A55_20, BRH65A45_15, BRH65A45_20, BRH65A55_15 e BRH65A55_20. Por causa da grande quantidade de figuras, optou-se por não mostrar as tensões nas barras das armaduras dos modelos sem viga de travamento, podendo-se observar esses valores na tabela 5.5. A unidade das tensões é o Megapascal.
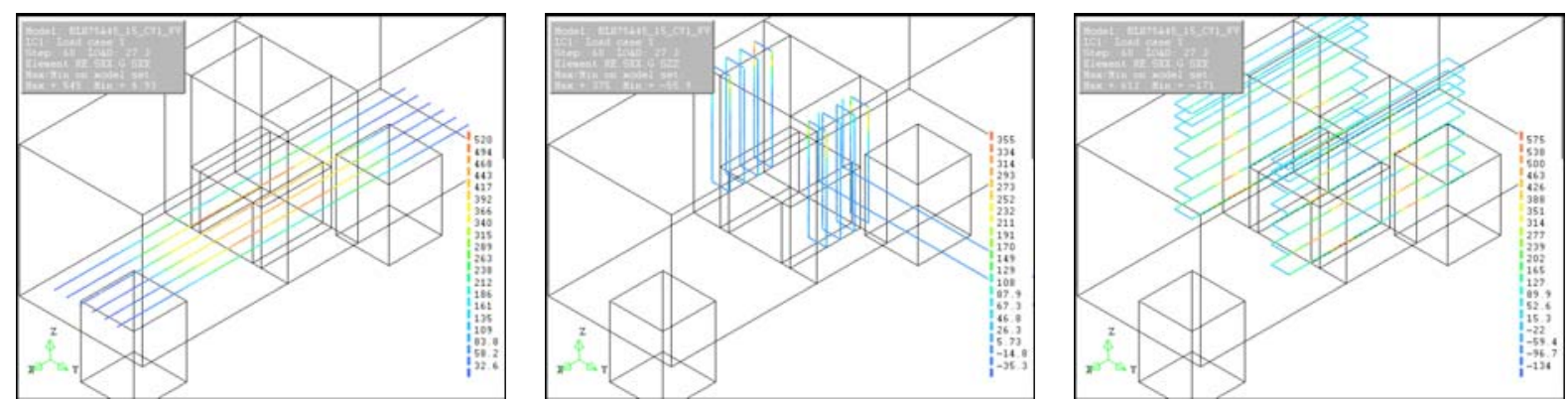

Figura 5. 40 - BLH75A45_15_cv1
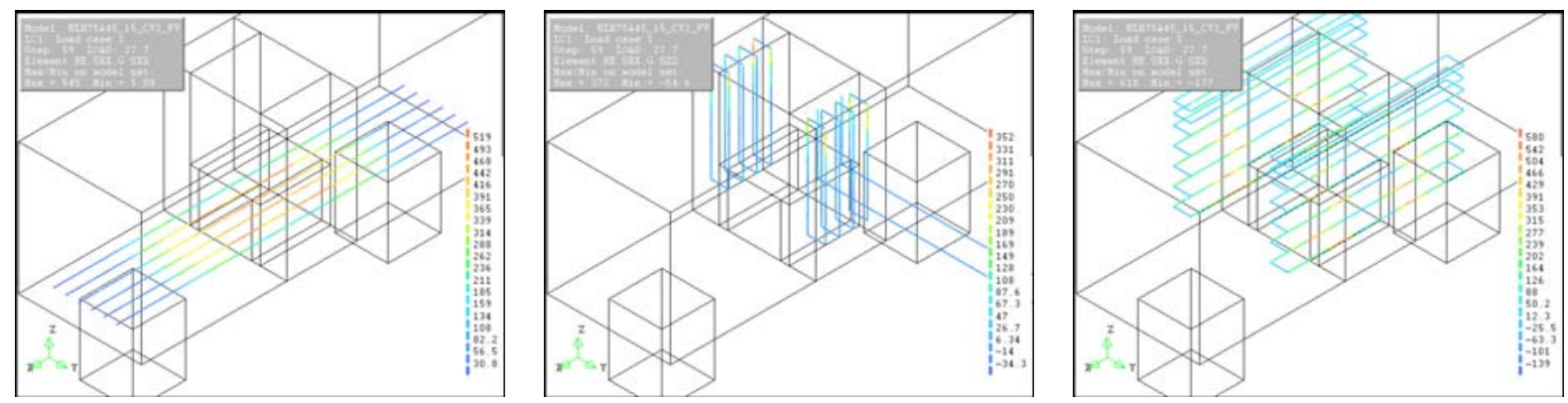

Figura 5. 41 - BLH75A45_15_cv2
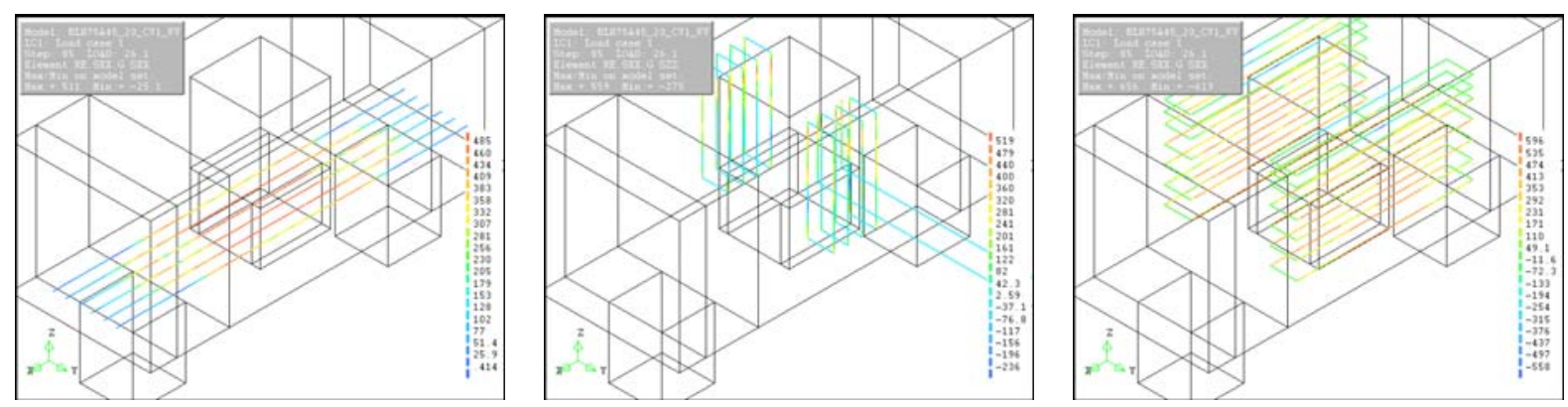

Figura 5. 42 - BLH7545_20_cv1 

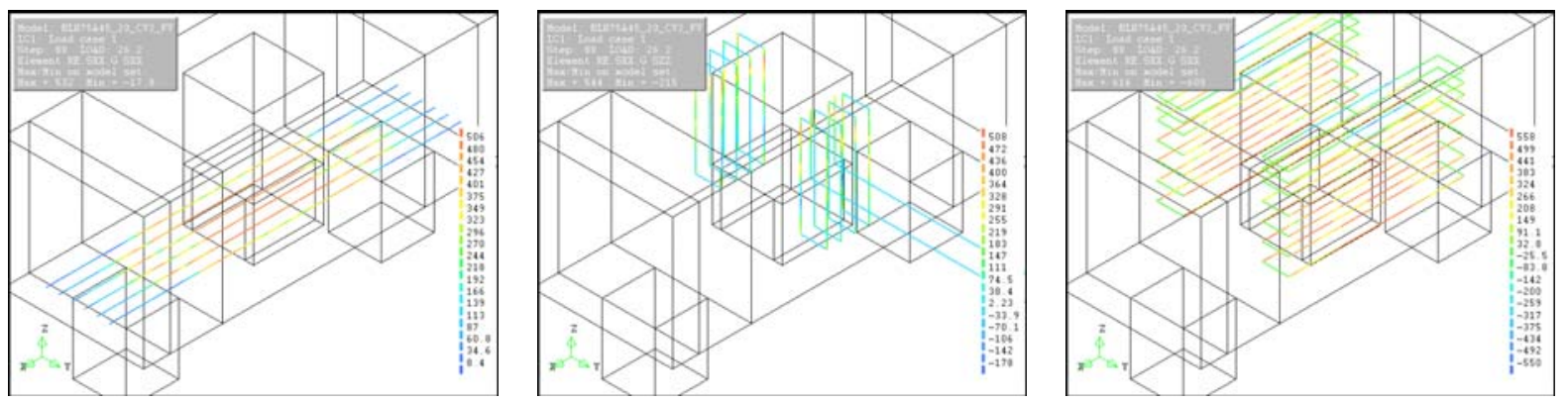

Figura 5. 43 - BLH75A45_20_cv2
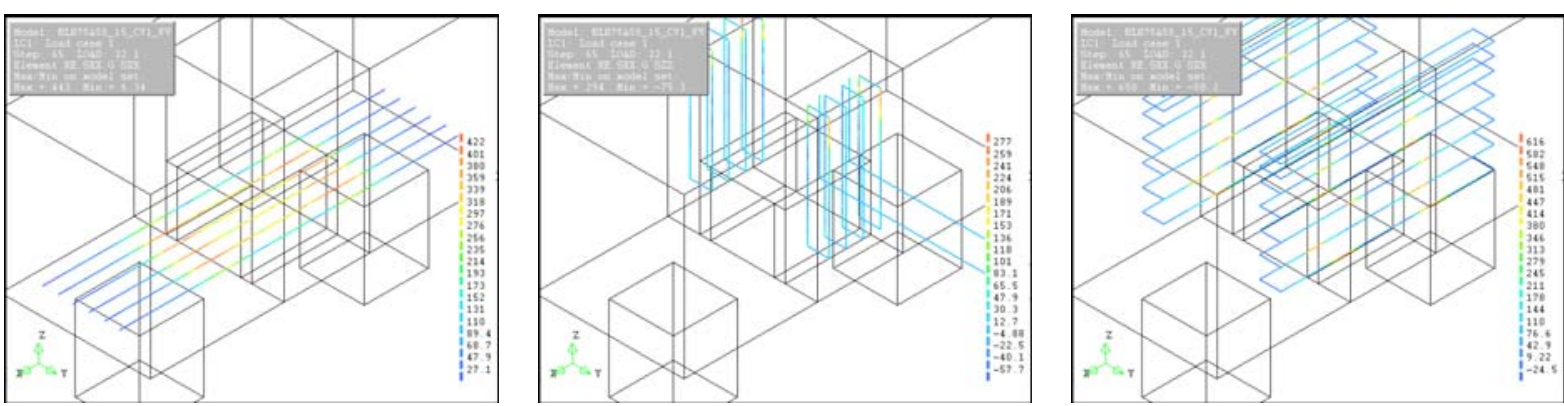

Figura 5. 44 - BLH75A55_15_cv1
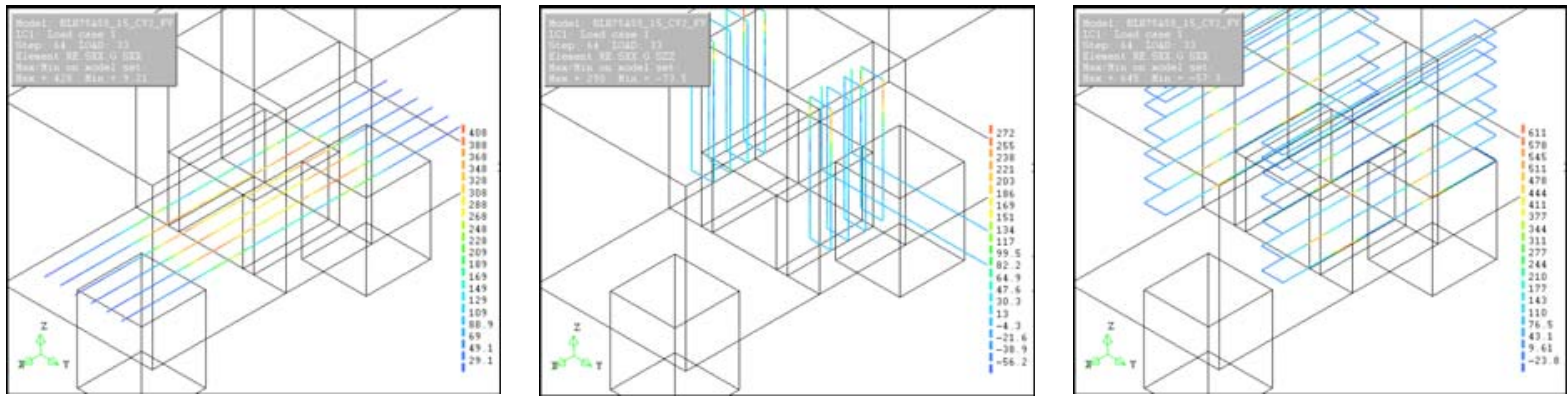

Figura 5. 45 - BLH75A55_15_cv2
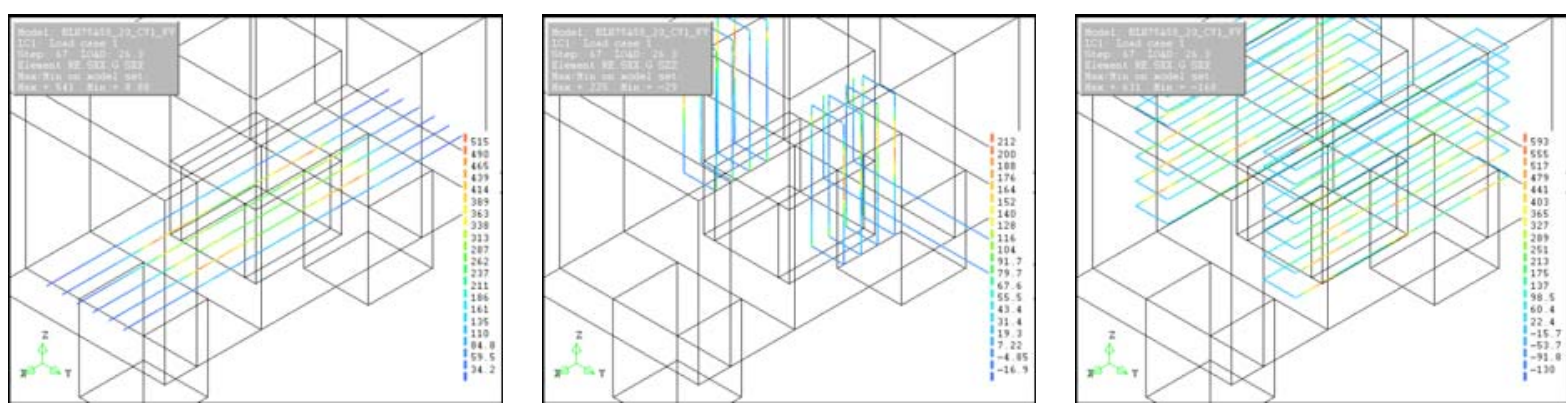

Figura 5. 46 - BLH75A55_20_cv1 

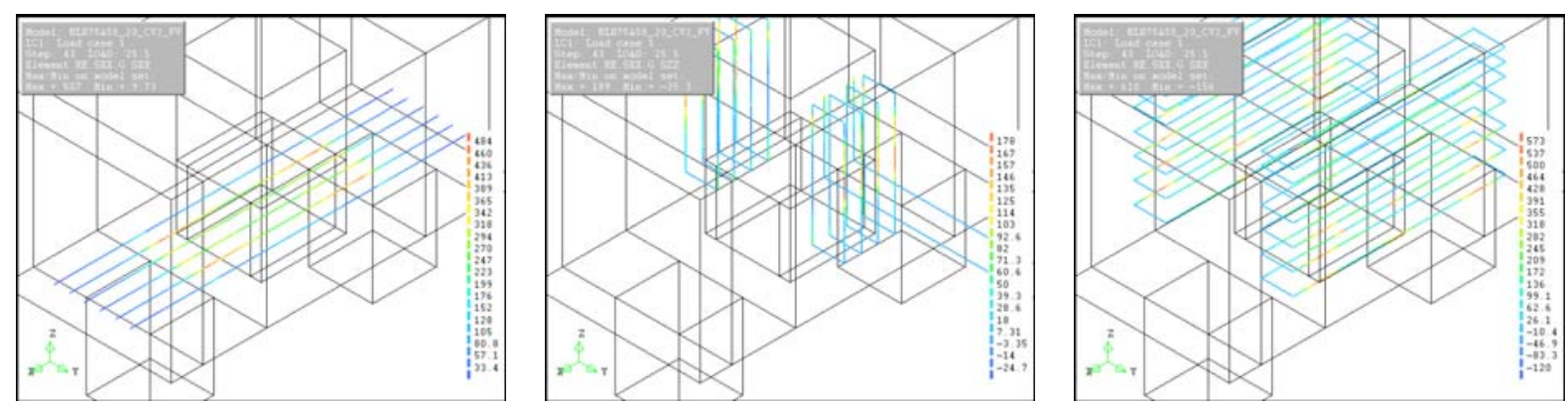

Figura 5. 47 - BLH75A55_20_cv2
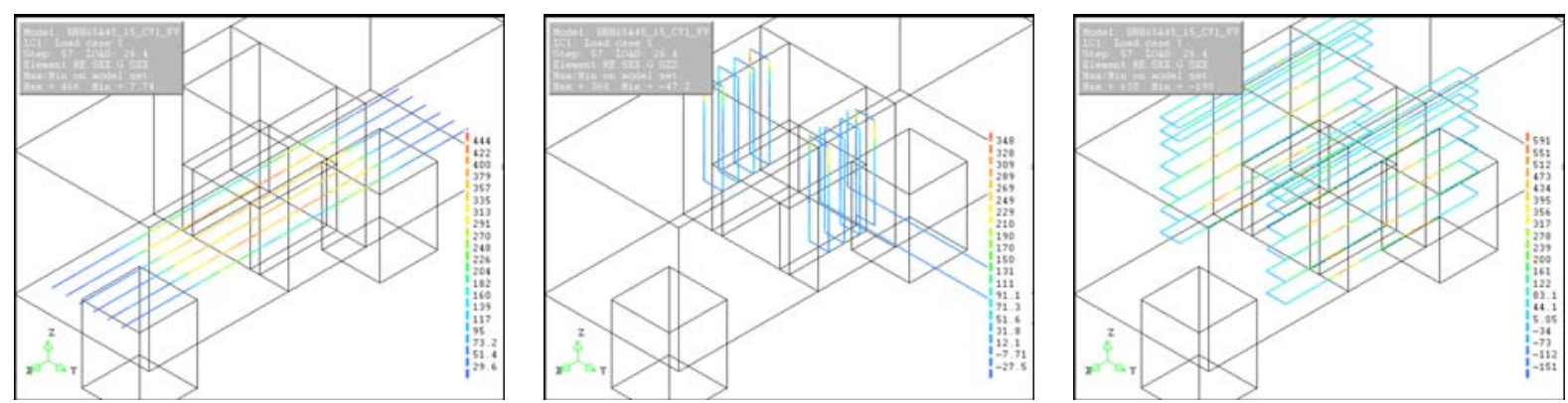

Figura 5. 48 - BRH65A45_15_cv1
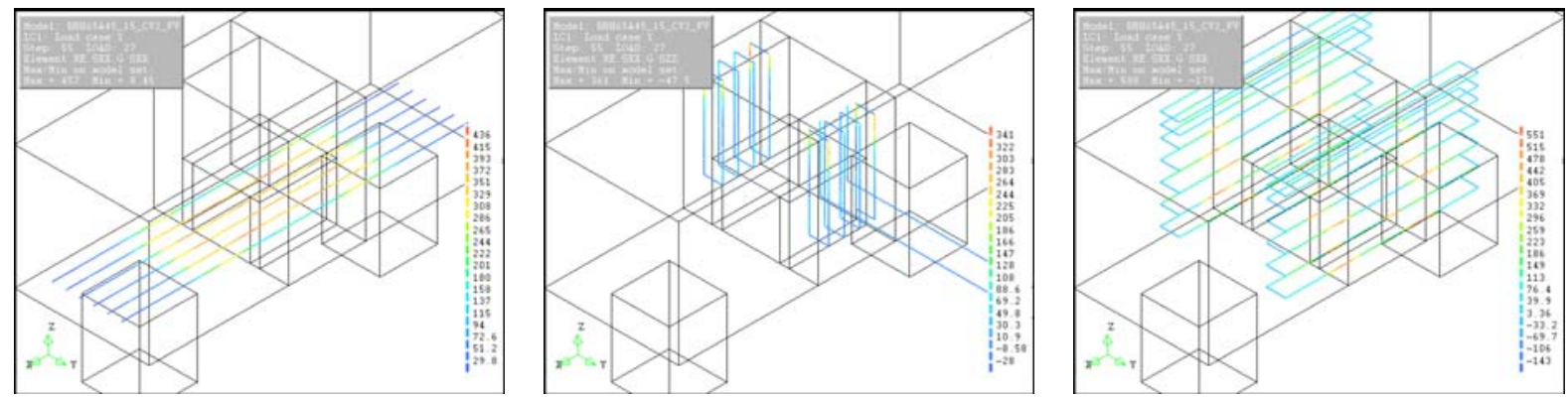

Figura 5.49 - BRH65A45_15_cv2
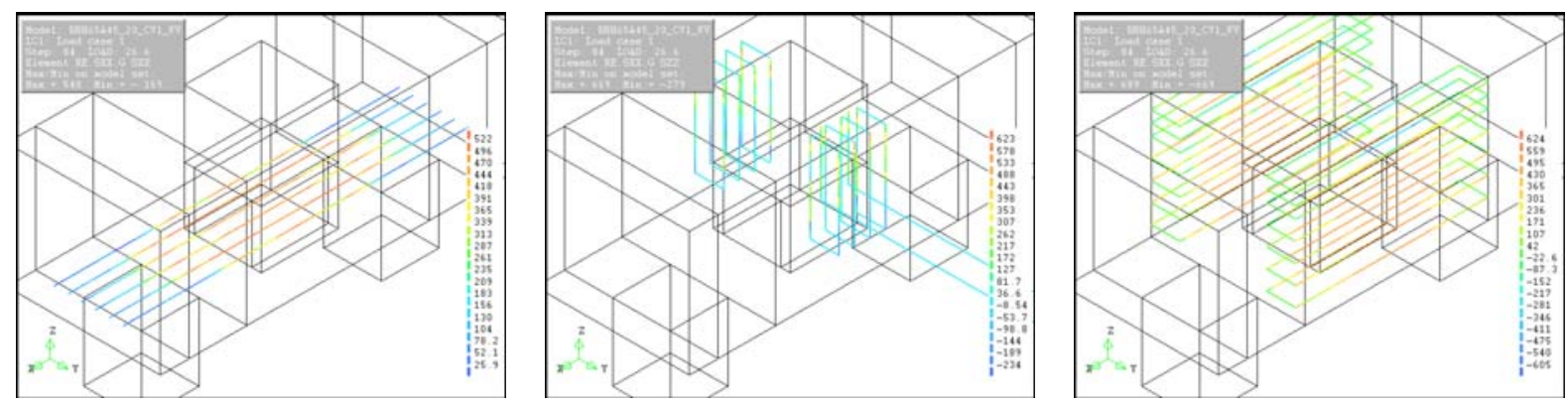

Figura 5. 50 - BRH65A45_20_cv1 

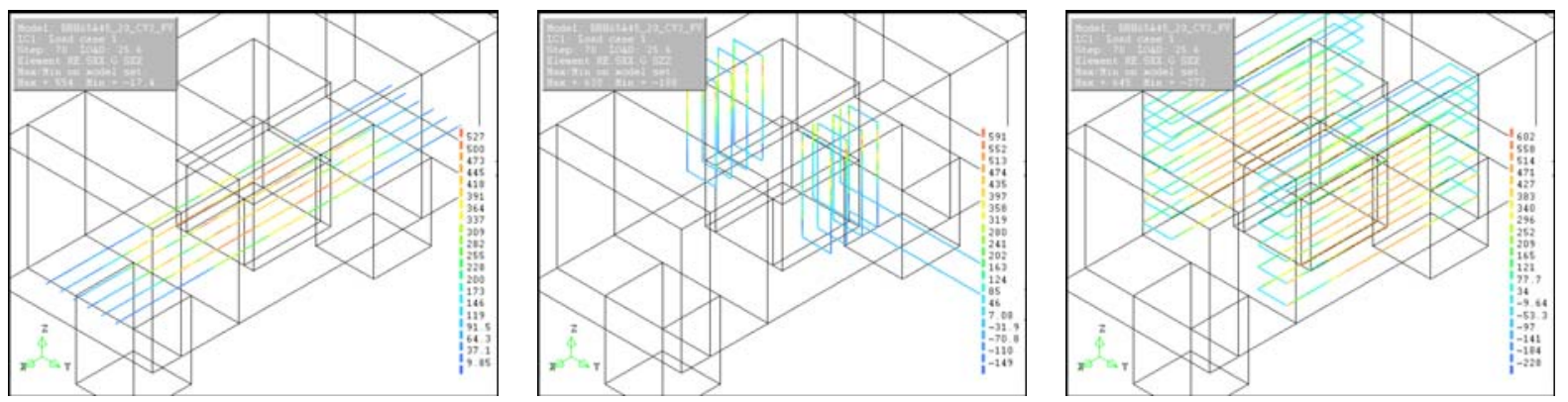

Figura 5. 51 - BRH65A45_20_cv2
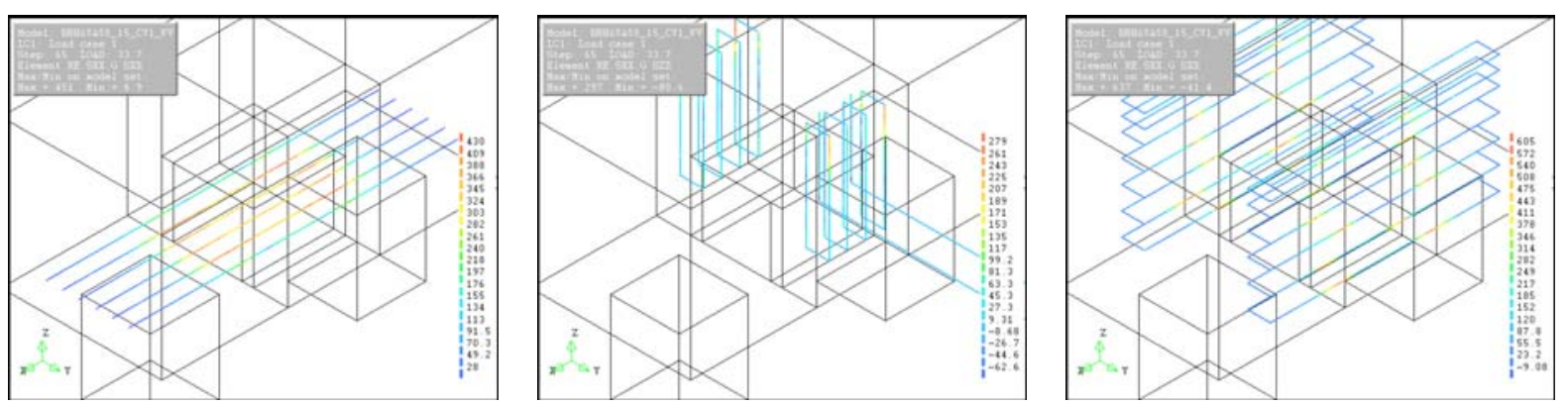

Figura 5. 52 - BRH65A55_15_cv1
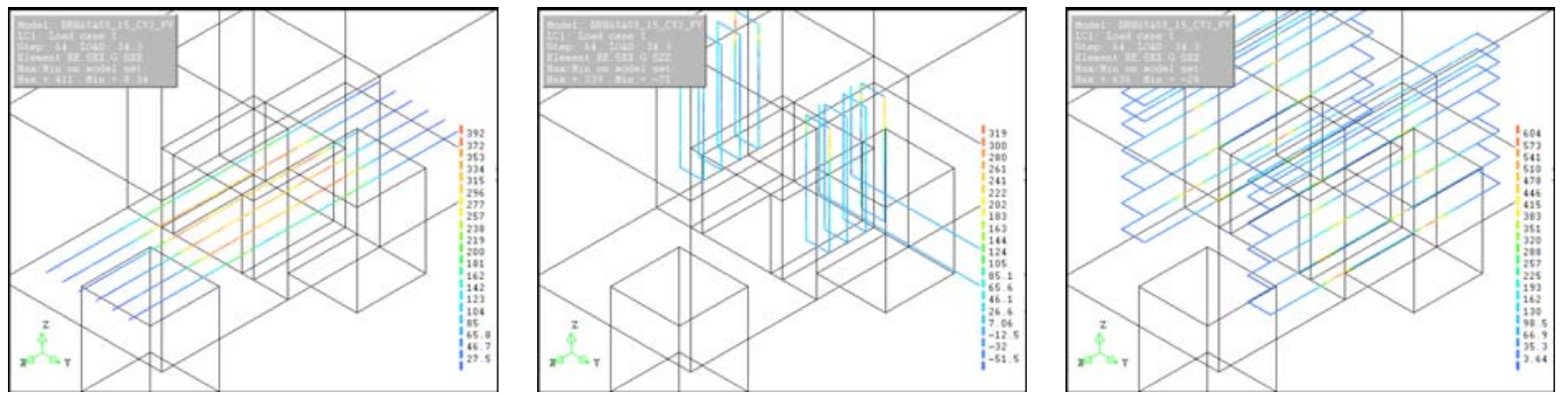

Figura 5. 53 - BRH65A55_15_cv2
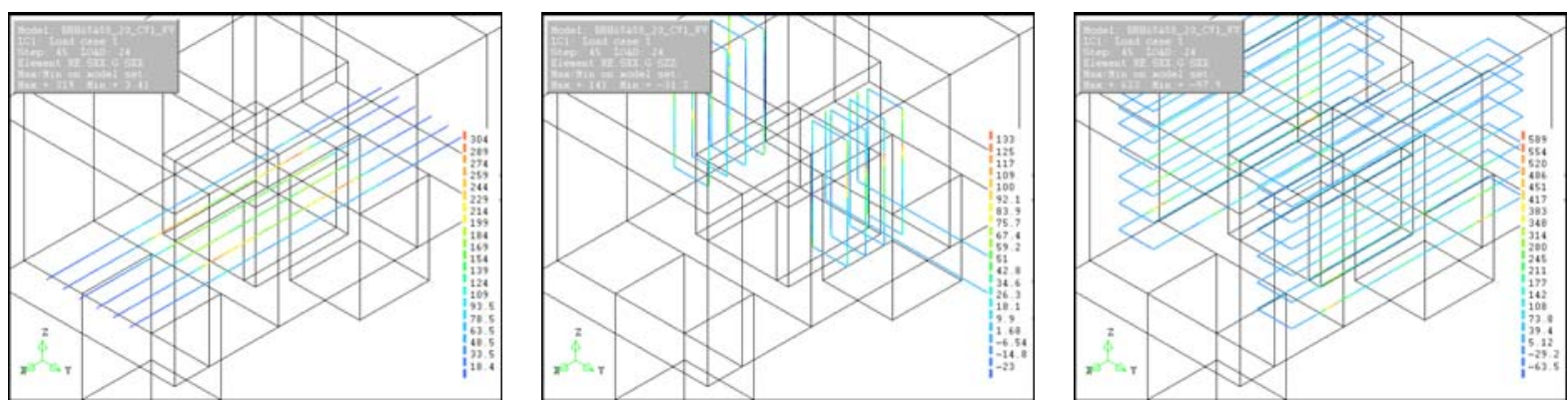

Figura 5. 54 - BRH65A55_20_cv1 

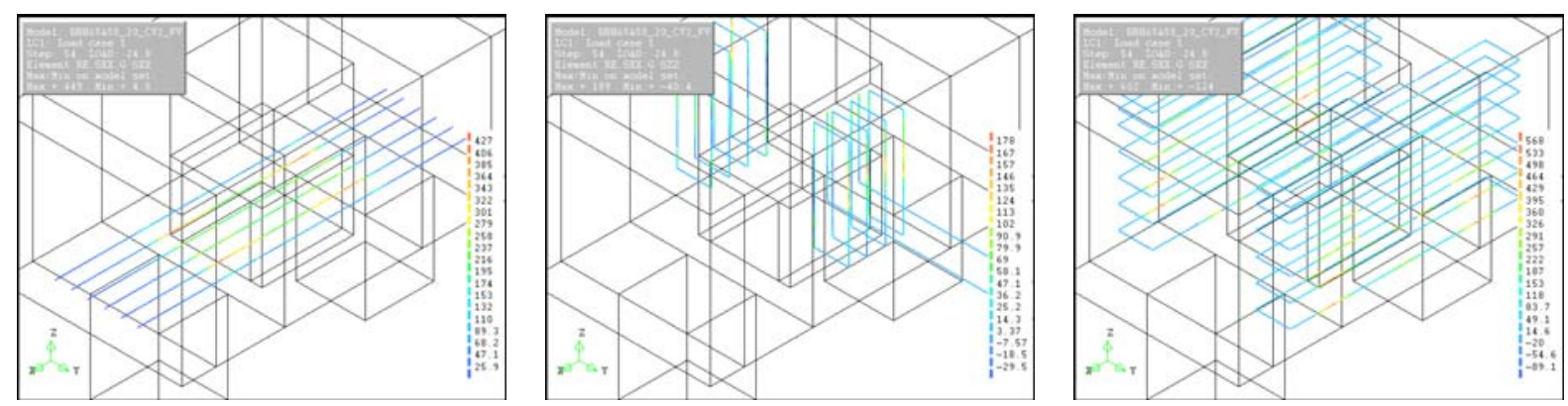

Figura 5. 55 - BRH65A55_20_cv2

\subsection{Resultados numéricos versus resultados analíticos}

Nesse item alguns resultados analíticos são comparados aos resultados obtidos por meio do modelo numérico para a análise de blocos com cálice embutido. A tabela 5.5 apresenta o valor de força atuante no pilar e na viga de travamento no último incremento de força, bem como o valor da máxima tensão normal na armadura principal do tirante.

Tabela 5.5 - Força última nos blocos sobre duas estacas com cálice embutido

\begin{tabular}{c|c|c|c}
\hline \hline MODELO & $\begin{array}{c}\text { Força última } \\
\text { no pilar (kN) }\end{array}$ & $\begin{array}{c}\text { Força última } \\
\text { na viga (kN/m) }\end{array}$ & $\begin{array}{c}\boldsymbol{\sigma}_{\text {máx no tirante }} \\
(\mathbf{M P a})\end{array}$ \\
\hline BLH75A45_15 & 2429 & - & 539 \\
\hline BLH75A45_15_cv1 & 2458,8 & 16,83 & 545 \\
\hline BLH75A45_15_cv2 & 2495,7 & 26,34 & 544 \\
\hline BLH75A45_20 & 2253,6 & - & 531 \\
\hline BLH75A45_20_cv1 & 2347,2 & 16,07 & 466 \\
\hline BLH75A45_20_cv2 & 2357,1 & 24,88 & 509 \\
\hline BLH75A55_15 & 2880 & - & 434 \\
\hline BLH75A55_15_cv1 & 2892,6 & 19,8 & 441 \\
\hline BLH75A55_15_cv2 & 2495,7 & 31,32 & 543 \\
\hline BLH75A55_20 & 2396,7 & - & 539 \\
\hline BLH75A55_20_cv1 & 2370,6 & 16,23 & 507
\end{tabular}


Tabela 5.5 - Força última nos blocos sobre duas estacas com cálice embutido (continuação)

\begin{tabular}{c|c|c|c}
\hline \hline MODELO & $\begin{array}{c}\text { Força última } \\
\text { no pilar }(\mathbf{k N})\end{array}$ & $\begin{array}{c}\text { Força última } \\
\text { na viga }(\mathbf{k N} / \mathbf{m})\end{array}$ & $\begin{array}{c}\boldsymbol{\sigma}_{\text {máx no tirante }} \\
\mathbf{( M P a})\end{array}$ \\
\hline BRH65A45_15 & 2377,8 & - & 455 \\
\hline BRH65A45_15_cv1 & 2376,8 & 16,27 & 466 \\
\hline BRH65A45_15_cv2 & 2430 & 25,65 & 456 \\
\hline BRH65A45_20 & 2298 & - & 543 \\
\hline BRH65A45_20_cv1 & 2394 & 16,39 & 500 \\
\hline BRH65A45_20_cv2 & 2302 & 24,30 & 514 \\
\hline BRH65A55_15 & 3298 & - & 337 \\
\hline BRH65A55_15_cv1 & 3033 & 20,76 & 451 \\
\hline BRH65A55_15_cv2 & 3082 & 32,53 & 410 \\
\hline BRH65A55_20 & 2858 & - & 490 \\
\hline BRH65A55_20_cv1 & 2155 & 14,75 & 319 \\
\hline BRH65A55_20_cv2 & 2101 & 22,18 & 578 \\
\hline \hline
\end{tabular}

Como pode ser observado na tabela 5.5, alguns valores de tensão normal nas barras da armadura principal do tirante foram superiores a tensão de escoamento igual a $500 \mathrm{MPa}$ adotada para as barras de armadura. Analisando um pouco mais os modelos, verificou-se que esses valores eram pontuais, e por isso não devem ser tomados como representativos para obtenção da força atuante no tirante $\mathrm{R}_{\text {st. }}$

Com o intuito de encontrar um valor representativo para a força atuante no tirante, optou-se por verificar os valores de tensão em cada uma das seis barras utilizadas como armadura principal na seção onde atua o maior valor de tensão, isto é, próximo ao meio do bloco. As Figuras 5.58 à 5.65 apresentam a distribuição de tensões normais nas seis barras da armadura principal do tirante. Observa-se por meio dessa figuras que na seção próxima ao meio do bloco, os maiores valores de tensão não ocorrem nas barras 3 e 4 no centro da seção, 
mas sim nas barras intermediária (barra 2 e barra 5), conforme Figura 5.56. Esse comportamento foi verificado em quase todos os modelos analisados, exceto para os modelos BLH75A45_20_cv1, BRH65A45_20_cv1 e BRH65A55_15.

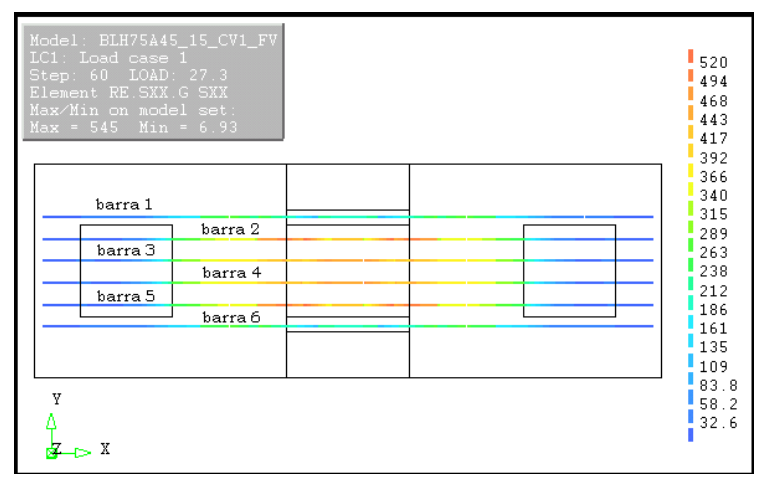

Figura 5. 56 - Barras da armadura principal do tirante

Com os valores de tensão normal em cada barra, é possível obter um valor médio para a tensão nas barras da armadura principal do tirante, a partir do qual multiplicando pelo valor da área dessas barras, pode-se encontrar o valor da força resultante $\mathrm{R}_{\mathrm{st}}$ atuante em cada um dos modelos.

Com o valor da força $\mathrm{R}_{\mathrm{st}}$ e da força última atuante no pilar, por meio do polígono de forças da Figura 5.57 é possível encontrar o valor da força de compressão $R_{c b}$ atuante nas bielas de compressão. É possível também encontrar o valor do ângulo de inclinação da biela de cada um dos modelos estudados, e compará-los com os valores teóricos obtidos analiticamente no dimensionamento dos blocos

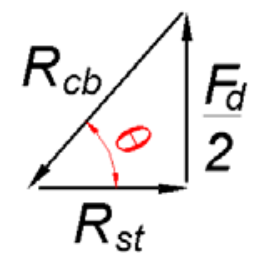

Figura 5. 57 - Polígono de forças 

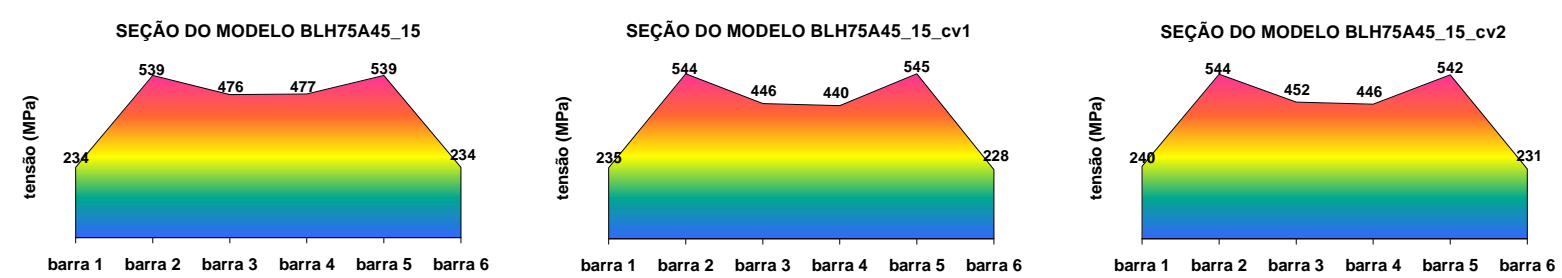

Figura 5. 58 - Tensão nas barras das armaduras dos modelos BLH75A45_15
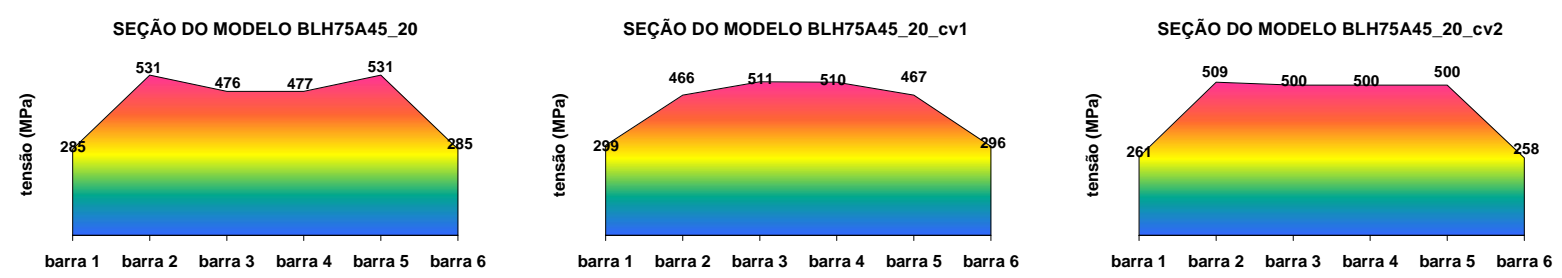

Figura 5. 59 - Tensão nas barras das armaduras dos modelos BLH75A45_20
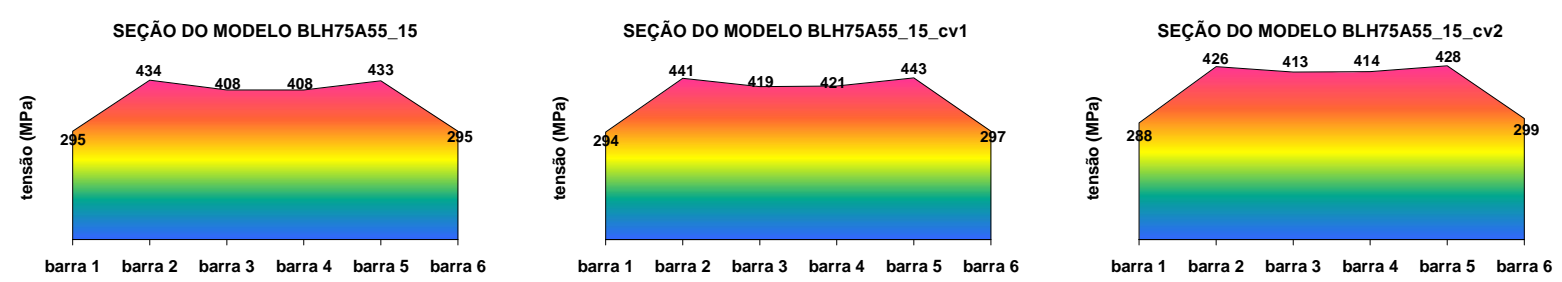

Figura 5. 60 - Tensão nas barras das armaduras dos modelos BLH75A55_15
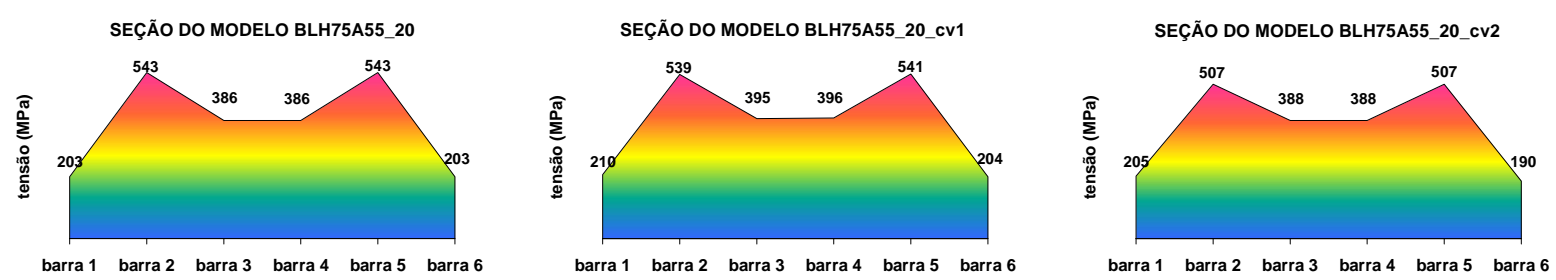

Figura 5. 61 - Tensão nas barras das armaduras dos modelos BLH75A55_20
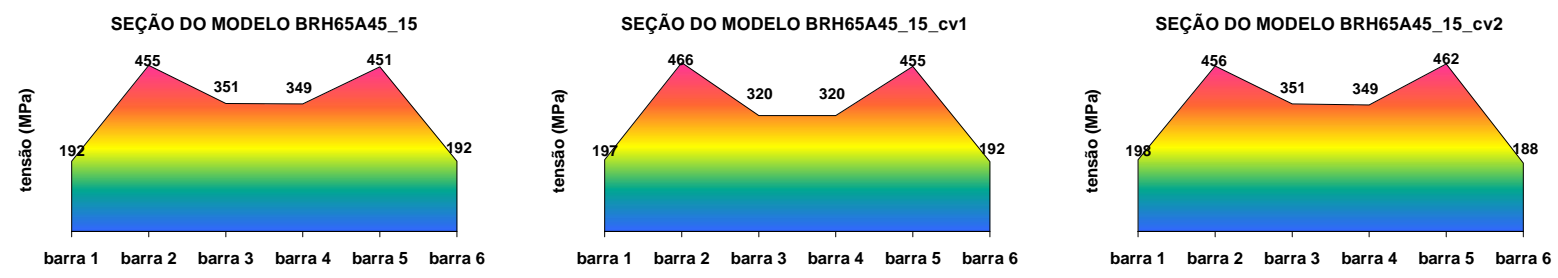

Figura 5. 62 - Tensão nas barras das armaduras dos modelos BRH65A45_15 

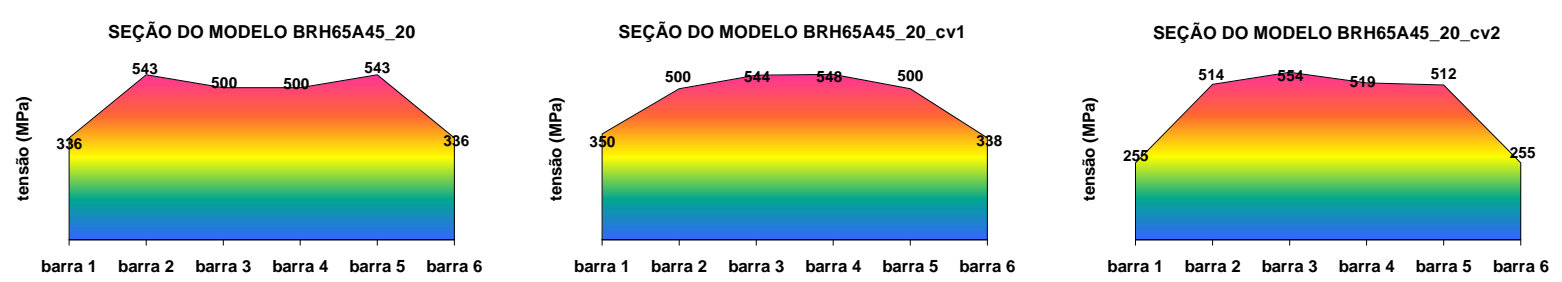

Figura 5. 63 - Tensão nas barras das armaduras dos modelos BRH65A45_20
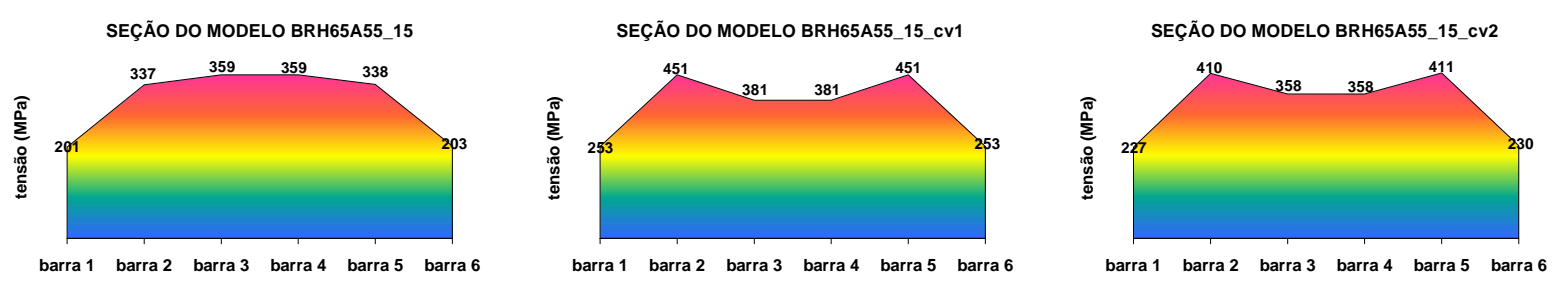

Figura 5. 64 - Tensão nas barras das armaduras dos modelos BRH65A55_15
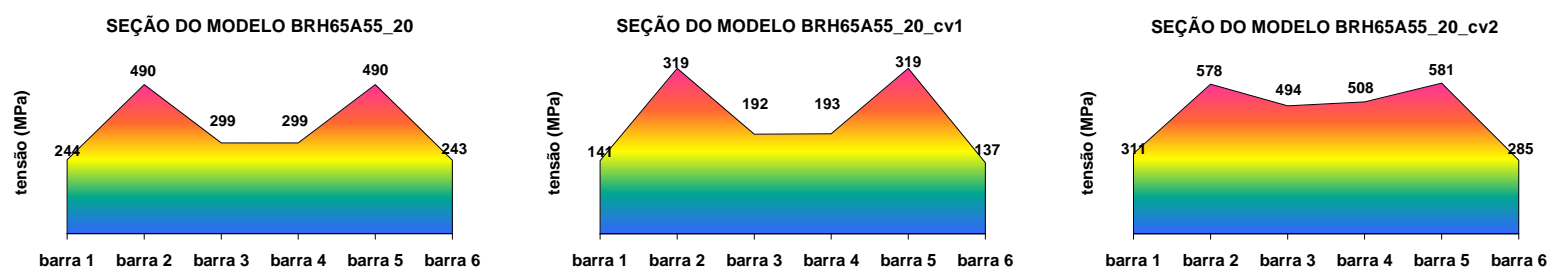

Figura 5. 65 - Tensão nas barras das armaduras dos modelos BRH65A55_20

Sabe-se que ao calcular o ângulo de inclinação da biela utilizando a força atuante no pilar, não está sendo considerada a parcela de contribuição da ação proveniente da viga de travamento. Entretanto, essa simplificação pode ser feita em virtude da ação atuante na viga apresentar pouca intensidade comparada à ação proveniente do pilar.

A tabela 5.6 apresenta os valores das forças atuantes no tirante, na biela de compressão, o valor do ângulo de inclinação da biela, bem como as tensões normais na região de encontro do bloco com o pilar e do bloco com a estaca. A tabela 5.7, por sua vez, apresenta o valor das tensões limites nas regiões nodais, obtidos por meio das expressões apresentadas no capítulo 3, tabela 3.1 
Tabela 5.6 - Força última nos blocos sobre duas estacas com cálice embutido

\begin{tabular}{|c|c|c|c|c|c|}
\hline MODELO & $\begin{array}{c}\text { Força } R_{\text {st }} \\
(\mathbf{k N})\end{array}$ & $\begin{array}{c}\text { Força } R_{\text {cb }} \\
(\mathbf{k N})\end{array}$ & $\begin{array}{l}\text { Ângulo da } \\
\text { biela }\end{array}$ & $\begin{array}{c}\sigma_{\mathrm{cb}, \mathbf{p}} \\
(\mathrm{MPa})\end{array}$ & $\begin{array}{c}\sigma_{\text {cb,e }} \\
(\mathrm{MPa})\end{array}$ \\
\hline BLH75A45_15 & 785 & 1446 & $57^{\circ}$ & 38,27 & 19,13 \\
\hline BLH75A45_15_cv1 & 812 & 1389 & $54^{\circ}$ & 38,05 & 19,02 \\
\hline BLH75A45_15_cv2 & 714 & 1607 & $64^{\circ}$ & 39,87 & 19,93 \\
\hline BLH75A45_20 & 711 & 1394 & $59^{\circ}$ & 36,01 & 18,01 \\
\hline BLH75A45_20_cv1 & 625 & 1343 & $62^{\circ}$ & 33,73 & 16,86 \\
\hline BLH75A45_20_cv2 & 866 & 1439 & $53^{\circ}$ & 40,05 & 20,03 \\
\hline BLH75A55_15 & 564 & 1743 & $71^{\circ}$ & 40,94 & 20,47 \\
\hline BLH75A55_15_cv1 & 648 & 1569 & $66^{\circ}$ & 38,30 & 19,15 \\
\hline BLH75A55_15_cv2 & 765 & 1448 & $58^{\circ}$ & 37,92 & 18,96 \\
\hline BLH75A55_20 & 800 & 1421 & $56^{\circ}$ & 38,22 & 19,11 \\
\hline BLH75A55_20_cv1 & 742 & 1452 & $59^{\circ}$ & 37,56 & 18,78 \\
\hline BLH75A55_20_cv2 & 794 & 1421 & $56^{\circ}$ & 38,08 & 19,04 \\
\hline BRH65A45_15 & 727 & 1619 & $63^{\circ}$ & 40,27 & 20,13 \\
\hline BRH65A45_15_cv1 & 717 & 1386 & $59^{\circ}$ & 36,00 & 18,00 \\
\hline BRH65A45_15_cv2 & 712 & 1646 & $64^{\circ}$ & 40,57 & 20,29 \\
\hline BRH65A45_20 & 686 & 1339 & $59^{\circ}$ & 34,65 & 17,33 \\
\hline BRH65A45_20_cv1 & 612 & 1337 & $63^{\circ}$ & 33,43 & 16,71 \\
\hline BRH65A45_20_cv2 & 873 & 1482 & $54^{\circ}$ & 40,76 & 20,38 \\
\hline BRH65A55_15 & 598 & 1354 & $64^{\circ}$ & 33,54 & 16,77 \\
\hline BRH65A55_15_cv1 & 819 & 1413 & $55^{\circ}$ & 38,55 & 19,27 \\
\hline BRH65A55_15_cv2 & 681 & 1663 & $66^{\circ}$ & 40,51 & 20,26 \\
\hline BRH65A55_20 & 408 & 1152 & $69^{\circ}$ & 27,39 & 13,69 \\
\hline BRH65A55_20_cv1 & 626 & 1663 & $68^{\circ}$ & 39,90 & 19,95 \\
\hline BRH65A55_20_cv2 & 866 & 1362 & $50^{\circ}$ & 39,21 & 19,61 \\
\hline
\end{tabular}


Tabela 5.7 - Tensão nas regiões nodais segundo diferentes critérios

\begin{tabular}{c|c|c}
\hline \hline Critérios & $\begin{array}{c}\sigma_{\mathbf{c b}, \mathbf{p}} \\
(\mathbf{M P a})\end{array}$ & $\begin{array}{c}\sigma_{\mathbf{c b}, \mathbf{e}} \\
(\mathbf{M P a})\end{array}$ \\
\hline Blévot \& Frémy (1967) & 35 & 25 \\
\hline Schäfer \& Schlaich (1988) & 16,70 & 12,14 \\
\hline Schlaich \& Schäfer(1991) & 19,64 & 14,29 \\
\hline CEB-FIP (1990) & 13,66 & 9,64 \\
\hline CSA (2004) & 12,75 & 11,25 \\
\hline ACI (2008) & 20,00 & 15,00 \\
\hline
\end{tabular}

De um modo geral, percebe-se que os ângulos de inclinação da biela apresentam valores superiores aos ângulos teóricos utilizados no dimensionamento, exceto o do modelo BRH65A55_20_cv2 que apresentou ângulo igual a 50 .

Para os modelos com ângulo teórico igual a $45^{\circ}$, observou-se que o menor valor de ângulo de inclinação da biela foi de $53^{\circ}$ e o maior foi de $64^{\circ}$, pertencentes aos modelos BLH75A45_20_cv2 e BLH75A45_15_cv2, respectivamente.

Em relação aos modelos com ângulo teórico igual a $55^{\circ}$, observou-se que o menor valor de ângulo de inclinação da biela foi de $50^{\circ}$ e o maior foi de $71^{\circ}$, pertencentes aos modelos BRH65A55_20_cv2 e BLH75A55_15, respectivamente. Como o modelo BRH65A55_20_cv2 foi o único dos vinte e quatro modelos analisados a apresentar ângulo da biela inferior ao teórico utilizado no dimensionamento, acredita-se que esse modelo tenha tido algum problema numérico no seu processamento, o que ocasionou sua ruína precocemente. Caso esse modelo seja desconsiderado, o menor valor de ângulo da biela passa a ser o dos modelos BLH75A55_20_cv2 e BLH75A55_20, ambos com inclinação igual a 56

Em relação às tensões nas regiões nodais, verifica-se de uma maneira geral que, de acordo com os critérios de Blévot \& Frémy (1967) utilizado para o dimensionamento dos modelos, a ruína ocorre em virtude das tensões de compressão na região de encontro do pilar 
com o bloco serem superior a tensão limite sugerida pelos pesquisadores, a menos do modelo BRH65A55_20.

Comparando as tensões obtidas nos modelos numéricos com a tensão limite sugerida pelos demais pesquisadores e códigos normativos, verifica-se que em todos os modelos as tensões obtidas são muito superiores aos limites recomendados da tabela 5.7, tanto na região de encontro do bloco com o pilar como no encontro do bloco com a estaca.

Esse resultado pode ser explicado pelo fato de, no ultimo incremento de carga, a força atuante no modelo ser superior a força de projeto, e que deve ser utilizada na comparação dos valores sugeridos pelos pesquisadores.

O fato da tensão nas regiões nodais no último incremento de carga serem maiores a sugeridas pelos pesquisadores é favorável, e aponta que os modelos de calculo estão a favor da segurança. 


\section{Capítulo}

\section{Conclusão}

\subsection{Comentários finais}

O presente trabalho teve por objetivo principal avaliar o comportamento de blocos sobre duas estacas com cálice totalmente embutido, utilizado na ligação pilar-fundação de estruturas pré-moldadas, mediante presença de viga de travamento. Para avaliação desse comportamento, foi proposta análise numérica utilizando o programa DIANA versão 9.2, baseado no método dos elementos finitos.

O comportamento de blocos de fundação com cálice totalmente embutido é objeto de muitas dúvidas no meio técnico, uma vez que na literatura existem poucos trabalhos que abordam o assunto. Esse trabalho representa apenas um primeiro passo na tentativa de sanar essas dúvidas.

Em relação à utilização de um programa de elementos finitos, sabe-se que os mesmos são ferramentas poderosas e apresentam avanços significativos em diversas linhas de pesquisas. Entretanto, a utilização desses programas requer do usuário atenção e cautela, de modo que os aspectos de engenharia não fiquem comprometidos mediante o uso indiscriminado desses programas. Entender o funcionamento dos mesmos, partindo de problemas mais simples cuja solução já é conhecida, é uma boa alternativa para novos usuários desse tipo de programa. 


\subsection{Principais conclusões}

Uma das grandes dúvidas em relação aos blocos com cálice totalmente embutido é sobre o início da formação da biela de compressão. Os resultados da distribuição do fluxo de tensões principais, obtidos por meio da análise dos vinte e quatro modelos estudados, indicaram que em todos os modelos a formação da biela se inicia a partir do encontro do pilar com o bloco. Esse resultado ocorreu tanto para os cálices com configuração da parede rugosa, como para os com configuração da parede lisa.

Outro aspecto importante do bloco sobre estacas com cálice totalmente embutido é o comportamento da região compreendida entre o fundo do cálice e o fundo do bloco. Os resultados indicaram que existe um grande fluxo de tensões nessa região, ocasionado pela ação proveniente do pilar pré-moldado. Deve-se, portanto, atentar para a verificação dessa região durante a fase de projeto, a fim de evitar a ruína do bloco por punção.

Verificou-se também que, de um modo geral, a presença da viga de travamento nos modelos de blocos com cálice totalmente embutidos, não alterou de modo significativo o comportamento do bloco. Ou seja, a parede do cálice consegue transmitir de modo eficaz as ações provenientes da viga, sem comprometer o funcionamento do bloco. Esse resultado só foi diferente para os blocos com configuração da parede rugosa e inclinação da biela igual a $55^{\circ}$, nos quais a presença da viga de travamento fez com que a força última dos blocos diminuísse entre 7\% e 14\%. Com esses resultados, destaca-se a importância de se considerar a presença das vigas de travamento nos projetos estruturais, uma vez que a mesma não prejudica a utilização dos blocos.

Tratando-se dos blocos com cálice embutido e sem a presença de viga, verificou-se que os blocos com inclinação da biela de compressão igual a $45^{\circ}$ apresentaram a mesma tendência de comportamento, independente da espessura e da configuração das paredes do cálice. Em 
contra partida, os blocos com inclinação igual a $55^{\circ}$ tiveram comportamento distintos em relação à configuração e espessura das paredes do cálice. Os blocos com parede rugosa apresentaram-se mais rígidos e tiveram força última superior do que a dos blocos com parede lisa.

Em relação à espessura da parede do cálice, de um modo geral, os modelos com espessura da parede igual a $15 \mathrm{~cm}$ apresentaram força última superior aos modelos cuja espessura da parede era igual a $20 \mathrm{~cm}$. Esse resultado se repetiu independente do ângulo da inclinação da biela, do tipo de conformação das paredes do cálice, bem como da presença ou não da viga de travamento. Um fator que pode ter contribuído para esse resultado pé a discretização da malha de elementos finitos nessa região. Outra possível causa é o fato de que os blocos com parede igual a $20 \mathrm{~cm}$ apresentavam uma distância entre a face do bloco e a face da estaca maior do que a recomendada pelos critérios usuais de projeto.

Quanto à intensidade das ações nas vigas de travamento, verificou-se que os dois valores utilizados na simulação numérica não alteraram o comportamento do bloco, apresentando praticamente a mesma curva força versus deslocamento em todos os modelos estudados.

A distribuição de tensões principais nas estacas indica que essas tensões podem variar de acordo com as condições de contorno empregadas nos modelos. Ao se restringir as translações em todas as direções, os maiores valores de tensão são encontrados partindo da parte superior da face interna da estaca em direção a parte inferior da face mais externa da estaca.

Em relação às barras da armadura principal do tirante, constatou-se que a distribuição de tensões não é uniforme, e, pôde-se construir um diagrama de tensões representando a seção mais solicitada do bloco. Verificou-se, também, que as tensões e deformações nessas barras diminuem consideravelmente na região sobre as estacas. Esse fenômeno ocorre em função do efeito benéfico da biela de compressão proveniente do pilar. 
Com os diagramas de tensões das barras da armadura principal, foi possível calcular a força atuante no tirante. Combinando esse valor com a força proveniente do pilar, foi possível calcular a força atuante na biela de compressão, bem como a inclinação efetiva das bielas de compressão pouco antes da ruína do bloco. Verificou-se que, de um modo geral, o ângulo de inclinação da biela foi maior do que o obtido analiticamente quando do dimensionamento.

Observou-se também que as barras das armaduras transversais que atravessam as bielas apresentam maior intensidade de tensões. Esse fato foi constatado tanto para os estribos verticais, como para as barras da armadura de costura utilizada no meio do bloco.

Em relação aos modelos constitutivos disponíveis nos programas baseados no método dos elementos finitos, acredita-se, ser necessário melhorar esses modelos constitutivos para representação do material concreto nesses tipos de programa.

\subsection{Sugestões para trabalhos futuros}

Com o intuito de contribuir nas pesquisas envolvendo a ligação pilar-fundação em estruturas pré-moldadas, seguem as seguintes sugestões para pesquisas futuras:

- Analisar numericamente a influência que as condições de contorno provocam em blocos sobre estacas;

- Analisar minuciosamente a região compreendia entre o fundo do cálice de fundação e o fundo do bloco, variando essa distância;

- Fazer uso dos diversos modelos de interface disponíveis no programa DIANA, analisando-os a fim de encontrar a melhor representação da interação existente entre o pilar e o graute e o graute e o bloco;

- Avaliar o modelo constitutivo proposto por Maekawa (Modified Maekawa Concrete Model) indicado para modelagens tridimensionais; 
- Estudar numericamente outros modelos de blocos com cálice totalmente embutido sobre várias estacas;

- Analisar experimentalmente o comportamento de blocos sobre estacas com cálice de fundação totalmente externo, parcialmente embutido e totalmente embutido. 


\section{Referências bibliográficas}

ADEBAR, P.; KUCHMA, D.; COLLINS, M. P. (1990). Strut-and-tie models for design of pile caps: an experimental study. ACI Journal, v. 87, p. 81-91, Jan/Feb;

ALONSO, U. R. (1983). Exercícios de Fundações. Ed. Edgard Blücher Ltda., São Paulo;

AMERICAN CONCRETE INSTITUTE (1983). Design Handbook, v. 1: Beams, one-way, brackets, footings and pile caps (ACI 340. IR-84). ACI SP-17;

AMERICAN CONCRETE INSTITUTE (1994). ACI 318M - Building code requirements for reinforced concrete. Detroit, USA;

AMERICAN CONCRETE INSTITUTE (2008) ACI 318-08 - Building Code Requirements for Structural Concrete and Commentary, Farmington Hills, USA;

ASSOCIAÇÃO BRASILEIRA DE NORMAS TÉCNICAS (2003). NBR 6118:2003 Projeto de estruturas de concreto. Rio de Janeiro;

ASSOCIAÇÃO BRASILEIRA DE NORMAS TÉCNICAS (1996). NBR 6122:1996Projeto e execuções de fundações. Rio de Janeiro;

ASSOCIAÇÃO BRASILEIRA DE NORMAS TÉCNICAS (1992). NBR 6152:1992 Materiais metálicos - determinação das propriedades mecânicas à tração: método de ensaio. Rio de Janeiro;

ASSOCIAÇÃO BRASILEIRA DE NORMAS TÉCNICAS (2007). NBR 7480:2007 - Aço destinado a armaduras para estruturas de concreto armado - Especificação. Rio de Janeiro; 
ASSOCIAÇÃO BRASILERIA DE NORMAS TÉCNICAS (1985). NBR 9062:1985 Projeto e execução de estruturas de concreto pré-moldado. Rio de Janeiro;

BANGASH, M.Y.H. (2001). Manual of numerical methods in concrete: modeling and applications by experimental and site-monitoring data.. Ed. Thomas Telford Ltd, 1 Heron Quay, London E14 4JD;

BLÉVOT, J.; FRÉMY, R. (1967). Semelles sur piex. Analles d'Institut Techique du Bâtiment et des Travaux Publics, Paris, v. 20, n. 230, p. 223-295, fev;

BRITISH STANDARD FOR STRUCTURAL USE OF CONCRETE (1985). BS 8110 Code of practice for design and construction. Part I;

CALAVERA, J. (1991). Calculo de estrutucturas de cimentacion. Instituto Técnico de Materiales y Construcciones - INTEMAC. Ed. Torreangulo Arte Gráfico, ed. $3^{\text {a }}$, Madrid, Espanha;

CAMPOS, L. A.; MARCELLINO, N. A. (2008). Análise experimental de blocos de fundação sobre duas estacas para estruturas pré-fabricadas submetido à ação de força centrada. Anais do $50^{\circ}$ Congresso Brasileiro do Concreto, Setembro, Salvador;

CANHA, R. M. F. (2004). Estudo teórico-experimental da ligação pilarfundação por meio de cálice em estruturas de concreto pré-moldado. Tese (Doutorado), Escola de Engenharia de São Carlos, Universidade de São Paulo, São Carlos;

CARNAÚBA, M.; MORAES, M.C.; HERVÉ NETO, E. (2008) Travamento interblocos sobre estacas-1. Lista de discussão eletrônica, comunidade calculistas-ba. Disponível em $<$ http://br.groups.yahoo.com/group/calculistas-ba/message/21587> e comunidade TQS. Disponível em $\quad<$ http://br.groups.yahoo.com/group/comunidadeTQS/message/25166>. Acessos em 24 jun. 2008 e 27 jun. 2008; 
CHEN, W.F.(1982). Plasticity in reinforced concrete. Ed. McGraqw-Hill Book Company. 474 p. New York;

COMISIÓN PERMANENTE DEL HORMIGÓN (2002). Ministerio de Fomento. Centro de Publicaciones. Instrucción española de hormigón armado (EHE), Madrid;

COMITE EURO-INTERNACIONAL DU BÉTON (1970). CEB-FIP, Recommandations particulières na calcul et à l'execution des semelles de fundations. Bulletin D'Information, Paris, n. 73;

COMITE EURO-INTERNACIONAL DU BÉTON (1990). CEB-FIP Model code for concrete structures. Bulletin D’Information, Paris, n. 203-205, July;

CONSIGLIO NAZIONALE DELLE RICHERCHE (1998) CNR-1005- Instruzioni per II progetto, l'esecuzione Ed Il controllo delle strutture prefabricate in calcestruzzo. ITEC/La prefabricazione. Roma, ITEC;

CSA STANDARD A23.3-04 (2004). Design of Concrete Structures with Explanatory Notes. Canadian Portland Cement Association, Ontario, Canadá;

DELALIBERA, R. G.; GIONGO, J. S. (2004 - a). Simulação numérica não-linear de blocos de concreto armado. XXXI Jornadas Sul-Americanas de Engenharia Estrutural. CDROM, Mendonza, Argentina;

DELALIBERA, R. G.; GIONGO, J. S. (2004 - b). Influência da rigidez do bloco de coroamento nos estaqueamentos em linha. $\mathbf{4 6}^{\circ}$ Congresso Brasileiro do Concreto. CDROM, Florianópolis;

DELALIBERA, R. G. (2006). Análise teórica e experimental de blocos de concreto armado sobre duas estacas submetidos a ação de força centrada e excêntrica. Tese (Doutorado) - Escola de Engenharia de São Carlos, Universidade de São Paulo, São Carlos; 
DIANA (2005a). DIANA Finite Element Analysis. User's manual release 9. Element Library. TNO DIANA, Delft, Netherland;

DIANA (2005b). DIANA Finite Element Analysis. User's manual release 9. Material Library. TNO DIANA, Delft, Netherland;

EBELING, E. B. (2006). Análise da base de pilares pré-moldados na ligação com cálice de fundação. Dissertação (Mestrado), Escola de Engenharia de São Carlos, Universidade de São Paulo, São Carlos;

EL DEBS, M. K. (2000). Concreto pré-moldado: fundamentos e aplicações. Projeto REENGE. Escola de Engenharia de São Carlos, Universidade de São Paulo, São Carlos;

ELLIOTT, K. S. (1996) Multi-storey precast concrete framed structures. Oxford, Blackwell Science;

FARIAS, R, S. (2008) Estudo teórico-experimental do efeito da laje na transferência de forças em ligações viga-pilar misto preenchido. Dissertação (Mestrado), Escola de Engenharia de São Carlos, Universidade de São Paulo, São Carlos;

GUERRIN A. (1955), Traité de Béton Arme, Les Fondations, Dunod, Tome III, Paris;

INDIAN STANDARD (1979). IS 2911 - Code of practice for design and construction of pile foundation. Part I, Sec. 3;

IYER, P. K.; SAM, C. (1991). 3-D elastic analysis of three-pile caps. Journal of Engineering Mechanics, ASCE, v. 117, n. 12, p. 2862-2883, Dec;

IYER, P. K.; SAM, C. (1992). Three-dimensional analysis of pile caps. Computers and Structures, v. 42, n. 3, p. 395-411, Feb; 
IYER, P. K.; SAM, C. (1995 - a). Nonlinear finite element analysis of reinforced concrete four-pile caps. International Journal of Structures, v. 15, n. 1, p. 18-34, Jan/Jun;

JAGUARIBE JÚNIOR, K. B. (2005). Ligação pilar-fundação por meio de cálice em estrutuas de concreto pré-moldado com profundidade de embutimento reduzida. Dissertação (Mestrado), Escola de Engenharia de São Carlos, Universidade de São Paulo, São Carlos;

LEONHARDT, F. \& MÖNNIG, E. (1978). Construções de concreto. Ed. Interciência, v. 01, 02, 03 e 04, Rio de Janeiro;

MAUTONI, M. (1972). Blocos sobre dois apoios. São Paulo, Grêmio Politécnico;

MELO, C. E. E. (2004). Manual Munte de Projetos em Pré-Fabricados de Concreto. São Paulo, Editora Pini;

MIGUEL, G. M. (2000). Análise experimental e numérica de blocos sobre três estacas. Tese (Doutorado) - Escola de Engenharia de São Carlos, Universidade de São Paulo, São Carlos;

MONTOYA, P. J.; MESEGUER, A.; CABRE, M. (2000). Hormigón armado. 14a Edición basada em EHE ajustada al Código Modelo y al Eurocódigo. Gustavo Gili, Barcelona, Espanha;

MUNHOZ, F. S. (2004). Análise do comportamento de blocos de concreto armado sobre estacas submetidos à ação de força centrada. Dissertação (Mestrado), Escola de Engenharia de São Carlos, Universidade de São Paulo, São Carlos;

NORI, V.V.; THARVAL, M. (2007). Design of pile caps - Strut and tie model method. The indian concrete journal, Point of view. p. 13-19, Abril; 
NUNES, V. C. P. (2009). Estudo de cálice de fundação com ênfase nos esforços nas paredes transversais do colarinho. Dissertação (Mestrado) - Escola de Engenharia de São Carlos, Universidade de São Paulo;

OLIN, J.; HAKKARAINEN, T.; RÄMÄ,M. (1985). Connections and Joints between precast concrete units. Espoo, Julkaisija-Utgivare;

OSANAI, Y.; WATANABE, F.; OKAMOTO, S. (1996). Stress transfer mechanism of socket base connections with precast concrete columns. ACI Structural journal, v. 93, n. 3, p. 226276, May/June;

RAMOS, F. A. C. (2007). Análise numérica de blocos sobre dez estacas: Cálculo das reações de apoio. Dissertação (Mestrado) - Escola de Engenharia de São Carlos, Universidade de São Paulo;

SCHAFER, K.; SCHALICH, J. (1988). Consistent design of structural concrete using strut and tie models. Colóquio sobre comportamento de projeto de estruturas, 5 . Anais, PUC RJ, Rio de Janeiro - RJ;

SCHIEL, F. (1957). Estática das construções. Publicação No ${ }^{\circ}$ 10, Escola de Engenharia de São Carlos, Universidade de São Paulo, São Carlos;

SCHLAICH, J.; SCHAFER, K.; JENNEWEIN, M. (1987). Toward a consistent design of reinforced structural concrete. Journal of Prestressed Concrete Institute, v. 32, n. 3, p. 74150, May-June;

SCHLAICH, J., SCHAFER, K. (1991). Design and detailing of structural concrete using strut-and-tie models. The Structural Engineer, v.69, n.6, p.113-125, March;

SILVA, A. M. S. (1998). Ligações entre elementos pré-fabricado de betão. Dissertação (Mestrado), Universidade Técnica de Lisboa, Instituto Superior Técnico, Lisboa; 
SILVA, R, C.; GIONGO, J. S. (2000). Modelos de bielas e tirantes aplicados a estruturas de concreto armado. Projeto REENGE, Escola de Engenharia de São Carlos, Universidade de São Paulo, São Carlos;

SOUZA, R. A.; BITTENCOURT, T. N. (2006). Análise não-linear de blocos rígidos sobre quatro estacas. Revista Ibracon de Estruturas. Vol. 2, nº.3, p. 310-319, setembro;

SOUZA, R. A. (2004). Concreto estrutural: análise e dimensionamento de elementos com descontinuidades. Tese (Doutorado), Escola Politécnica da Universidade de São Paulo, São Paulo;

TAYLOR, H. P. J.; CLARKE, J. L. (1976). Some detailing problems in concrete frame structures. The Structural Engineer, January;

TJHIN, T. N.; KUCHMA, D. (2002). Computer-Based Tools for Design by Strut-and-Tie Method: Advances and Challenges. ACI Structural Journal, p. 586-594, Sep/Oct;

WILLERT, O.; KESSER, E. (1983). Foundations for botton-end fixed precast concrete columns. Betonwerk+Fertigteil-Technik, v.49,n.3,p.137-142. 
